\title{
Maternal care in Georgia
}

\author{
Citation for published version (APA):
}

Shengelia, L. (2020). Maternal care in Georgia: An empirical analysis of quality, access and affordability during health care reform. [Doctoral Thesis, Maastricht University]. Maastricht University. https://doi.org/10.26481/dis.20200319ls

Document status and date:

Published: 01/01/2020

DOI:

10.26481/dis.20200319ls

Document Version:

Publisher's PDF, also known as Version of record

\section{Please check the document version of this publication:}

- A submitted manuscript is the version of the article upon submission and before peer-review. There can be important differences between the submitted version and the official published version of record.

People interested in the research are advised to contact the author for the final version of the publication, or visit the DOI to the publisher's website.

- The final author version and the galley proof are versions of the publication after peer review.

- The final published version features the final layout of the paper including the volume, issue and page numbers.

Link to publication

\footnotetext{
General rights rights.

- You may freely distribute the URL identifying the publication in the public portal. please follow below link for the End User Agreement:

www.umlib.nl/taverne-license

Take down policy

If you believe that this document breaches copyright please contact us at:

repository@maastrichtuniversity.nl

providing details and we will investigate your claim.
}

Copyright and moral rights for the publications made accessible in the public portal are retained by the authors and/or other copyright owners and it is a condition of accessing publications that users recognise and abide by the legal requirements associated with these

- Users may download and print one copy of any publication from the public portal for the purpose of private study or research.

- You may not further distribute the material or use it for any profit-making activity or commercial gain

If the publication is distributed under the terms of Article $25 \mathrm{fa}$ of the Dutch Copyright Act, indicated by the "Taverne" license above, 


\section{MATERNAL CARE IN GEORGIA:}

An empirical analysis of quality,

access and affordability during

healthcare reform

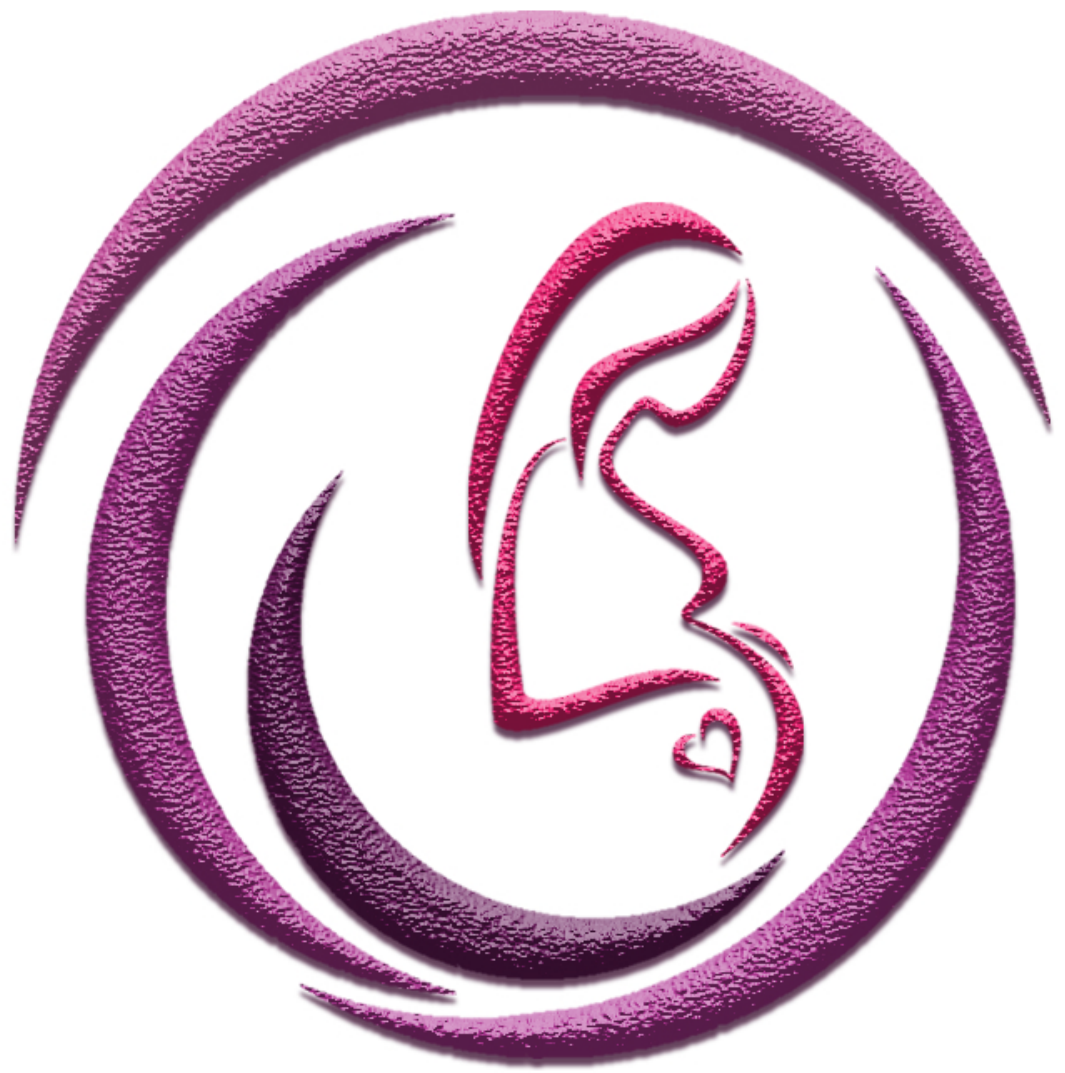

Lela Shengelia 


\title{
Maternal care in Georgia:
}

\section{An empirical analysis of quality, access and affordability during healthcare reform}

\author{
DISSERTATION \\ To obtain the degree of Doctor at Maastricht University \\ on the authority of the Rector Magnificus, \\ Prof. Dr. Rianne M. Letschert \\ in accordance with the decision of the Board of Deans, \\ to be defended in public \\ on Thursday 19 March 2020, at 12.00 hours
}

By

Lela Shengelia 


\section{Promoter:}

Prof. Dr. Wim Groot

\section{Co-Promoter:}

Dr. Milena Pavlova

\section{Assessment Committee:}

Prof. Dr. Silvia Evers (chair)

Prof. Dr. Rob Ruiter

Prof. Dr. Leopold Curfs

Prof. Dr. Didi Braat (Radboud University)

Prof. Dr. Tengiz Asatiani (Tbilisi State Medical University)

\section{Acknowledgement of funding:}

The study is financed by a NUFFIC scholarship from the Netherlands government (Grant 309574427N). The content of the publication is the sole responsibility of the author and it in no ways represents the views of NUFFIC.

The research presented in this thesis was conducted at CAPHRI Care and Public Health Research Institute, Department Health Services Research of Maastricht University.

CAPHRI participates in the Netherlands School of Public Health and Care Research CaRe. 


\section{Contents}

Chapter 1 General Introduction 5

Chapter 2 Impact of Healthcare Reform on Universal Coverage

in Georgia: A Systematic Review

Chapter 3 Changes in Maternal Care during the Healthcare Reforms in Georgia

Chapter 4 Stakeholders' Views on the Strengths and Weaknesses of Maternal Care Financing and Its Reform in Georgia

Chapter 5 Quality and Access to Maternal Care in Georgia: A Qualitative Study among Stakeholders

Chapter 6 Women's Satisfaction with Maternal Care Services in Georgia

$\begin{array}{lll}\text { Chapter } 7 \text { General Discussion } & 135\end{array}$

Valorization

References

Appendix

Summary 


\section{Abbreviations}

$\begin{array}{ll}\text { BBP } & \text { Basic Benefit Package } \\ \text { CPD } & \text { Continuous professional development } \\ \text { C-section } & \text { Caesarean sections } \\ \text { FGD } & \text { Focus group discussion } \\ \text { GDP } & \text { Gross Domestic Product } \\ \text { GEL } & \text { Georgian currency LARI } \\ \text { IDI } & \text { In-depth interviews } \\ \text { HeSPA } & \text { Health and Social Program Agency Programme } \\ \text { HMO } & \text { Health Maintenance Organizations } \\ \text { MAP } & \text { Medical Assistance Program } \\ \text { MDG } & \text { Millennium Development Goal } \\ \text { MMR } & \text { Maternal Mortality Ratio } \\ \text { MoLHSA } & \text { Ministry of Internal Displaced Persons from Occupied Territories, } \\ & \text { Labor, } \\ \text { HHE } & \text { Health and Social Affairs } \\ \text { NCDC } & \text { National Center for Disease Control and Public Health of Georgia } \\ \text { OPP } & \text { Out-of-pocket payment } \\ \text { RAMOS } & \text { Reproductive Age Mortality Study } \\ \text { RHS } & \text { Reproductive Health Surveys } \\ \text { SIP } & \text { State Insurance Program } \\ \text { SMIC } & \text { State Medical Insurance Company } \\ \text { STI-AIDS/HIV } & \text { Sexually transmitted infection - acquired immunodeficiency } \\ \text { UHC } & \text { syndrome / } \\ \text { UNFPA } & \text { human immunodeficiency virus } \\ \text { USAID } & \text { State United Social Insurance fund } \\ \text { WHOlted Heations Population Fund } \\ \text { Universal Health Coverage }\end{array}$




\section{Chapter}

General Introduction 



\subsection{THE SCOPE OF THE DISSERTATION}

Ending preventable causes of maternal mortality remains one of the world's most critical challenges according to the 2030 Agenda for the Sustainable Development (1). However, to address maternal health conditions, health behaviors, and health systems factors which affect health, well-being, and quality of life of women, children and families, countries need to improve access to high-quality maternal care services (2). The health and survival of mothers is indissolubly linked to a coordinated, integrated "continuum of care" approach that optimizes the health benefits for both the mother and infant (3).

Maternal health, among other things, depends on the functioning of the health system of a country and in particular, on the adequacy of maternal care services. These services are crucial for promoting health, saving lives, preventing disabilities and deaths (4). Maternal care services, as all other healthcare services, are characterized by three dimensions:access to care, quality of care, and costs of care $(4,5)$.

Financial and geographical access to maternal care services remains a challenge for mothers in low- and middle-income countries (3). To minimize the barriers to highquality maternal care services, Universal Health Coverage (UHC) is one of the targets of the Global Strategy for Women's, Children's and Adolescents' Health, 2016-2030 (6). The goal is to address the needs of the mothers and new-borns in a holistic manner, and to minimize inequities between the rich and the poor (7). Mothers from lowincome population groups are vulnerable to the effects of costs incurred during childbirth (8). Fees paid by women might be especially high for emergency and technological procedures such as Caesarean section (C-section). These payments sometimes reach catastrophic levels, which pushes families into poverty $(4,5)$. It is recognized that theinvestigation of factors which influence access, quality and cost of maternal care services, is essential in developing policy interventions to optimize maternal care outcomes (4).

Maternal health outcomes have changed drastically in post-Soviet Georgia as in other post - Soviet countries. Following its independence in 1991, Georgia initiated healthcare reforms and maternal care was one of the priorities of the reform $(2,6)$. The State maternal care program was implemented in the late 1990 s and the main objective of that program was to improve maternal health in Georgia. Despite the recognized progress in the reduction of maternal mortality and morbidity in the period from 2000 to 2015, the target for the Millennium Development Goal (MDG) 5 was not achieved. The UN Maternal Mortality Estimation Interagency Group estimated that in 2015, the Maternal Mortality Ratio (MMR) in Georgia was 36 deaths per 100,000 live 
births, which was more than twice as high as its MDG5 target, and one of the highest MMR in the World Health Organization (WHO) European region (3). The shortcomings in access, quality and financing of maternal care that persisted during the transition period, are important factors attributable to this public health problem in Georgia (6). Therefore, a comprehensive analysis of these shortcomings is crucial to improve health and well-being of mothers in Georgia.

This dissertation helps to increase our understanding on access, quality and financing of maternal care services in Georgia. It explores access, quality and financing of maternal care from the perspective of all main stakeholders of maternal care services such as policy makers, representatives of national and international organizations, service providers and - foremost - women. This dissertation includes a systematic literature review, secondary data analysis, qualitative and quantitative studies. The dissertation focuses on changes in maternal care during the transitional period as well as on factors influencing the outcomes of these changes. It provides an analysis of women's experience and opinion about maternal care services in Georgia. The findings in this dissertation emphasize the urgent need of patient-centered caring practices of maternal care in Georgia.

\subsection{THE CONCEPT OF ACCESS, QUALITY AND FINANCING}

The healthcare "iron triangle" which consists of access, quality and cost, is tightly interlocked (7). It aims to optimize health system performance along three dimensions: improving the experience of care, reducing per capita costs of healthcare, and improving the health of populations $(8,9)$. The health and survival of mothers could be improved by the implementation of coordinated, integrated maternal care that requires optimizing the healthcare resources to maximize benefits. In this situation, cost and quality with the access to maternal care services are key aspects of the health system, especially in countries with limited resources (10). The concept of the "iron triangle" is applied here to maternal care services in Georgia. Guided by this conceptual basis, this dissertation examines changes which were implemented during the transitional period in the Georgian health system and factors influencing access, quality and cost of maternal health in Georgia. Access is defined as financial and geographical access to maternal care services. Quality is further divided into clinical quality, social quality, and continuity of care and comprehensiveness of maternal care $(11,12)$. 
For clinical quality, we investigated the physicians' knowledge and skills of diagnosis and treatment, and the physicians' and nurses' responsiveness to patients' needs. We assessed social quality using the following aspects: maintenance of privacy and respect for the mothers, mental support, attentiveness to the problems presented, communication and tangibility. Continuity was assessed in terms of mothers' adherence to physicians and specific maternal care facilities. We also assessed the effects of the physician-client relationship on the continuity of maternal care. Comprehensiveness of maternal care was assessed in terms of "one door shopping"; in other words, the availability of essential maternal care services in a single facility $(11,12)$.

\subsection{THE GEORGIAN HEALTHCARE SECTOR}

The independent Georgia established a presidential government system during the transition period that followed the collapse of the Soviet Union. The country is located on the crossroad of Europe and Asia, which is the reason for the distinct mixture of nationalities and cultures. Next to the capital region of Tbilisi, there are 10 other administrative regions. Each region consists of various districts, totaling 67 districts nationally (13). About $58 \%$ of the total population is living in urban areas and $42 \%$ in rural areas. About 1.1 million citizens live in the capital of Tbilisi. The life expectancy at birth was 77 years in 2009 year (14). Adult literacy rate is about 99.7\% (15).

The country is a lower-middle income country which ranks 70th among 188 countries on the Human Development Index, having experienced progressive growth over the years (15). In 2017, $11.65 \%$ of the total population lived below the national poverty level (15). Since the independence in 1991, Georgia moved towards an open-market economy with a public- private mixed market system. The economy of Georgia is traditionally based on the Black Sea tourism, viticulture, agriculture and some mining (mainly manganese and copper). The remittances from the external migrants' present an important share of the Gross Domestic Product (GDP) (15). Over the past decade, the Georgia's economy has grown at an average annual rate of 5\%. In 2017, the GDP per capita was 3864 US\$ (16).

Georgia inherited a centralized Semashko health system model (17). It was difficult to develop a new Georgian health system as a part of the market economy (18). Nevertheless, the healthcare reforms included a reorganization of the health system, the creation and implementation of State medical programs, the development of the pharmaceutical sector, the privatization of healthcare facilities and the launch of social health insurance. Eventually, the centralized health system model at the start of the 
transition turned into a decentralized health system. During $1994-2003$, the period of the first stage of the health reforms, the government decentralized the health sector to the local government. It was done without prior assessment and adequate capacity building of the local government. Moreover, the local government was given no autonomy in taking decisions and controlling the health system. For that reason, the aims of decentralization were not achieved. Ultimately the decentralization process was interrupted and a process of re-centralization was set in progress that was followed by and turned into massive privatization of the State- owned health institutions (6).

The Georgian health system covers both primary care and hospital services. The medical facilities providing outpatient services (e.g. policlinics, family Medicine Centers, women consultation centers, maternal houses/unites) are functioning in the large cities, as well as in the regional and rational centers. The existence of the institute of rural physicians has to be mentioned, as it is responsible for healthcare provision in villages (18). However, most of the medical facilities are located in the capital of Tbilisi. This causes geographical and financial barriers for households as it increases direct and indirect costs such as transportation and accommodation costs (19).

Following the last political changes in October 2012, the government announced that all Georgians would be eligible for State-funded health insurance and "universal coverage" would be provided. In addition to the existing Medical Insurance Program targeting the poor and other vulnerable population groups, the basic universal health service package was introduced in February 2013. The extension of entitlements has been backed up by a $90 \%$ increase in the levels of public funding for health from $1.8 \%$ of GDP in 2012 to $7.4 \%$ in 2014 (20). The UHC program covers a wide spectrum of services for the Georgian population, including four antenatal visits for pregnant women, maternal care (both physiological and surgical) and new-born care. The UHC program is an important initiative to ensure equity and to improve access to and utilization of healthcare services. As a result, the share of out-of-pocket expenditure significantly decreased from 79\% in 2012 to $57 \%$ in 2014 (21), protecting each citizen from disastrous costs for healthcare services, including that for maternal care. The UHC program meets the basic health needs of the population; however, the UHC program is a significant financial burden for the country.

The government plans to continue the politics of ensuring every citizen with access to a basic benefit package (BBP) by gradual increasing the package of healthcare services; investing more financial resources in preventive services to increase primary, secondary and tertiary prevention of serious diseases to reduce the burden of 
morbidity and mortality; as well as financial support of maternal and child medical service including a full cycle of antenatal, obstetric and neonatal services. Despite these government intentions, a unified approach to financing inpatient services and establishing appropriate prices for healthcare services still needs to be developed (22).

In order to improve geographical access to healthcare services, in 2013, under the influence of the government, private owners constructed and equipped 82 new outpatient facilities in different municipalities of Georgia. During 2010-2013, 150 medical hospitals were built/rehabilitated in the country. In 2013, a census of medical facilities was carried out in the whole country, followed by the development of detailed passports of healthcare facilities containing information regarding the volume of infrastructure, human and administrative resources (23).

\subsection{MATERNAL CARE IN GEORGIA}

The healthcare reforms significantly influenced maternal care, which is rather complex and fragmented in Georgia. Maternal care services are concentrated in specialized networks of obstetrics/gynecology specialty facilities, such as women's consultation centers and maternal houses. Over $95 \%$ of these facilities are private and most commonly are part of private hospital networks. More than $50 \%$ of obstetric care facilities have fewer than 500 births per year. Although antenatal care coverage with four full visits was $81.2 \%$ in 2016 (24), there are discrepancies between women in rural and urban areas in terms of the initiation of the first visit before 12 weeks of pregnancy, $86 \%$ vs $93 \%$ respectively (23). At the same time, preconception and postpartum care in Georgia is largely non-existent and gynecologic routine healthcare visits (outside pregnancy) are rare. Unlike antenatal care, post-natal care services are not part of the State-funded programs (25).

Although the coverage of facility based childbirth increased from 92\% in 1999 to $99.9 \%$ in 2016 (24), there is a scope to explore the adequacy of mechanisms for a timely detection of high-risk pregnant women, proper referral to the appropriate levels of care and information sharing and feedback between the levels of care (village ambulatory, women's consultation center, maternal hospital and emergency obstetric care facility). Often, perinatal healthcare centers, particularly in rural areas, which lack capacity to deal with obstetric and neonatal emergencies (shortage of personnel, medicines, equipment, blood bank etc.), either do not give referrals to higher level facilities, or do so with substantial delays (24). 
The quality of maternal care is influenced by the absence of mandatory continuing professional development (CPD) in the country. CPD is essential for the acquisition and retention of knowledge, attitudes, skills, behaviors and clinical outcomes, being a fundamental factor in the maintenance of certification of service providers (25). However, the Ministry of Internal Displaced Persons from Occupied Teritories, Labor, Health and Social Affairs (MoLHSA) does not have the legal power to control quality in the private medical facilities, which has created a policy challenge because of the massive privatization in the Georgian healthcare sector. The privatization process was not followed by appropriate regulation to protect patients' rights for receiving safe and quality medical services, as well as physicians' rights with regard to a systemic analysis and management of medical errors. The regulations on medical facilities licensing/permit and accreditation have to be revisited, primarily with regards to the infrastructure and human resources, in order to ensure compliance of the integrated model of medical service with internationally recognized criteria (26).

Also, the massive privatization made it possible for private providers to manipulate user fees in maternal care (26). Antenatal care visits beyond the four visits covered by the State, all medical tests, medications and extra child-birth costs are being paid out of pocket. In this regard, problematic pregnancies are charged much higher by providers. However, the vertical State programs only cover cases with serious complications, which may encourage women to postpone care-seeking behavior (25, $26,27)$. Consequently, access to high quality maternal care in Georgia is expensive and the State programs do not effectively protect women from this financial risk. Furthermore, there are substantial differences in the quality of care between providers, and women report difficulties in accessing those providers they deem wellqualified (28).

\subsection{AIMS AND OBJECTIVES OF THE DISSERTATION}

As outlined above, during the last three decades, Georgia was challenged by healthcare reforms, which also influenced maternal health. There is an urgent need of empirical evidence to support policy-makers to understand the barriers of improving maternal health in the country. Despite the common researchers' interest and an increasing body of evidence on maternal care worldwide, the evidence regarding various aspects of access, quality and cost of maternal care are still absent in Georgia and other post-Soviet countries. Therefore, the dissertation aims to increase our understanding of factors of maternal care financing, access, and quality in Georgia. Five principal research objectives underpin this dissertation, which are outlined below. 
The first objective of this dissertation is to explore the empirical evidence on the outcomes of the reform and to provide an evidence-based appraisal of the reform. The assessment of the waves of financial healthcare reforms and the impact of the reforms on the efficiency and quality of healthcare provision, as well as on equity in healthcare in Georgia will enable an understanding of the Georgian healthcare context compared with other neighbor countries. Adequate knowledge and application of outcome measures on health financing will assist in addressing disparities in maternal care in Georgia. Overall, a critical examination of the Georgian health financing system is important to identify how a market- based approach and privatization of public facilities influence the outcomes of the reforms in terms of sustainability in healthcare financing, equity, efficiency, quality and cost control. An investigation in this direction can provide evidence for policies to improve health financing, efficiency, equity and quality of healthcare. For health researchers, such investigation is important because it can outline the strengths and weaknesses of defining local context factors during the transition period for measuring the progress towards UHC of the population.

Financial sustainability and cost-effective interventions in healthcare sector are the main challenges for low- and middle-income countries and one of the determinants of maternal care outcomes in those countries (29). To understand the adequacy of the healthcare financing system and the outcomes of the Georgian healthcare reforms, a desk research is undertaken and the method of systematic literature review is applied to collect and analyze data. For the analytical appraisal of the healthcare reforms, the following indicators are used: financial sustainability, allocative and technical efficiency, equity in access and finance, transparency and accountability, utilization and quality of care. The review fills a gap in our knowledge on healthcare financing in Georgia and provides more insight into the determinants of healthcare financing. This allows outlining the strengths and the weaknesses of UHC program applied in Georgia. It also indicates ways of improvement.

Although, the government of Georgia prioritized reproductive health, particularly maternal care services from the very beginning of health system reform, existing studies have not fully examined access, quality and cost of maternal care. The second objective of the dissertation is to provide evidence on the changes in maternal care during the healthcare reforms in Georgia. Information on basic maternal care service exists $(28,30,31)$, with little evidence on how maternal care services were changed during the last few decades. Additionally, the few studies in Georgia applied a mix of quantitative and qualitative approaches to better understand maternal care barriers $(25,27,28)$. By applying a combination of qualitative and quantitative approaches, this dissertation triangulates the views of stakeholders regarding access, quality and financing of maternal care services. Such analysis provides an in-depth 
understanding of stakeholders' views on maternal care weaknesses in Georgia.

As a response to the United Nations (UN) international conference in 1994 in Cairo on Population and Development that defined reproductive health as a priority for the countries' health system development (32), in 1999, the Georgian Minister of Health of Georgia developed a national program entitled "Development of Reproductive Services in Georgia" and prioritized maternal health (2). Prior to the development of this national program, the country adapted the four-free antenatal visits model in 1996, which was in line with the WHO recommendation at that time, although this recommendation was later modified by the WHO (33). However, the country did not have a reliable health information system, which made it diffuclt to understand the health-related challenges and the need of relevant healthcare programs (34).

To address the second objective, data from three Reproductive Health Surveys (RHSs) are used. By applying secondary statistical analysis, this dissertation describes the changes in maternal care during the transition period. Such analysis provides an understanding of the utilization of antenatal and natal service and care during the two decades of healthcare reform. In addition, primary data were collected using qualitative techniques.

To explore the adequacy of maternal care financing and access of mothers to such services in Georgia is the third objective of this dissertation (4). Delivering patientcenter maternal care services requires multi stakeholders' involvement. Evidence on top-down uncoordinated planning and provision of maternal care services exists (6, 30). However, evidence on stakeholders' involvement in the decision-making process and their perspectives on addressing shortcoming of maternal care service do not exist. It is important to focus on providers, clients, decision makers and other stakeholders' attitude and participation in the assessment of maternal care services with the aim to capture mothers' needs with regard to financing of maternal care services. This dissertation examines the views of stakeholders about service provision and cost of maternal care services. Such investigation is important because it can outline the strengths and weaknesses of maternal care financing in Georgia, defining the context factors in the capital and two big regions of Georgia.

The involvement of stakeholders in the development of the maternal care system helps to identify and address barriers that are crucial. This is essential in countries with limited resources (4), like Georgia. Almost at all stages of the healthcare reform, Georgia prioritized maternal care and provided free antenatal care according to the guidelines of WHO and also several times during the reform, the State provided free childbirth care. However, problems related to the sufficiency and adequacy of these services are important issues in the fragmented health financial system. 
A qualitative design is used to address this objective. With this study, we explore the following topics: changes in maternal care financing and financial protection of pregnant women in Georgia and stakeholders' arguments in support of the current mechanism of maternal care financing. Lastly, we compare these arguments with stakeholders' arguments against the same system.

To study factors influencing maternal care in terms of quality and access is the fourth objective of this dissertation. Stakeholders' understanding of local context strategies that improve maternal care provision in terms of quality, access, continuity and comprehensiveness may enhance maternal utilization of maternal care services. To capture gaps in maternal care, this dissertation provides evidence on the quality, access, continuity and comprehensiveness of maternal care in the capital and two big regions of Georgia.

The implementation of free antenatal and natal services is essential for financial accessibility. However, the effectiveness of the implementation is crucial for reducing maternal mortality (35). According to the latest WHO guidelines, a normal uncomplicated pregnancy should result in the birth of a healthy child. To achieve the best outcomes of a pregnancy, it is required to model maternal care services, which ensure access to a good quality maternal care (36). As the stakeholders play a significant role in the development of maternal care services, an exploration of their opinions is important to understand the deficits in the maternal care system. Again, data collected in the qualitative study mentioned above, are used.

To study women's satisfaction with maternal care services in Georgia is the fifth objective of this dissertation. Existing empirical evidence on women's satisfaction shows that it is strongly influenced and shaped by socio-demographic characteristics of women as well as by a number of personal factors such as values, attitudes, threshold of pain, health literacy, and personal support $(29,39,40,41)$. Measuring consumer's satisfaction is an essential part of the assessment of healthcare services in terms of service quality, access and health system responsiveness. Studies about women's satisfaction with maternal care services in Georgia do not exist. Evidence on women's views and their satisfaction with maternal care services is important to inform maternal health program planners and implementers about the context factors that affect the acceptance of women and their households when they utilize maternal care services in Georgia. Based on survey data collected in a cross-section study, this dissertation explores the key factors influencing expected and perceived specific service quality as the predictors of clients' satisfaction. This evidence on women's satisfaction with maternal care services is important to identify the relationships between perceived specific service quality, satisfaction level, and reactions of the clients to the 
maternal care system Georgia. This is necessary for improving maternal care in Georgia.

Patient's satisfaction with healthcare services is predictive of patient's decisions regarding the choice of healthcare plans $(42,43)$ and treatment outcomes $(44)$. The patient characteristics associated with the general patient satisfaction including demographic factors, socioeconomic status (45-48) and general health status. Also, satisfaction is influenced by the manner in which healthcare is delivered, such as type of healthcare setting $(48,49)$ and characteristics of the medical provider $(50,51)$.

\subsection{RELEVANCE OF THE DISSERTATION}

Following the healthcare reforms, Georgia faced challenges in the health system and maternal care particularly. As maternal health is one of the most sensitive areas of the health system, frequent changes in the system affect maternal care outcomes. Due to the ambiguity of the effects of the resource allocation in maternal care program, concerns were raised. Access and quality of maternal care services is often the subject of public discourse $(11,12)$.

Although the dissertation focuses on Georgia, it is relevant for other post-Soviet countries as well because these countries have a similar background and all of them inherited the so called "Semashko" model of the health system. Findings from this dissertation provide countries in the post-Soviet space with strategies for delivering patient-centered maternal care. In addition, policy actions on the roles of stakeholders' views, policy implementation and monitoring will further enhance maternal service quality and satisfaction among the rural population. The emphasis in this dissertation is on the need for local context outcome measures. It is important to identify gaps in maternal care. To unearth evidence related to the knowledge gaps outlined above, this dissertation employs a broad perspective on maternal care. It challenges the adequacy of existing outcome measures in improving maternal care in Georgia. The study findings are of interest due to a lack of information about healthcare reforms done in Georgia since its independence. Evidence from stakeholders provides a baseline for the evaluation of the stakeholder support of maternal care.

The dissertation has social relevance and is directed to the protection of mothers and their households from high healthcare expenditure related to maternal care services. The dissertation focuses on generating new empirical evidence and understanding of existing policy trends to deliver patient-centered maternal care services. 


\subsection{OUTLINE OF THE DISSERTATION}

Following this introduction chapter, the main body of the dissertation is divided into five chapters in accordance with the research objectives

In chapter 2, we describe and discuss health financing in Georgia. The literature review is focused on the post-Soviet period of the country and explores all waves of healthcare reforms. The chapter also provides the characteristics of the current health system.

In chapter 3, we present a secondary analysis of three waves of RHSs that were done in Georgia in 1999-2000, 2005 and 2010. The chapter outlies the changes of maternal care services that took place over the years due to reforms.

Chapter 3 and 4 are based on a qualitative study that presents new evidence on maternal health financing, access and quality of care. Maternal care in terms of cost, quality and access were the main domains of these chapters. Quality is divided into clinical quality, social quality, and continuity of care and comprehensiveness of maternal care. For access, we focus on spatial (geographical) and temporal access.

Chapter 5 focuses on women's satisfaction with maternal care services. A new quantitative study is used to address this study objective. The presented analysis allows drawing conclusions on the determinants of satisfaction.

The dissertation is completed with Chapter 7 where the main findings are summarized and discussed. Recommendations to strengthen maternal care in Georgia are formulated. 



\section{Chapter 2}

Impact of Healthcare Reform on Universal Coverage in Georgia: A Systematic Review

This chapter draws upon:

Shengelia, L., Pavlova, M., \& Groot, W. Impact of Healthcare Reform on Universal Coverage in Georgia: A Systematic Review. 2016. Diversity and Equality in Health and Care, 13(5), 349-356. 



\section{ABSTRACT}

\section{Background}

To ensure UHC, Georgia has implemented reforms of its health system. A marketbased approach and privatization of public facilities were the major characteristics of the reform process.

\section{Methods}

In this chapter a systematic review is carried out to analyze the outcomes of the reforms in terms of sustainability in healthcare financing, equity, efficiency, quality and cost control.

\section{Results}

The evidence shows that because of a lack of strategic policy making capacity, the reforms were not successful. Subsequent changes in the reforms have undermined the sustainability of health financing, efficiency, equity and quality of healthcare. Massive privatization of the health sector without effective regulatory mechanisms has led to an impending risk of market failure.

\section{Conclusion}

To improve efficiency and effectiveness in the healthcare sector in terms of improving UHC, healthcare quality, financial protection of the general population and sustainability in health financing, improvement in the regulatory framework and a public-private mix regulatory system is a priority. 


\subsection{INTRODUCTION}

As in all fifteen Soviet Republics, healthcare financing in Georgia was a tax-based and centralized system providing UHC. After the collapse of the Soviet Union in 1991, the ability of the Georgian government to maintain this system diminished. Georgia was not in a position to tackle the sudden political and socio-economic changes. During the initial transitional phase, the government took initiatives to reform all public sectors including healthcare. Since then the country has been facing multiple challenges to ensure universal access to healthcare. This is witnessed by the fact that about $90 \%$ of healthcare expenses are currently financed through out-of-pocket payments (OPPs). The rapid transformation of the tax-based financing into financing through OPPs, was accompanied by reduced accessibility, affordability and utilization of healthcare facilities. Consequently, the changes were accompanied with increases in morbidity and mortality. This resulted in general dissatisfaction among the population and mistrust of the health system $(52,53)$.

The core financial reforms in the healthcare sector have focused on privatization along with a radical shift of the strongly hierarchical and centralized system towards a liberal market- based health system. During the first stage of the reform, Georgia implemented a system of social health insurance, which in the second stage was abolished and replaced by a system of private health insurance. However, the reform process was not successful to achieve universal access to healthcare and the transition process is still unfinished.

This chapter focuses on the reforms in the Georgian healthcare sector. The chapter reviews empirical evidence on the outcomes of the reform and to provide an evidencebased appraisal of the reform. To achieve this aim, the chapter first outlines the content of the reforms. Then, the impact of the reform on the efficiency and quality of healthcare provision, as well as on equity in healthcare, is analyzed based on a systematic review of evidence in previous publications. Finally, the chapter provides conclusions. The results presented here are relevant for policy making in Georgia but are also useful for other low- and middle-income countries that are contemplating ways to ensure UHC for their populations. 


\subsection{THE REFORM OF THE GEORGIAN HEALTHCARE SECTOR}

Though the socio-economic and political situation in Georgia changed during the postSoviet period, some citizen charters of the Soviet system that shaped the social, cultural and moral perspective of the people have remained unchanged. The population demand to retain the Semashko model of tax-funded universal free-of-charge healthcare services and for the preservation of the highly bureaucratic governance system are two examples out of others.

After becoming independent Georgia experienced a gradual economic recession, which had already started in the last decade of the Soviet era (54-57). The government faced multidimensional challenges including ensuring basic life-needs of citizens, political instability caused by the economic crisis, corruption, bureaucracy and weak governance $(58,59)$. As a result, government funding of the health system dropped. In 1991, total health expenditure (THE) was reduced to $1 \%$ of GDP. The insufficient resources for the healthcare sector coupled with a highly expensive health system and weak governance in healthcare seriously challenged the aim to provide universal coverage of basic healthcare needs. Most of the huge healthcare infrastructure required extensive repair and renovation. This shortfall was worsened by the shortage of equipment and diagnostic facilities. All those factors reduced access to healthcare services as well as the government's ability to assure healthcare provision with good quality and adequate access $(2,60)$.

\section{First stage of the reform}

Given the above-mentioned shortcomings, in 1994, the government took the initiative for a health system reform. In 1995, the government amended the Constitution and implemented the first stage of the healthcare reform. This reform stage was a devolution type of reform as the regional governments were given the responsibility to allocate resources, to contract with providers, to monitor service quality, and for budgeting, planning and implementing of local healthcare programs. However, the shortage of resources and weak governance became prominent barriers to the success of the reform (2). Practically, the planning, management, administration and decisionmaking process in the Health system suffered from interference from the central government, which made the reform process ineffective.

The introduction of social insurance was an important step during the first stage of the reform. A State Health Fund was created in 1995 to pool payroll contributions from employers and employees (at the rate of $3 \%$ and $1 \%$ of monthly salaries respectively). 
A government contribution covered for the unemployed, children and pensioners. The State Health Fund became the State Medical Insurance Company (SMIC) in 1997. In the same year, the government formed the Insurance State Supervision Service of Georgia to regulate the insurance system through an independent body $(2,60-64)$.

The government designed the BBP to cover basic healthcare needs of the population. The services included in the BBP were jointly funded by the SMIC, the municipality health fund and MoLHSA $(2,6,65,66)$. Services covered by the BBP were usually free of charge, but included co-payments for some selective diseases such as cancer treatment. The aim of the BBP was to ensure healthcare for the general population. However, it was an expensive and ambitious program for the newly independent Georgia. Underfunding, inadequate healthcare management and corruption became barriers to the successful implementation of the BBP and thereby, reduced general access to healthcare services.

The first stage of the reforms, including the SHI and the BBP, was stopped in 2004. In the same year, the government took the initiative to develop a private health insurance system along with the privatization of public healthcare facilities. The SMIC was reorganized and a new agency named the Health and Social Program Agency (HeSPA) was formed. One of the purposes of the HeSPA was to implement the State Health Insurance program. Later, in 2011, the HeSPA also was abolished and the MoLHSA took over its responsibilities.

\section{Second stage of the reform}

As the first stage of health reform was not successful in improving universal access to healthcare, the government initiated a second stage of health reform in 2004 . The main characteristics of the second reform stage were: re-centralization followed by privatization, reform of the primary healthcare sector, provision of private health insurance and a reorganization of the hospital sector.

A remarkable element of the second stage of the healthcare reforms was the withdrawal of all authority from the local governments to the central government. The central government took full authority of the healthcare budgeting and decision making related to health service provision and purchasing. However, the maintenance of the expensive healthcare infrastructure and excess staff were beyond the ability of the government. Added to that was the strong lobby and influence of the powerful private health providers that motivated the government to sell healthcare facilities to the private sector. Ultimately, the second stage of the healthcare reforms turned into a massive privatization of the health sector where nearly $100 \%$ of the government 
health facilities were sold to private owners by 2010.

The decision to privatize nearly all public health facilities was motivated by the obsolescence of the healthcare infrastructure, as well as by the over staffing, low motivation and low responsiveness of staff in these facilities. Also, the financial crisis, weak governance, population dissatisfaction, a new easy licensing and accreditation system and a strong influence of affluent private investors on the government played a role in the privatization decision (6). Large and influential pharmaceutical companies, who had already established a monopoly in the drug market, became the major owners of the privatized healthcare facilities. Due to the lack of regulatory control over the costs, the resulting monopolies in healthcare increased prices leaving the general population increasingly at risk of catastrophic health expenditure.

Private insurance was regulated by the Law of Insurance and Civil Code. At the beginning there were three health insurance companies. Since then, a private insurance market has emerged as an expanding actor in the Georgian health system. Also, during this period of the healthcare reform, private healthcare providers established private insurance companies and/or pharmaceutical companies. The goal was to maintain market competition, transparency, accountability and sustainability of the insurance market. The expansion of the private health insurance market in Georgia was implemented without assessing the needs and demands of the population, and without sufficient guaranties for financial aid for those who cannot afford to pay for healthcare and without formulating adequate control mechanisms over insurers to protect clients. As a result, cream skimming was not uncommon due to a lack of control and reliance on self-control of insurance companies.

In 2007, the government decided to buy insurance for the most vulnerable population groups of the country at private insurance companies. The government started a special programme for this purpose called "the State health insurance programme". Initially the government insured only people below the national poverty line, but later in 2009 , other population groups that were included as priority populations in that programme were internally displaced people, orphans, teachers, national actors, painters and laureates of the Rustaveli prize ${ }^{1}$.

The privatization of healthcare facilities and the financing system of the healthcare sector, was initiated without a national consensus $(2,6)$. As a result, the total system was under threat of reversal after a political transition. Ultimately, this financial reform did not contribute to an improved universal access to healthcare services.

1 Rustaveli prize was the highest prize from the government during Soviet power and laureates of this prize were scientists, artists, actors and etc. 


\section{Current stage of the reforms}

As a result of the healthcare reform, THE increased substantially. In 2011, it was 9.9\% of GDP. General Government healthcare expenditure as a percentage of THE increased from $19.8 \%$ in 2009 to $22.1 \%$ in 2011 (67). In 2011, Private Health Expenditure as a percentage of THE, was $77.9 \%$, of which contributions to private insurance companies and OPPs were about $4.4 \%$ and $89.2 \%$, respectively. The high percentage of OPPs indicates that the population is at risk of catastrophic health payments (68). By 2012, nearly $38 \%$ of the countries' population was insured by the State, and $8 \%$ enjoyed private and corporate insurance and the rest approximately $54 \%$ remained without any health insurance (69).

As already mentioned in the introduction, the government maintained the already existing State Health Insurance program and in February 2013, the UHC program "Health for All" was launched for more than two million citizens. With the implementation of the new program the government gave a healthcare guarantee to the entire population. The goals of UHC are: to increase geographic and financial access to primary healthcare; to rationalize expensive and high-tech hospital services by increasing PHC utilization; and to increase financial access to urgent hospital and outpatient services (69).

The first stage of the UHC program stipulated services of primary healthcare doctors/local (district) doctors and the management of emergencies both at the inpatient and the outpatient level. More than $80 \%$ of clinics nationwide were involved in the realization of the UHC program countrywide. From February 28 until July 1 of 2013, three blocks of services were provided under the UHC program: urgent outpatient assistance, urgent hospital assistance, scheduled outpatient and policlinic services. The second stage of the UHC program started on July 1, 2013. Contrary to the first stage, the MoLHSA offered six blocks of medical services to citizens: primary healthcare services, urgent outpatient assistance, extended urgent hospitalization, planned surgeries, treatment of oncological diseases, and childbirth. Besides, the volume of primary healthcare and emergency inpatient services has increased significantly (69). 


\subsection{METHODOLOGY}

To review the empirical evidence on the outcomes of the healthcare reforms in Georgia, a desk research is conducted. For the analytical appraisal of the healthcare reforms the following indicators are used: financial sustainability, allocative and technical efficiency, equity in access and finance, transparency and accountability, utilization and quality of care. The main motivation of using these indicators is to identify key actors and to analyze their roles in the health system of Georgia. The aim is to identify the challenges for health financing and universal access to healthcare and to determine interventions that may help to overcome barriers to the implementation of the reforms.

The following keywords and word combinations are used for the literature search: Georgia, healthcare reform, financing, efficiency, equity, quality, Georgia healthcare, Georgia health financing. Synonyms and variations in spelling are considered. The search for relevant publications with the above-mentioned keywords is conducted in the following databases: PubMed, Sciencedirect and Google Scholar. The literature was searched in September, 2014.

The language of publications is limited to English, Georgian and Russian. The search process excludes publications that provide only a general discussion of the effect of the healthcare reforms in Georgia without presenting relevant data, as well as publications prior to the implementation of such reforms that do not discuss its design or potential effects. Grey literature studies and informational papers are also captured. Publications are identified as relevant if they present empirical evidence and the results of original analysis on the quality, equity, efficiency and sustainability effects of the Georgian healthcare reforms (micro-and macro-level parameters). Quality of the selected articles is assessed by the Critical Appraisal Skills Programme (CASP)(70).

Publications from before the healthcare reforms are taken into account to outline the determinants, expectations and concerns related to the implementation of each step of the reform. Publications after the actual implementation of the Georgian healthcare reform are reviewed to analyze to what extent prior expectations and concerns are realized. 


\subsection{RESULTS}

\section{Description of the publications included in the review}

The initial search yielded 57 articles and reports in English and 10 in Georgian. Most of the articles and reports only provided a description of the reform focusing on the implementation stages. They included discussions and authors' personal perceptions about achievements and challenges of the ongoing reform but no empirical evidence. These articles and reports were excluded from the review. Only 36 articles and reports in English and 3 in Georgian met the relevance criteria (provided empirical evidence) and were included in the literature review (Appendix 1).

The characteristics of the publication included in the review are presented in the Table 2.1 and Appendix 1. As indicated in Table 2.1, the number of evidence-based publications on the health system reforms in Georgia has been growing since 1995. In English publications, attention is given to the entire reform period starting from 1991. The Russian articles are mainly focused on the analysis of the Soviet health system before Soviet era. The Georgian publications focus on the last stage of the reform. They mostly recent policy documents, unpublished papers for MoLHSA and health insurance companies as well as the national reports of MoLHSA are included as well. 
Table 2.1: Characteristics of evidence-based publications included in the review

\begin{tabular}{|c|c|c|}
\hline Number of publications & & References in Appenx 1 \\
\hline \multicolumn{3}{|l|}{ Year of publication } \\
\hline $1989-2000$ & 6 & $3,4,5,6,11,17,29$ \\
\hline $2001-2014$ & 33 & $\begin{array}{l}1,2,7,8,9,10,12,13,14,15,16,18,19,20,21,22 \\
23,24,25,26,27,28,29,30,31,32,33,34,35,36,37 \\
38,39\end{array}$ \\
\hline \multicolumn{3}{|l|}{ Reform period addressed } \\
\hline $1991-1995$ & 4 & $1,6,11,17$ \\
\hline $1996-2003$ & 12 & $2,7,8,9,10,12,13,15,17,36,37,38$ \\
\hline $2004-2014$ & 22 & $\begin{array}{l}12,14,15,16,18,19,20,21,22,23,24,25,26,27,28 \\
29,30,32,33,34,35,39\end{array}$ \\
\hline \multicolumn{3}{|l|}{ Type of publication } \\
\hline Journal article & 9 & $1,2,3,6,7,10,13,27,34$ \\
\hline Report & 23 & $\begin{array}{l}3,8,9,11,12,15,16,17,20,21,23,24,25,26,28,29 \\
30,33,33,35,36,37,38,39\end{array}$ \\
\hline Policy note & 1 & 14 \\
\hline Unpublished manuscript & 1 & 41 \\
\hline \multicolumn{3}{|l|}{ Type of empirical data } \\
\hline General statistics & 16 & $\begin{array}{l}7,9,11,14,15,16,17,18,19,20,21,23,24,25,26 \\
30,34,35\end{array}$ \\
\hline Survey data & 13 & $8,9,12,13,27,28,29,33,36,37,38,39$ \\
\hline $\begin{array}{l}\text { Mass media/publication } \\
\text { review }\end{array}$ & 2 & 5,22 \\
\hline \multicolumn{3}{|l|}{ Aim of the study } \\
\hline Macro parameters & 10 & $3,4,5,7,9,14,15,16,24,25$ \\
\hline Micro parameters & 22 & $\begin{array}{l}1,3,4,5,7,8,9,10,11,12,14,15,16,18,21,23,26 \\
27,28,29,30,32,34,35\end{array}$ \\
\hline Reform impact & 19 & $\begin{array}{l}2,6,7,9,12,13,15,16,21,28,29,32,33,35,36,37 \\
38,39\end{array}$ \\
\hline \multicolumn{3}{|c|}{ Classification of major findings } \\
\hline Financial sustainability & 23 & $\begin{array}{l}3,4,7,8,9,10,11,12,14,15,16,17,21,22,23,26 \\
27,28,29,32,34,36,37,38,39\end{array}$ \\
\hline Effects on efficiency & 12 & $7,9,12,15,16,20,21,22,28,29,34,39$ \\
\hline Equity of care & 14 & 8. $9,12,13,14,15,16,22,23,27,28,33,34,35,36,37$ \\
\hline Quality and use of care & 12 & $9,13,15,16,23,28,29,33,36,37$ \\
\hline
\end{tabular}


Most publications aim to study the micro and macro parameters of the health system. To assess the impact of the healthcare reform is also stated as a primary objective of some studies. As indicated in Table 2.1, we divided the major findings reported in the publications, into the following sub-groups: financial sustainability, allocative and technical efficiency, equity in access and finance, transparency and accountability, utilization and quality of care. Each sub-group is discussed separately.

\section{Effects on financial sustainability (system funding)}

Our review suggests that the development of the health system was negatively influenced by the frequent policy changes and the transition periods that accompanied the above- mentioned changes. The direction and priorities of the reforms depend on the ruling party and this corroborates the principal -"new lords, new laws".

The high level of OPPs indicates the inability of the public and private sector to ensure solidarity in the funding of the system. The population is unable to pay premiums for private insurance and moreover, consumers' trust in the private insurance companies is very low. Given the resource constraints people face, the utilization of healthcare services fell radically during the last two decades. The state could not maintain adequate service provision throughout the country (29). The situation changed dramatically in 2012, when the aim of the reform process shifted from the establishment of a market-regulated health system (69) to the achievement of UHC (71). With the purpose to protect the population, the new government doubled the budget of the MoLHSA in spite of the fact that the economic growth in the country was just $2.3 \%$ in 2013 (72). THE as a percentage of GDP in Georgia is typical for lowermiddle income countries (66). However, the State has implemented the new health program "Health for All" with the aim to ensure the basic needs of all population groups irrespective of their economic status (71). The literature provides no information about the effectiveness of the implemented the BBP.

The "Health for All" has been implemented through various insurance companies. The Social Service Agency is responsible for monitoring the program (71). Previously, private health insurance companies were actively involved in the hospital sector development project and in the state insurance program (SIP). After the implementation of the "Health for All" policy, the administrative body was changed. And the administration of the SIP is carried out by the State not by the health insurance companies themselves. Within one year after the start of the UHC program, one of the insurance companies announced bankruptcy due to debts to the health facilities. Another insurance company reported that the economic value of the 
insurance company had fallen by 35 percent in 2013. Our findings also show a gradual replacement of private health insurance companies with the development of the UHC program and their full exclusion from the SIP in 2014 (73). Some experts suggest that the private health insurance companies involved in the SIP will face financial difficulties and that the State will have to support them to avoid bankruptcy $(73,74)$. As a result, the private insurance sector will be forced to leave the Georgian hospital sector and the state may be confronted with the task to (re-)nationalize a big part of the hospital sector (73).

\section{Effects on efficiency and cost control}

The results of our review indicate that the introduction of the private health insurance mechanism in Georgia did not establish a purchaser-provider separation. The regulation of purchaser-provider relationships has not been updated and this is a significant gap in the current health legislation. Specifically, a healthcare provider is providing services through the State health insurance program. Private health insurance companies purchase the BBP for the State program "Health for All" as well as for the population below the poverty line and for voluntary schemes from their own health facilities. On the one hand, the State is purchasing healthcare services indirectly through the health insurance companies; on the other hand, the health insurance companies purchase health services from the facilities. The MoLHSA is contracting out the health insurance companies through tenders (72).

In the first stage of the reform in Georgia, the low official reimbursement rates and patient unawareness of the official hospital costs created an environment conducive to the shift of a large part of the real hospital costs to the patients, resulting in illegal patient charges (75). During the second stage of the healthcare reform, the key focus of the efficiency-oriented changes was to downsize the huge infrastructure of the health system because of the high maintenance costs. As a result, the utilization of hospital services and the average cost per patient stay decreased due to a reduction in the length of stay $(6,65,29)$. Following massive privatization, old health facilities were sold and replaced by health centers with multiple services provision. In 2012, hospital beds reduced by $9.9 \%$ compared to the previous year (76).

The optimum use of human resources is the indicator as well as objective of efficiency in healthcare. Some documents show that across the regions of Georgia, physicians' productivity increased from 25 patients to 29 patients annually per fulltime-equivalent physician during 2005-2007. At the same time, physicians' productivity failed to meet any reasonable standards and ranks, and it remained the lowest in the European and 
Commonwealth of Independent States region (65). Several reports have indicated that cost control was not an objective throughout the reform process. Fee-for-services reimbursement varied widely between facilities. Since there was no cost control mechanism, private investors were able to increase costs to maximize profits. Moreover, in the private market there are mergers between pharmaceutical companies and health facilities. As a result, supplier induced demand of healthcare services, was quite common in the private health market. As a consequence, there is the potential risk of impoverishing health expenditures for patients (6). We did not find publications that described the implementation of cost-containment mechanisms or that specifically addressed problems with allocative and technical efficiency.

\section{Effects on equity}

The publications in our review suggest that during the reform period, the situation with regard to equity changed dramatically since free access to healthcare services was no longer a key health policy principle. During the early 1990s, insured individuals lacked the right to choose their own providers and facilities. Due to information asymmetry and corruption, healthcare services were affordable only for a small elite group of people (77). In 2006, the State implemented the Medical Assistance Program (MAP) to provide health insurance to the poor population (6). The program was launched with the aim of improving equity and reducing the burden of catastrophic health expenditure for the poor population. Generally, the program was effective but the burden of the pharmaceutical cost was still high. A study showed that due to the exclusion of pharmaceutical cost from the basic BBP, the overall utilization of healthcare services did not increase (6). Changes in the eligibility criteria for BBP also proved to be a hurdle to improve service utilization (6). From the beginning of the MAP, most of the poor population was covered by the program. The State developed a proxy-means-tested system to identify poor households. Later due to budget constraints, the government changed the eligibility for the MAP (78-60).

In the second stage of the reform after the implementation of the private health insurance, the insurance companies freely manipulated the selection criteria and riskrated premiums for their own profits. Thereby, cream skimming was common (6). Moreover, there was a scope to improve access to healthcare service information in the private sector (both at health facilities and insurance companies), which is important for transparency, accountability and survival of the healthcare market in the state that intends to create a market for healthcare. Also, information asymmetry negatively influenced accessibility and utilization of healthcare services. People were discouraged to obtain insurance voluntarily and the risk of impoverishment remained 
because of unpredicted and unbearable healthcare expenses (6). OPPs created barriers for access to healthcare services. In the recent past when only one third of the population was covered by the various State Healthcare Programs, the majority of the households devoted a higher share of their monthly expenditure to healthcare. Some studies showed that OPPs were the result of declining economic status and worsening health outcomes of households (6). OPPs appeared as a burden for middle income households (81- 64). The implementation of the Health Maintenance Organizations (HMO) model increased inequity in the health system. The population did not have a chance to choose the health provider freely. They were obliged to get services from the local healthcare providers. The situation changed after the implementation of the UHC program. According to the order of the MoLHSA, every person is free to choose his or her own health provider.

\section{Effects on quality of care}

Among the inheritance of the Soviet area was a low medical quality of care especially in the regions. Since that period, one of the purposes of all stages of the healthcare reform was to improve the quality of health services. But so far, the evidence shows no significant changes in the quality of care since the start of the healthcare reform (69, 74).

The market-based health system had a negative effect on the quality of healthcare during the second stage of the healthcare reform. The lack of regulation and the abolishment of the accreditation system diminished the importance of quality of care for the health providers $(6,65)$. Some studies showed that consumers perceived quality of care as poor and stated the necessity to improve the quality of services, especially at the primary care level $(76,85,86)$. Since the implementation of the "Health for All" program, the MoLHSA has taken steps to improve quality of care. For example, by applying an evidence-based approach, an assessment of maternal care services was conducted throughout the county. As a result, perinatal service providers have been graded by their functional capabilities and a reorganization of the referral and emergency system has started (87). However, according to experts' opinion, this did not help to improve quality of care (74). The experts are also conservative about future changes in quality levels (74). We did not find publications that described healthcare quality. 


\subsection{DISCUSSION AND CONCLUSIONS}

Independence was a sudden political, social and economic turning event for Georgia. Politicians tried to cope with the challenges in all state sectors including healthcare. This chapter has reviewed the available empirical evidence on the effects of the Georgian healthcare reforms. We acknowledge the limitations of our review since we might have missed relevant studies that have not yet been reported. Nevertheless, the publications that we reviewed provide several points relevant to healthcare policy making in Georgia. The review indicates that population-centered political decisions towards achieving better health were not stable and successful. This was associated with the lack of strategic health policy making, lack of economic strength, quick transition of healthcare provision from the inherited centralized to a private market without control mechanisms, changes in the socio- cultural structure and lack of national consensus. As a result, the frequent changes in the healthcare reform processes have undermined the sustainability of health financing, efficiency and equity and quality of healthcare provision, and have resulted in market failures in terms of cost control and access to information, as well as in weak clients' trust in the healthcare sector.

As suggested by our results, the BBP and SHI system in the first stage of the reform were ambitious in terms of financial sustainability and regulatory capability. The government shifted most of the responsibility for healthcare provision to the market by transforming the inherent centralized health system into a market-based system, privatizing the public health facilities and establishing the insurance system. This, however, resulted in a reduction of accessibility and affordability of healthcare services. The root factor of that unsuccessful reform was clearly an asymmetry among government decision making and political foresight in terms of financial and regulatory capacity. In 2012, the new government took the political decision to achieve the "Health for All" objectives, which does not differ from the health reform objectives of the previous governments. Further, the government doubled the health budget despite the limited GDP growth (2.3\%) in 2013.

Based on above mentioned examples such as frequent changes of health policy, it is not unusual to doubt the financial sustainability of the Georgian healthcare sector. Again, sceptics predict the exclusion of private insurance companies from the SIP, which may result in public-private tension rather than partnership in health with further instability in the public health financing. 
Another crucial factor that seems to be associated with the instability of public financing of the healthcare sector is the unsuccessful reform towards a purchaser-provider split. As suggested by our review, there was in fact integration since during the second stage of reform, the influential monopoly owners of the pharmaceutical companies became the owners of the private facilities. Further, the healthcare market in Georgia, as in the other sectors of the economy, follows the principles of a complete open market economy free from any government control. Hence, the healthcare costs in the private market are the autonomy of the monopoly healthcare providers. This might be associated with the high OPPs even while THE as percentage of GDP in Georgia is considerably higher than in many other low and middle-income countries $(2,8)$.

Further, the publications reviewed suggest that equity in the Georgian healthcare sector has yet to improve even after decades of health reform initiatives. Though the government took initiatives to secure the poor population from impoverishing health expenditure, it was not adequately successful because of the financial constraint, lack of cost control in the private market and supplier induced demand. However, while the clients' right to choose their own provider was restricted in the HMO model in Georgia, it has been established in the recent "Health for All" reform strategy. Thus, it means that there might be some improvement in the coming future. Our review also indicates problems with healthcare quality. Low quality of healthcare services was in fact inherited from the Soviet era but so far there is no evidence that quality improvement has become a key objective during the reform stages. Moreover, in the private healthcare market, regulated competition is necessary for quality care. The influence of mergers and monopoly in the private market in Georgia has hindered healthcare quality. The abolition of the accreditation system and the lack of regulatory control also contributed to the lack of quality healthcare. Without the implementation of evidencebased strategic regulation, the current reform model might be least contributory to improve healthcare quality. Because of the lack of strategic policy making capacity in Georgia, the health reform initiatives of Georgia have not been successful. Due to the lack of regulatory control over private market, there exists an information asymmetry, an absence of regulated market competition and cost control; hence resulting in market failures. High OPPs with instability in the public health financing is related to inequity in the healthcare sector. While the healthcare market is privatized, an effective partnership between public and private parties is necessary. However, the present reform strategy may turn to public-private tension that may again result in the inadequate achievement of the current reform strategy. 



\section{Chapter}

\section{Changes in Maternal Care during the Healthcare Reforms in Georgia}

This chapter draws upon:

Shengelia, L., Pavlova, M., \& Groot, W. Changes in Maternal Care During the Healthcare Reforms in Georgia. Accepted 17 October, 2019 by International Journal of Childbirth. 



\section{ABSTRACT}

\section{Background}

Since 1991, the health system of Georgia has passed through several phases of reform. The aim of this study was to analyze the changes in the utilization of, and access to maternal care services during the period 1999-2010.

\section{Methods}

Secondary analysis was done using data from three national RHSs. From the three RHSs we selected 7,684 women who experienced childbirth/s during the 5 -years before each survey. We analyzed data on pregnancy outcome, type of childbirth, access and utilization of antenatal, natal and immediate post-natal care, and looked at associations with maternal age, ethnicity, educational level, employment status, residence, religion, and economic status.

\section{Results}

We found that the overall utilization of antenatal care services was quite high; in the first wave, it was $92.1 \%$ then increased to $95.1 \%$ and $98.1 \%$ in the second wave and in the third wave respectively. Rural dwellers, women with lower education level and women with lower income were less likely to utilize antenatal check-ups.

\section{Conclusion}

According to the findings, there were improvements in access to antenatal and natal care as well as the utilization of maternal care services over the years. Overall, the use of maternal care has improved during the reforms. 


\subsection{INTRODUCTION}

During the Soviet period, women in Georgia gave birth in large, damp, freezing maternal rooms, four to six women in a room, without a partner or family being present (90). Pregnant women were sometimes given useless or harmful medications and interventions, including unnecessarily induced labor and C-sections (90). The situation was similar in other Soviet republics and some Eastern European countries (6). As already mentioned in Chapter 1, Georgia has gone through a long period of socioeconomic and political transition and in 1995, the country-initiated healthcare reforms and took measures to improve the quality of healthcare, including maternal care (6).

The reform of the maternal health system was necessitated by the high and increasing pregnancy-related mortality and morbidity. In 1997, 112 per 1000 cases of complications with livebirth were registered, and the MMR was 70.8 per 100000 livebirths but it was reduced to 51.3 by 1999 (30). This was higher than in some other former-Soviet countries. In 1995, for example MMR in Armenia was 50 per 100000 livebirths and in Azerbaijan 86 per 100000 livebirths which in 2000, was reduced to 40 per 100000 livebirths and 48 per 100000 livebirths respectively (89).

In 1999, the Georgian Minister of Health initiated a national program titled "Development of Reproductive Services in Georgia" and prioritized the improvement of the reproductive health and maternal health system (2). Because of the absence of a health information system, as part of that program, in 1999-2000, the first populationbased RHS was conducted.

The RHS was repeated in 2005 and 2010. In fact, the RHS still is the only source of information about reproductive health in Georgia. Each wave provides basic information about the utilization of, and access to maternal care services. The surveys' outcomes provide program officials, researchers, and policymakers with information about the characteristics of women with health needs and about the factors that are associated with maternal morbidity and mortality, and other aspects of women's reproductive health behavior. Each wave of the RHS was conducted during a particular stage of the healthcare reform and reflected the impact of the changes in the health system $(31,90)$.

The first wave of RHS was conducted after a series of decrees, resolution and laws issued in the 1990s by the newly independent country. In particular, in 1997 a compulsory medical insurance based on payroll taxes, was implemented to cover all citizens of Georgia $(2,6)$. Prior to that, less than $2 \%$ of GDP was allocated to 
healthcare. This was increased to $3.7 \%$ in 2000 (30). During the late 1990s, total spending on health was about ten times higher than the amount allocated from the central budget and almost $87 \%$ of healthcare expenditure was out-of-pocket expenses (91). The fertility rate was slightly more than two births per woman and the MMR, although this had declined by 1999 (see above), was still higher than in most countries in Europe. As mentioned above, in 1999, the Minister of Health implemented the national program on the development of Reproductive Services with several components, such as family planning, STI-AIDS/HIV (sexually transmitted infection acquired immunodeficiency syndrome / human immunodeficiency virus) program, antenatal and perinatal surveillance, sexual education; and training for health professionals (30).

The second wave of the RHS was conducted after the rose revolution in 2003 (30). During this period, the MMR further declined but was still high at 45.5 per 100000 live births according to official sources (92). Additionally, the regional and socioeconomic disparities within the country were substantial. Several programs on reproductive health have been implemented since 2000. Most of them focused on client-centered family planning and reproductive health services, training of health professionals and public awareness campaigns about reproductive health (30). The State United Social Insurance fund of Georgia (SUSIF) covered the BBP for obstetric care, which included four free-of-charge antenatal visits at 13, 20- 22, 30- 32 and 36 weeks of pregnancy. Visits included taking down oral history, clinical examination, laboratory tests and ultrasound examination at 20- 22 weeks of pregnancy. It also included screening for syphilis, RH isoimmunization, and HIV. The SUSIF also covered the costs for threatened premature childbirth, pre- eclampsia/eclampsia and kidney pathologies (92). Beside these, the State provided a voucher of 400 Georgian currency "LARI" (GEL) (1 GEL = 2.98 Euro) for childbirth for socially vulnerable population groups. Vouchers for pregnant women from other social groups covered only $200 \mathrm{GEL}$ of childbirth cost (98).

The third wave of the RHS was conducted in 2010 after the massive privatization and liberalization of the health market (90). During this period, several maternal health programs were implemented. One of the programs, the Healthy Women in Georgia, was implemented by the United States Agency for International Development (USAID) with the primary focus on evidence-based, women-friendly, and client-focused family planning and reproductive health services (92).

Shortage and even absence of reliable data on the healthcare sector was a characteristic of all post-Soviet countries. The RHS surveys are an instrument for policy makers to assess reproductive needs of the population in Georgia. The RHS provide information that documents the changes in the maternal system in Georgia over the 
past two decades. We use these data to analyze the trends in the utilization of antenatal, natal and post-natal services. A similar study has not been done yet. The development of the Georgian health system stands out in the region because it has rapidly transformed from the centralized Soviet-type health system to a totally privatized one. Few countries have transformed so rapidly and completely, and many countries could learn from Georgia's reform process and its outcomes.

\subsection{METHODOLOGY}

The RHS was a joint venture between the National Center for Disease Control and Public Health of Georgia (NCDC), the United Nations Population Fund (UNFPA) and the Centers for Disease Control and Prevention, US. The key objective was to assess the country's progress on some specific indicators of reproductive health. The waves were designed to collect information from a representative sample of women of reproductive age (15-44 years) throughout Georgia.

The sampling frame and data collection for all three waves were similar except of the first wave when oversampling was done because of internally displaced people. Details about sampling frame are presented below.

The first RHS wave in 1999-2000 was conducted by in-person, face-to-face interviews with 7,798 women at their homes. The first stage of the three-stage sample design was a selection of census sectors with a probability proportional to the number of households. This was accomplished by a systematic sample with a random start in each stratum. This first sampling stage included 300 sectors. In the second stage of sampling, clusters of households were randomly selected in each census sector chosen in the first stage. The cluster-size was determined by the number of households required. The objective was to obtain an average of 20 completed interviews per cluster (38 households, on average). The total number of households in each cluster took into account the number of unoccupied houses, the average number of women aged 15-44 per household, the interview of only one respondent per household, and an estimated response rate of $90 \%$ in urban areas and $92 \%$ in rural areas. The field work for this first wave was conducted between November 7, 1999 and March 31, 2000. Thirty interviewers, specially trained in interview techniques, questionnaire content interviewers, mostly physicians, conducted the fieldwork. The desired sample size was about 6,000 respondents for the household sample, including an oversample of women in the Imereti region, and about 1,500 respondents for the sample of internally displaced people. Because the response rates were higher than expected, the actual sample size exceeded the projected sample size. In the 7,896 households 
with at least one eligible woman, 7,798 women were successfully interviewed (only one respondent was randomly selected per household), yielding a response rate of $98.8 \%$.

The second wave of the RHS took place in 2005 which was a population-based household survey similar to the first RHS. Approximately 6,000 women of reproductive age (15-44 years) participated in the survey. Face to face interviews with women were conducted regardless of marital status. Conversely from the first RHS, the sampling was done based on the Census 2002 (93). The sample design was based on the selection of census sectors, with the probability of selection proportional to the number of households in each of the 11 regional sectors. A systematic sampling process with a random starting point was used in each stratum. In total, 310 census sectors were selected as primary sampling units (PSUs). In the next stage of the sampling, clusters of households were randomly selected from each census sector chosen in the first stage. The approach to involve the household and the respondent in the survey was same as in the first RHS. Out of the 12,338 households selected in the household sample, 6,402 included at least one eligible woman (aged 15-44 years). Of these identified respondents, 6,376 women were interviewed, yielding a response rate of $99 \%$. The sampling frame for the third wave of RHS in 2010 was identical to that of the RHS 2005.

A similar questionnaire was used in all three waves except for some questions that were added in the last two surveys. For example, in case of maternal care, the question about "person provided the antenatal care during the last pregnancy" was added. The household questionnaire included questions on the household's composition, questions about the educational attainment of the household members and school readiness, and attendance among children and youth, socioeconomic characteristics of the household, and questions about the availability and type of social assistance received by household members. The questionnaire included questions on woman's education, employment, living arrangements, and other background characteristics as well as a marital history, sexual experience, pregnancy history and contraceptive use. Additional questions were included about maternal and child health, health-risk behaviors which may affect reproductive health (including smoking and drinking habits), women's health screening practices, and domestic violence.

We obtained the three datasets for our analyses after all personal information had been removed. For the purpose of our study, we selected a sample of women who had experienced childbirth during the last 5 years. This was done to minimize recall bias. Overall, 7684 respondents from all three waves met this criterion: 3050 womenrespondents from the 1999-2000 wave, as well as 2017 and 2617 women-respondents from the 2005 and 2010 waves respectively. We only analyzed data on pregnancy 
outcome, type of childbirth, access and utilization of antenatal, natal and immediate post-natal care, which are the main indicators for the evaluation of maternal care. These were our dependent variables. We also used data on socio-demographic and health status characteristics of the women-respondents, which were our independent (explanatory) variables.

Descriptive analysis of dependent and independent variables was done. Means and standard deviations of all variables were computed. We also applied regression analysis to examine the associations between each dependent variable and the set of independent variables, namely age, ethnicity, educational level, employment, residence, religion and economic status. Depending on the nature of the dependent variable, binary and multinomial regression analysis was performed using the backward selection technique. Nagelkerke $R^{2}$ was calculated for each regression model. Statistical Package for the Social Sciences (SPSS) (version 21) was used for data processing and analysis. We only interpret coefficients which are statistically significant $(p \leq 0.05$ or $p \leq 0.1)$.

\subsection{RESULTS}

The socio-demographic characteristics of the respondents included in our study are presented in Table 3.1. The sample for 1999- 2000 (3050 women) was larger than the samples for 2005 (2017 women) and 2010 (2617 women). 
Table 3.1: Socio-demographic characteristics of women included in the study per RHS wave

\begin{tabular}{|c|c|c|c|c|}
\hline & Variable categories & $\begin{array}{c}\text { RHS } \\
1999-2000 \\
(\mathrm{~N}=3050) \\
n(\%)\end{array}$ & $\begin{array}{c}\text { RHS } 2005 \\
\text { ( } N=2017) \\
n(\%)\end{array}$ & $\begin{array}{c}\text { RHS } 2010 \\
(\mathrm{~N}=2617) \\
n(\%)\end{array}$ \\
\hline \multirow[t]{6}{*}{ Age } & $15-19$ & $158(5.2 \%)$ & $102(5.1 \%)$ & $69(2.7 \%)$ \\
\hline & $20-24$ & $880(28.9 \%)$ & $571(28.3 \%)$ & $666(25.4 \%)$ \\
\hline & $25-29$ & 989 (32.4\%) & $652(32.3 \%)$ & $909(34.7 \%)$ \\
\hline & $30-34$ & $592(19.4 \%)$ & $410(20.3 \%)$ & $583(22.3 \%)$ \\
\hline & $35-39$ & $337(11.0 \%)$ & 199 (9.9\%) & $299(11.4 \%)$ \\
\hline & $40-44$ & $94(3.1 \%)$ & $83(4.1 \%)$ & $91(3.5 \%)$ \\
\hline \multirow{3}{*}{$\begin{array}{l}\text { Marital } \\
\text { status }\end{array}$} & Never married & $2(0.1 \%)$ & $1(0.0 \%)$ & - \\
\hline & Separated/divorced/widow & $106(3.5 \%)$ & $50(2.5 \%)$ & $85(3.2 \%)$ \\
\hline & Married/living with partner & $2942(96.5 \%)$ & $1966(97.5 \%)$ & $2532(96.8 \%)$ \\
\hline \multirow[t]{3}{*}{$\begin{array}{l}\text { Educational } \\
\text { status }\end{array}$} & $\begin{array}{l}\text { Complete secondary and } \\
\text { lower level }\end{array}$ & $342(11.2 \%)$ & $934(46.3 \%)$ & $1160(44.3 \%)$ \\
\hline & Technical education & $1052(34.5 \%)$ & $375(18.6 \%)$ & $332(12.7 \%)$ \\
\hline & $\begin{array}{l}\text { High school } \\
\text { level/postgraduate }\end{array}$ & $1656(54.3 \%)$ & 708 (35.1\%) & $1125(43.0 \%)$ \\
\hline \multirow{2}{*}{$\begin{array}{l}\text { Employment } \\
\text { status }\end{array}$} & No & $406(13.3 \%)$ & $293(14.5 \%)$ & $407(15.6 \%)$ \\
\hline & Yes & $2644(86.7 \%)$ & $1724(85.5 \%)$ & $2210(84.4 \%)$ \\
\hline \multirow{2}{*}{$\begin{array}{l}\text { Place } \\
\text { of living }\end{array}$} & Rural & $1466(48.1 \%)$ & 896 (44.4\%) & $1193(45.6 \%)$ \\
\hline & Urban & $1584(51.9 \%)$ & $1121(55.6 \%)$ & $1424(54.4 \%)$ \\
\hline \multirow{4}{*}{$\begin{array}{l}\text { Ethnic } \\
\text { background }\end{array}$} & Georgian & $2522(82.7 \%)$ & $1673(83 \%)$ & $2248(86 \%)$ \\
\hline & Armenian & $114(3.7 \%)$ & $130(6.4 \%)$ & 145 (5.5\%) \\
\hline & Azeri & 326 (10.7\%) & 151 (7.5\%) & $145(5.5 \%)$ \\
\hline & Other & $88(2.9 \%)$ & $63(3.1 \%)$ & 79 (3.0\%) \\
\hline \multirow[t]{3}{*}{ Religion } & Christian & 2534 (83.1\%) & $1700(84 \%)$ & 2306 (88.1\%) \\
\hline & Muslim & 448 (14.7\%) & 276 (14\%) & 248 (9.5\%) \\
\hline & Other & $68(2.2 \%)$ & $41(2.0 \%)$ & $63(2.4 \%)$ \\
\hline \multirow{3}{*}{$\begin{array}{l}\text { Socio- } \\
\text { economic } \\
\text { status }\end{array}$} & Low & 1392 (45.6\%) & 930 (46.1\%) & 304 (11.6\%) \\
\hline & Middle & 1357 (44.5\%) & 809 (40.1\%) & $1173(44.8 \%)$ \\
\hline & High & 301 (9.9\%) & 278 (13.8\%) & $1140(43.6 \%)$ \\
\hline
\end{tabular}


The majority of the women in all three RHS waves, were within the age bracket 20-34 years ( $N=6252)$. Most of them were highly educated and the absolute majority of them were married or living in partnership. Most of the women in the survey were Georgians and identified themselves as Christians; e.g. about $82.7 \%$ of the women in the 1999-2000 sample were ethnic Georgians', and their share increased to $86 \%$ during the RHS in 2010. The share of Christians was $83.1 \%$ in 1999 and increased slightly to $84 \%$ and $88.1 \%$ in 2005 and 2010 respectively.

Economic wealth seems to have increased between 1999 and 2010. The share of households with a low income was about 3-4 times lower in the 2010 wave compared with the RHS waves of 1999-2000 and 2005 respectively. At the same time, in the 2010 wave, there were more high-income households (Table 3.1). Most of the women in the survey were not employed.

Table 3.2 presents the utilization of maternal care services in the three waves. As shown in the table, the share of women who utilized antenatal care services was quite high, even during the first wave this share was $92.1 \%$. This share increased to $95.1 \%$ in the second wave and to $98.2 \%$ in the third wave. The mean number of antenatal visits increased through the waves of the survey, from about 7 in RHS 1999-200 to about 9 visits in RHS 2010.

The place where women received maternal care, changed through the years. According to the RHS 1999- 2000, antenatal care services in Georgia were provided mostly through women's consultation centers and ambulatories (78.2\%). Antenatal care was also provided by maternal hospitals but less often (13.7\%). In the RHS 2005 data, the share of women who received antenatal care in maternal hospitals was higher (39.8\%). Participants in the RHS 2010 were even more divided between the two categories; $45.3 \%$ receive antenatal care in maternal hospitals and $52.7 \%$ in women's consultation centers and ambulatories.

The share of mothers who got an ultrasound during the last pregnancy increased over the years. In 1999-2000, only 55.7\% women stated that they had ultrasound during the last pregnancy but the share of those who received ultrasound was higher in the last two waves and was $78.7 \%$ and $95.7 \%$, respectively. 
Table 3.2: Utilization of maternal care services according to RHS 1999-2000, 2005 and 2010

\begin{tabular}{|c|c|c|c|c|}
\hline \multicolumn{2}{|c|}{ Variable categories } & $\begin{array}{c}\text { RHS 1999-2000 } \\
\left(\begin{array}{c}\mathrm{N}=3050) \\
\mathrm{n}(\%)\end{array}\right. \\
\end{array}$ & \multirow{2}{*}{$\begin{array}{l}\text { RHS } 2005 \\
\text { (N=2017) } \\
\text { n (\%) } \\
98(4.9 \%)\end{array}$} & \multirow{2}{*}{$\begin{array}{c}\begin{array}{c}\text { RHS } 2010 \\
(\mathrm{~N}=2617) \\
\text { n (\%) }\end{array} \\
46(1.8 \%)\end{array}$} \\
\hline Antenatal care visits & No & $241(7.9 \%)$ & & \\
\hline pregnancy & Yes & 2809 (92.1\%) & 1919(95.1\%) & $2571(98.2 \%)$ \\
\hline \multirow{3}{*}{$\begin{array}{l}\text { Number of antenatal } \\
\text { visits during the last } \\
\text { pregnancy }\end{array}$} & Mean & 7.1335 & 8.2718 & 9.0707 \\
\hline & SD & 7.10997 & 9.42012 & 8.49249 \\
\hline & Missing & $241(7.9 \%)$ & $100(5.0 \%)$ & $42(1.6 \%)$ \\
\hline \multirow{3}{*}{$\begin{array}{l}\text { Place of the antenatal } \\
\text { care visits during } \\
\text { the last pregnancy }\end{array}$} & Home/other/missing & $249(8.1 \%)$ & $111(5.5 \%)$ & $53(2.0 \%)$ \\
\hline & Maternal hospital & 417 (13.7\%) & 802 (39.8\%) & $1186(45.3 \%)$ \\
\hline & $\begin{array}{l}\text { Women's consultation } \\
\text { center/ambulatory }\end{array}$ & $2384(78.2 \%)$ & $1104(54.7 \%)$ & $1378(52.7 \%)$ \\
\hline \multirow{4}{*}{$\begin{array}{l}\text { Person who provided the } \\
\text { antenatal care during the } \\
\text { last pregnancy }\end{array}$} & Nurse/midwife & No data & $11(0.5 \%)$ & $4(0.1 \%)$ \\
\hline & Physician & & 1906 (94.5\%) & $2571(98.1 \%)$ \\
\hline & Other/unattended & & - & $42(1.8 \%)$ \\
\hline & Missing & & $100(5.0 \%)$ & - \\
\hline \multirow{2}{*}{$\begin{array}{l}\text { Blood pressure } \\
\text { measurement during the } \\
\text { last pregnancy }\end{array}$} & No/don't remember & 341 (7.5\%) & $266(13.2)$ & 149 (5.7\%) \\
\hline & Yes & 2709 (92.5\%) & 1751 (86.8\%) & $2468(94.3 \%)$ \\
\hline \multirow{2}{*}{$\begin{array}{l}\text { Ultrasound examination } \\
\text { during last pregnancy }\end{array}$} & No & $1350(44.3 \%)$ & $430(21.3 \%)$ & $113(4.3 \%)$ \\
\hline & Yes & $1700(55.7 \%)$ & 1587 (78.7\%) & $2504(95.7 \%)$ \\
\hline \multirow{2}{*}{$\begin{array}{l}\text { Place of birth during the } \\
\text { last pregnancy }\end{array}$} & Home/other & $200(6.5 \%)$ & 154 (7.4\%) & $34(1.3 \%)$ \\
\hline & Hospital maternal & 2850 (93.5\%) & $1863(92.6 \%)$ & $2583(98.7 \%)$ \\
\hline \multirow{3}{*}{$\begin{array}{l}\text { Outcome of } \\
\text { the last pregnancy }\end{array}$} & Live birth (single) & 2995 (98.2\%) & $1982(98.3 \%)$ & 2595 (99.2\%) \\
\hline & Live birth (multiple) & $4(0.1 \%)$ & $1(0.4 \%)$ & - \\
\hline & Stillbirth & $51(1.7 \%)$ & $34(1.3 \%)$ & $22(0.8 \%)$ \\
\hline \multirow{3}{*}{ Type of childbirth } & Cesarean section & $194(6.4 \%)$ & $237(11.8 \%)$ & $588(22.5 \%)$ \\
\hline & $\begin{array}{l}\text { Vaginal childbirth/forceps/ } \\
\text { vacuum extraction }\end{array}$ & $2656(87.0 \%)$ & $1626(80.6 \%)$ & $2001(76.4 \%)$ \\
\hline & Missing & $200(6.6 \%)$ & $154(7.6 \%)$ & $28(1.1 \%)$ \\
\hline \multirow{3}{*}{$\begin{array}{l}\text { Professional who } \\
\text { attended the last } \\
\text { childbirth }\end{array}$} & Nurse/midwife & $141(4.7 \%)$ & $122(6.1 \%)$ & $37(1.4 \%)$ \\
\hline & Physician & $2862(93.8 \%)$ & $1819(90.2 \%)$ & 2545 (97.3\%) \\
\hline & $\begin{array}{l}\text { Other/unattended/ } \\
\text { traditional birth attendant }\end{array}$ & $47(1.5 \%)$ & $76(3.7 \%)$ & 35 (1.3\%) \\
\hline \multirow{2}{*}{$\begin{array}{l}\text { Post-natal visit after } 6 \\
\text { weeks }\end{array}$} & $\begin{array}{l}\text { No/don't } \\
\text { remember/missing }\end{array}$ & 2724 (89.3\%) & $1613(78 \%)$ & $2006(76.7 \%)$ \\
\hline & Yes & $326(10.7 \%)$ & $404(20.0 \%)$ & $611(23.3 \%)$ \\
\hline \multirow{2}{*}{$\begin{array}{l}\text { Complications required } \\
\text { medical attention during } \\
\text { the last pregnancy }\end{array}$} & No/don't remember & $2657(87.1 \%)$ & $1781(88.3 \%)$ & 2237 (85.5\%) \\
\hline & Yes & 393 (12.9\%) & 236 (11.7\%) & $380(14.5 \%)$ \\
\hline
\end{tabular}


In all RHS waves, the presence of skilled birth attendance was quite high as the absolute majority of Georgian women give birth in maternal hospitals.

The RHS 1999-2000 reported that $93.5 \%$ of births happened in maternal hospitals, which slightly decreased to $92.6 \%$ as shown by the RHS 2005 , and increased again in the last RHS wave to $98.7 \%$. Childbirth was mostly done by medical doctors, namely obstetricians. Their share in the total number of births was $97.3 \%$ according to the RHS 2010. Utilization of post-natal services was quite low in the country. According to the RHS $1999-2000$ only $10.7 \%$ of mothers utilized post-natal services 6 weeks after childbirth. Use of such services has increased over the years and was 23.3\% in 2010.

For further analysis of these data, binary logistic regression and multinomial regression was performed to identify the factors associated with maternal care. The analysis contains the following explanatory variables: age, educational and employment status, place of living, ethnic background, religion and social status. The full models containing all predictors, were statistically significant at $p<0.01$.

The strongest predictors of reporting antenatal visits were educational level, place of living, religion, socioeconomic status (see Table 3.3). Women with a secondary or lower education level, less often reported using antenatal care services compared to those with high school or postgraduate education. Similarly, women who lived in rural areas, less often reported using antenatal care services compared to those who live in urban places. Moreover, the highest income group more often utilizes antenatal care services compared to the other socioeconomic groups. Women in the age group 15-24 and 25-29 were more likely to utilize antenatal care services compared to the oldest age groups. Overall, pregnant women in the RHS 2010 were more likely to utilize antenatal care services compared to women in the previous waves.

Table 3.3 further shows that the utilization of ultrasonogram was less likely in the first wave and second wave than during the last RHS wave. Utilization of ultrasound was less likely for pregnant women with low socioeconomic status. Moreover, rural dwellers were less likely to utilize ultrasonogram compared to the reference categories. Measuring blood pressure was reported less often during the RHS 2005 than in the RHS 2010. C-sections became more frequent during the years while the cases of home-based childbirth decreased. Complications and utilization of ultrasound examination during the last pregnancy were less likely among women with secondary and lower education level compared to women with high school and postgraduate education level. Our study also showed that ethnic minorities, namely Azeri, Armenian and other groups were less likely to utilize post-natal care service compared to Georgians. 
Multinomial regression analysis (Table 3.4) showed that according to respondents in the RHS 1999-2000 and RHS 2005, nurse or/midwifes were more likely to attend childbirth. Muslim women and low-income pregnant women were more likely to be unattended compared to the respective reference groups. Respondents in the RHS 1999-2000 and RHS 2005 were less likely to utilize antenatal care services in the maternal hospitals than in women consultation centers. At the same time, the Armenian ethnic minority was more likely to utilize antenatal services and check-ups in a maternal hospital compared to Georgians. 
Table 3.3: Results of binary logistic regression

\begin{tabular}{|c|c|c|c|c|c|c|c|c|}
\hline & \multicolumn{2}{|c|}{$\begin{array}{c}\text { Antenatal care visit } \\
(\mathrm{N}=7684) \\
\text { No }=0 ; \text { Yes }=1\end{array}$} & \multicolumn{2}{|c|}{$\begin{array}{l}\text { Ultrasonogram } \\
(N=7684) \\
\text { No }=0 ; \text { Yes }=1\end{array}$} & \multicolumn{2}{|c|}{$\begin{array}{l}\text { Blood pressure measured } \\
(\mathrm{N}=7684) \\
\text { No }=0 ; \text { Yes }=1\end{array}$} & \multicolumn{2}{|c|}{$\begin{array}{c}\text { Pregnancy complication } \\
(\mathrm{N}=7684) \\
\text { No }=0 ; \text { Yes }=1\end{array}$} \\
\hline & $B(\mathrm{SE})$ & $p$-value & $B(\mathrm{SE})$ & $p$-value & $B(\mathrm{SE})$ & $p$-value & $B(\mathrm{SE})$ & $p$-value \\
\hline Constant & $6.01(0.47)$ & $<.01$ & $4.38(0.23)$ & $<.01$ & $3.83(0.37)$ & $<.01$ & $-1.46(0.19)$ & $<.01$ \\
\hline \multicolumn{9}{|l|}{ RHS } \\
\hline RHS $1999-2000$ & $-0.87(0.19)$ & $<.01$ & $-2.46(0.11)$ & $<.01$ & $0.34(0.15)$ & .03 & $0.03(0.08)$ & .95 \\
\hline RHS 2005 & $-0.42(0.20)$ & .03 & $-1.28(0.11)$ & $<.01$ & $-0.58(014)$ & $<.01$ & $-0,12(0.09)$ & .17 \\
\hline \multicolumn{9}{|l|}{ RHS 2010 (reference) } \\
\hline \multicolumn{9}{|l|}{ Residence } \\
\hline Rural & $-0.39(0.12)$ & $<.01$ & $-0.30(0.06)$ & $<.01$ & $-0.09(0.11)$ & .40 & $-0.06(0.07)$ & .35 \\
\hline \multicolumn{9}{|l|}{ Urban (reference) } \\
\hline \multicolumn{9}{|l|}{ Age category } \\
\hline Age group $15-24$ & $0.98(0.28)$ & $<.01$ & $0.25(0.18)$ & .16 & $-0.15(0.33)$ & .63 & $-0.07(0.18)$ & .69 \\
\hline Age group $25-29$ & $0.83(0.28)$ & $<.01$ & $0.01(0.17)$ & .94 & $-0.06(032)$ & .85 & $-0.22(0.18)$ & .22 \\
\hline Age group $30-34$ & $0.59(0.29)$ & .04 & $0.31(0.18)$ & .08 & $0.10(0.10)$ & .75 & $-0.11(0.18)$ & .54 \\
\hline Age group $35-39$ & $-0.20(0.31)$ & .51 & $-0.07(0.11)$ & .72 & $0.27(0.37)$ & .46 & $-0.30(0.20)$ & .12 \\
\hline \multicolumn{9}{|l|}{$\begin{array}{l}\text { Age group } 40-44 \\
\text { (reference) }\end{array}$} \\
\hline \multicolumn{9}{|l|}{ Religion } \\
\hline Muslim & $0.56(0.27)$ & .04 & $0.37(0.19)$ & .21 & $0.94(0.33)$ & .77 & $0.18(0.29)$ & .52 \\
\hline Other & $1.88(0.16)$ & $<.01$ & $0.71(0.11)$ & $<.01$ & $0.79(0.21)$ & $<.01$ & $0.38(0.17)$ & .02 \\
\hline Christian (reference) & & & & & & & & \\
\hline
\end{tabular}


Table 3.3: Results of binary logistic regression (continuation)

\begin{tabular}{|c|c|c|c|c|c|c|c|c|}
\hline & \multicolumn{2}{|c|}{$\begin{array}{c}\text { Antenatal care visit } \\
(N=7684) \\
\text { No }=0 ; \text { Yes }=1\end{array}$} & \multicolumn{2}{|c|}{$\begin{array}{c}\text { Ultrasonogram } \\
(\mathrm{N}=7684) \\
\text { No }=0 ; \mathrm{Yes}=1\end{array}$} & \multicolumn{2}{|c|}{$\begin{array}{c}\text { Blood pressure measured } \\
(\mathrm{N}=7684) \\
\text { No }=0 ; \text { Yes }=1\end{array}$} & \multicolumn{2}{|c|}{$\begin{array}{l}\text { Pregnancy complication } \\
(\mathrm{N}=7684) \\
\text { No }=0 ; \text { Yes }=1\end{array}$} \\
\hline & $B(\mathrm{SE})$ & $p$-value & $B(\mathrm{SE})$ & $p$-value & $B(\mathrm{SE})$ & $p$-value & $B(\mathrm{SE})$ & $p$-value \\
\hline \multicolumn{9}{|l|}{ Education } \\
\hline Secondary and less & $-1.21(0.21)$ & $<.01$ & $-0.92(0.09)$ & $<.01$ & $-0.24(0.15)$ & .10 & $-032(0.09)$ & $<.01$ \\
\hline Technical education & $-0.42(0.24)$ & .08 & $-0.46(0.08)$ & $<.01$ & $-0.12(0.17)$ & .49 & $-0.10(0.09)$ & .28 \\
\hline \multicolumn{9}{|c|}{$\begin{array}{l}\text { High school/postgraduate } \\
\text { (reference) }\end{array}$} \\
\hline \multicolumn{9}{|l|}{ Employment status } \\
\hline Unemployed & $-0.04(0.22)$ & .84 & $0.21(0.10)$ & .03 & $-0.22(0.19)$ & .23 & $0.13(0.10)$ & .19 \\
\hline \multicolumn{9}{|l|}{ Employed (reference) } \\
\hline \multicolumn{9}{|l|}{ Socioeconomic status } \\
\hline Low income & $-2.21(0.35)$ & $<.01$ & $-1.73(0.13)$ & $<.01$ & $-0.39(0.18)$ & .03 & $-0.31(0.11)$ & $<.01$ \\
\hline Middle income & $-1.15(0.36)$ & $<.01$ & $-0.73(0.13)$ & $<.01$ & $-0.01(0.16)$ & .90 & $-0.01(0.09)$ & .99 \\
\hline \multicolumn{9}{|c|}{ High income (reference) } \\
\hline \multicolumn{9}{|l|}{ Ethnicity } \\
\hline Armenian & $0.57(0.26)$ & .03 & $-0.52(0.19)$ & $<.01$ & $0.40(0.32)$ & .21 & $-1.22(0.30)$ & $<.01$ \\
\hline Azeri & $0.87(0.23)$ & $<.01$ & $0.19(0.15)$ & .21 & $0.76(0.25)$ & $<.01$ & $-0.35(0.18)$ & .05 \\
\hline Other & $0.41(0.31)$ & .19 & $-0.22(0.18)$ & .22 & $-0.31(0.29)$ & .28 & $-0.72(0.24)$ & $<.01$ \\
\hline \multicolumn{9}{|l|}{ Georgian (reference) } \\
\hline Nagelkerke $\mathbf{R}^{\mathbf{2}}$ & \multicolumn{2}{|c|}{0.255} & \multicolumn{2}{|c|}{0.380} & \multicolumn{2}{|c|}{0.072} & \multicolumn{2}{|c|}{0.028} \\
\hline
\end{tabular}


Table 3.3: Results of binary logistic regression (continuation)

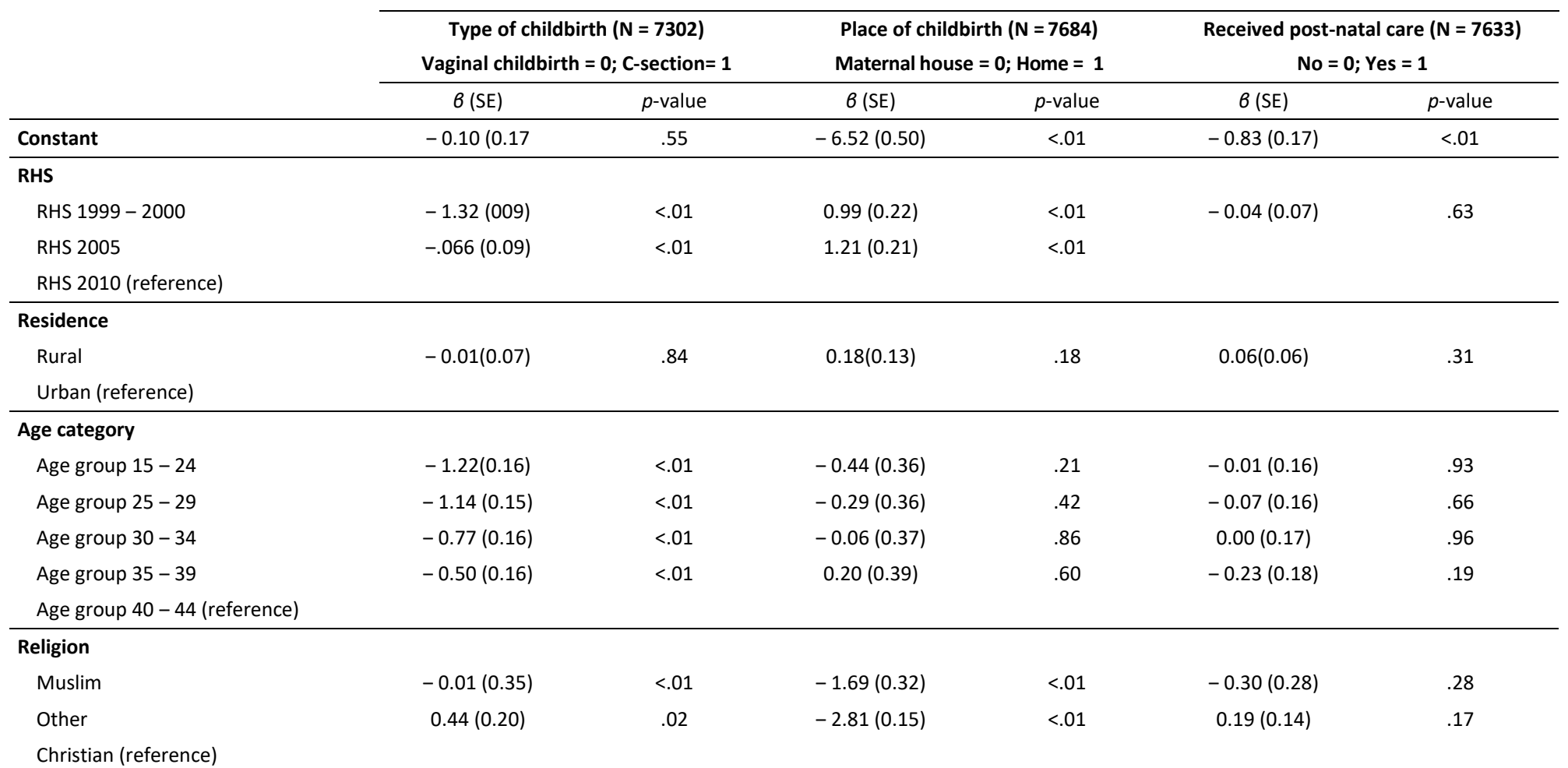


Table 3.3: Results of binary logistic regression (continuation)

\begin{tabular}{|c|c|c|c|c|c|c|}
\hline & \multirow{2}{*}{\multicolumn{2}{|c|}{$\begin{array}{c}\text { Type of childbirth }(\mathrm{N}=7302) \\
\text { Vaginal childbirth }=0 ; \mathrm{C} \text {-section }=1\end{array}$}} & \multirow{2}{*}{\multicolumn{2}{|c|}{$\begin{array}{l}\text { Place of childbirth }(\mathrm{N}=7684) \\
\text { Maternal house }=0 ; \text { Home }=1\end{array}$}} & \multirow{2}{*}{\multicolumn{2}{|c|}{$\begin{array}{c}\text { Received post-natal care }(\mathrm{N}=7633) \\
\text { No }=0 ; \text { Yes }=1\end{array}$}} \\
\hline & & & & & & \\
\hline & $B(\mathrm{SE})$ & $p$-value & $B(\mathrm{SE})$ & $p$-value & $B(\mathrm{SE})$ & $p$-value \\
\hline \multicolumn{7}{|l|}{ Education } \\
\hline Secondary and less & $-0.37(0.09)$ & .09 & $1.04(0.22)$ & $<.01$ & $-0.47(0.81)$ & $<.01$ \\
\hline Technical education & $-0.23(0.10)$ & .02 & $-0.42(0.17)$ & .15 & $-0.24(0.89)$ & .02 \\
\hline \multicolumn{7}{|c|}{$\begin{array}{l}\text { High school level/postgraduate } \\
\text { (reference) }\end{array}$} \\
\hline \multicolumn{7}{|l|}{ Employment status } \\
\hline Unemployed & $0.11(0.09)$ & .23 & $0.11(0.25)$ & .69 & $0.08(0.08)$ & .35 \\
\hline \multicolumn{7}{|l|}{ Employed (reference) } \\
\hline \multicolumn{7}{|l|}{ Socioeconomic status } \\
\hline Low income & $-0.14(0.11)$ & .20 & $1.76(0.32)$ & $<.01$ & $-0.39(0.99)$ & $<.01$ \\
\hline Middle income & $0.01(0.08)$ & .88 & $0.53(0.32)$ & .10 & $-0.17(0.07)$ & .02 \\
\hline \multicolumn{7}{|c|}{ High income (reference) } \\
\hline \multicolumn{7}{|l|}{ Ethnicity } \\
\hline Armenian & $-0.39(0.35)$ & .27 & $-0.97(0.26)$ & $<.01$ & $-1.24(0.26)$ & $<.01$ \\
\hline Azeri & $0.29(0.23)$ & .20 & $-1.18(0.24)$ & $<.01$ & $-0.26(0.16)$ & $<.01$ \\
\hline Other & $-0.53(0.30)$ & .08 & $-0.21(0.32)$ & .51 & $-1.05(0.24)$ & $<.01$ \\
\hline \multicolumn{7}{|l|}{ Georgian (reference) } \\
\hline Nagelkerke $\mathbf{R}^{\mathbf{2}}$ & \multicolumn{2}{|c|}{0.116} & \multicolumn{2}{|c|}{0.363} & \multicolumn{2}{|c|}{0.073} \\
\hline
\end{tabular}


Table 3.4: Results of multinomial logistic regression (continuation)

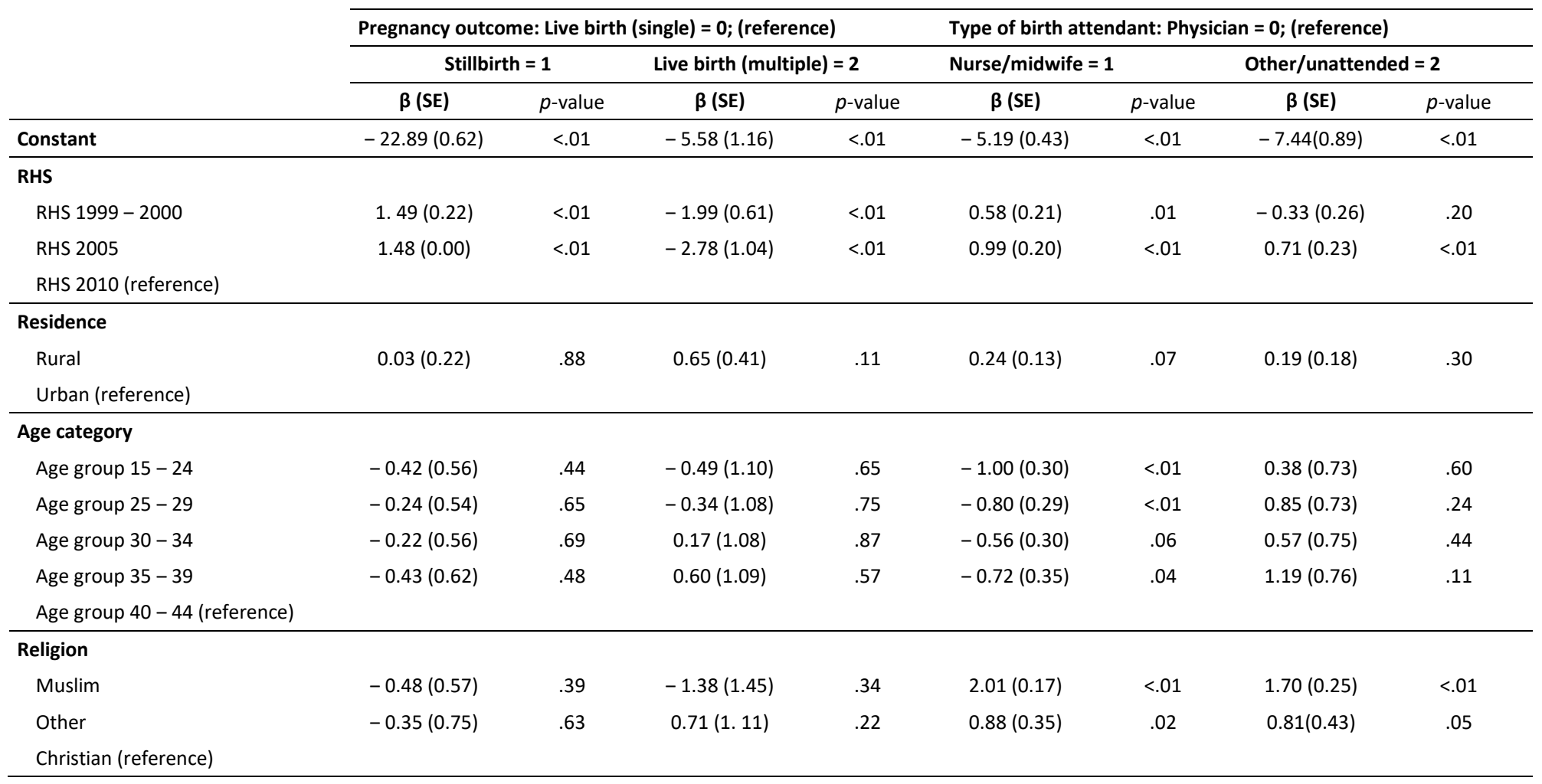


Table 3.4: Results of multinomial logistic regression

\begin{tabular}{|c|c|c|c|c|c|c|c|c|}
\hline & \multirow{2}{*}{\multicolumn{4}{|c|}{ Pregnancy outcome: Live birth (single) = 0; (reference) }} & & & & \\
\hline & & & & & \multicolumn{4}{|c|}{ Type of birth attendant: Physician = 0; (reference) } \\
\hline & \multicolumn{2}{|c|}{ Stillbirth = 1} & \multicolumn{2}{|c|}{ Live birth (multiple) = 2} & \multicolumn{2}{|c|}{ Nurse/midwife = 1} & \multicolumn{2}{|c|}{ Other/unattended = 2} \\
\hline & $\beta$ (SE) & $p$-value & $\beta$ (SE) & $p$-value & $\beta$ (SE) & $p$-value & $\beta$ (SE) & $p$-value \\
\hline \multicolumn{9}{|l|}{ Education } \\
\hline Secondary and less & $0.41(0.29)$ & .16 & $0.99(0.55)$ & .07 & $0.80(0.20)$ & $<.01$ & $0.47(0.26)$ & .06 \\
\hline Technical education & $-0.16(0.34)$ & .62 & $1.24(0.56)$ & .02 & $-0.14(0.25)$ & .57 & $-0.20(0.33)$ & .54 \\
\hline \multicolumn{9}{|c|}{$\begin{array}{l}\text { High school/postgraduate } \\
\text { (reference) }\end{array}$} \\
\hline \multicolumn{9}{|l|}{ Employment status } \\
\hline Unemployed & $-0.43(0.30)$ & .15 & $-0.03(0.57)$ & .94 & $-0.06(0.22)$ & .78 & $1.20(0.47)$ & $<.01$ \\
\hline \multicolumn{9}{|l|}{ Employed (reference) } \\
\hline \multicolumn{9}{|l|}{ Socioeconomic status } \\
\hline Low income & $-0.29(0.37)$ & .43 & $-0.38(0.68)$ & .57 & $1.66(0.32)$ & $<.01$ & $1.18(0.35)$ & $<.01$ \\
\hline Middle income & $-0.03(0.35)$ & .92 & $-0.05(0.45)$ & .91 & $0.83(0.32)^{*}$ & $<.01$ & $0.54(0.33)$ & .10 \\
\hline \multicolumn{9}{|c|}{ High income (reference) } \\
\hline \multicolumn{9}{|l|}{ Ethnicity } \\
\hline Armenian & $-0.39(0.60)$ & .51 & $-1.47(2.83)$ & .99 & $-0.07(0.32)$ & .81 & $0.38(0.37)$ & .30 \\
\hline Azeri & $0.06(0.68)$ & .92 & $1.90(1.46)$ & .19 & $-0.36(0.19)$ & .06 & $0.23(0.27)$ & .39 \\
\hline Other & $0.95(0.45)$ & .03 & $0.07(1.09)$ & .94 & $0.28(0.31)$ & .37 & $1.33(0.30)$ & $<.01$ \\
\hline \multicolumn{9}{|l|}{ Georgian (reference) } \\
\hline Nagelkerke $\mathbf{R}^{2}$ & \multicolumn{4}{|c|}{0.105} & \multicolumn{4}{|c|}{0.214} \\
\hline
\end{tabular}


Table 3.4: Results of multinomial logistic regression (continuation)

\begin{tabular}{|c|c|c|c|c|}
\hline & \multicolumn{4}{|c|}{ Women consultation center/ambulatory= 0 ; (reference) } \\
\hline & \multicolumn{2}{|c|}{ Maternal hospital = 1} & \multicolumn{2}{|c|}{ Home/Other = 2} \\
\hline & $\beta$ (SE) & $p$-value & $\beta(\mathrm{SE})$ & $p$-value \\
\hline Constant & $-0.02(0.16)$ & .86 & $-4.97(1.24)$ & .<.01 \\
\hline \multicolumn{5}{|l|}{ RHS } \\
\hline RHS $1999-2000$ & $-1.74(0.07)$ & $<.01$ & $-0.61(0.50)$ & .21 \\
\hline RHS 2005 & $-0.31(0.06)$ & $<.01$ & $0.32(0.48)$ & .50 \\
\hline \multicolumn{5}{|l|}{ RHS 2010 (reference) } \\
\hline \multicolumn{5}{|l|}{ Residence } \\
\hline Rural & $-0.55(0.05)$ & $<.01$ & $-1.15(0.45)$ &.$<.01$ \\
\hline \multicolumn{5}{|l|}{ Urban (reference) } \\
\hline \multicolumn{5}{|l|}{ Age category } \\
\hline Age group $15-24$ & $0.06(0.15)$ & .70 & $-1.27(0.82)$ & .12 \\
\hline Age group $25-29$ & $0.14(0.15)$ & .34 & $-1.35(0.82)$ & .09 \\
\hline Age group $30-34$ & $0.03(0.15)$ & .82 & $-0.88(0.83)$ & .29 \\
\hline Age group $35-39$ & $-0.03(0.16)$ & .98 & $-0.11(0.84)$ & .88 \\
\hline \multicolumn{5}{|c|}{ Age group $40-44$ (reference) } \\
\hline \multicolumn{5}{|l|}{ Religion } \\
\hline Muslim & $-0.48(0.13)$ & .71 & $1.61(0.53)$ & $<.01$ \\
\hline Other & $-0.44(0.20)$ & .03 & $-1.40(0.00)$ & $<.01$ \\
\hline \multicolumn{5}{|l|}{ Christian (reference) } \\
\hline \multicolumn{5}{|l|}{ Education } \\
\hline Secondary and less & $0.03(0.07)$ & .60 & $-0.13(0.46)$ & .07 \\
\hline Technical education & $0.07(0.07)$ & .03 & $-1.25(0.78)$ & .11 \\
\hline \multicolumn{5}{|c|}{$\begin{array}{l}\text { High school/postgraduate } \\
\text { (reference) }\end{array}$} \\
\hline \multicolumn{5}{|l|}{ Employment status } \\
\hline Unemployed & $-0.02(0.08)$ & .77 & $1.79(1.04)$ & .08 \\
\hline \multicolumn{5}{|l|}{ Employed (reference) } \\
\hline \multicolumn{5}{|l|}{ Socioeconomic status } \\
\hline Low income & $0.36(0.08)$ & $<.01$ & $-0.25(0.58)$ & .66 \\
\hline Middle income & $0.07(0.07)$ & .83 & $-0.33(0.50)$ & .50 \\
\hline \multicolumn{5}{|c|}{ High income (reference) } \\
\hline \multicolumn{5}{|l|}{ Ethnicity } \\
\hline Armenian & $0.31(0.12)$ & $<.01$ & $-1.93(0.00)$ & .11 \\
\hline Azeri & $0.17(0.16)$ & .27 & $-0.61(0.69)$ & .37 \\
\hline Other & $-0.54(0.18)$ & $<.01$ & $0.72(0.67)$ & .10 \\
\hline \multicolumn{5}{|l|}{ Georgian (reference) } \\
\hline Nagelkerke $\mathrm{R}^{2}$ & & & & \\
\hline
\end{tabular}




\subsection{DISCUSSION}

In this study, we analyzed the changes in the utilization of maternal care services during the period 1999-2010 based on data from the RHS. The key findings in this study are that during the period 1999-2010, the use of maternal care services increased while the type of maternal care facilities and professionals who delivered the care changed. The utilization of primary care facilities as well as services delivered by nurses decreased. At the same time, the uses of hospital-based care and services delivered by physicians increased. We also found that women's education, economic status and living place, among other factors, influence the utilization of maternal care services.

The first wave of the RHS was done in 1999-2000, at a time when the immediate effect of the transition period and the consecutive healthcare reform was felt. The centralized public provision of healthcare was reformed through a market-based massive privatization of healthcare facilities and the delivery system, including maternal care. Antenatal care providers gradually changed from urban circumscriptions or rural dispensaries to women consultation centers and maternal houses. Prior to the first wave, the women consultation centers and maternal houses/units were managerially independent and incorporated under corporate law. Still, they remained in public ownership through $100 \%$ government shareholding, i.e. the government had the responsibility for budgeting and contracting (6). In this situation, the maternal health system was at least formally managed by the State. However, the weak regulation of the publicly-owned healthcare providers created an environment of informal payments, low quality and lack of access. Mothers received antenatal services in the women consultation centers, which were the only provider of this kind of services during the Soviet period and in the early 1990s (30). As our findings showed, only $13.7 \%$ of women received antenatal care in maternal hospitals/units according to the RHS 1999-2000 data. Later, in 2003, the second stage of the healthcare reforms started and maternal houses and women consultation centers were privatized. The process of privatization finished in 2007 (6). As our results show, the utilization of antenatal services increased between 1999 and 2005. During this period the number of providers ofantenatal care services increased as the maternal houses started providing antenatal check-ups and they established women consultation centers within the maternal houses. More women could freely use antenatal services in maternal houses and could choose their own provider, i.e., "personal doctor" (6). In the market-based healthcare provision, competition between providers to offer good quality care became evident, which was nearly absent in the previous centralized public health system. 
Unlike Georgia, Azerbaijan and Armenia maintained the centralized public health system as it was during the Semashko system. Accordingly, maternal care in Azerbaijan and in Armenia is organized through an extensive system of ambulatory polyclinic and maternity hospitals. The network of ambulatory health care in both countries is organized within geographical regions and is offered through women's consultation polyclinics and rural health facilities. Obstetric care is offered at obstetricgynecological departments in hospitals, regional maternity hospitals located in urban areas, and national centers for specialized (tertiary) care. The same system of maternal care is maintained in Ukraine and Russia $(94,95)$.

As mentioned above, our findings show that the utilization of maternal health facilities increased over the years. For example, mothers used more antenatal services and had childbirth in the maternal houses more frequently in the RHS 2010 than in the previous two RHS waves, which is due to the increased availability of comprehensive maternal care services in the maternal houses including antenatal care, childbirth care and immediate post-natal care. Availability and continuity of care during pregnancy is crucial to motivate mothers to use necessary maternal care. As there was no link between the separately standing women consultation centers and maternal houses, women preferred to have a specialist who is in charge of pregnancy monitoring and at the same time can care for them during childbirth and provide immediate post-natal care $(30,31)$. Provision of antenatal and natal services at the same place was one of the positive effects of the reform.

We found that most of the childbirths were facility-based and conducted by skilled birth attendants. Following the Soviet period, the health system faced a serious regulatory and financial crisis. In particular, the number of home-based childbirths increased. As shown by the RHS 1999-2000 data, the share of home births or otherplace births was $8.1 \%$. This dropped to $2 \%$ in the last RHS wave $(30,31,90)$. After the healthcare reform, the country started the State maternal care programs that were accessible only through the women consultation centers or maternal houses, and access to maternal care services was improved. As a result, the share of home-based childbirth declined. The Soviet-style health system relied on hospital-based specialized care including intrapartum care, which was also inherited by independent Georgia. Throughout the former Soviet countries, childbirths outside of health facilities were uncommon and occurred mainly in rural areas among elderly multiparous women, as well as illiterate or low-educated women (96). For example, only $1 \%$ of total childbirths in Ukraine took place outside of health facilities. Home-based births were more common in the Caucasus region. In Azerbaijan, $26 \%$ of the total childbirths occurred outside of health facilities, which were over three times higher than in Georgia and Armenia (97). 
The healthcare privatization in Georgia also changed the access to and quality of maternal care services. The number of maternal houses increased after the privatization (90). One reason for this might be that maternal care has always been linked with the State funding programs, which provided a very good income for the health facility owners as the State implemented programs for antenatal and natal care through private hospitals. For example, as we found, the average number of antenatal visits, was seven throughout all RHS waves, while only four antenatal care visits were fully reimbursed by the State. Additional visits were usually suggested by the providers and had to be paid for out of pocket (98). Some studies indicated that the health reforms in Georgia had mixed effects on maternal care (99). However, other empirical studies found that the reforms had a negative impact on maternal care service provision and utilization, as the change process could strain working relationships or overload health workers $(27,100,101)$. Instead, the impact on maternal care depended on the structure of the health system, and the lack of reforms could be equally problematic (99). For example, a lack of reforms has been seen in some former Soviet countries, e.g. Ukraine, Armenia, Azerbaijan, and Russia. The transition from the Soviet period came with a lack of progress in many health indicators $(27,100-104)$.

At the same time, the reform of the Georgian health system shows that there was no simple linear relation between a set of reform measures and their impact. For example, the introduction of user fees reduced the utilization of maternal care services $(6,93)$. However, the removal of user fees did not increase the use of services due to a number of interlinked access barriers, including informal fees and deficient perceived quality (99). The utilization of maternal care services was quite high in other post-Soviet countries like Ukraine, Russia, Azerbaijan, and Armenia as well. Although maternal care services were supported by the governments in these countries, out-of-pocket payments for maternal care services were stubbornly high $(94,95,103,104,105)$

As mentioned above, our study found that a significant predictor of the use of antenatal care visits is education: low and mid-level educated women utilize maternal care services less often than women with high education. Moreover, rural women utilized such services less. Therefore, the healthcare reforms in Georgia aimed to ensure access to the basic services including maternal care services, specifically antenatal care. However, there are additional factors that also influence access to services, such as religion and socioeconomic status. All these factors were strong predictors of the use of services and they played a role even if access to basic antenatal service was ensured. For example, we found that the lowest income group used ultrasound services less often and pregnancy-related complications were identified less among them comparing to other groups. It is possible that the high-income group was capable of paying out of pocket for those services and the State program for the lowest income 
group did not cover sufficient services. The RHS waves provide limited information about the quality of maternal care. The presented secondary analysis only provides proxy indicators of quality of maternal care, like blood pressure measurement and utilization of ultrasound examination during the last pregnancy of respondents, which had gradual increasing trends over the years.

Our finding indicates a gradual increase in C-sections in Georgia since the early 2000s. $\mathrm{C}$-sections are effective in saving maternal and infant lives in complicated pregnancies (106). A higher fee for a C-section than for vaginal childbirth is one of the reasons for providers to promote C-section among pregnant women (106).

\section{Study strengths and weaknesses}

This study provides evidence on the changes of maternal care use during the different phases of reforms on maternal care in Georgia using population-based data. However, the data were not collected for this study specifically and we have no influence on what information was provided in the survey. Thus, the RHSs provide limited information about maternal care cost, quality and access indicators; these variables may be included in future surveys. This chapter is the first to assess the changes in maternal care in Georgia but we were not able to study causality given the crosssectional nature of the data. Therefore, our results should only be interpreted in terms of associations.

\subsection{CONCLUSIONS}

This study has provided an analysis of three waves of the RHS in Georgia that were carried out in 1999-2000, 2005 and 2010 years; a transition period of massive privatization of the public health facilities including market-based reforms in health system took place. We found improvement in maternal care use, specific antenatal care services such as ultrasound services, and childbirth care facilities. Also, the increased skilled birth attendances were among the improvements during this period. Nevertheless, an increase in C-sections was observed but the exact reasons could not be identified through this data analysis. Overall, there has been a positive change in maternal care use during the healthcare reforms; however, there is still a room for further improvements in terms of accessibility and quality of care. 


\section{Chapter 4}

\section{Stakeholders' Views on the Strengths and Weaknesses of Maternal Care Financing and Its Reform in Georgia}

This chapter draws upon:

Shengelia, L., Pavlova, M., \& Groot, W. Stakeholders' Views on the Strengths and Weaknesses of Maternal Care Financing and Its Reform in Georgia. 2017. BMC Health Services Research, 17, 544. 



\section{ABSTRACT}

\section{Background}

The improvement of maternal health has been one of the aims of the health financing reforms in Georgia. This study aimed to assess the strengths and weakness of the maternal care financing in Georgia in terms of adequacy and effects.

\section{Methods}

A qualitative design was used to explore the opinions of key stakeholders about the adequacy of maternal care financing and financial protection of pregnant women in Georgia. Women, who had used maternal care during the past 4 years along with healthcare providers, policy makers, and repre-sentatives of international partner organizations and national professional body, were the respondents in this study.

\section{Results}

The evidence shows that there is a consensus among maternal care stakeholder groups on the influence of the healthcare financing reforms on maternal health. Specifically, the privatization of the maternal care services has had positive effects because it significantly improved the environment and technical capacity of the maternal houses. However, the privatization was done without strict regulation and provided the possibility to private providers to manipulate the formal user fees in maternal care.

\section{Conclusion}

The total privatization of the maternal care services has had positive effects because it significantly improved the environment and the technical capacity of the maternal house. Financial protection of mothers should be further studied to identify vulnerable groups who should be targeted in future programs. 


\subsection{INTRODUCTION}

Many countries have not reached the MDG 5 for the MMR although remarkable improvements have been observed (107). Financial accessibility to appropriate maternal care has been identified as one of the important determinants of the state of maternal morbidity and mortality (102). Like in the MDGs, the equitable access to maternal care has also been given ample importance in the new Sustainable Development Goals because of its social, health and economic development impacts on households as well as countries' health system (107).

In Georgia, the target for MMR (i.e. $12 / 100,000$ live births) has not been achieved. MMR amounted to 36/ 100,000 live births in 2015 (6). Since the independence in 1991, like other former Soviet countries, Georgia has gone through several phases of health financing reform to improve access to healthcare, including maternal care. These reforms have influenced the utilization of healthcare services due to an increase in the burden of formal fees for services applied in the context of informal patient payments $(107,108)$. As discussed in Chapter 1 and Chapter 2, the total privatization of the health system, including a purchaser- provider split, is the most noticeable outcome of the reforms (109).

As already mentioned in the previous chapters, privatization was implemented in an environment with a weak state capacity to regulate the private market. Private providers' interest is in making profits, which potentially compromises patients' health and economic safety. Therefore, the government is investing a considerable amount of money to purchase healthcare including maternal care from private providers. This is also in line with the current reform for the implementation of the UHC program (110).

As mentioned in Chapter 1, MoLHSA is the state agency, which receives the general government health budget to purchase healthcare for the population, including maternal care, from the private providers. Maternal care in Georgia is provided by a countrywide network of women consultation centers and maternal houses.

The MoLHSA allocates a certain part of the total Government Health budget to implement maternal care through multiple agencies which are responsible for different vertical and horizontal maternal care programs. For example, the NCDC purchases the logistics for antenatal screening tests and distributes money to private providers. Along with the services, as mentioned in Chapter 1 above, the following other free-of-charge maternal care services are also included: antenatal screening for HIV, Hepatitis B and C, and syphilis, folic acid and iron supplementations, physiological childbirths and C-sections (109). The social agency is responsible for the provision of 
antenatal care, early detection and management of high-risk pregnancy and congenital anomalies. The same agency is responsible for payments for both physiological childbirths and C-sections through the UHC program. Practically, the provision as well as financing of maternal health programs is fragmented because of the involvement of several agencies controlling vertical and horizontal maternal care programs.

Despite the publicly provided four free-of-charge antenatal visits as well as childbirth services, OPPs remained a considerable burden for households because of additional antenatal care visits and fees for "personal doctor" ${ }^{2}$. For example, the average OPPs for a C- section and a physiological childbirth were 667.2 GEL and 385.3 GEL respectively (107). Women in the highest income quartile paid higher OPPs for childbirth of any type than the lowest quartile $(73,111)$. Moreover, the cost of medicines is nearly three times higher than the average cost in other European countries which is also directly linked to high OPPs (14). According to the Curatio International Foundation, the high OPPs are related to delays in medications and the utilization healthcare services such as outpatient care, hospital and additional maternal care services, which are not included in the UHC program (14).

The goal of the health financial reform is equitable access to healthcare with the aim to provide health and economic protection for the population. In Georgia, nearly $20.1 \%$ of the total population lives below the poverty level (112). The current OPPs for maternal care in the private market present a risk, which may hinder the health and socio-economic protection of households and may also be an obstacle for achieving the goals of the state UHC program. An in-depth investigation is essential to assess the key stakeholders' opinions about strengths and weakness of the current maternal care financing. Thus, this study aimed to assess the strengths and weakness of the maternal care financing reforms in Georgia in terms of adequacy and effects.

\subsection{METHODOLOGY}

We used a qualitative design to explore the opinions of key stakeholders about the adequacy of maternal care financing and financial protection of pregnant women in Georgia. The study was conducted in May and June 2015 in the capital Tbilisi and in two regions of Georgia, namely Imereti and Adjara. Women who had used maternal care during the past 4 years along with healthcare providers, policy makers, and representatives of international partner organizations and national professional body

2 Personal doctor means to hire a gynecologist/obstetrician during pregnancy or childbirth who is responsible to manage pregnancy or childbirth. 
were the respondents in this study. An ethical approval of the study was obtained from the National Center for Disease and Public Health of Georgia (Appen-dix 2).

We conducted six focus group discussions (FGDs) to collect data from the target women, and 15 face-to-face in-depth interviews (IDIs) to collect data from the other stakeholders. Each FGD consisted of 7-8 women. Two FGDs were carried out at each of the target settings (i.e. Tbilisi, Imereti and Adjara). The target women at each location were divided into two groups; one group with women had one child, and another group with women had more than one child. This was done for a better understanding of the differences in the women's experience of childbirth/s based on parity (i.e. primipara or multipara).

In each region, two research assistants identified the target women. We selected the target women in each location through the hospital registry and snowballing method. Two-thirds women were sampled from the selected hospital registries consecutively provided they fulfilled the inclusion criteria. Random sampling was not possible since there are no separate registries only for the target mothers, thus no usable sampling frames were available. Information from those mothers was used to identify the target mothers in the community which allowed sampling the rest one-third mothers through snowballing. We did this to enhance the possibility of selecting women who gave childbirth at different facilities rather than a single facility; thereby, to get data from women with diverse experience of maternal care. There were no age or economic status stratification criteria applied to allow exploring the opinion of women in reproductive age representing diverse socio-economic groups.

For the IDIs with the other stakeholders, we selected three policy makers, three private health facility representatives, two representatives of international organizations partnering in the development of maternal care, one representative of national professional organization and six maternal care providers (physicians). We used a convenience sampling method to select target mothers and a purposive sampling method for the respondents of the IDIs.

The objective was to investigate the adequacy of maternal care financing and economic protection of pregnant women from the perspective of different stakeholders. Focus group and in-depth interview discussion topics were formulated using primary literature review. The guides were developed in English (Appendix 3 and 4) and then translated into local Georgian language by the principal investigator. The data collection instruments (i.e. the guides) were pre-tested. The FGD and in-depth interview guides were pre-tested and adapted as needed. Informed written consents were given by all respondents prior to each FGD and interview. All FGD sessions were conducted by a Facilitator with longstanding experience of conducting FGDs. The 
Principal Investigator acted as moderator for the FGDs and, conducted all IDIs. Confidentiality of the collected data was maintained. Each session was audio-tapped.

The need of audio taping of each FGD session and in-depth interview was explained to all respondents and permission for recording was obtained. All FGDs and IDIs were conducted in Georgian language. This was translated into English by an English language expert. The Principal Investigator compared and validated the Georgian and English versions of the transcripts. Data were collected during May and June, 2015.

We investigated stakeholders' opinions about the strengths and weakness of the current maternal care financing reform in terms of its adequacy and effects. We applied the method of directed qualitative content analysis as defined by Hsieh and Shannon (114). Specifically, the focus was on identifying data in the transcripts related to two main themes: [1] arguments in support of the current maternal care financing, and [2] arguments against the current maternal care financing. We extracted and analyzed the data manually. An abstract coding approach was applied to develop a set of codes (115) related to the two themes. Two researchers independently coded the data based on the key attributes of financing of maternal care as outlined above and consensus on any discrepancies were built through discussions. The results were synthesized in a narrative manner.

\subsection{RESULTS}

A total of 41 women (primipara $n=19$; multipara $n=22$ ) participated in six FGDs and 15 other stakeholders (i.e. policymakers; $n=3$; health insurers, $n=2$, providers, $n=4$; and representatives of national professional, $n=1$; and international organizations, $n=$ 2; and physicians, $n=3$ ) participated in IDIs. Below, we present the key stakeholders' opinions about the strengths and weaknesses in terms of the adequacy and effects of the current maternal care financing reform. 


\section{Arguments in support of the current maternal care financing system}

- Adequacy in terms of financial allocation and maternal care service package

Policy makers, providers and physicians mentioned that the implementation of the UHC program as part of the current health financing reform, improved the financial allocation in healthcare. Also, the majority of the participants stated that the financial protection of the population in healthcare including maternal care has improved. According to policy makers, through the UHC program and several vertical programs, the state has improved coverage for maternal care as well as financial protection of households. The target mothers also supported this statement; additionally, some mothers stated that the current UHC program met most of their needs related to childbirth. Relevant quotes are presented in Table 4.1.

Policy makers mentioned that geographical and financial access to maternal care has improved. They stated that basic antenatal care (i.e. four visits), high risk pregnancies and transportation in case of pregnancy complications are covered under the State vertical maternal care program and that the UHC program covers childbirths (i.e., physiological childbirth and C-section). Respondents of IDIs also indicated that any additional services which are not included in the vertical and the UHC programs: for example, antenatal care more than four visits, preeclampsia and near miss services need to be paid by OPPs. All respondents mentioned that pregnant women have the freedom to choose facilities and providers, which are not included in the State programs for example, "personal doctor", and medical investigations. However, they have to pay out of pocket for these services.

According to most of the respondents, the private health insurance supplements the maternal care program; however, the predominant opinion was that all individuals who are able to pay have to purchase insurance. This will facilitate the State to expand the package for the poor and the unemployed people (Table 4.1). 
Table 4.1 Statements in support of the current maternal care financing reform

\section{In- depth interviews}

- The fees should apply for additional services such as food and room or patient comfort;

- The state covers everyone pretty much; the high-risk pregnancies are covered by the vertical program;

- I am for co-payment. I think $10-20 \%$ co-payment could well exist. Copayment also means some kind of responsibility from the client's side. But it should not be a burden for the population;

- Privatization supported the legalization of incomes of physicians;

- Informal payments have been eliminated;

- Some people cannot pay. Therefore, the State should provide full coverage of maternalcare.

\section{Focus group discussions}

- Families try to be prepared for the childbirth and most families are willing to pay;

- I had private insurance. It helped me to pay everything, except pharmaceuticals;

- We gave to the doctor a gift as a token of gratitude;

- I had a complicated childbirth and was transferred to Tbilisi. The total cost was covered by the State completely.

\section{- Maternal care financing versus OPPS}

Participants of IDIs stated that despite the UHC program and vertical programs, pregnant women are commonly paying for additional services by themselves.

OPPs are mostly related to medications and diagnostics, which are not included in any of the State programs. According to the women, the presence of OPPs was preferable if the pregnant women were asking for additional services, such as a private room, a "personal doctor" etc. Some providers think that OPPs prevent overuse of services. Women mentioned that family and relatives are the main sources of OPPs. One woman said - "pregnancy is expected and improves the status of women in families. For this, families and relatives are willing to pay any extra costs relating to maternal care".

Informal payment in healthcare was a major financial burden for households previously, which is now completely eliminated due to new laws and the influence of the privatization in healthcare. However, sometimes mothers and families present gifts to medical doctors/nurses as a form of gratitude, which is not an informal payment; instead it is an expression of a good patient-doctor/nurse relationship. 


\section{Arguments against the current maternal care financing system}

- Financial allocation versus maternal care package

According to some private providers, the current allocation of $55 \mathrm{GEL}$ (equivalent to 20 Euro) for four antenatal visits is not sufficient to provide good quality of care. Also, often four antenatal visits and the content of services did not meet the needs of pregnant women. Because of this limited allocation and service contents, early detection of high-risk pregnancies are often missed. In support of this statement, one woman mentioned that "I needed extra antenatal visits and tests and all costs were provided by my family". One of the private providers mentioned that the government allocation for specific services is quite marginal to make a profit. This oftencompromised private providers' interest of joining public healthcare programs.

Some policy makers and providers expressed concern about the quality of maternal care especially antenatal care, due to the current financing reform. Relevant quotes from the transcripts are presented in Table 4.2. Providers also mentioned that the current financing system has fragmented the State maternal care programs. For example, one agency is purchasing antenatal screening tests for HIV, Hepatitis B and C, syphilis, while another agency is responsible for the implementation of the antenatal check-up. Some of the maternal care providers as well as policymakers indicated that the government should finance only the poor population by providing them with a wider package and others should pay out of pocket for maternal care services.

In the current situation, the equal financing of poor and rich people leads to the problem of regressive financing. Representatives of national and international organizations questioned the regulation of financing of C-sections: "The number of Csection has significantly increased in the country", according to one of the key stakeholders. Many C-sections are conducted because of either demand of women or providers' income interests rather than a real medical need. Use of state resources for such unjustified C-sections causes a waste of resources. The government should strictly regulate this issue for the proper use of resources. 
Table 4.2 Statements against the current maternal care financing reform

\section{In-depth interviews}

- I think all people who work have to purchase an insurance package and plan for pregnancy. But if a person does not have an income, maternal care should be financed by the government;

- She needs to do screening on bacteriuria but she said "I don't have money" and the doctor reported that "she refused screening";

- Near miss services should not have any OPPs because this is something you cannot predict or plan;

\section{Focus group discussions}

- I was asked for additional lab tests. At last I found that this was not necessary. I complained to MoLHSA and the facility was penalized;

- Private providers are increasing fees frequently and suggest more consultations than needed;

- Only emergency services are financed but not preventive measures even for high risk pregnancies.

\section{- Opinions about OPPs}

Two women mentioned that specialized laboratory tests are not included in the current government programs and some are not even available in the country. One of them mentioned-"I was suggested to take a genetic test which was expensive and not available in Georgia. The doctor asked me to send the sample to Germany. It was costly and I could not manage to do that." Some providers mentioned that the burden of OPPs is significant for maternal care in case of complications. The State program for the management of pregnancy complications exists but the program has very strict inclusion criteria. According to the opinion of one of the providers, the management of near-miss cases is often difficult with the available facilities in the country. However, most of the cases might be prevented if necessary measures are taken on time. Moreover, there is no rehabilitation program for women who undergo near miss cases. During the FGDs in Kutaisi and Batumi, women actively raised the issue of pregnancyrelated complications. Women from rural areas mentioned that some of them faced complications such as bleeding and preeclampsia, and they were transferred to tertiary level facilities in region or in Tbilisi. According to them, due to severe complications, they did not pay and the government covered all expenses.

\section{- Regulation}

A few women expressed their dissatisfaction because of the strict rule of registering before 12 weeks of pregnancy. One of the mothers said that women may not be registered with the system because of different reasons and for this they should not be 
deprived from state provision of financial support. She mentioned- "I was not given a voucher because of attending the clinic after 13 weeks of pregnancy. I did not do it intentionally but I could not manage to go before 12 weeks because of family problems".

Strengthening the regulation in the healthcare sector and particularly maternal care is essential according to the participants. One of the private providers mentioned that because of the cost-of transportation, pregnant women delay referrals and this negatively affects the outcome of maternal care as well. The transportation system is not included in the UHC program.

\subsection{DISCUSSION}

This chapter describes stakeholders' opinions about the strengths and weakness in terms of adequacy and effects of maternal care financing reforms in Georgia. The study gives us an opportunity to examine the influence of the privatization on maternal health in Georgia. All stakeholders indicated that the recent financial reform in the healthcare sector has decreased financial hardship for mothers. But also, there is consensus among the groups that in case of pregnancy complications, and personal choice of facility and provider out of state programs, the burden of the OPPs is significant.

Privatization plays a crucial role in service provision in the healthcare sector. In Georgia, it influences the development of the health system. As in other European countries, the privatization is a response to public sector failure (116). The decision of the government to privatize the entire health sector is an outcome of a policy-driven process, but it is not followed by strong regulation mechanisms and this gives room to private ownership of health facilities, particularly owners of the maternal houses, to manipulate the user fees. Specifically, our study shows that there is consensus among stakeholders that the latest decision of the government to implement the UHC program protects mothers from financial burden. However, the weaknesses in regulation are also observed.

Specifically, the privatization of the healthcare service, particularly in the maternal care field, has improved the infrastructure. Some authors argue that privatization in the healthcare sector simulates competition, which leads to improvement of quality of care and the service package (117). In Georgia, competition between the private maternal houses is mainly associated with improvements in technical efficiency and the infrastructural capacity of the facilities. Opposite to Georgia, Armenia and Ukraine 
maintained a public health system similar to that established during the Soviet era with a focus on curative care. In spite of the fact that post-soviet countries chose their own path of developing their own health system, all countries experience the same problems and challenges in maternal care.

As our study shows, one of the advantages of the privatization in Georgia is the abolishment of informal payments. In the country, informal payments existed during the soviet era and became more common in the early 1990's. Even at the beginning of the 21 century, informal payments were directly paid to the provider, and were demanded by providers as well as influenced by a Soviet culture of gratitude $(116,118)$. Informal payments provided a way to obtain medical care immediately $(117,118)$. This is also confirmed by our findings. Thus, the elimination of informal patient payments is not the result of a more efficient resource allocation or more adequate regulation by the State, but an outcome of private owners' efficient managerial capability in this regard. At the same time, there is evidence that in other post-Soviet countries such as Ukraine, informal payments for maternal care are still widely spread (119).

Nevertheless, our findings indicate that formal OPPs are a significant burden for pregnant women in Georgia. During the FGDs, some mothers mentioned that beside the initial payments, they were requested to pay some additional amounts for additional services in case of complications, which they paid officially. Moreover, respondents of the IDIs also stated that during the antenatal period, most women required additional visits and because of this, they paid extra out of pocket. The OPPs are also increasing due to phenomenon of "personal doctor". The phenomenon is not unique for Georgia.

Women have autonomy in choosing the facility, provider and diagnostics, and even the mode of childbirth, and then they are also kept responsible for the payment, when they have the ability to pay. The current financial reform is regressive since both the poor and the rich are getting equal state funding. Whenever needed, the richer segment has access to specialized services through OPPs but the poor segment is not supported by the state program for the specialized services. A progressive financing system could protect both the poor and the rich pregnant women.

Women in Ukraine and Armenia also use this type of service but in these countries, they mostly pay for it informally $(99,118)$. As identified in our study the main push factors to search and pay extra for a personal obstetrician are: safety, responsiveness and personal comfort. It is clear from our study that pregnant women and their families prefer to pay more for the service of a personal obstetrician and ensure "high quality of care". However, they choose a personal obstetrician according to their ability to pay as well as taking into account direct and indirect costs. This situation 
leads to inequities and disparities among mothers as not everybody can afford a personal physician and might receive substandard care. For example, one of the participants of the FGDs mentioned that her mother had to pay all expenses for the last pregnancy. Moreover, epidemiological surveillance of maternal mortality done by the NCDC of Georgia showed that maternal mortality is higher among lower middle- and low-income groups because lower income groups utilize fewer maternal care services due to direct and indirect cost (119). This is found in our study as well.

The implementation of the UHC program in Georgia is influenced by an increased burden of OPPs and a decreased utilization of health services (120). The UHC program, including the coverage of maternal care, remains a priority in the post- 2015 agenda (120). The goal of the UHC implementation in Georgia is to protect the health of the entire population and to promote a sustainable economic and social development, as it is targeted by WHO in 2010 (121).

Our study shows that after the implementation of the UHC program, the utilization of healthcare services became easier and catastrophic healthcare expenditure reduced as the UHC program finances childbirth and C-section services. In Georgia, the share of Csections is high (41.5\% in 2015) compared with European countries (122). According to participants in the FGDs and IDIs, the State finances C-section on demand. The UHC program pays $500 \mathrm{GEL}$ for a C-section performed on demand of the patient and 800 GEL in case of a medical indication. However, the price for a C-section on demand is the same as for a normal vaginal childbirth. However, the potential short-term maternal outcome of a vaginal childbirth compared with elective C-section includes a shorter length of hospital stay, lower infection rates, fewer anesthetic complications, and higher breastfeeding initiation rates (122). Beside this, our study shows that the fees for services of childbirth and C-section varied from 900 to $3500 \mathrm{GEL}$ among healthcare providers. The variation in the fee-for-service rates depends on the reputation of the maternal house and what additional comfort they provide to the users. However, the UHC financing of any type of childbirth protects the mothers and their families from catastrophic health expenditure.

Compared to Georgia, C-sections are lower in Ukraine and Armenia; two former-Soviet states. In 2013, the number of C-sections per 1000 live birth was quite high and reached 371.09 in Georgia while it was 238.07 and 168.88 in Armenia and Ukraine respectively (124). The opponents of the positive influence of maternal care financing on maternal health are quite open about the negative effect of the fragmentation of the vertical and horizontal maternal health programs due to high administrative costs. This raises the issue of efficiency (125). In this situation, the organization of antenatal care through several agencies without a monitoring and evaluation mechanism needs 
attention from the policy makers. Since 1997, Georgia offers 4 free antenatal services in accordance with WHO recommendations (125). Many maternal houses do not participate in the program because of two reasons: first, because of insufficient compensation per package and second, the service content of the antenatal care package does not cover all antenatal care needs. Mothers as well as providers and representatives of national and international organizations, strongly advocate an increase of the antenatal care package financing.

Since 1995, the antenatal care package has remained the same and the government pays the same amount (55 GEL) (109) in spite of the inflation and changes in user fees. Almost all women-participants mentioned that they visited antenatal care clinics at the request of the physician nearly 10 or more times, and paid out of pocket. This finding indicates that the interest of the maternal houses that participate in the State antenatal care programs is to recruit pregnant women and then encourage them to utilize more services than necessary. All these findings indicate that there is supplierinduced demand in Georgian maternal care and a providers' interest to increase their income. This raises the question of the efficiency and effectiveness of the maternal care programs. The fragmentation of maternal care programs and high pharmaceutical costs are common in Ukraine and Armenia as well. Both countries are facing challenges in the equity of healthcare financing $(99,118)$.

Universal coverage of maternal care reflects the individual rights of pregnant women and social solidarity (116). However, it should focus on equity and should take into account the social determinants and needs of subgroups and those who are vulnerable (104). Georgia is a lower-middle-income country. In 2014, the Gross National Income per capita was 4490.00 (122). In this situation, the burden of the UHC without the regulation and monitoring mechanism is significant for the country.

\section{Study strengths and weaknesses}

We triangulated the stakeholders' opinions to strengthen the validity and reliability of the results. A wide range of stakeholders were included in the study that gives a picture of maternal care in Georgia. However, a small number of settings were included in this study. Thus, the results cannot be extrapolated to the entire country. However, as in any qualitative study, the primary research objective is to collect in-depth information on the views of the stakeholders rather than representative data for the country. 
Accordingly, the results are important because they provide an in-depth understanding of the problem. Further, experienced facilitators managed the FGDs and also explored the in- depth opinions of the target women. Thus, we mitigate the facilitator-related bias by choosing an experienced moderator and interviewers, and by applying a guide to assist them during the data collection process. Also, we pre-tested the guide before the field work. By involving experts in the translation process, we diminish such bias to a certain extent.

\subsection{CONCLUSIONS}

This qualitative study was done in two regions and in Tbilisi and aimed to elicit stakeholders' opinions about maternal health financing in Georgia. The results of our study suggest a consensus among stakeholder groups on the influence of the healthcare financing reform on maternal care. The total privatization of the maternal care services has had positive effects because it significantly improved the environment and the technical capacity of the maternal house. But the privatization was done without strict regulation, which negatively influenced the reform process and provided the possibility to private providers to manipulate user fees in maternal care.

Stakeholders also indicate that the UHC program implemented at the last stage of the healthcare financing reform protects the mothers from catastrophic health expenditure. Besides UHC program, the State implemented several vertical maternal health programs and maintained financial access to basic maternal care services. These programs protect pregnant women from catastrophic healthcare spending for maternal care. In addition, stakeholders reported that the healthcare reforms eliminated the informal payments. However, vulnerable groups are facing difficulties in paying the formal fees for some lab tests that are not in the BBP and also because of transportation cost for antenatal care. As participants indicated, an increase in the basic antenatal care package and it's financing, as well as strengthening the regulation in the healthcare sector, especially regarding the unjustified use of C-sections, are essential for Georgian maternal care services.

In spite of the significant steps taken by the government to improve maternal health and to reduce maternal mortality, the target was not achieved. Therefore, the financial protection of mother should be further studied to identify the needs of the vulnerable groups who should be targeted in future programs. 


\section{Chapter}

\section{Quality and Access to Maternal Care in Georgia: A Qualitative Study among Stakeholders}

This chapter draws upon:

Shengelia, L., Pavlova, M., \& Groot, W. Quality and Access to Maternal Care in Georgia: A Qualitative Study among Stakeholders (abstract). 2019. European Journal of Obstetrics \& Gynecology and Reproductive Biology, 234, e32-e33. 



\section{ABSTRACT}

\section{Background}

During the last decade, the Georgian government has emphasized the importance of improving the maternal care system. Access and quality of maternal health remain a concern for the country. The aim of this study is to assess the stakeholders' opinion on quality of and access to maternal care in Georgia.

\section{Methods}

A qualitative study with six FGDs and fifteen face-to-face IDIs was conducted in the capital Tbilisi, as well as in Adjara and Imereti regions of Georgia in May/June 2015. Each FGD consisted of 7-6 mothers. Policy makers, medical doctors, and representatives of private health facilities, international organizations, professional organization and medical doctors were participants of the IDIs.

\section{Results}

Access to basic maternal care was found to be adequate in general, but insufficient for complicated pregnancy. Lack of quality in both basic and emergency maternal care was seen to affect maternal morbidity and mortality rates. Weaknesses in the medical and nursing curricula, absence of continuous professional development and gaps in the referral system were seen as causes of inadequate access to and quality of maternal care.

\section{Conclusion}

Despite some improvements in the maternal care system, to achieve the target outcomes of maternal care, improvements in quality and access to maternal care are needed in Georgia. 


\subsection{INTRODUCTION}

Maternal mortality and morbidity are directly related to the organization of the maternal care system. During the last decade, the Georgian government has emphasized the importance of improving the maternal care system. However, the improvement of maternal health and the reduction of the MMR remain an important concern for the country. Despite a significant decrease in the MMR in Georgia from $60 / 100,000$ live births in 2000 to 36/100,000 live births in 2015, the targeted MDGs for maternal mortality was not achieved (89). In Georgia, preeclampsia, eclampsia, sepsis, and bleeding are the most common causes of preventable maternal deaths (118). The 2014 Reproductive Age Mortality Study (RAMOS) showed that ill-defined causes of maternal deaths are still prevalent. There are large socio-economic inequalities in maternal health outcomes. Maternal deaths are higher among low-income groups than among wealthier people (124). To improve maternal health outcomes, improvements in the system are a priority.

As already mentioned in Chapter 1 and Chapter 3, following the Soviet period, the health system of Georgia has undergone several reforms including those in maternal care. Privatization has been one of the key reforms. In 2013, to improve financial protection and geographical access to basic healthcare services the Georgian government introduced a UHC program for the entire population. The UHC program is a government-funded healthcare program administrated by the Social Service Agency and delivered by private healthcare providers that covers most of the childbirth-related care. Additionally, the State provides several vertical and horizontal maternal health programs, such as free antenatal care, identification and management of high-risk pregnancies, early detection of congenital anomalies, antenatal screening for HIV, syphilis, Hepatitis B, and Hepatitis C. Free supply of folic acid and iron supplements to pregnant women are also in these programs.

Along with socio-economic factors, the healthcare structure and geographic distribution potentially influence maternal health outcomes. Good maternal care is related not only to healthcare financing but also to healthcare delivery characteristics such as access and quality of care $(11,85)$. Improvement of the quality of maternal care and maintaining access to basic maternal care services was prioritized in the healthcare reforms $(2,6)$. However, due to the total privatization of the healthcare sector and the lack of regulation and monitoring of the private health sector, the State has limited possibilities to measure and ensure quality (6). Thus, it remains to be seen whether the target of equitable access to good quality maternal care is achieved. This study provides new insights on the quality and access to maternal care in Georgia from the perspective of the key maternal care stakeholders. 
Maternal care in Georgia is provided by the women consultation centers and maternal houses. women consultation centers are primary level facilities that provide only antenatal care. The maternal houses are secondary level facilities providing antenatal care, vaginal childbirths, C-sections and emergency obstetric care. Although the country has made efforts to ensure access to maternal care for normal and high-risk pregnancies, the management of pregnancy complications is still a challenge (65). To reduce $M M R$, access to quality emergency obstetric care is needed.

The aim of this study is to provide an in-depth investigation of the opinions of the key stakeholders (i.e. women, policy makers, providers, professional organization, and partner organizations) on the factors influencing maternal care in terms of quality and access. As these stakeholders play a significant role in the development of maternal care in Georgia, exploration of their opinions is important to understand the deficits in the maternal care system.

\subsection{METHODOLOGY}

We used the data on the opinions of key stakeholders about the maternal care system in Georgia that were used in Chapter 4 as well. The study was conducted in May and June of 2015 in the capital Tbilisi and in two regions of Georgia, namely Imereti and Adjara. Detailed information about the methodological approach is provided in Chapter 4. In Chapter 4, we discuss findings of the same qualitative study from a different angle such as the adequacy of maternal care financing and financial protection of pregnant women. In this chapter, we explore the other domains of maternal care, namely quality and access.

We developed the guides for IDI and FGD based on published literature, mainly Berki \& Ashcraft (11) and Abiiro \& De Allegri (12) (Appendix 3 and 4). Maternal care in terms of quality and access were the main domains. Quality was further divided into clinical quality, social quality, continuity of care and comprehensiveness of maternal care. For access we focus on spatial (geographical) and temporal access. The different dimensions of quality and access were defined as follows:

(i) Clinical and social quality. For clinical quality, we asked the respondents' opinions about medical doctors' knowledge and skills in the diagnosis and treatment and the medical doctors' and nurses' responsiveness to patients' needs. We also asked about the quality of lab investigations. We assessed social quality using the following aspects: maintenance of privacy and respect for the mothers, mental support, attentiveness to 
the problems presented, communication (i.e. explanation about the mothers' health condition, treatment plan, and involving mothers in decision making), and tangibility (i.e. overall outlook and cleanliness of healthcare facilities).

(ii) Continuity was assessed in terms of mothers' compliance with the advice of medical doctors and specific maternal care facilities. We also assessed the effects of the doctor-client relationship on the continuity of maternal care.

(iii) Comprehensiveness of maternal care was assessed in terms of "one door shopping", in other words the availability of essential maternal care services in facilities

(iv) Spatial and temporal access. We assessed spatial access in terms of the geographical distribution of maternal care facilities both in rural and urban areas. Temporal access was assessed in terms of the respondents' opinions about waiting time for ambulatory and emergency care and the referral process.

\subsection{RESULTS}

A total of 41 women and 15 other key stakeholders participated in the FGDs and IDIs respectively. In this section, we present the key findings on the stakeholders' perceptions about the maternal care delivery system in Georgia in terms of quality and access.

\section{Clinical quality}

All respondents of the IDIs mentioned that maternal mortality has reduced during the last decades. However, the MDG for MMR has not been achieved. Some of them also reported that pre-eclampsia, sepsis and severe bleeding are the most common preventable causes of maternal deaths. There are deficiencies in early diagnosis and proper management of pregnancy complications. Several participants mentioned that the weaknesses in the medical and nursing curriculum and training of medical doctors and nurses are the key barriers to having skilled professionals in maternal care. Many of them mentioned that there is no CPD program for medical doctors, nurses and midwives. 
The policy makers also mentioned that the low quality of antenatal care is directly related to the high maternal morbidity and mortality rates. This statement was supported by some providers and representative of the national professional organization. Although, some providers mentioned that the situation had improved, this opinion was opposed by the providers from Tbilisi: "The identification of high-risk pregnancies is often missed because of incompetent skills in antenatal care which is related to delayed referral and late stage complications".

The mothers and most of the respondents of the IDIs mentioned that many medical doctors are prescribing unnecessary drugs, diagnostics and medical procedures. Two issues were identified behind this statement. Firstly, the prescribers' lack of knowledge and secondly, the providers interest to increase his/her income. Some women expressed doubts about the quality of laboratory tests. Disappointments about repeated laboratory investigations were also identified; one woman mentioned: "doctors often did not accept the diagnostics from a laboratory other than the one of their own choice".

According to the policymakers, the quality of physiological childbirth has improved. However, there are wide differences in the quality to manage complicated pregnancies. Policymakers and representatives of international and national organizations also mentioned that the proportion of C-sections to total childbirths was unusually high. Many of them stated two underlying factors of that problem. Firstly, medical doctors were doing this for their own financial interest and because they wanted to have control over their busy schedules. Secondly, this was a choice made by women and families. They also mentioned that because of the privatization and inadequate regulation, private maternal care providers exercise autonomy over cost and quality of health are. All respondents mentioned that the government should take more control over the cost and quality of maternal care.

\section{Social quality}

Most of the mothers expressed satisfaction about the respect and privacy given by medical doctors. However, many mothers stated that medical doctors were often not adequately attentive to the women's problems because of their busy schedules. Regarding mental support, women reported mixed experiences. Some of them mentioned that they got adequate support to overcome their fear of childbirth but other stated that they did not receive any mental support throughout antenatal care or before childbirth. 
Many mothers also expressed mixed experiences with medical doctors and nurses' attentiveness. For example, one of them mentioned that she had complications after childbirth and she experienced a lack of attentiveness to her complaints mostly from nurses rather than from medical doctors. Although one woman from outside Tbilisi mentioned that she had her second childbirth in the same facility as the first one, because she was provided with adequate attention, mental support and other necessary care from the facility. Another mother reacted differently: "I will never visit that maternal house again because I had a complication after the spinal anaesthesia and needed support but I only got it after long suffering".

All women and participants of IDIs mentioned that the cleanness and overall outlook of the health facilities have improved markedly during recent years. Regarding communication, some mothers said that medical doctors explained the health conditions and laboratory test reports clearly, while other women mentioned that during the consultation, the medical doctors did not give adequate explanation. This was also supported by the participants of the IDIs. In general, the opinion of women was that they had minimal involvement in the decision-making process for maternal care.

\section{Continuity of maternal care}

The women mentioned that they were served by different medical doctors for antenatal, natal and post-natal cares. Due to a lack of communication between medical doctors, the women indicated gaps in the dissemination of patients' information between different medical doctors. They also mentioned that changes in medical doctors were associated with repetition of laboratory investigations and changes in medications. This caused mistrust between medical doctors and patients as well as imposed costs on households. This finding was also supported by many other respondents. Many multiparas women stated that to avoid this situation, they chose their "personal doctor" to ensure continuity of care. Although the financial support for maternal care did not cover the total costs related to this autonomous choice of "personal doctor", they found "personal doctor" was more convenient for them in terms of good relations with medical doctors as well as quality of services. One of the urban dwelling mothers mentioned that "I have a good relationship with my "personal doctor" and I am willing to receive his services in the future and also to pay additional money for these services". The representative of the professional organization also stated that "service of a personal doctor is very common in the country and households are willing to pay for good quality maternal care". 


\section{Comprehensiveness of maternal care}

Many of the women mentioned that most facilities offered basic maternal care services including laboratory investigations. However, many of them said that they were referred to other facilities for some special laboratory investigation and services. For a few diagnostics, which they were not able to name, they were even advised to perform those in other countries since those diagnostics were not available in Georgia.

The women mentioned that during the pregnancy period they faced difficulties to travel from one facility to another. To reduce this burden, they expected that the primary facilities should manage those services in collaboration with other facilities without mothers having to travel to another facility. Two mothers who gave premature birth mentioned that they were transferred from remote facilities to the capital for incubator services to their babies. One mother said: "an incubator should be available in all facilities to reduce stress for both mothers and premature babies".

The participants of the IDIs, specifically providers, stated that it was not feasible and cost effective either for government or private providers to make all types of services available in all facilities. A good referral system and collaboration among providers and facilities should be enhanced in order to reduce the burden for pregnant women and new born babies.

\section{Spatial and temporal access}

Women from both rural and urban areas mentioned that they had adequate geographical access to basic antenatal care services including four antenatal visits and physiological childbirth for free. They also mentioned that some emergency obstetric care, such as uncomplicated C-sections, were also available in most areas. Geographic access to services for management of seriously complicated pregnancies and some special diagnostic tests were identified as a problem in rural areas since these facilities were only available in urban areas. One of the mothers from a remote area stated: "We have to travel to city areas to get care for pregnancy complications. It is time consuming and also costly". Another mother said that the arrangements of referrals and transports most often were delayed. These statements were also supported by the respondents of the IDIs.

Most of the women mentioned that because of an established appointment system, getting services for ambulatory antenatal care were not delayed. However, access to the emergency and referral care for complicated pregnancies was commonly seen as a 
serious problem because of the following reasons. Firstly, a delay in the clerical processes of referral, secondly, inadequate transport facilities; and thirdly, insufficient communication and collaboration between concerned facilities.

Most of the respondents in the IDIs also agreed to the problems related to temporal access. However, the policy makers stated that the transport and referral system have been improved to reduce the delays in managing pregnancy complications.

\subsection{DISCUSSION}

In this study, we have investigated women's and other key stakeholders' opinions about quality and access to maternal care in Georgia. The key findings of our study are subsequently discussed.

\section{Quality - medical and nursing education and training}

Good clinical and social quality is essential to assure good maternal health outcomes (i.e. healthy mother and healthy baby). Our findings suggest that a lack of clinical skills of medical doctors is related to misdiagnosis and delay in identification of pregnancy complications. These are key barriers to reach MMR target. In the early stage of the Georgian healthcare reform the privatization of the health market was simultaneously associated with a discontinuity in the provision of CPD for medical doctors and nurses. The lack of CPD and clinical auditing negatively influences the appropriateness and effectiveness of maternal care. Skilled birth attendance in Georgia is nearly $100 \%$ (126). However, academic certificates are the only indicators of skills of those professionals rather than proof of their actual clinical skills. This is due to loopholes in the medical and nursing curriculum, inadequate institutional training, and absence of CPD. Moreover, according to the WHO, to deliver good quality services, a nursephysician ratio should be $4: 1$, which in Georgia is nearly $4: 5$ (126). There is a substantial shortage of nurses in the country, which is related to the high work load and burnout among nurses.

\section{Quality - C-section versus vaginal childbirth}

The share of C-sections among all childbirths is high in Georgia (i.e. $41.5 \%$ of all births in 2015) compared with other European countries (126). According to our findings, this 
is related to providers' interest to increase their income and to exert control over their schedules, and also a result of women's demands for C-sections. These findings are consistent with other studies. For example, a 2011 study showed that nearly $63 \%$ of Csections in Georgia were performed based on patients' demands (127). Mostly pain-free and low awareness were the underlying reasons. The inclusion of C-section in the UHC program may also influence providers to convince clients in favor of C-section for financial gains. Empirical evidence shows that unjustified C-sections are related to short and long term health risks of mothers and financial loss of the households (89).

\section{Quality - privatization of maternal care}

As indicated by our findings, the privatization of the health system has improved overall social quality in terms of tangibility of maternal care facilities, and medical doctors and nurses respect for the patients. With regard to social quality, some women in our study express satisfaction with the privacy, respect, cleanliness and overall outlook of the health facilities following privatization. Responsiveness in terms of waiting time has also been improved because of the appointment system. However, mothers are dissatisfied because of the brief consultation times and insufficient responses of nurses to mothers' needs, specifically immediately after childbirth. In general, reliability in terms of prescribing necessary laboratory tests and drugs has to be improved. The private sector plays a significant role in maternal care provision in countries having adequate market regulation (98). In an inadequately regulated private market, as in Georgia, providers are often involved in unethical practices; for example, by prescribing unnecessary drugs and laboratory tests. This is supported by our findings as well. To improve this situation, regulation of the private market and a system of clinical auditing and awareness building are essential.

\section{Quality - continuity of maternal care}

Continuity of maternal care is important for mothers' satisfaction, the outcome of the pregnancy, economic safety of households and trust in the healthcare delivery system. In Georgia, as shown by our results, there are gaps in the continuity of care which are related to mistrust in the system and financial costs for families, a recognized barrier to attain the goals of the UHC program. Following the privatization of the healthcare sector, most of the maternal care services are provided and led by medical doctors in the facilities. However, continuity of care is interrupted because of the lack of skills of medical doctors, providers' financial interest and an ineffective referral system. The current UHC reform allocates considerable amounts of money to protect the health and 
wealth of the citizens. In practice, maternal care outcomes through this program could be enhanced by adopting strategic evidence-based structural changes that have been proven to work elsewhere. For example, home-based skilled care and follow-up of mothers throughout the maternal period by midwives, and good collaboration between them and medical doctors, could improve the continuity of care $(128,129)$. This would also ensure cost-effective maternal care in a familiar environment.

\section{Quality - comprehensiveness of maternal care}

Our findings suggest that overall mothers expect that all types of services should be available in all facilities from rural to urban areas. In a private market, financial returns drive the decision to invest. Therefore, it is not ensured that all types of services are available in all facilities. Mothers' expectations and private providers' limitations to meet the needs of pregnant women in Georgia indicate that there are gaps between providers and maternal care users regarding the healthcare delivery system. To improve this, a referral system and effective collaboration and cooperation among healthcare providers at different levels of facilities are important.

\section{Access - urbanization of maternal care}

Overall the findings indicate an urbanization of the major maternal care services in Georgia. Urbanization of market-based health facilities is a phenomenon both in developed and developing countries (130). Our findings are also consistent with this. In Georgia, because of massive privatization of public health facilities, healthcare facilities including maternal houses are concentrated in big cities rather than in remote towns. However, because of business interests, private investors are not willing to develop health facilities in some of the remote areas, where the State has owned those facilities as part of UHC. Thus, spatial (i.e. geographic) access to basic maternal care services has been improved as an outcome of the recent reform. However, services for managing complicated pregnancies and special laboratory investigations are usually available in facilities in regional and capital cities. This is related to a lack and urbanization of skilled human resources. Compared to many developed and developing countries, Georgia has quite a high physician-population ratio, nearly 1:153 (126). This indicates that the curriculum and training of health professionals are not aligned with the population healthcare needs. 


\section{Access - emergency maternal care services}

In Georgia, common causes of maternal deaths are seriously complicated pregnancies such as preeclampsia, eclampsia and severe bleeding (126). We found that timely access to appropriate services to manage those complicated pregnancies is challenging because of the inadequate transport system, delays in the referral process, lack of collaboration between facilities; and because preeclampsia has not been included in the UHC program. Any delay in access to emergency maternal care at this stage mostly depends on the responsiveness of the care providers and good collaborative relations between providers of all concerned facilities. Moreover, preparedness to handle emergency situations in terms of providing maternal care and quick transportation are also important. To improve access to comprehensive maternal care services and to reduce $M M R$, enhancement of maternal care delivery system including good referral and inclusion of preeclampsia in the UHC program are high priorities.

\section{Study strengths and weaknesses}

The statements of women were triangulated by insights of other maternal care stakeholders. Other than native Georgian mothers, no mothers from other ethnic groups were included in this study. We investigated the opinions of the medical doctors. However, midwives and nurses were not included in the study because of financial limitations, which may lead to the risk of selection bias.

\subsection{CONCLUSIONS}

This study has provided an in-depth investigation of the key maternal care stakeholders' opinions (i.e. women, policy makers, providers, partner organizations) on factors influencing the Georgian maternal care system in terms of quality and access. Overall, there have been some improvements in the maternal care system. However, to meet the population's expectations and to achieve the target outcomes of maternal care, substantial improvements in quality and access need to be made. The medical and nursing curricula need to become more focused on the population healthcare needs. Furthermore, improvement in the institutional training of nurses and increases in the number of skilled nurses and mid-wives are essential to improve quality of maternal care. CPD and clinical auditing are necessary to update knowledge and skills and to assure evidence-based medical practices. An organized referral system is also a high priority to improve maternal care quality. 



\section{Chapter \\ 6}

\section{Women's Satisfaction with}

Maternal Care Services in Georgia

This chapter draws upon:

Shengelia, L., Pavlova, M., \& Groot, W. Women's Satisfaction with Maternal Care Services in Georgia. 2019. Submitted for publication. 


\section{ABSTRACT}

\section{Background}

Patient satisfaction is a key indicator of healthcare quality. The chapter aims to investigate women's satisfaction with antenatal, natal and immediate post-natal care.

\section{Methods}

The study was conducted in the capital and two regions of Georgia. Women, who gave birth to healthy babies during the preceding twelve months before the date of data collection, were the target population. Women's opinion about the organization of maternal care (tangibility, availability, accessibility) and process characteristics (responsiveness, reliability, empathy, communication and courtesy) were measured.

\section{Results}

The respondents' perception about the tangibility of maternal houses was quite positive, more than three quarter of the respondents agreed or strongly agreed with the statements that maternal houses/units were attractive and medical equipment was up to date. Regression analysis showed that those who paid for services were less satisfied than those who did not pay. Women in urban areas were more satisfied with antenatal and natal services than in rural areas.

\section{Concussion}

In general, women are satisfied with maternal care in Georgia. The high level of satisfaction can be due to the improvement in structural factors of maternal care such as tangibility, availability and accessibility. 


\subsection{INTRODUCTION}

Patients' satisfaction with healthcare services is predictive of patients' choice of healthcare plans and treatment $(42,43)$. Patients' satisfaction gains in importance if patients become actively involved in the decision-making about the treatment they receive and have more freedom of choice of healthcare provider $(40,131,132)$. Satisfaction is the most frequently reported indicator of quality of healthcare (133). Improvement of patients' satisfaction is one of the goals of any health system (134).

Accordingly, women's satisfaction with maternal care services, such as care during the antenatal, natal and immediate post-natal period, should be of central interest to healthcare providers, administrators, and policy makers $(134,136)$. Some studies show that women's satisfaction with childbirth care is related to a healthy outcome of the childbirth and a healthy baby $(133,135)$. Contrary to that, dissatisfaction is associated with information asymmetry, poor post-natal psychological adjustment, negative feelings towards the infant and breast-feeding problems $(133,137,138)$.

Measuring patient satisfaction has become an essential part of the assessment of healthcare services in terms of service quality, access and health system responsiveness $(139,140)$. Patient's characteristics that are associated with the level of general satisfaction with healthcare services include demographic factors, socioeconomic status $(44,43,45,46)$ and general health status. Also, this type of satisfaction is influenced by the process of healthcare delivery $(46,48)$ and the characteristics of the healthcare provider $(50,51)$.

With regard to maternal care, studies have shown that socio-demographic characteristics (the level of education, age, marital status, and economic status) of women and their perceptions (values, attitudes, threshold of pain, health literacy, and personal support) also influence their level of satisfaction with maternal care services $(39,40,41,130)$. It is challenging for a health system to satisfy pregnant women and their households with every aspect of maternal care $(26,141)$.

Concepts and approaches to measure satisfaction with maternal care services differ. A common approach is to measure women's satisfaction directly by asking them how satisfied they are with different aspects of maternal care. Satisfaction can also be measured indirectly through assessing expectations of health service quality. Often, healthcare structures and process features are assessed as indirect indicators of quality as well $(142,143)$. Combined measurement of direct and indirect indicators of satisfaction provides a more comprehensive evidence about service quality (144). 
As the WHO recommends, there is a need of monitoring and evaluating maternal satisfaction in the health sector to improve the quality and efficiency of healthcare during pregnancy, childbirth, and immediate post-natal period (145). According to these recommendations, countries have implemented various tools to assess women's satisfaction with maternal care services $(144,146)$. For evidence-based policy making to improve maternal care, it is essential to determine factors influencing maternal care quality and women's satisfaction with it. No such study has been conducted in Georgia before.

Thus, the objectives of this study are: to assess the women's level of satisfaction with antenatal natal and immediate post-natal care; to assess the association between direct measures of women's satisfaction and background characteristics like age, education level, economic status, residence, etc.; to assess if these background characteristics are associated with their perception of healthcare quality. The study contributes to policy making by providing evidence on satisfaction with maternal care in Georgia. Countries in the region with similar context could also benefit from this study by comparing the situation in their maternal care sectors to that in Georgia.

\subsection{METHODOLOGY}

We conducted a survey during September - December 2017 in Tbilisi, the capital city of Georgia, as well as in the Imereti and Adjara regions. Those purposively selected regions represent nearly three-fifths of the total population of the country (147). Women who gave birth to healthy babies during the preceding twelve months before the date of data collection were the target population.

A sample size of 400 women was estimated to be needed, using the sampling table developed by Israel (52). This was based on the sample size for an infinite population, with $95 \%$ confidence intervals, $\pm 5 \%$ precision and $50 \%$ variability including a $5 \%$ nonresponse rate. We selected five of the biggest maternal houses in the capital Tbilisi, as well as two rural facilities and one urban facility in each of the two regions, Imereti and Adjara. Those facilities were selected purposively aiming to sample women from both rural and urban areas with different socio-economic status. Out of the total eleven sampled facilities, three were tertiary level, six were secondary level and two were primary level facilities. The maternal records of those facilities were used as the sampling base. The 'probability proportionate to size' sampling method was used to determine the number of participants from each region. The total number of childbirths in Tbilisi, Imereti and Adjara regions in 2016 were 25565, 7382 and 6260 
respectively $(128,147)$. Therefore, of the total sample size of 400 , the number of participants from Tbilisi, Imereti and Adjara were 260, 75 and 65 respectively. The target mothers were selected consecutively from the hospital registry and then contacted by mobile phone. If a mother did not agree to participate, the next registered mother was contacted. The mothers who agreed to participate were interviewed at their homes mostly.

We prepared an interviewer-administered questionnaire in English with mostly closed questions and a few open questions, which was then translated into Georgian by the Principal Investigator (PI). The questionnaire was developed based on previous studies $(30,31,90,139)$ and based on the questionnaires used in the RHSs carried out in Georgia in 1999, 2000 and 2010 (30, 31, 90). We included in the study those features that were not covered by the RHSs (Chapter 3). The mothers' level of satisfaction about antenatal care including childbirth and immediate post-natal care was investigated both directly and indirectly. Both questions on structural features (i.e., tangibility, accessibility, availability) and process features (i.e., responsiveness, reliability, empathy, communication and courtesy) of antenatal, natal and immediate post-natal care were included, as well as questions on the satisfaction with the care received. All closed-question items were measured on five-point Likert scales (1=strongly disagree, 2 = disagree, $3=$ neither agree nor disagree, $4=$ agree, $5=$ strongly agree). A pre-test was conducted involving 12 mothers to ensure usability of the tool and also to test the skills of the research assistants. The text was simplified based on the comments of the research assistants. Appendix 5 shows the English version of the questionnaire used in the study.

Five experienced female research assistants with a social science background collected the data. A one-day training was given to the research assistants by the PI. Written informed consent was obtained from each respondent prior to the interview. Each interview took approximately 40 minutes. The Principal Investigator coordinated and monitored the field work. Confidentiality of data was maintained by anonymizing the datafile. An ethical approval for the study was obtained from the NCDC (Appendix 6).

Descriptive statistics were used to assess the women's level of satisfaction with antenatal, natal and immediate post-natal care. Ordinal regression was the key statistical model to assess the association of women's background characteristics (i.e., income, age, educational level, economic status, residence, employment) with their indirect and direct measures of satisfaction level (see Appendix 5). According to the National Statistics Office of Georgia, the average monthly salary was 900 GEL (1 GEL $=2.98$ Euro) and the subsistence minimum for a working age male was about $200 \mathrm{GEL}$ in $2016(14,147)$ Thus, people with a monthly income less than $200 \mathrm{GEL}$ are people 
below the national poverty line. Nagelkerke pseudo $\mathrm{R}^{2}$ was used to assess the goodness of fit of the estimated regressions. Software package SPSS version 21 was used for data processing and analysis.

\subsection{RESULTS}

A total of 400 women were interviewed. The socio-demographic characteristics of the participants are presented in Table 6.1. The age groups 25 to 29 and 30 to 34 years constitute $66.3 \%$ of the sample. In total, $94 \%$ of the sample is Georgians. Additionally, $79 \%$ are highly educated (belonging either to the group of college education or university) and nearly half of the sample are housewives. Nearly half of the study participants belonged to the two lowest income group (monthly income $200 \mathrm{GEL}$ to 900 GEL or lower than $200 \mathrm{GEL})$.

Table 6.2 shows the use of maternal care. In total, $99.5 \%$ of women received antenatal care and only $0.5 \%$ did not visit medical doctor during the antenatal period. Also, $90.3 \%$ of the study participants received antenatal care either at a women's consultation center or a city maternal house. Nearly $85 \%$ received more than 8 antenatal visits. In $98.9 \%$ of the cases, the antenatal care providers were obstetrician and $70.8 \%$ of the participants paid for the antenatal care visits. All participants had childbirth by a skilled birth attendant in one of the maternal houses.

Having only a midwife present during the childbirth was reported by $2.8 \%$ of the participants. Immediate post-natal care as well as natal and antenatal care was for the absolute majority of cases provided by the obstetrician. In total, $80.5 \%$ of the mothers in our study paid for childbirth services and for immediate post-natal care services (Table 6.2). 
Table 6.1 Socio-demographic characteristics of study participants ( $N=400)$

\begin{tabular}{|c|c|}
\hline Socio-demographic characteristics & $n(\%)$ \\
\hline \multicolumn{2}{|l|}{ Age range } \\
\hline $18-24$ years old & $81(20.2 \%)$ \\
\hline $25-29$ years old & $157(39.2 \%)$ \\
\hline $30-34$ years old & $108(27.0 \%)$ \\
\hline $35-39$ years old & $47(11.8 \%)$ \\
\hline $40-44$ years old & $7(1.8 \%)$ \\
\hline \multicolumn{2}{|l|}{ Ethnicity } \\
\hline Georgian & $376(94.0 \%)$ \\
\hline Armenian & $12(3.0 \%)$ \\
\hline Azeri & $8(2.0 \%)$ \\
\hline Russian & $4(1.0 \%)$ \\
\hline \multicolumn{2}{|l|}{ Place of residence } \\
\hline Urban & $124(31.0 \%)$ \\
\hline Rural & $276(69.0 \%)$ \\
\hline \multicolumn{2}{|l|}{ Religion } \\
\hline Christian & $386(96.5 \%)$ \\
\hline Islam & $14(3.5 \%)$ \\
\hline \multicolumn{2}{|l|}{ Educational level } \\
\hline Grade $1-4$ & $0(0 \%)$ \\
\hline Grade $5-6$ & $4(1.0 \%)$ \\
\hline Grade $10-12$ & $80(20.0 \%)$ \\
\hline College (technical education) & $76(19.0 \%)$ \\
\hline University & $240(60.0 \%)$ \\
\hline \multicolumn{2}{|l|}{ Employment status } \\
\hline Housewife & $191(47.7 \%)$ \\
\hline Own business & $10(2.5 \%)$ \\
\hline Student & $33(8.3 \%)$ \\
\hline Day-labor & $10(2.5 \%)$ \\
\hline Public job & $53(13.3 \%)$ \\
\hline Private job & $103(25.7 \%)$ \\
\hline Household monthly income ${ }^{a}$ & \\
\hline$<200 \mathrm{GEL}$ & $19(4.8 \%)$ \\
\hline $200-<900 \mathrm{GEL}$ & $175(43.7 \%)$ \\
\hline $900-1,500 \mathrm{GEL}$ & $116(29.0 \%)$ \\
\hline$>\quad 1,500 \mathrm{GEL}$ & $90(22.5 \%)$ \\
\hline Family receives social benefits & \\
\hline Yes & $22(5.5 \%)$ \\
\hline No & $378(94.5 \%)$ \\
\hline & $=2.98$ Euro \\
\hline
\end{tabular}


Table 6.2 Utilization of antenatal, natal and immediate post-natal services by the study participants *

\begin{tabular}{|c|c|}
\hline Utilization variables & $n(\%)$ \\
\hline \multicolumn{2}{|l|}{ Received antenatal care, $\mathrm{N}=400$} \\
\hline No & $2(0.2 \%)$ \\
\hline Yes & $398(99.8 \%)$ \\
\hline \multicolumn{2}{|c|}{ Average number of antenatal visits $\geq 8, N=400$} \\
\hline No & $60(15.0 \%)$ \\
\hline Yes & $340(85.0 \%)$ \\
\hline \multicolumn{2}{|c|}{ Type of antenatal care facility, $\mathrm{N}=400$} \\
\hline None & $2(0.5 \%)$ \\
\hline Women's consultation center & $150(37.3 \%)$ \\
\hline Regional maternal house & $16(4.0 \%)$ \\
\hline City maternal house & $211(53.0 \%)$ \\
\hline Referral hospital & $21(5.2 \%)$ \\
\hline \multicolumn{2}{|c|}{ Who provided most antenatal care, $N=400$} \\
\hline None & $2(0.5 \%)$ \\
\hline Midwife & $1(0.3 \%)$ \\
\hline Family physician & $1(0.3 \%)$ \\
\hline Obstetrician/gynecologist & $396(98.9 \%)$ \\
\hline \multicolumn{2}{|l|}{ Antenatal complications, $\mathrm{N}=\mathbf{4 0 0}$} \\
\hline No & $317(79.2 \%)$ \\
\hline Yes & $83(20.8 \%)$ \\
\hline \multicolumn{2}{|c|}{ Hospitalized due to complication, $N=400$} \\
\hline No & $376(94.0 \%)$ \\
\hline Yes & $24(6.0 \%)$ \\
\hline \multicolumn{2}{|c|}{ Out-of-pocket payments for antenatal care, $\mathrm{N}=400$} \\
\hline No & $116(29.2 \%)$ \\
\hline Yes & $284(70.8 \%)$ \\
\hline
\end{tabular}


Table 6.2 Utilization of antenatal, natal and immediate post-natal services by the study participants * (continuation)

\begin{tabular}{|c|c|}
\hline Utilization variables & n (\%) \\
\hline \multicolumn{2}{|l|}{ Place of childbirth, $N=400$} \\
\hline Home & $0(0 \%)$ \\
\hline Primary level facility & $20(5.0 \%)$ \\
\hline Secondary level facility & $308(77.0 \%)$ \\
\hline Tertiary level facility & $72(18.0 \%)$ \\
\hline \multicolumn{2}{|l|}{ Mode of childbirth, $N=400$} \\
\hline C-section & $179(44.8 \%)$ \\
\hline Vaginal childbirth & $221(55.2 \%)$ \\
\hline \multicolumn{2}{|l|}{ Childbirth provider, $\mathbf{N}=\mathbf{4 0 0}$} \\
\hline Midwife & $11(2.8 \%)$ \\
\hline Obstetrician & $389(97.2 \%)$ \\
\hline \multicolumn{2}{|c|}{ Immediate post-natal care provider, N = 400} \\
\hline Midwife & $1(0.3 \%)$ \\
\hline Nurse & $186(46.4 \%)$ \\
\hline Obstetrician & $213(53.3 \%)$ \\
\hline \multicolumn{2}{|c|}{ Out-of-pocket payments natal and immediate post-natal care, $N=400$} \\
\hline No & 78 (19.5\%) \\
\hline Yes & 322 (80.5\%) \\
\hline
\end{tabular}

* $\mathrm{N}$ varies due to missing data 
The frequency distribution of the indirect and direct measures of quality of maternal care can be found in Table 6.3a, 6.3b, 6.3c and 6.3d.

Table 6.3a presents the results on the perceived service quality in antenatal care. In general, we find that women are satisfied with maternal care services. Most respondents agreed with the statement that the condition of the medical facilities and medical equipment is good. They also generally agreed that the facility was clean and the prescriptions were clear. Most of the respondents agreed with the statement that common and specific diagnostic tests, necessary specialized care and medicines were available and the service costs were affordable. Only few of the participants strongly disagreed or disagreed with the statement that the consultation fee $(4.3 \%$ and $3.8 \%$ respectively), the cost of medicines ( $8.3 \%$ and $6.3 \%$ respectively), diagnostics $(5.3 \%$ and $8.5 \%$ respectively) and the cost of transportation $(2.0 \%$ and $8.3 \%$ respectively) were not affordable for them.

In total, $56.8 \%$ of the participants agreed with the statement that the waiting time was acceptable for them (average waiting time was 20 minutes). However, 17.8\% strongly disagreed and $8.8 \%$ disagreed with the same statement. Of all participants, $66.2 \%$ mentioned that antenatal care givers considered their financial ability, but $23 \%$ kept neutral regarding this statement. The majority of the respondents (83.6\%) agreed that the antenatal caregiver was respectful. They also agreed that information related to healthy lifestyle was clearly explained.

Table $6.3 \mathrm{~b}$ presents the direct measure of women's agreement with aspects of quality of antenatal care. Our findings show that the majority of the respondents agreed or strongly agreed that they will recommend their physician to others (93.4\%) and recommend to others the facilities they used (82\%).

Table $6.3 \mathrm{c}$ presents the results on the perceived service quality of childbirth and immediate post-natal care. Women's perception about tangibility of maternal houses was quite positive, $77.8 \%$ agreed or strongly agreed with the statements that maternal houses/units were attractive and $75.7 \%$ agreed or strongly agreed with the statements that medical equipment was up-to-date. Most women in the study agreed or strongly agreed that common diagnostic tests (79.9\%) and specific diagnostic tests $(70.5 \%)$ were available in most cases. In total, $78 \%$ of women agreed or strongly agreed with that statement that the fees for childbirth care were affordable. More than $90 \%$ of the respondents agreed or strongly agreed that the decision of the care provider about the method of childbirth was correct. Of all participants, $63.7 \%$ agreed and $7.5 \%$ strongly agreed with the statement that the caregivers consider their financial ability. Most respondents agreed with statements about communication and courtesy of the caregivers during childbirth. 
As shown in Table 6.3d, the satisfaction with childbirth care and immediate post-natal care was also very high. Participants were satisfied with the adequacy of childbirth care and immediate post-natal care. More than $90 \%$ of them agreed or strongly agreed that they will recommend their care provider to others. For maternal care facility, this share was $87.4 \%$. 
Table 6.3a: Frequency distribution of items regarding the perceived service quality in antenatal care

\begin{tabular}{|c|c|c|c|c|c|c|c|c|c|}
\hline & Statement & $\begin{array}{l}\text { Strongly } \\
\text { disagree }\end{array}$ & Disagree & Neutral & Agree & $\begin{array}{c}\text { Strongly } \\
\text { agree }\end{array}$ & Missing & Mean & SD \\
\hline \multirow{4}{*}{ 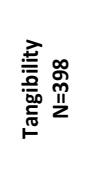 } & Clinic building and environment was attractive & $7(1.8 \%)$ & $3(0.8 \%)$ & $33(8.2 \%)$ & $303(75.7 \%)$ & $52(13.0 \%)$ & $2(0.5 \%)$ & 3.98 & 0.635 \\
\hline & Medical equipment was up-dated & $4(1.0 \%)$ & $10(2.5 \%)$ & $32(8.0 \%)$ & $302(75.5 \%)$ & $50(12.5 \%)$ & $2(0.5 \%)$ & 3.96 & 0.630 \\
\hline & Cleanliness was maintained & $3(0.8 \%)$ & $4(1.0 \%)$ & $28(7.0 \%)$ & $292(73.0 \%)$ & $71(17.7 \%)$ & $2(0.5 \%)$ & 4.07 & 0.594 \\
\hline & Prescriptions were clearly written and attractive & $5(1.3 \%)$ & $7(1.8 \%)$ & $19(4.8 \%)$ & $297(74.1 \%)$ & $70(17.5 \%)$ & $2(0.5 \%)$ & 4.06 & 0.636 \\
\hline \multirow{4}{*}{ 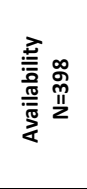 } & Common diagnostic tests were available & $2(0.5 \%)$ & $8(2.0 \%)$ & $44(11.0 \%)$ & $299(74.7 \%)$ & $45(11.3 \%)$ & $2(0.5 \%)$ & 3.95 & 0.589 \\
\hline & Specialized diagnostic tests were available & $12(3.0 \%)$ & $17(4.3 \%)$ & $85(21.0 \%)$ & $251(62.7 \%)$ & $33(8.5 \%)$ & $2(0.5 \%)$ & 3.69 & 0.804 \\
\hline & Necessary specialized care was available & $7(1.8 \%)$ & $13(3.3 \%)$ & $35(8.8 \%)$ & $301(75.1 \%)$ & $42(10.5 \%)$ & $2(0.5 \%)$ & 3.90 & 0.688 \\
\hline & Necessary medicines were available & $12(3.0 \%)$ & $17(4.3 \%)$ & $40(10.0 \%)$ & $299(74.7 \%)$ & $30(7.5 \%)$ & $2(0.5 \%)$ & 3.80 & 0.761 \\
\hline \multirow{4}{*}{ 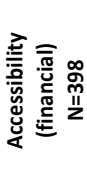 } & Consultation fee was affordable & $17(4.3 \%)$ & $15(3.8 \%)$ & $50(12.5 \%)$ & $285(71.2 \%)$ & $31(7.7 \%)$ & $2(0.5 \%)$ & 3.75 & 0.823 \\
\hline & Costs of required medicines were affordable & $33(8.3 \%)$ & $25(6.3 \%)$ & $73(18.3 \%)$ & $251(62.5 \%)$ & $16(4.6 \%)$ & $2(0.5 \%)$ & 3.48 & 0.978 \\
\hline & Costs of required diagnostics were affordable & $21(5.3 \%)$ & $34(8.5 \%)$ & $92(23.0 \%)$ & $243(60.7 \%)$ & $8(2.0 \%)$ & $2(0.5 \%)$ & 3.46 & 0.882 \\
\hline & Costs of transport were affordable & $8(2.0 \%)$ & $33(8.3 \%)$ & $96(24.0 \%)$ & $254(63.4 \%)$ & $7(1.8 \%)$ & $2(0.5 \%)$ & 3.55 & 0.755 \\
\hline \multirow{4}{*}{ 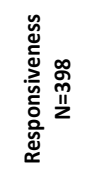 } & Waiting time was acceptable & $71(17.8 \%)$ & $35(8.8 \%)$ & $39(9.8 \%)$ & $227(56.6 \%)$ & $26(6.5 \%)$ & $2(0.5 \%)$ & 3.26 & 1.254 \\
\hline & Physician/midwife was timely available & $47(11.8 \%)$ & $38(9.4 \%)$ & $55(13.8 \%)$ & $234(58.5 \%)$ & $24(6.0 \%)$ & $2(0.5 \%)$ & 3.38 & 1.122 \\
\hline & Pharmacist was timely available & $29(7.2 \%)$ & $26(6.5 \%)$ & $44(11.0 \%)$ & $280(70 \%)$ & $19(4.8 \%)$ & $2(0.5 \%)$ & 3.59 & 0.953 \\
\hline & Laboratory staff and reports were timely available & $10(2.5 \%)$ & $29(7.2 \%)$ & $29(7.2 \%)$ & 308 (77.1\%) & $22(5.5 \%)$ & $2(0.5 \%)$ & 3.76 & 0.768 \\
\hline \multirow{4}{*}{ 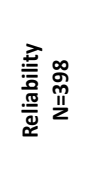 } & Antenatal caregiver was professionally competent & $5(1.3 \%)$ & $4(1.0 \%)$ & $6(1.5 \%)$ & $321(80.2 \%)$ & $62(15.5 \%)$ & $2(0.5 \%)$ & 4.08 & 0.564 \\
\hline & I felt secured to his/her care and decisions & $5(1.3 \%)$ & $7(1.8 \%)$ & $20(5.0 \%)$ & 308 (77.1\%) & $58(14.3 \%)$ & $2(0.5 \%)$ & 4.02 & 0.616 \\
\hline & I think, no excess tests were advised & $30(7.5 \%)$ & $21(5.3 \%)$ & $59(14.8 \%)$ & $250(62.4 \%)$ & $38(9.5 \%)$ & $2(0.5 \%)$ & 3.62 & 0.994 \\
\hline & I think, the prescribed drugs were needed & $3(0.8 \%)$ & $1(0.3 \%)$ & 11 (2.7\%) & 337 (84.2\%) & 46 (11.5\%) & $2(0.5 \%)$ & 4.06 & 0.467 \\
\hline
\end{tabular}


Table 6.3a: Frequency distribution of items regarding the perceived service quality in antenatal care (continuation)

\begin{tabular}{|c|c|c|c|c|c|c|c|c|c|}
\hline & Statement & $\begin{array}{l}\text { Strongly } \\
\text { disagree }\end{array}$ & Disagree & Neutral & Agree & $\begin{array}{l}\text { Strongly } \\
\text { agree }\end{array}$ & Missing & Mean & SD \\
\hline \multirow{3}{*}{ 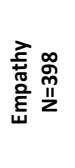 } & Antenatal caregiver was attentive to listen my problems & $8(2.0 \%)$ & $3(0.8 \%)$ & $26(6.5 \%)$ & $314(78.4 \%)$ & $47(11.8 \%)$ & $2(0.5 \%)$ & 3.98 & 0.628 \\
\hline & $\begin{array}{l}\text { Antenatal caregiver provided adequate mental support and assurance } \\
\text { to overcome my concerns of pregnancy }\end{array}$ & $10(2.5 \%)$ & $7(1.8 \%)$ & $59(14.5 \%)$ & $293(73.5 \%)$ & $29(7.2 \%)$ & $2(0.5 \%)$ & 3.81 & 0.696 \\
\hline & Antenatal caregiver considered my financial ability & $12(3.0 \%)$ & $4(1.0 \%)$ & $92(23.0 \%)$ & $265(66.2 \%)$ & $25(6.3 \%)$ & $2(0.5 \%)$ & 3.72 & 0.727 \\
\hline \multirow{3}{*}{ 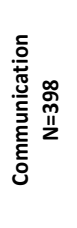 } & $\begin{array}{l}\text { Antenatal caregiver clearly explained information related to nutrition, } \\
\text { alcohol abuse, smoking, contraception, childbirth, child care with } \\
\text { breastfeeding }\end{array}$ & $31(7.8 \%)$ & $5(1.3 \%)$ & $44(11.0 \%)$ & $287(71.6 \%)$ & $31(7.8 \%)$ & $2(0.5 \%)$ & 3.71 & 0.926 \\
\hline & $\begin{array}{l}\text { Antenatal caregiver clearly explained information related to pregnancy } \\
\text { complications }\end{array}$ & $35(8.8 \%)$ & $3(0.8 \%)$ & $44(11.0 \%)$ & $295(73.6 \%)$ & $21(5.3 \%)$ & $2(0.5 \%)$ & 3.66 & 0.935 \\
\hline & I was given adequate time for consultation & $6(1.5 \%)$ & $1(0.3 \%)$ & $30(7.5 \%)$ & $331(82.7 \%)$ & $30(7.5 \%)$ & $2(0.5 \%)$ & 3.95 & 0.543 \\
\hline \multirow{3}{*}{ 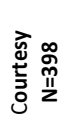 } & Antenatal caregiver was respectful & $1(0.3 \%)$ & $0(0 \%)$ & $19(4.8 \%)$ & $335(83.6 \%)$ & $43(10.8 \%)$ & $2(0.5 \%)$ & 4.05 & 0.420 \\
\hline & Antenatal caregiver maintained my privacy & $3(0.8 \%)$ & $2(0.5 \%)$ & $20(5.0 \%)$ & $349(87.2 \%)$ & $24(6.0 \%)$ & $2(0.5 \%)$ & 3.98 & 0.446 \\
\hline & Antenatal caregiver was friendly & $1(0.3 \%)$ & $4(1.0 \%)$ & $12(3.0 \%)$ & 354 (88.4\%) & $27(6.8 \%)$ & $2(0.5 \%)$ & 4.01 & 0.401 \\
\hline
\end{tabular}


Table 6.3b: Frequency distribution of items regarding the satisfaction with antenatal care

\begin{tabular}{|c|c|c|c|c|c|c|c|c|c|}
\hline & Statement & $\begin{array}{l}\text { Strongly } \\
\text { disagree }\end{array}$ & Disagree & Neutral & Agree & $\begin{array}{l}\text { Strongly } \\
\text { agree }\end{array}$ & Missing & Mean & SD \\
\hline \multirow{6}{*}{ 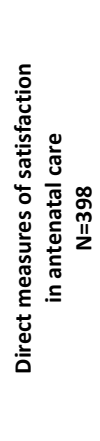 } & I am adequately satisfied with antenatal care services? & $9(2.3 \%)$ & $1(0.3 \%)$ & $12(3.0 \%)$ & $353(88.1 \%)$ & $23(5.8 \%)$ & $2(0.5 \%)$ & 3.95 & 0.547 \\
\hline & I am adequately satisfied with the dealings of antenatal caregivers? & $37(9.3 \%)$ & $1(0.3 \%)$ & $13(3.3 \%)$ & $320(80.4 \%)$ & $27(6.8 \%)$ & $2(0.5 \%)$ & 3.75 & 0.941 \\
\hline & $\begin{array}{l}\text { I am adequately satisfied with overall services of the antenatal care } \\
\text { facility? }\end{array}$ & $9(2.3 \%)$ & $0(0 \%)$ & $66(16.5 \%)$ & $303(75.7 \%)$ & $20(5.0 \%)$ & $2(0.5 \%)$ & 3.82 & 0.621 \\
\hline & I shall recommend others about my physician for antenatal care & $7(1.8 \%)$ & $2(0.5 \%)$ & $14(3.8 \%)$ & $351(87.4 \%)$ & $24(6.0 \%)$ & $2(0.5 \%)$ & 3.96 & 0.524 \\
\hline & I would consider this antenatal service in future if I need & $12(3.0 \%)$ & $4(1.0 \%)$ & $28(7.0 \%)$ & $328(82.0 \%)$ & $26(6.5 \%)$ & $2(0.5 \%)$ & 3.89 & 0.661 \\
\hline & I shall recommend others to use this antenatal care facility & $36(9.0 \%)$ & $4(1.0 \%)$ & $32(8.0 \%)$ & $287(72.2 \%)$ & $39(9.8 \%)$ & $2(0.5 \%)$ & 3.73 & 0.979 \\
\hline
\end{tabular}


Table 6.3c: Frequency distribution of items regarding the perceived service quality of childbirth and immediate post-natal care

\begin{tabular}{|c|c|c|c|c|c|c|c|c|}
\hline & Statement & $\begin{array}{l}\text { Strongly } \\
\text { disagree }\end{array}$ & Disagree & Neutral & Agree & $\begin{array}{c}\text { Strongly } \\
\text { agree }\end{array}$ & Mean & SD \\
\hline \multirow{4}{*}{ 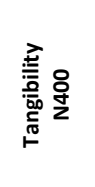 } & Childbirth facility building was attractive & $5(1.3 \%)$ & $5(1.3 \%)$ & 79 (19.6\%) & $276(69.0 \%)$ & $35(8.8 \%)$ & 3.83 & 0.647 \\
\hline & Medical equipment was up-dated & $5(1.3 \%)$ & $6(1.5 \%)$ & $86(21.5 \%)$ & $257(64.2 \%)$ & $46(11.5 \%)$ & 3.83 & 0.690 \\
\hline & Cleanliness was maintained & $13(3.3 \%)$ & $1(0.3 \%)$ & $23(5.8 \%)$ & $314(78.5 \%)$ & $49(12.1 \%)$ & 3.96 & 0.640 \\
\hline & Prescriptions were clearly written and attractive & $10(2.5 \%)$ & $3(0.8 \%)$ & $22(5.5 \%)$ & $325(81.2 \%)$ & $40(10.0 \%)$ & 3.96 & 0.640 \\
\hline \multirow{4}{*}{ 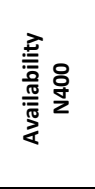 } & Common diagnostic facilities were available & $3(0.8 \%)$ & $13(3.3 \%)$ & $64(16.0 \%)$ & $289(72.2 \%)$ & $31(7.7 \%)$ & 3.83 & 0.638 \\
\hline & Specialized diagnostic facilities were available & $3(0.8 \%)$ & $26(6.5 \%)$ & $89(22.2 \%)$ & $258(64.5 \%)$ & $24(6.0 \%)$ & 3.69 & 0.716 \\
\hline & Necessary specialized care was available & $4(1.0 \%)$ & $15(3.8 \%)$ & $56(14.0 \%)$ & $292(73.0 \%)$ & $33(8.2 \%)$ & 3.84 & 0.661 \\
\hline & Necessary medicines were available & $3(0.8 \%)$ & $20(5.0 \%)$ & $67(16.8 \%)$ & $274(68.4 \%)$ & $36(9.0 \%)$ & 3.80 & 0.661 \\
\hline \multirow{4}{*}{ 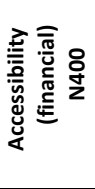 } & Fee for childbirth (NVD or C/Section) was affordable & $10(2.5 \%)$ & $18(4.5 \%)$ & $60(15.0 \%)$ & $288(72.0 \%)$ & $24(6.0 \%)$ & 3.75 & 0.743 \\
\hline & Costs of required medicines were affordable & $15(3.8 \%)$ & $15(3.8 \%)$ & $65(16.2 \%)$ & $279(69.8 \%)$ & $26(6.4 \%)$ & 3.72 & 0.797 \\
\hline & Costs of required diagnostics were affordable & $15(3.8 \%)$ & $19(4.8 \%)$ & $66(16.3 \%)$ & $275(68.8 \%)$ & $25(6.3 \%)$ & 3.69 & 0.813 \\
\hline & Costs of hospitalization were affordable & $12(3.0 \%)$ & $14(3.5 \%)$ & $67(16.7 \%)$ & $291(72.8 \%)$ & $16(4.0 \%)$ & 3.71 & 0.732 \\
\hline \multirow{3}{*}{ 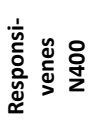 } & Waiting time was acceptable & $8(2.0 \%)$ & $11(2.8 \%)$ & $38(9.4 \%)$ & $315(78.8 \%)$ & $28(7.0 \%)$ & 3.86 & 0.661 \\
\hline & Physician/midwife was timely available during childbirth & $5(1.3 \%)$ & $3(0.7 \%)$ & 29 (7.2\%) & 311 (77.8\%) & $52(13.0 \%)$ & 4.01 & 0.588 \\
\hline & Physician/midwife was timely available during post-natal period & $5(1.3 \%)$ & $2(0.5 \%)$ & $10(2.5 \%)$ & $352(88.0 \%)$ & $31(7.7 \%)$ & 4.01 & 0.534 \\
\hline
\end{tabular}


Table 6.3c: Frequency distribution of items regarding the perceived service quality of childbirth and immediate post-natal care (continuation)

\begin{tabular}{|c|c|c|c|c|c|c|c|c|}
\hline & Statement & $\begin{array}{l}\text { Strongly } \\
\text { disagree }\end{array}$ & Disagree & Neutral & Agree & $\begin{array}{l}\text { Strongly } \\
\text { agree }\end{array}$ & Mean & SD \\
\hline \multirow{5}{*}{ 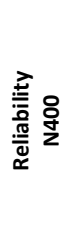 } & Natal and post-natal caregiver was adequately skilled & $4(1.0 \%)$ & $1(0.3 \%)$ & $24(6.0 \%)$ & $321(80.2 \%)$ & $50(12.5 \%)$ & 4.01 & 0.534 \\
\hline & I felt secured to childbirth care and decisions & $4(1.0 \%)$ & $0(0 \%)$ & $25(6.2 \%)$ & $331(82.8 \%)$ & $40(10.0 \%)$ & 4.03 & 0.503 \\
\hline & Physician's decision of method of childbirth was correct & $5(1.3 \%)$ & $1(0.3 \%)$ & $27(6.8 \%)$ & $313(78.1 \%)$ & $54(13.5 \%)$ & 4.03 & 0.570 \\
\hline & I think, no excess tests were advised & $5(1.3 \%)$ & $6(1.5 \%)$ & $25(6.3 \%)$ & $328(82.4 \%)$ & $36(8.5 \%)$ & 3.96 & 0.569 \\
\hline & I think, the prescribed drugs were needed & $5(1.3 \%)$ & $1(0.3 \%)$ & $22(5.5 \%)$ & $342(85.4 \%)$ & $30(7,5 \%)$ & 3.98 & 0.503 \\
\hline \multirow{5}{*}{ 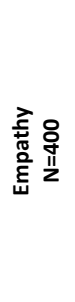 } & Childbirth and post-natal caregivers were attentive to listen my problems & $4(1.0 \%)$ & $0(0 \%)$ & $51(12.8 \%)$ & $302(75.4 \%)$ & $43(10.8 \%)$ & 3.95 & 0.569 \\
\hline & $\begin{array}{l}\text { Childbirth and post-natal caregiver provided adequate mental support and } \\
\text { assurance to overcome my concerns of childbirth and my baby }\end{array}$ & $5(1.3 \%)$ & $3(0.8 \%)$ & $57(14.2 \%)$ & $299(74.7 \%)$ & $36(9.0 \%)$ & 3.90 & 0.604 \\
\hline & $\begin{array}{c}\text { My wishes were considered for making decision about childbirth post-natal } \\
\text { period }\end{array}$ & $5(1.3 \%)$ & $6(1.5 \%)$ & $73(18.2 \%)$ & $290(72.5 \%)$ & $26(6.5 \%)$ & 3.82 & 0.622 \\
\hline & My financial ability was considered by care providers & $8(2.0 \%)$ & $20(5.0 \%)$ & $87(21.8 \%)$ & $255(63.7 \%)$ & $30(7.5 \%)$ & 3.70 & 0.763 \\
\hline & I could timely see and touch my baby when I wanted & $10(2.5 \%)$ & $7(1.7 \%)$ & $33(8.3 \%)$ & $328(82.0 \%)$ & $22(5.5 \%)$ & 3.86 & 0.644 \\
\hline \multirow{3}{*}{ 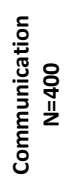 } & $\begin{array}{l}\text { Childbirth and post-natal caregiver clearly explained information related to } \\
\text { nutrition, contraception, child care with breastfeeding }\end{array}$ & $17(4.3 \%)$ & $18(4.5 \%)$ & $24(6.0 \%)$ & $320(80.0 \%)$ & $21(5.2 \%)$ & 3.78 & 0.791 \\
\hline & $\begin{array}{l}\text { Childbirth and post-natal caregiver clearly explained post-natal } \\
\text { complications }\end{array}$ & $21(5.2 \%)$ & $26(6.5 \%)$ & $24(6.0 \%)$ & $314(78.5 \%)$ & $15(3.8 \%)$ & 3.69 & 0.858 \\
\hline & I was given adequate time during and after childbirth & $6(1.5 \%)$ & $2(0.5 \%)$ & $28(7.0 \%)$ & $342(85.5 \%)$ & $22(5.5 \%)$ & 3.93 & 0.525 \\
\hline \multirow{3}{*}{ 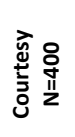 } & Childbirth and post-natal caregiver/s were respectful & $6(1.5 \%)$ & $2(0.5 \%)$ & $28(7.0 \%)$ & $331(82.8 \%)$ & $33(8.2 \%)$ & 3.96 & 0.554 \\
\hline & Childbirth and post-natal caregiver maintained my privacy & $3(0.8 \%)$ & $4(1.0 \%)$ & $22(5.5 \%)$ & $340(85.0 \%)$ & $31(7.7 \%)$ & 3.98 & 0.490 \\
\hline & Childbirth and post-natal caregiver/s were friendly & $3(0.8 \%)$ & $0(0 \%)$ & $19(4.7 \%)$ & 364 (91.0\%) & $14(3.5 \%)$ & 3.95 & 0.547 \\
\hline
\end{tabular}


Table 6.3d: Frequency distribution of items regarding the satisfaction with childbirth care and immediate post-natal care

\begin{tabular}{|c|c|c|c|c|c|c|c|c|}
\hline & Statement & $\begin{array}{l}\text { Strongly } \\
\text { disagree }\end{array}$ & Disagree & Neutral & Agree & $\begin{array}{l}\text { Strongly } \\
\text { agree }\end{array}$ & Mean & SD \\
\hline \multirow{6}{*}{ 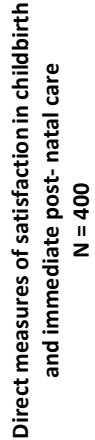 } & I am adequately satisfied with childbirth and post-natal care services? & $9(2.3 \%)$ & $2(0.5 \%)$ & $22(5.5 \%)$ & $321(80.2 \%)$ & 46 (11.5\%) & 3.98 & 0.627 \\
\hline & $\begin{array}{l}\text { I am adequately satisfied with overall dealings of childbirth and } \\
\text { post-natal caregivers? }\end{array}$ & $8(2.0 \%)$ & $2(0.5 \%)$ & 30 (7.5\%) & $321(80.2 \%)$ & $39(9.8 \%)$ & 3.96 & 0.609 \\
\hline & $\begin{array}{l}\text { I am adequately satisfied with overall services of the childbirth and } \\
\text { post-natal? }\end{array}$ & $4(1.0 \%)$ & $3(0.8 \%)$ & $29(7.2 \%)$ & 330 (82.5\%) & $34(8.5 \%)$ & 3.77 & 0.526 \\
\hline & $\begin{array}{l}\text { I shall recommend others about my physician / midwife for childbirth } \\
\text { and post-natal }\end{array}$ & $4(1.0 \%)$ & $3(0.8 \%)$ & $27(6.8 \%)$ & $329(82.1 \%)$ & $37(9.3 \%)$ & 3.98 & 0.529 \\
\hline & $\begin{array}{l}\text { I would consider this childbirth and post-natal service in future } \\
\text { if I need }\end{array}$ & $15(3.8 \%)$ & $2(0.5 \%)$ & $40(10 \%)$ & 303 (75.7\%) & $40(10 \%)$ & 3.88 & 0.737 \\
\hline & $\begin{array}{l}\text { I shall recommend others to use this childbirth and post-natal care } \\
\text { facility }\end{array}$ & $11(2.8 \%)$ & $4(1.0 \%)$ & $35(8.8 \%)$ & 308 (77.0\%) & $42(10.4 \%)$ & 3.92 & 0.688 \\
\hline
\end{tabular}


Ordinal logistic regression was performed to study the factors associated with satisfaction with maternal care services in Georgia. The results are presented in Table $6.4 \mathrm{a}$ to $6.4 \mathrm{~d}, 6.5 \mathrm{a}$ to $6.5 \mathrm{~d}, 6.6 \mathrm{a}$ and $6.6 \mathrm{~b}$. The analysis contains the following explanatory variables: age, education, employment status, place of living, ethnic background, religion, monthly income, antenatal care complication and payments for maternal care. A statistically significant level of $p<0.05$ was used in the analysis.

Regarding antenatal care, Table 6.4 a to $6.4 \mathrm{~d}$ show that younger age groups less often agreed with the statement that maternal care facility buildings and environment were attractive. The younger age groups also less often agreed that common diagnostic tests were available compared to the reference age group (40- 44 years). Women aged 25- 29 years less often agreed that pregnancy related complications were explained to them clearly, while, the $30-34$ years old respondents more often agreed with the same statement compared to the reference age group. The latter age groups more often agreed that privacy was well- maintained. Regarding childbirth and postnatal care, Table $6.5 \mathrm{a}$ to $6.5 \mathrm{~d}$ show that younger age groups more often agreed that specialized diagnostic tests were available during childbirth as well as immediate postnatal care compared to the reference group of $40-44$ years old. At the same time, younger age groups more often agreed with the statement that physicians consider their financial ability during natal and immediate post-natal period compared to the reference group.

Table $6.4 \mathrm{a}$ to $6.4 \mathrm{~d}$ and Table $6.5 \mathrm{a}$ to $6.5 \mathrm{~d}$ also show that the lowest educated groups more often agreed with the statements about tangibility than the reference group (university educated). They also more often agreed with the statement that common diagnostic tests and necessary medicines were available during antenatal care. The same education group also more often agreed that antenatal care givers were professionally competent compared to the highest education group (the reference group). The participants in the lowest education group less often agreed with the statement that cost for medicine were affordable during antenatal care. At the same time, they also more often agreed that they will consider antenatal services which they utilized during the last pregnancy.

As shown in Table $6.4 \mathrm{a}$ to $6.4 \mathrm{~d}, 6.5 \mathrm{a}$ to $6.5 \mathrm{~d}$, compared to respondents in the rural areas, respondents living in urban areas, more often agreed with the statement on the tangibility of antenatal care providers and they were more positive about natal and immediate post- natal care facilities. They also less often stated that waiting time was acceptable during antenatal visits. Our findings also show that in the urban areas, women more often agreed that the provider was timely available. Those who had antenatal complications more often agreed with statement about the affordability of 
consultation fee for antenatal care, however they less often agreed that the costs for medicines were affordable compared to women without complications.

According to our results (Table 6.4a to $6.4 \mathrm{~d}, 6.5 \mathrm{a}$ to $6.5 \mathrm{~d}$ ) women with an income from 200 to 900 GEL more often agreed with statements about the attractiveness of antenatal clinics and the condition of the medical equipment compared to women in the highest income group (the reference group). They were also more often positive about the availability of necessary clinical tests during antenatal care compared to the highest-income category. The lowest income group less often agreed with the statement "I felt secured to care givers services and decisions" during antenatal care. They also less often agreed with the statement about the necessity of prescribed drugs. Compared with the highest income group, women in the income group $200-<900 \mathrm{GEL}$ more often agreed with statements about communication. The lowest income group respondents also less often agreed with the statement that the cost of medicine was acceptable during childbirth and immediate post- natal care. The income group 200 $<900$ GEL more often agreed than other income groups that the price for hospitalization was affordable when they received care in the maternal houses/unites.

Compared to those who did not pay, the respondents who paid for the antenatal care less often agreed with the statements about tangibility. At the same time, they more often agreed that common diagnostic tests were available but not necessary medicines. They agreed less with the statement that the waiting time was acceptable. However, they more often agreed that they felt secure with caregivers and that the medicines prescribed during antenatal care, were needed. Those who paid, less often agreed that they felt respect but more often agreed that they felt privacy in the contact with the antenatal care providers.

According to the ordinal regression on the satisfaction with antenatal, natal and immediate post-natal care (Table 6.6a and 6.6b), Georgian women and those who paid for maternal care services were less satisfied with antenatal care than those who did not pay. Also, women in urban areas were more often satisfied with antenatal, natal and immediate post- natal care. Those who paid for services were less motivated to recommend the services to others compared to women who did not pay, but those with complications more often considered recommending their (post-natal) provider. 
Table 6.4a: Ordinal regression of perceived service quality in antenatal care

( 1 = strongly disagree, 2 = disagree, 3 = neither agree nor disagree, 4 = agree, $5=$ strongly agree)

\begin{tabular}{|c|c|c|c|c|c|c|c|c|}
\hline & \\
\hline & \multicolumn{4}{|c|}{$\begin{array}{c}\text { Tangibility } \\
\mathrm{N}=398\end{array}$} & \multicolumn{4}{|c|}{$\begin{array}{c}\text { Availability } \\
\mathrm{N}=398\end{array}$} \\
\hline & $\begin{array}{l}\text { Clinic building } \\
\text { and environment } \\
\text { were attractive }\end{array}$ & $\begin{array}{l}\text { Medical } \\
\text { equipment was } \\
\text { up-dated }\end{array}$ & $\begin{array}{l}\text { Cleanliness } \\
\text { was } \\
\text { maintained }\end{array}$ & $\begin{array}{l}\text { Prescriptions were } \\
\text { clearly written } \\
\text { and attractive }\end{array}$ & $\begin{array}{l}\text { Common diagnostic } \\
\text { tests were } \\
\text { available }\end{array}$ & $\begin{array}{c}\text { Specialized diagnostic } \\
\text { tests } \\
\text { were available }\end{array}$ & $\begin{array}{c}\text { Necessary } \\
\text { specialized care } \\
\text { was available }\end{array}$ & $\begin{array}{c}\text { Necessary } \\
\text { medicines } \\
\text { were available }\end{array}$ \\
\hline & \multicolumn{4}{|c|}{ Coefficient E (S.E) } & \multicolumn{4}{|c|}{ Coefficient E (S.E) } \\
\hline \multicolumn{9}{|l|}{ Age (years) } \\
\hline $15-24=0$ & $-1.826(0.978)^{*}$ & $-1.060(0.936)$ & $-0.160(1.007)$ & $-0.813(0.947)$ & $-1.686(0.912)^{*}$ & $0.247(0.828)$ & $-1.517(0.965)$ & $-1.049(0.858)$ \\
\hline $25-29=1$ & $-1.523(0.942)^{*}$ & $-0.695(0.896)$ & $0.128(0.974)$ & $-0.484(0.910)$ & $-1.597(0.876)^{*}$ & $0.291(0.798)$ & $-1.156(0.930)$ & $-1.344(0.266)$ \\
\hline $30-34=2$ & $-2.022(0.950)^{*}$ & $-1.408(0.907)$ & $-0.247(0.979)$ & $-0.907(0.916)$ & $-1.472(0.880)^{*}$ & $0.431(0.805)$ & $-1.474(0.935)$ & $1.015(0.986)$ \\
\hline $35-39=3$ & $-1.080(0.982)$ & $-0.444(0.938)$ & $-0.470(1.010)$ & $-0.141(0.951)$ & $-1.187(0.918)$ & $0.564(0.842)$ & $-0.973(0.972)$ & $0.991(1.026)$ \\
\hline $40-44=4$ & oa & oa & oa & oa & oa & oa & oa & oa \\
\hline \multicolumn{9}{|l|}{ Education } \\
\hline Grade $5-6=0$ & $1.984(1.070)^{*}$ & $1.237(1.149)$ & $1.873(1.056)^{*}$ & $1.753(1.049)^{*}$ & $1.498(1.131)^{*}$ & $0.997(1.098)$ & $1.754(1.191)$ & $2.313(0.216)^{*}$ \\
\hline Grade $10-12=1$ & $-0.582(0.351)^{*}$ & $0.257(0.343)$ & $0.016(0.336)$ & $-0.685(0.348)^{*}$ & $-0.153(0.336)$ & $-0.367(0.294)$ & $0.302(0.341)$ & $0.967(1.174)$ \\
\hline College $=2$ & $0.531(0.343)$ & $0.480(0.335)$ & $-0.214(0.331)$ & $0.164(0.338)$ & $0.474(0.333)$ & $0.305(0.297)$ & $1.369(0.352)^{*}$ & $0.329(0.355)^{*}$ \\
\hline University $=3$ & oa & oa & oa & oa & oa & oa & oa & oa \\
\hline \multicolumn{9}{|l|}{ Place of living } \\
\hline Urban $=0$ & $0.923(0.466)^{*}$ & $0.894(0.465)^{*}$ & $0.789(0.452)^{*}$ & $-0.530(0.467)$ & $0.815(0.468)$ & $-0.289(0.240)$ & $0.574(0.476)$ & $0.497(0.467)$ \\
\hline Rural = 1 & oa & oa & oa & oa & oa & oa & oa & oa \\
\hline \multicolumn{9}{|c|}{ Antenatal care complication } \\
\hline Yes $=0$ & $-0.028(0.290)^{*}$ & $-0.345(0.287)$ & $-0.065(0.283)^{*}$ & $0.279(0.254)$ & $0.181(0.284)$ & $0.211(0.247)$ & $0.205(0.289)$ & $0.517(0.255)^{*}$ \\
\hline No $=1$ & oa & oa & oa & oa & oa & oa & oa & oa \\
\hline \multicolumn{9}{|l|}{ Monthly income a } \\
\hline$<200 \mathrm{GEL}=0$ & $-0.080(0.664)$ & $1.066(0.658)$ & $0.226(0.650)$ & $0.157(0.672)$ & $0.108(0.612)$ & $0.015(0.570)$ & $0.955(0.670)$ & $0.723(0.127)$ \\
\hline $200-<900 \mathrm{GEL}=1$ & $0.858(0.358)^{*}$ & $0.826(0.353)^{*}$ & $0.411(0.343)$ & $0.409(0.352)$ & $0.442(0.335)$ & $0.901(0.307)^{*}$ & $0.063(0.347)$ & $-0.218(0.671)$ \\
\hline $900-1,500 \mathrm{GEL}=2$ & $0.622(0.364)^{*}$ & $0.411(0.358)$ & $0.052(0.354)$ & $-0.251(0.360)$ & $-0.428(0.339)$ & $-0.391(0.296)$ & $-0.471(0.349)$ & $-0.343(0.349)$ \\
\hline$>1,500 \mathrm{GEL}=3$ & oa & oa & oa & oa & oa & oa & oa & oa \\
\hline
\end{tabular}


Table 6.4a: Ordinal regression of perceived service quality in antenatal care

( 1 = strongly disagree, 2 = disagree, 3 = neither agree nor disagree, 4 = agree, $5=$ strongly agree) (continuation)

\begin{tabular}{|c|c|c|c|c|c|c|c|c|}
\hline & \multirow{2}{*}{\multicolumn{4}{|c|}{$\begin{array}{l}\text { Tangibility } \\
\mathrm{N}=398\end{array}$}} & & & & \\
\hline & & & & & \multicolumn{4}{|c|}{$\begin{array}{l}\text { Availability } \\
\mathrm{N}=398\end{array}$} \\
\hline & $\begin{array}{l}\text { Clinic building } \\
\text { and environment } \\
\text { were attractive }\end{array}$ & $\begin{array}{c}\text { Medical } \\
\text { equipment was } \\
\text { up-dated }\end{array}$ & $\begin{array}{l}\text { Cleanliness } \\
\text { was } \\
\text { maintained }\end{array}$ & $\begin{array}{l}\text { Prescriptions were } \\
\text { clearly written } \\
\text { and attractive }\end{array}$ & $\begin{array}{l}\text { Common diagnostic } \\
\text { tests were } \\
\text { available }\end{array}$ & $\begin{array}{c}\text { Specialized diagnostic } \\
\text { tests } \\
\text { were available }\end{array}$ & $\begin{array}{c}\text { Necessary } \\
\text { specialized care } \\
\text { was available }\end{array}$ & $\begin{array}{c}\text { Necessary } \\
\text { medicines } \\
\text { were available }\end{array}$ \\
\hline & \multicolumn{4}{|c|}{ Coefficient E (S.E) } & \multicolumn{4}{|c|}{ Coefficient E (S.E) } \\
\hline \multicolumn{9}{|l|}{ Nationality } \\
\hline Other $=0$ & $1.501(0.486)$ & $-0.499(0.262)$ & $-1.821(0.466)^{*}$ & $0.818(0.445)^{*}$ & $1.638(0.462)^{*}$ & $1.145(0.453)^{*}$ & $1.733(0.454)^{*}$ & $-0.522(0.501)$ \\
\hline Georgian $=1$ & oa & oa & oa & oa & oa & oa & oa & oa \\
\hline \multicolumn{9}{|l|}{ Occupation } \\
\hline Other $=0$ & $-0.289(0.290)$ & $-0.053(0.234)$ & $-0.078(0.231)$ & $-0.126(0.231)$ & $-0.162(0.232)$ & $-0.075(0.204)$ & $0.255(0.235)$ & $-0.285(0.233)$ \\
\hline Housewife $=1$ & oa & oa & oa & oa & oa & oa & oa & oa \\
\hline \multicolumn{9}{|c|}{$\begin{array}{l}\text { Out-of-pocket payments during } \\
\text { antenatal period }\end{array}$} \\
\hline Yes $=0$ & $-0.759(0.267)^{*}$ & $-0.894(0.465)^{*}$ & $-0.254(0.481)^{*}$ & $0.220(0.266)$ & $0.515(0.257)^{*}$ & $0.166(0.226)$ & $0.012(0.259)$ & $-0.537(0.266)^{*}$ \\
\hline $\mathrm{No}=1$ & oa & oa & oa & oa & oa & oa & oa & oa \\
\hline Nagelkerke $\mathbf{R}^{2}$ & 0.230 & 0.219 & 0.119 & 0.213 & 0.150 & 0.158 & 0.175 & 0. .167 \\
\hline Trashold $\mathrm{a}_{1}$ & $-5.983(1.475)^{*}$ & $-6.271(1.409)^{*}$ & $-7.407(1.697)^{*}$ & $-6.452(1.579)^{*}$ & $-8.174(1.514)^{*}$ & $-4.654(1.269)^{*}$ & $-6.188(1.461)^{*}$ & $-6.275(1.564)^{*}$ \\
\hline Trashold $a_{2}$ & $5.611(1.460)^{*}$ & $-4.973(1.344)^{*}$ & $-6.524(1.640)^{*}$ & $-5.554(1.541)^{*}$ & $-6.528(1.374)^{*}$ & $-2.681(1.248)^{*}$ & $-5.097(1.428)^{*}$ & $-5.328(1.548)^{*}$ \\
\hline Trashold $a_{3}$ & $-2.944(1.428)^{*}$ & $-2.534(1.320)^{*}$ & $-4.654(1.591)^{*}$ & $-4.508(1.520)^{*}$ & $-4.644(1.339)^{*}$ & $-1.895(1.233)$ & $-2.935(1.415)^{*}$ & $-4.282(1.539)^{*}$ \\
\hline Trashold $\mathrm{a}_{4}$ & $0.889(1.415)$ & $1.239(1.307)^{*}$ & $0.189(1.556)$ & $0.221(1.491)$ & $-0.246(1.311)$ & $1.820(1.238)$ & $0.653(1.396)$ & $0.416(1.513)^{*}$ \\
\hline
\end{tabular}

a $1 \mathrm{GEL}=2.98$ Euro; $*$ p $\leq 0.05$ 
Table 6.4b: Ordinal regression of perceived service quality in antenatal care

( 1 = strongly disagree, 2 = disagree, 3 = neither agree nor disagree, 4 = agree, $5=$ strongly agree)

\begin{tabular}{|c|c|c|c|c|c|c|c|}
\hline \multicolumn{4}{|c|}{$\begin{array}{l}\text { Accessibility } \\
\quad N=398\end{array}$} & \multicolumn{4}{|c|}{$\begin{array}{c}\text { Responsiveness } \\
\mathrm{N}=39\end{array}$} \\
\hline $\begin{array}{l}\text { Consultation fee was } \\
\text { affordable }\end{array}$ & $\begin{array}{l}\text { Costs of required } \\
\text { medicines were } \\
\text { affordable }\end{array}$ & $\begin{array}{l}\text { Costs of required } \\
\text { diagnostics were } \\
\text { affordable }\end{array}$ & $\begin{array}{c}\text { Transport } \\
\text { costs } \\
\text { were affordable }\end{array}$ & $\begin{array}{l}\text { Waiting time } \\
\text { was } \\
\text { acceptable }\end{array}$ & $\begin{array}{c}\text { Physician/midwife was } \\
\text { timely } \\
\text { available }\end{array}$ & $\begin{array}{c}\text { Pharmacist } \\
\text { was timely } \\
\text { available }\end{array}$ & $\begin{array}{l}\text { Laboratory staff and } \\
\text { reports were } \\
\text { timely available }\end{array}$ \\
\hline
\end{tabular}

\begin{tabular}{|c|c|c|c|c|c|c|c|c|}
\hline \multicolumn{9}{|l|}{ Age (years) } \\
\hline $15-24=0$ & $-1.157(0.975)$ & $0.121(0.878)$ & $-0.479(0.906)$ & $-0.029(0.920)$ & $-0.376(0.835)$ & $0.634(0.891)$ & $-0.381(0.936)$ & $-0.060(1.078)$ \\
\hline $25-29=1$ & $-1.320(0.946)$ & $-0.038(0.849)$ & $-0.064(0.880)$ & $0.254(0.893)$ & $-0.629(0.808)$ & $-1.016(0.866)$ & $-0.591(0.907)$ & $-0.333(1.048)$ \\
\hline $30-34=2$ & $-0.633(0.947)$ & $0.401(0.855)$ & $0.083(0.884)$ & $0.625(0.900)$ & $-0.073(0.813)$ & $-0.233(0.870)$ & $0.153(0.914)$ & $-0.068(1.052)$ \\
\hline $35-39=3$ & $-0.387(0.984)$ & $0.368(0.889)$ & $0.062(0.027)$ & $0.109(0.926)$ & $-0.217(0.843)$ & $-0.650(0.898)$ & $-0.121(0.948)$ & $0.121(1.097)$ \\
\hline $40-44=4$ & oa & oa & oa & oa & oa & oa & oa & oa \\
\hline \multicolumn{9}{|l|}{ Education } \\
\hline Grade $5-6=0$ & $0.404(1.095)$ & $-0.495(0.944)^{*}$ & $-0.470(0.943)$ & $-1.240(0.951)$ & $0.025(0.967)$ & $-0.143(0.959)$ & $-1.065(0.978)$ & $2.251(1.142)^{*}$ \\
\hline Grade $10-12=1$ & $-0.019(0.311)$ & $0.187(0.288)$ & $0.355(0.289)$ & $0.142(0.294)$ & $0.113(0.281)$ & $-0.062(0.285)$ & $0.095(0.320)$ & $-0.245(0.331)$ \\
\hline College $=2$ & $0.444(0.322)$ & $0.377(0.298)$ & $0.129(0.293)$ & $-0.113(0.294)$ & $0.032(0.279)$ & $-0.221(0.281)$ & $-0.393(0.307)$ & $-0.448(0.322)$ \\
\hline University $=3$ & oa & oa & oa & oa & oa & oa & oa & oa \\
\hline \multicolumn{9}{|l|}{ Place of living } \\
\hline Urban $=0$ & $-0.511(0.449)$ & $0.457(0.412)^{*}$ & $0.331(0.437)^{*}$ & $-0.478(0.443)$ & $-0.887(0.394)^{*}$ & $0.971(0.370)^{*}$ & $0.319(0.455)^{*}$ & $0.649(0.288)^{*}$ \\
\hline Rural = 1 & oa & oa & $0^{a}$ & oa & oa & oa & oa & oa \\
\hline \multicolumn{9}{|l|}{ Antenatal care } \\
\hline complication & $0.634(0.281)^{*}$ & $-0.430(0.244)^{*}$ & $0.252(0.245)$ & $0.364(0.247)$ & $0.634(0.281)$ & $0.022(0.249)$ & $0.044(0.267)$ & $-0.160(0.298)$ \\
\hline $\begin{array}{l}\text { Yes }=0 \\
\text { No }=1\end{array}$ & oa & oa & $0^{a}$ & $0^{a}$ & oa & oa & oa & oa \\
\hline \multicolumn{9}{|l|}{ Monthly income ${ }^{a}$} \\
\hline$<200 \mathrm{GEL}=0$ & $-0.498(0.619)$ & $0.783(0.597)$ & $0.873(0.637)$ & $0.679(0.626)$ & $-0.498(0.619)$ & $0.698(0.535)$ & $-0.273(0.591)$ & $-0.036(0.688)$ \\
\hline $200-<900 \mathrm{GEL}=1$ & $0.114(0.326)$ & $0.269(0.299)$ & $-0.337(0.304)$ & $-0.078(0.305)$ & $0.114(0.326)$ & $-0.024(0.280)$ & $-0.459(0.312)$ & $0.397(0.351)$ \\
\hline $900-1,500 \mathrm{GEL}=2$ & $-0.327(0.323)$ & $0.003(0.302)$ & $-0.390(0.309)$ & $0.102(0.312)$ & $-0.327(0.323)$ & $0.135(0.286)$ & $-0.029(0.319)$ & $-0.388(0.346)$ \\
\hline$>1,500 \mathrm{GEL}=3$ & $0 a$ & oa & oa & oa & oa & oa & oa & oa \\
\hline
\end{tabular}


Table 6.4b: Ordinal regression of perceived service quality in antenatal care

( 1 = strongly disagree, 2 = disagree, 3 = neither agree nor disagree, 4 = agree, $5=$ strongly agree) (continuation)

\begin{tabular}{|c|c|c|c|c|c|c|c|}
\hline \multicolumn{4}{|c|}{$\begin{array}{c}\text { Accessibility } \\
\mathrm{N}=398\end{array}$} & \multicolumn{4}{|c|}{$\begin{array}{c}\text { Responsiveness } \\
\mathrm{N}=\mathbf{3 9}\end{array}$} \\
\hline $\begin{array}{l}\text { Consultation } \\
\text { fee was } \\
\text { affordable }\end{array}$ & $\begin{array}{l}\text { Costs of required } \\
\text { medicines } \\
\text { were affordable }\end{array}$ & $\begin{array}{l}\text { Costs of required } \\
\text { diagnostics } \\
\text { were affordable }\end{array}$ & $\begin{array}{c}\text { Transport } \\
\text { costs } \\
\text { were affordable }\end{array}$ & $\begin{array}{l}\text { Waiting time } \\
\text { was } \\
\text { acceptable }\end{array}$ & $\begin{array}{c}\text { Physician/midwife was } \\
\text { timely } \\
\text { available }\end{array}$ & $\begin{array}{c}\text { Pharmacist } \\
\text { was timely } \\
\text { available }\end{array}$ & $\begin{array}{l}\text { Laboratory staff and } \\
\text { reports were } \\
\text { timely available }\end{array}$ \\
\hline \multicolumn{4}{|c|}{ Coefficient E (S.E) } & \multicolumn{4}{|c|}{ Coefficient E (S.E) } \\
\hline
\end{tabular}

\begin{tabular}{|c|c|c|c|c|c|c|c|c|}
\hline & & & & & & & & \\
\hline \multirow{3}{*}{$\begin{array}{l}\text { Other }=0 \\
\text { Georgian }=1\end{array}$} & \multirow{3}{*}{$\begin{array}{c}0.603(0.480) \\
0 \mathrm{a}\end{array}$} & & & & & & & \\
\hline & & \multirow{2}{*}{$\begin{array}{c}0.249(0.427) \\
0 \mathrm{a}\end{array}$} & \multirow{2}{*}{$\begin{array}{c}-0.106(0.434) \\
0 a\end{array}$} & \multirow{2}{*}{$\begin{array}{c}-0.013(0.436) \\
0 \mathrm{a}\end{array}$} & \multirow{2}{*}{$\begin{array}{c}0.603(0.480)^{*} \\
0 \mathrm{a}\end{array}$} & \multirow{2}{*}{$\begin{array}{c}1.575(0.464)^{*} \\
0 \mathrm{a}\end{array}$} & \multirow{2}{*}{$\begin{array}{c}0.401(0.482) \\
0 a\end{array}$} & \multirow{2}{*}{$\begin{array}{c}-0.007(0.522) \\
0 a\end{array}$} \\
\hline & & & & & & & & \\
\hline \multicolumn{9}{|l|}{ Occupation } \\
\hline Other $=0$ & $-0.993(0.235)^{*}$ & $0.648(0.208)^{*}$ & $0.829(0.206)^{*}$ & $0.679(0.209)^{*}$ & $-0.993(0.235)$ & $-0.129(0.197)$ & $0.283(0.219)$ & $-0.046(0.239)$ \\
\hline Housewife $=1$ & oa & oa & oa & oa & oa & oa & oa & oa \\
\hline \multicolumn{9}{|c|}{$\begin{array}{l}\text { Out-of-pocket payments } \\
\text { during antenatal period }\end{array}$} \\
\hline Yes $=0$ & $0.495(0.254)^{*}$ & $-0.356(0.235)$ & $-0.127(0.226)$ & $-0.304(0.228)$ & $-0.652(0.199)^{*}$ & $-0.567(0.236)^{*}$ & $-0.122(0.243)$ & $0.096(0.267)$ \\
\hline No $=1$ & oa & oa & oa & oa & oa & oa & oa & oa \\
\hline Nagelkerke $\mathbf{R}^{2}$ & 0.156 & 0.083 & 0.144 & 0.075 & 0.009 & 0.122 & 0.079 & 0.109 \\
\hline Threshold a1 & $-5.304(1.409)^{*}$ & $-2.493(1.305)^{*}$ & $-5.167(1.387)^{*}$ & -4.641 (1.299)* & $-2.404(1.243)$ & $-3.598(1.306)^{*}$ & $-2.689(1.379)^{*}$ & $-3.809(1.545)^{*}$ \\
\hline Threshold a2 & $-4.606(1.398)^{*}$ & $-2.833(1.299)^{*}$ & $-4.041(1.374)^{*}$ & $-2.856(1.257)^{*}$ & $-2.874(1.240)$ & $-2.867(1.301)$ & $-1.957(1.373)^{*}$ & $-2.315(1.520)$ \\
\hline Threshold a3 & $-2.443(1.388)$ & $-1.715(1.293)$ & $-2.589(1.366)^{*}$ & $-1.215(1.248)$ & $-2.394(1.239)$ & $-2.117(1.299)$ & $-1.179(1.370)$ & $-1.620(1.516)$ \\
\hline Threshold a4 & $0.932(1.374)$ & $2.371(1.306)$ & $2.189(1.385)$ & $3.749(1.301)^{*}$ & $1.135(1.229)^{*}$ & $1.629(1.295)^{*}$ & $3.178(1.387)^{*}$ & $3.189(1.530)^{*}$ \\
\hline
\end{tabular}

a $1 \mathrm{GEL}=2.98$ Euro; $^{*} p \leq 0.05$ 
Table 6.4c: Ordinal regression of perceived service quality in antenatal care

( 1 = strongly disagree, 2 = disagree, 3 = neither agree nor disagree, 4 = agree, $5=$ strongly agree)

\begin{tabular}{|c|c|c|c|c|c|c|c|}
\hline & \multicolumn{4}{|c|}{ Reliability N=398 } & \multicolumn{3}{|c|}{ Empathy $N=398$} \\
\hline & $\begin{array}{c}\text { Antenatal caregiver } \\
\text { was professionally } \\
\text { competent }\end{array}$ & $\begin{array}{l}\text { I felt secured } \\
\text { to his/her care } \\
\text { and decisions }\end{array}$ & $\begin{array}{l}\text { I think, no excess } \\
\text { tests } \\
\text { were advised }\end{array}$ & $\begin{array}{l}\text { I think, the prescribed } \\
\text { drugs } \\
\text { were needed }\end{array}$ & $\begin{array}{c}\text { Antenatal caregiver } \\
\text { was attentive to listen } \\
\text { my problems }\end{array}$ & $\begin{array}{c}\text { Antenatal caregiver } \\
\text { provided adequate } \\
\text { mental support }\end{array}$ & $\begin{array}{l}\text { Antenatal caregiver } \\
\text { considered my } \\
\text { financial ability }\end{array}$ \\
\hline & \multicolumn{4}{|c|}{ Coefficient E (S.E) } & \multicolumn{2}{|c|}{ Coefficient E (S.E) } & \\
\hline \multicolumn{8}{|l|}{ Age (years) } \\
\hline $15-24=0$ & $-1.026(1.098)$ & $-1.241(0.990)$ & $0.012(0.823)$ & $-0.475(1.096)$ & $-0.350(1.001)$ & $0.023(0.898)$ & $0.526(0.883)$ \\
\hline $25-29=1$ & $-0.489(1.055)$ & $-0.757(0.953)$ & $0.352(0.795)$ & $-0.259(1.055)$ & $-0.239(0.966)$ & $0.243(0.903)$ & $-0.011(0.849)$ \\
\hline $30-34=2$ & $-0.068(1.054)$ & $-0.448(0.954)$ & $0.518(0.799)$ & $-0.987(1.070)$ & $-0.598(0.971)$ & $-0.290(0.904)$ & $0.302(0.853)$ \\
\hline $35-39=3$ & $-0.510(1.100)$ & $-0.958(0.998)$ & $0.152(0.829)$ & $-0.310(1.103)$ & $-0.212(1.007)$ & $0.395(0.947)$ & $0.479(0.889)$ \\
\hline $40-44=4$ & oa & oa & oa & oa & oa & oa & oa \\
\hline \multicolumn{8}{|l|}{ Education } \\
\hline Grade $5-6=0$ & $1.096(1.207)^{*}$ & $1.036(1.139)$ & $1.266(1.091)$ & $1.194(1.194)$ & $1.610(1.146)$ & $-1.535(1.039)$ & $-1.174(1.017)$ \\
\hline Grade $10-12=1$ & $0.111(0.379)$ & $-0.312(0.350)$ & $0.282(0.294)$ & $0.442(0.407)$ & $0.003(0.358)$ & $-0.296(0.326)$ & $-0.634(0.306)^{*}$ \\
\hline College $=2$ & $0.530(0.360)^{* *}$ & $0.390(0.339)$ & $0.170(0.287)$ & $0.716(0.389)$ & $0.632(0.346)^{* *}$ & $0.475(0.335)$ & $-0.103(0.307)$ \\
\hline University $=3$ & oa & oa & oa & oa & oa & oa & oa \\
\hline \multicolumn{8}{|l|}{ Place of living } \\
\hline Urban $=0$ & $-1.317(0.354)$ & $-1.752(0.298)^{*}$ & $-0.255(0.232)^{*}$ & $1.058(0.322)^{*}$ & $-0.382(0.284)$ & $0.153(0.263)$ & $0.881(0.263)^{*}$ \\
\hline Rural = 1 & oa & oa & oa & oa & oa & oa & oa \\
\hline \multicolumn{8}{|c|}{ Antenatal care complication } \\
\hline Yes $=0$ & $0.068(0.291)$ & $0.283(0.293)$ & $0.434(0.247)^{*}$ & $0.309(0.395)$ & $0.026(0.341)$ & $0.470(0.281)$ & $0.317(0.251)$ \\
\hline $\mathrm{No}=1$ & oa & oa & oa & oa & oa & oa & oa \\
\hline \multicolumn{8}{|l|}{ Monthly income a } \\
\hline$<200 \mathrm{GEL}=0$ & $-0.106(0.782)^{*}$ & $-0.036(0.688)^{* *}$ & $0.573(0.590)$ & $-0.645(0.840)^{*}$ & $-0.117(0.693)$ & $0.150(0.627)$ & $0.320(0.611)$ \\
\hline $200-<900 \mathrm{GEL}=1$ & $0.573(0.378)$ & $0.397(0.351)$ & $-0.202(0.296)$ & $-0.018(0.404)$ & $0.450(0.356)$ & $1.013(0.329)^{*}$ & $0.882(0.309)^{*}$ \\
\hline $900-1,500 \mathrm{GEL}=2$ & $0.344(0.394)$ & $-0.142(0.357)$ & $-0.373(0.298)$ & $-0.182(0.408)$ & $-0.275(0.362)$ & $0.710(0.327)^{*}$ & $0.321(0.304)$ \\
\hline$>1,500 \mathrm{GEL}=3$ & oa & oa & oa & oa & oa & oa & oa \\
\hline
\end{tabular}


CHAPTER 6

Table 6.4c: Ordinal regression of perceived service quality in antenatal care

( 1 = strongly disagree, 2 = disagree, 3 = neither agree nor disagree, 4 = agree, $5=$ strongly agree) (continuation)

\begin{tabular}{|c|c|c|c|c|c|c|c|}
\hline & \multicolumn{4}{|c|}{ Reliability N=398 } & \multicolumn{3}{|c|}{ Empathy $\mathrm{N}=398$} \\
\hline & $\begin{array}{c}\text { Antenatal caregiver } \\
\text { was professionally } \\
\text { competent }\end{array}$ & $\begin{array}{l}\text { I felt secured } \\
\text { to his/her care } \\
\text { and decisions }\end{array}$ & $\begin{array}{l}\text { I think, no excess } \\
\text { tests } \\
\text { were advised }\end{array}$ & $\begin{array}{l}\text { I think, the prescribed } \\
\text { drugs } \\
\text { were needed }\end{array}$ & $\begin{array}{c}\text { Antenatal caregiver } \\
\text { was attentive to listen } \\
\text { my problems }\end{array}$ & $\begin{array}{c}\text { Antenatal caregiver } \\
\text { provided adequate } \\
\text { mental support }\end{array}$ & $\begin{array}{l}\text { Antenatal caregiver } \\
\text { considered my } \\
\text { financial ability }\end{array}$ \\
\hline & \multicolumn{4}{|c|}{ Coefficient E (S.E) } & \multicolumn{2}{|c|}{ Coefficient E (S.E) } & \\
\hline \multicolumn{8}{|l|}{ Nationality } \\
\hline Other $=0$ & $-0.110(0.511)$ & $-0.770(0.465)^{*}$ & $-1.521(0.446)^{*}$ & $-0.253(0.553)$ & $0.532(0.496)$ & $-0.302(0.490)$ & $0.167(0.487)^{*}$ \\
\hline Georgian $=1$ & oa & oa & oa & oa & oa & oa & oa \\
\hline \multicolumn{8}{|l|}{ Occupation } \\
\hline Other $=0$ & $0.075(0.239)$ & $0.137(0.242)$ & $-0.265(0.203)$ & $-0.125(0.282)$ & $0.306(0.248)$ & $0.024(0.227)$ & 0. .067 (0.211)* \\
\hline Housewife $=1$ & $0^{a}$ & oa & oa & oa & oa & oa & oa \\
\hline \multicolumn{8}{|c|}{$\begin{array}{l}\text { Out-of-pocket payments during } \\
\text { antenatal period }\end{array}$} \\
\hline Yes $=0$ & $-0.096(0.267)$ & $0.598(0.266)^{*}$ & $-0.080(0.234)$ & $0.619(0.304)^{*}$ & $-0.164(0.273)$ & $0.020(0.252)$ & $-0.097(0.245)$ \\
\hline $\mathrm{No}=1$ & oa & oa & oa & oa & oa & oa & oa \\
\hline Nagelkerke $\mathbf{R}^{2}$ & 0.165 & 0.098 & 0.135 & 0.105 & 0.088 & 0.101 & 0.095 \\
\hline Threshold $a_{1}$ & $-5.554(1.652)^{*}$ & $-5.561(1.489)^{*}$ & $-2.743(1.175)^{*}$ & $-6.040(1.781)^{*}$ & $-4.694(1.463)^{*}$ & $-2.757(1.334)^{*}$ & $-3.877(1.354)^{*}$ \\
\hline Threshold $\mathrm{a}_{2}$ & $-4.950(1.625)^{*}$ & $-4.665(1.449)^{*}$ & $-2.125(1.169)^{*}$ & $-5.750(1.758)^{*}$ & $-4.365(1.452)^{*}$ & $-2.200(1.318)^{*}$ & $-3.576(1.347)^{*}$ \\
\hline Threshold $a_{3}$ & $-4.410(1.611)^{*}$ & $-3.621(1.430)^{*}$ & $-1.077(1.164)$ & $-4.628(1.149)^{*}$ & $-3.064(1.429)^{*}$ & $-0.457(1.303)$ & $-1.294(1.328)$ \\
\hline Threshold $\mathrm{a}_{4}$ & $1.266(1.568)$ & $0.920(1.410)$ & $2.503(1.174)$ & $1.415(1.667)$ & $1.531(1.419)$ & $3.863(1.326)$ & $2.769(1.335)^{*}$ \\
\hline
\end{tabular}

a $1 \mathrm{GEL}=2.98$ Euro; ${ }^{*} \mathrm{p} \leq 0.05$ 
Table 6.4d: Ordinal regression of perceived service quality in antenatal care

( 1 = strongly disagree, 2 = disagree, 3 = neither agree nor disagree, 4 = agree, $5=$ strongly agree)

\begin{tabular}{|c|c|c|c|c|c|c|}
\hline & \multirow{2}{*}{\multicolumn{3}{|c|}{ Communication $\mathrm{N}=398$}} & & & \\
\hline & & & & \multicolumn{3}{|c|}{ Courtesy $\mathbf{N}=\mathbf{3 9 8}$} \\
\hline & $\begin{array}{c}\text { Antenatal care } \\
\text { was explained } \\
\text { comprehensively }\end{array}$ & $\begin{array}{l}\text { Pregnancy complications } \\
\text { were clearly } \\
\text { explained }\end{array}$ & $\begin{array}{l}\text { Time for } \\
\text { consultations were adequate }\end{array}$ & $\begin{array}{l}\text { Antenatal care } \\
\text { provider was } \\
\text { respectful to me }\end{array}$ & $\begin{array}{l}\text { Antenatal care } \\
\text { provider } \\
\text { was friendly }\end{array}$ & $\begin{array}{c}\text { Antenatal care } p \\
\text { rovider maintained } \\
\text { my privacy }\end{array}$ \\
\hline & \multicolumn{3}{|c|}{ Coefficient E (S.E) } & \multicolumn{3}{|c|}{ Coefficient E (S.E) } \\
\hline \multicolumn{7}{|l|}{ Age (years) } \\
\hline $15-24=0$ & $0.246(0.901)$ & $0.305(0.925)$ & $0.288(1.181)$ & $1.664(1.113)$ & $1.053(1.166)$ & $2.430(1.236)^{*}$ \\
\hline $25-29=1$ & $0.166(0.864)$ & $-0.168(0.882)^{*}$ & $-0.510(1.080)$ & $1.355(1.068)$ & $0.796(1.119)$ & $1.678(1.171)$ \\
\hline $30-34=2$ & $0.546(0.873)$ & $0.132(0.888)^{*}$ & $0.049(1.146)$ & $1.926(1.119)$ & $1.185(1.133)$ & $2.417(1.191)^{*}$ \\
\hline $35-39=3$ & $0.192(0.906)$ & $-0.386(0.919)$ & $-0.478(1.188)$ & $0.857(1.082)$ & $0.800(1.189)$ & $1.749(1.233)$ \\
\hline $40-44=4$ & oa & oa & oa & oa & oa & oa \\
\hline \multicolumn{7}{|l|}{ Education } \\
\hline Grade $5-6=0$ & $-0.488(1.121)$ & $0.985(1.290)$ & $-1.130(1.174)$ & $-0.633(1.512)$ & $-0.304(1.726)$ & $-0.091(1.915)$ \\
\hline Grade $10-12=1$ & $-0.581(0.323)^{*}$ & $2.599(1.381)$ & $-0.043(0.386)$ & $-0.034(0.397)^{*}$ & $-0.389(0.435)$ & $-0.210(0.474)$ \\
\hline College $=2$ & $-0.125(0.323)$ & $-0.425(0.720)$ & $0.547(0.389)$ & $0.051(0.393)$ & $0.623(0.469)$ & $-0.012(0.462)$ \\
\hline University $=3$ & oa & oa & oa & oa & oa & oa \\
\hline \multicolumn{7}{|l|}{ Place of living } \\
\hline Urban $=0$ & $0.479(0.461)$ & $-0.140(0.489)$ & $0.143(0.539)$ & $0.854(0.510)$ & $0.534(0.626)$ & $0.219(0.627)$ \\
\hline Rural = 1 & oa & oa & oa & oa & oa & oa \\
\hline \multicolumn{7}{|c|}{ Antenatal care complication } \\
\hline Yes $=0$ & $0.203(0.276)$ & $0.087(0.282)$ & $0.400(0.340)$ & $0.136(0.340)$ & $0.929(0.398)^{*}$ & $0.207(0.390)$ \\
\hline No $=1$ & oa & oa & oa & oa & oa & oa \\
\hline \multicolumn{7}{|l|}{ Monthly income a } \\
\hline$<200 \mathrm{GEL}=0$ & $0.813(0.647)$ & $0.880(0.661)$ & $-0.319(0.741)$ & $-0.092(0.805)$ & & $1.305(0.994)$ \\
\hline $200-<900 \mathrm{GEL}=1$ & $1.072(0.331)^{*}$ & $1.020(0.329)^{*}$ & $0.762(0.399)^{*}$ & $0.472(0.405)$ & $0.358(0.874)$ & $1.585(0.519)^{*}$ \\
\hline $900-1,500 \mathrm{GEL}=2$ & $0.263(0.317)^{*}$ & $0.672(0.324)^{* *}$ & $0.007(0.393)$ & $-0.237(0.415)$ & $1.030(0.475)^{*}$ & $-0.107(0.504)$ \\
\hline$>1,500 \mathrm{GEL}=3$ & oa & oa & oa & oa & $0.016(0.458)$ & 0a \\
\hline \multicolumn{7}{|l|}{ Nationality } \\
\hline Other $=0$ & $1.850(0.470)^{*}$ & $1.051(0.522)^{*}$ & $1.5430 .513)^{*}$ & $1.034(0.506)^{*}$ & $-1.002(0.592)^{* *}$ & $-1.815(0.520)^{*}$ \\
\hline Georgian $=1$ & oa & oa & oa & oa & oa & oa \\
\hline
\end{tabular}


Table 6.4d: Ordinal regression of perceived service quality in antenatal care

( 1 = strongly disagree, 2 = disagree, 3 = neither agree nor disagree, 4 = agree, $5=$ strongly agree) (continuation)

\begin{tabular}{|c|c|c|c|c|c|c|}
\hline & \multicolumn{3}{|c|}{ Communication $\mathrm{N}=398$} & \multicolumn{3}{|c|}{ Courtesy $\mathrm{N}=398$} \\
\hline & $\begin{array}{c}\text { Antenatal care } \\
\text { was explained } \\
\text { comprehensively }\end{array}$ & $\begin{array}{c}\text { Pregnancy } \\
\text { complications were } \\
\text { clearly explained }\end{array}$ & $\begin{array}{c}\text { Time for } \\
\text { consultations were adequate }\end{array}$ & $\begin{array}{l}\text { Antenatal care } \\
\text { provider was } \\
\text { respectful to me }\end{array}$ & $\begin{array}{l}\text { Antenatal care } \\
\text { provider } \\
\text { was friendly }\end{array}$ & $\begin{array}{c}\text { Antenatal care } p \\
\text { rovider maintained } \\
\text { my privacy }\end{array}$ \\
\hline & & Coefficient E (S.E) & & & Coefficient E (S.E) & \\
\hline \multicolumn{7}{|l|}{ Occupation } \\
\hline Other $=0$ & $0.236(0.223)$ & $0.012(0.228)$ & $-0.338(0.272)$ & $0.072(0.313)$ & $0.022(0.310)$ & $0.140(0.326)$ \\
\hline Housewife $=1$ & oa & oa & oa & oa & oa & oa \\
\hline \multicolumn{7}{|c|}{$\begin{array}{l}\text { Out-of-pocket payments during } \\
\text { antenatal period }\end{array}$} \\
\hline Yes $=0$ & $0.104(0.248)$ & $-0.040(0.253)$ & $-0.277(0.272)$ & $-0.290(0.312)^{*}$ & $-0.790(0.355)^{*}$ & $0.091(0.360)^{*}$ \\
\hline No $=1$ & oa & oa & oa & oa & oa & oa \\
\hline Nagelkerke $\mathbf{R}^{2}$ & 0.134 & 0.126 & 0.097 & 0.087 & 0.171 & 0.141 \\
\hline Threshold $a_{1}$ & $-1.448(1.317)$ & $-1.802(1.447)$ & $-4.165(1.676)^{*}$ & $-4.528(1.896)^{*}$ & $-4.717(1.968)^{*}$ & $-3.380(2.001)^{*}$ \\
\hline Threshold $a_{2}$ & $-1.280(1.315)$ & $-1.708(1.446)$ & $-4.007(1.669)^{*}$ & $-1.472(1.634)$ & $-4.195(1.934)^{*}$ & $-1.738(1.793)$ \\
\hline Threshold $a_{3}$ & $-0.303(1.311)$ & $-0.758(1.442)$ & $-2.225(1.633)$ & $3.934(1.659)^{*}$ & $-2.508(1.894)$ & $-0.457(1.758)$ \\
\hline Threshold $\mathrm{a}_{4}$ & $3.994(1.337)^{*}$ & $3.954(1.465)^{*}$ & $2.981(1.644)^{*}$ & & $3.802(1.915)^{*}$ & $6.182(1.846)^{*}$ \\
\hline
\end{tabular}

a $1 \mathrm{GEL}=2.98$ Euro; ${ }^{*} p \leq 0.05$ 
Table 6.5a: Ordinal regression of perceived service quality of childbirth care and immediate post-natal care ( 1 = strongly disagree, 2 = disagree, 3 = neither agree nor disagree, 4 = agree, $5=$ strongly agree)

\begin{tabular}{|c|c|c|c|c|c|c|c|c|}
\hline & \multicolumn{4}{|c|}{ Tangibility $N=400$} & \multicolumn{4}{|c|}{ Availability $N=400$} \\
\hline & $\begin{array}{l}\text { Childbirth facility } \\
\text { building } \\
\text { was attractive }\end{array}$ & $\begin{array}{c}\text { Medical } \\
\text { equipment } \\
\text { was up-dated }\end{array}$ & $\begin{array}{l}\text { Cleanliness } \\
\text { was } \\
\text { maintained }\end{array}$ & $\begin{array}{c}\text { Prescriptions } \\
\text { were clearly written } \\
\text { and attractive }\end{array}$ & $\begin{array}{c}\text { Common diagnostic } \\
\text { tests } \\
\text { were available }\end{array}$ & $\begin{array}{c}\text { Specialized diagnostic } \\
\text { facilities } \\
\text { were available }\end{array}$ & $\begin{array}{l}\text { Necessary } \\
\text { specialized care } \\
\text { was available }\end{array}$ & $\begin{array}{c}\text { Necessary } \\
\text { medicines } \\
\text { were available }\end{array}$ \\
\hline & \multicolumn{4}{|c|}{ Coefficient E (S.E) } & \multicolumn{4}{|c|}{ Coefficient E (S.E) } \\
\hline \multicolumn{9}{|l|}{ Age } \\
\hline $15-24=0$ & $-0.603(0.919)$ & $-0.060(0.872)$ & $0.750(1.033)$ & $-0.743(1.164)$ & $0.909(0.937)$ & $1.654(0.831)^{*}$ & $-0.938(0.913)$ & $-0.074(0.902)$ \\
\hline $25-29=1$ & $-0.089(0.889)$ & $-0.029(0.844)$ & $0.932(1.003)$ & $-0.120(1.132)$ & $1.078(0.910)$ & $1.318(0.798)$ & $-0.525(0.924)$ & $-0.016(0.874)$ \\
\hline $30-34=2$ & $0.593(0.894)$ & $0.594(0.849)$ & 1.325 (1.010) & $0.676(1.136)$ & $0.754(0.887)$ & $1.405(0.802)^{* *}$ & $-0.710(0.927)$ & $-0.178(0.877)$ \\
\hline $35-39=3$ & $-0.087(0.926)$ & $0.566(0.882)$ & $1.474(1.056)$ & $0.672(1.175)$ & $1.512(0.921)$ & $1.474(0.837)^{* *}$ & $-0.395(0.965)$ & $0.317(0.913)$ \\
\hline $40-44=4$ & oa & oa & oa & oa & oa & oa & oa & oa \\
\hline \multicolumn{9}{|l|}{ Education } \\
\hline Grade $5-6=0$ & $-0.883(1.021)$ & $-1.320(1.011)$ & $-0.032(1.429)$ & $0.508(1.504)$ & $-0.165(1.098)$ & $-0.134(1.072)$ & $-0.341(1.090)$ & $0.354(1.094)$ \\
\hline Grade $10-12=1$ & $0.113(0.313)$ & $0.074(0.299)$ & $0.013(0.357)$ & $0.130(0.378)$ & $-0.297(0.306)$ & $-0.205(0.296)$ & $-0.397(0.307)$ & $-0.288(0.294)$ \\
\hline College $=2$ & $0.742(0.317)$ & $0.282(0.297)$ & $0.849(0.347)^{*}$ & $0.268(0.368)$ & $-0.163(0.309)$ & $-0.072(0.296)$ & $0.278(0.317)$ & $0.097(0.296)$ \\
\hline University $=3$ & oa & oa & oa & oa & oa & oa & oa & oa \\
\hline \multicolumn{9}{|l|}{ Place of living } \\
\hline Urban $=0$ & $1.076(0.497)^{*}$ & $-1.036(0.433)^{*}$ & $0.378(0.592)$ & $0.599(0.423)^{*}$ & $0.381(0.260)$ & $0.007(0.442)^{*}$ & $0.299(0.264)$ & $0.629(1.303)$ \\
\hline Rural $=1$ & oa & oa & oa & oa & oa & oa & oa & oa \\
\hline \multicolumn{9}{|l|}{ Antenatal care complications } \\
\hline Yes $=0$ & $0.288(0.264)$ & $0.151(0.256)$ & $0.787(0.316)$ & $-0.047(0.323)$ & $0.213(0.274)$ & $0.278(0.305)$ & $0.227(0.275)$ & $-0.003(0.265)$ \\
\hline No $=1$ & oa & oa & oa & oa & oa & oa & oa & oa \\
\hline \multicolumn{9}{|l|}{ Place of Natal Care } \\
\hline Primary care level $=0$ & $-0.301(0.540)$ & $0.236(0.528)$ & $0.471(0.630)$ & $0.751(0.673)^{*}$ & $0.347(0.578)$ & $0.471(0.630)$ & $0.954(0.593)$ & $0.769(0.562)$ \\
\hline Secondary care level $=1$ & $-0.145(0.287)$ & $0.115(0.270)$ & $0.146(0.325)$ & $0.686(0.342)^{*}$ & $0.280(0.290)$ & $0.146(0.325)$ & $0.376(0.289)$ & $0.295(0.277)$ \\
\hline Tertiary care level $=2$ & 0a & oa & oa & oa & oa & oa & oa & oa \\
\hline \multicolumn{9}{|l|}{ Mode of childbirth } \\
\hline C-section $=0$ & $-0.245(0.219)$ & $-0.051(0.208)$ & $0.787(0.248)$ & $-0.569(0.268)$ & $0.674(0.229)^{*}$ & $0.099(0.248)^{*}$ & $0.578(0.230)$ & $0.583(0.218)^{*}$ \\
\hline Vaginal Childbirth $=1$ & oa & oa & oa & oa & oa & oa & oa & oa \\
\hline
\end{tabular}


Table 6.5a: Ordinal regression of perceived service quality of childbirth care and immediate post-natal care

( 1 = strongly disagree, 2 = disagree, 3 = neither agree nor disagree, 4 = agree, $5=$ strongly agree) (continuation)

\begin{tabular}{|c|c|c|c|c|c|c|c|c|}
\hline & \multicolumn{4}{|c|}{ Tangibility N=400 } & \multicolumn{4}{|c|}{ Availability $N=400$} \\
\hline & $\begin{array}{l}\text { Childbirth facility } \\
\text { building } \\
\text { was attractive }\end{array}$ & $\begin{array}{l}\text { Medical } \\
\text { equipment } \\
\text { was up-dated }\end{array}$ & $\begin{array}{l}\text { Cleanliness } \\
\text { was } \\
\text { maintained }\end{array}$ & $\begin{array}{l}\text { Prescriptions } \\
\text { were clearly written } \\
\text { and attractive }\end{array}$ & $\begin{array}{c}\text { Common diagnostic } \\
\text { tests } \\
\text { were available }\end{array}$ & $\begin{array}{c}\text { Specialized diagnostic } \\
\text { facilities } \\
\text { were available }\end{array}$ & $\begin{array}{c}\text { Necessary } \\
\text { specialized care } \\
\text { was available }\end{array}$ & $\begin{array}{l}\text { Necessary } \\
\text { medicines } \\
\text { were available }\end{array}$ \\
\hline & \multicolumn{4}{|c|}{ Coefficient E (S.E) } & \multicolumn{4}{|c|}{ Coefficient E (S.E) } \\
\hline \multicolumn{9}{|l|}{ Monthly income a } \\
\hline$<200 \mathrm{GEL}=0$ & $1.141(0.637)^{*}$ & $0.871(0.596)$ & $1.039(0.711)$ & $0.651(0.738)$ & $-0.007(0.588)$ & $0.039(0.602)$ & $-0.133(0.656)$ & $0.078(0.622)^{*}$ \\
\hline $200-<900 \mathrm{GEL}=1$ & $0.498(0.316)^{*}$ & $0.653(0.301)^{*}$ & $0.464(0.367)$ & $-0.211(0.382)$ & $0.206(0.322)$ & $0.292(0.301)$ & $-0.492(0.338)$ & $-0.299(0.313)$ \\
\hline $900-1,500 \mathrm{GEL}=2$ & $0.014(0.312)$ & $0.260(0.300)$ & $0.187(0.376)$ & $-0.367(0.391)$ & $-0.384(0.325)$ & $-0.197(0.298)$ & $-0.869(0.340)^{*}$ & $-0.516(0.314)$ \\
\hline$>1,500 \mathrm{GEL}=3$ & oa & oa & oa & oa & oa & oa & oa & oa \\
\hline \multicolumn{9}{|l|}{ Nationality } \\
\hline Other $=0$ & $0.107(0.217)^{*}$ & $-0.001(0.208)$ & $-1.931(0.453)^{*}$ & $-1.709(0.469)^{*}$ & $1.253(0.486)^{*}$ & $1.931(0.453)^{*}$ & $0.925(0.490)$ & $0.437(0.463)^{*}$ \\
\hline Georgian $=1$ & oa & oa & oa & $\mathrm{o}^{\mathrm{a} *}$ & oa & oa & oa & oa \\
\hline \multicolumn{9}{|l|}{ Occupation } \\
\hline Other $=0$ & $-0.917(0.468)$ & $-1.367(0.437)$ & $0.229(0.250)$ & $-0.185(0.263)$ & $0.889(0.262)^{*}$ & $0.542(0.238)^{*}$ & $0.414(0.229)$ & $0.528(0.218)^{*}$ \\
\hline Housewife $=1$ & oa & oa & oa & oa & oa & oa & oa & oa \\
\hline \multicolumn{9}{|c|}{$\begin{array}{l}\text { Out-of-pocket payments } \\
\text { during natal \& post-natal }\end{array}$} \\
\hline $\begin{array}{l}\text { period } \\
\text { Yes }=0\end{array}$ & $0.383(0.270)^{*}$ & $0.544(0.272)^{*}$ & $0.699(0.325)^{*}$ & $0.135(0.331)$ & $0.173(0.289)$ & $0.787(0.316)^{*}$ & $-0.442(0.298)$ & $-0.219(0.279)$ \\
\hline $\begin{array}{l}\text { Yes }=0 \\
\text { No }=1\end{array}$ & oa & oa & oa & oa & oa & oa & oa & oa \\
\hline Nagelkerke $\mathrm{R}^{2}$ & 0.154 & 0.083 & 0. .245 & 0. .191 & 0.116 & 0.147 & 0.136 & 0.073 \\
\hline Threshold $\mathrm{a}_{1}$ & $-4.095(1.349)^{*}$ & $-4.776(1.337)^{*}$ & $-1.978(1.342)$ & $-4.838(1.592)^{*}$ & $-5.047(1.418)^{*}$ & $-4.161(1.339)^{*}$ & $-6.209(1.479)^{*}$ & $-6.948(1.438)^{* *}$ \\
\hline Threshold $a_{2}$ & $-3.380\left(1.3120^{*}\right.$ & $-3.958(1.297)^{*}$ & $-1.895(1.340)$ & $-4.556(1.584)^{*}$ & $-3.326(1.319)^{*}$ & $-1.758(1.225)$ & $-5.599(1.409)^{*}$ & $-4.836(1.332)^{*}$ \\
\hline Threshold $a_{3}$ & $-0.838(1.279)$ & $-1.442(1.263)$ & $-0.771(1.330)$ & $-3.448(1.565)$ & $1.797(0.956)^{*}$ & $0.060(1.219)^{*}$ & $-3.978(1.391)^{*}$ & $-3.206(1.317)^{*}$ \\
\hline Threshold $\mathrm{a}_{4}$ & $3.221(1.295)^{*}$ & $2.122(1.272)^{*}$ & $4.467(1.357)^{*}$ & $1.893(1.558)^{*}$ & $0.950(0.912)^{*}$ & $4.122(1.247)^{*}$ & $0.355(1.370)$ & $2.296(1.008)^{*}$ \\
\hline
\end{tabular}

a $1 \mathrm{GEL}=2.98$ Euro; $* p \leq 0.05$ 
Table 6.5b: Ordinal regression of perceived service quality of childbirth care and immediate post-natal care ( 1 = strongly disagree, 2 = disagree, 3 = neither agree nor disagree, 4 = agree, 5 = strongly agree

\begin{tabular}{|c|c|c|c|c|c|c|c|}
\hline & \multicolumn{4}{|c|}{ Accessibility $N=\mathbf{4 0 0}$} & \multicolumn{3}{|c|}{ Responsiveness $N=400$} \\
\hline & $\begin{array}{l}\text { Fee for childbirth } \\
\text { (NVD or C/Section) } \\
\text { was affordable }\end{array}$ & $\begin{array}{l}\text { Costs of required } \\
\text { medicines } \\
\text { were affordable }\end{array}$ & $\begin{array}{c}\text { Costs of required } \\
\text { diagnostics } \\
\text { were affordable }\end{array}$ & $\begin{array}{c}\text { Costs of } \\
\text { hospitalization } \\
\text { were affordable }\end{array}$ & $\begin{array}{l}\text { Physician/ } \\
\text { midwife } \\
\text { was timely }\end{array}$ & $\begin{array}{l}\text { Physician/midwife } \\
\text { was timely available } \\
\text { during childbirth }\end{array}$ & $\begin{array}{l}\text { Physician/midwife was timely } \\
\text { available during } \\
\text { post-natal period }\end{array}$ \\
\hline & \multicolumn{4}{|c|}{ Coefficient E (S.E) } & \multicolumn{3}{|c|}{ Coefficient E (S.E) } \\
\hline \multicolumn{8}{|l|}{ Age } \\
\hline $15-24=0$ & $-0.946(0.985)$ & $-0.799(0.943)$ & $-0.030(0.904)$ & $0.493(0.934)$ & $-0.759(0.995)^{* *}$ & $-0.029(1.007)$ & $-1.453(1.183)$ \\
\hline $25-29=1$ & $-0.383(0.956)$ & $-0.837(0.914)$ & $0.123(0.877)$ & $0.920(0.909)$ & $0.374(0.966)$ & $0.742(0.978)$ & $-0.963(1.123)$ \\
\hline $30-34=2$ & $-0.804(0.961)$ & $-0.930(0.917)$ & $0.050(0.880)$ & $0.413(0.909)$ & $0.425(0.970)^{* *}$ & $1.357(0.986)$ & $-0.201(1.110)$ \\
\hline $35-39=3$ & $-1.005(0.993)$ & $-0.623(0.952)$ & $0.176(0.915)$ & $0.371(0.943)$ & $1.262(1.025)$ & $1.391(1.024)$ & $0.048(1.155)$ \\
\hline $40-44=4$ & oa & oa & oa & oa & oa & oa & oa \\
\hline \multicolumn{8}{|l|}{ Education } \\
\hline Grade $5-6=0$ & $-0.195(1.040)$ & $0.929(1.181)$ & $-0.077(1.058)$ & $0.026(1.139)$ & $3.582(1.209)^{*}$ & $2.780(1.067)^{*}$ & $3.619(1.144)^{*}$ \\
\hline Grade $10-12=1$ & $-0.064(0.309)$ & $-0.583(0.306)^{* *}$ & $-0.218(0.301)$ & $0.020(0.318)$ & $0.378(0.358)$ & $0.342(0.353)$ & $0.257(0.456)$ \\
\hline College $=2$ & $0.138(0.319)$ & $-0.349(0.308)$ & $-0.262(0.303)$ & $-0.470(0.311)$ & $0.675(0.368)^{*}$ & $0.118(0.347)$ & $0.423(0.441)$ \\
\hline University = 3 & oa & oa & oa & oa & oa & oa & oa \\
\hline \multicolumn{8}{|l|}{ Place of living } \\
\hline Urban $=0$ & $0.445(0.459)^{*}$ & $0.182(0.446)^{*}$ & $0.689(0.438)^{* *}$ & $0.158(0.692)$ & $0.189(0.529)^{*}$ & $0.578(0.488)$ & $0.086(0.645)$ \\
\hline Rural = 1 & oa & oa & oa & oa & oa & oa & oa \\
\hline \multicolumn{8}{|l|}{ Antenatal care complications } \\
\hline Yes $=0$ & $0.331(0.277)$ & $0.046(0.273)$ & $0.037(0.269)$ & $0.005(0.282)$ & $0.475(0.306)$ & $0.130(0.301)$ & $0.073(0.385)$ \\
\hline $\mathrm{No}=1$ & oa & oa & oa & oa & oa & oa & oa \\
\hline \multicolumn{8}{|l|}{ Place of Natal Care } \\
\hline Primary care level $=0$ & $1.165(0.620)$ & $1.072(0.591)$ & $1.112(0.586)$ & $0.949(0.592)$ & $-0.503(0.659)$ & $-0.577(0.670)$ & $0.096(0.866)$ \\
\hline Secondary care level $=1$ & $0.320(0.295)$ & $0.415(0.284)$ & $0.408(0.279)$ & $-0.051(0.298)$ & $0.520(0.544)$ & $0.592(0.559)$ & $0.258(0.735)$ \\
\hline Tertiary care level $=2$ & oa & oa & oa & oa & oa & oa & oa \\
\hline \multicolumn{8}{|l|}{ Mode of childbirth } \\
\hline C-section $=0$ & $-0.892(0.239)^{*}$ & $0.614(0.224)^{*}$ & $0.664(0.221)^{*}$ & $-0.553(0.230)^{*}$ & $-0.109(0.247)$ & $-0.371(0.248)$ & $-0.550(0.319)$ \\
\hline Vaginal Childbirth $=1$ & oa & oa & oa & oa & oa & oa & oa \\
\hline
\end{tabular}


Table 6.5b: Ordinal regression of perceived service quality of childbirth care and immediate post-natal care ( 1 = strongly disagree, 2 = disagree, 3 = neither agree nor disagree, 4 = agree, $5=$ strongly agree)

\begin{tabular}{|c|c|c|c|c|c|c|c|}
\hline & \multicolumn{4}{|c|}{ Accessibility $N=400$} & \multicolumn{3}{|c|}{ Responsiveness $\mathrm{N}=400$} \\
\hline & $\begin{array}{l}\text { Fee for childbirth } \\
\text { (NVD or C/Section) } \\
\text { was affordable }\end{array}$ & $\begin{array}{l}\text { Costs of required } \\
\text { medicines } \\
\text { were affordable }\end{array}$ & $\begin{array}{l}\text { Costs of required } \\
\text { diagnostics } \\
\text { were affordable }\end{array}$ & $\begin{array}{c}\text { Costs of } \\
\text { hospitalization } \\
\text { were affordable }\end{array}$ & $\begin{array}{l}\text { Physician/ } \\
\text { midwife } \\
\text { was timely }\end{array}$ & $\begin{array}{c}\text { Physician/midwife } \\
\text { was timely available } \\
\text { during childbirth }\end{array}$ & $\begin{array}{l}\text { Physician/midwife was timely } \\
\text { available during } \\
\text { post-natal period }\end{array}$ \\
\hline & \multicolumn{4}{|c|}{ Coefficient E (S.E) } & \multicolumn{3}{|c|}{ Coefficient E (S.E) } \\
\hline \multicolumn{8}{|l|}{ Monthly income a } \\
\hline$<200 \mathrm{GEL}=0$ & $0.050(0.647)$ & $-1.076(0.636)^{* *}$ & $0.916(0.636)$ & $0.789(0.678)$ & $0.155(0.764)$ & $-0.288(0.696)$ & $-0.377(0.896)$ \\
\hline $200-<900 \mathrm{GEL}=1$ & $-0.518(0.338)^{*}$ & $0.205(0.317)$ & $-0.160(0.314)$ & $-0.188(0.330)^{*}$ & $0.904(0.402)$ & $0.453(0.358)$ & $0.163(0.452)$ \\
\hline $900-1,500 \mathrm{GEL}=2$ & $-0.616(0.344)$ & $0.081(0.323)$ & $-0.124(0.320)$ & $-0.023(0.340)$ & $0.287(0.401)$ & $0.501(0.363)$ & $-0.742(0.480)$ \\
\hline$>1,500 \mathrm{GEL}=3$ & oa & oa & oa & oa & oa & oa & oa \\
\hline \multicolumn{8}{|l|}{ Nationality } \\
\hline Other $=0$ & $1.319(0.508)^{*}$ & $0.159(0.474)$ & $0.532(0.480)$ & $0.379(0.458)^{*}$ & $0.426(0.539)$ & $1.940(0.466)^{*}$ & $-0.373(0.662)$ \\
\hline Georgian $=1$ & oa & oa & oa & oa & oa & oa & oa \\
\hline \multicolumn{8}{|l|}{ Occupation } \\
\hline Other $=0$ & $1.509(0.254)^{*}$ & $1.171(0.262)$ & $1.011(0.227)^{*}$ & $0.920(0.236)^{*}$ & $0.447(0.250)^{*}$ & $-0.171(0.247)$ & $0.087(0.313)$ \\
\hline Housewife $=1$ & oa & oa & oa & oa & oa & oa & oa \\
\hline \multicolumn{8}{|c|}{$\begin{array}{l}\text { Out-of-pocket payments } \\
\text { during natal \& post-natal }\end{array}$} \\
\hline period & $-0.513(0.308)^{*}$ & $-0.659(0.300)^{*}$ & $-0.655(0.297)^{*}$ & $-0.570(0.313)$ & $0.580(0.323)$ & $-0.110(0.309)$ & $-0.227(0.394)$ \\
\hline $\begin{array}{l}\text { Yes }=0 \\
\text { No }=1\end{array}$ & oa & oa & oa & oa & oa & oa & oa \\
\hline Nagelkerke $\mathbf{R}^{2}$ & 0. .101 & 0.150 & 0.122 & 0.095 & 0.113 & 0.123 & 0.122 \\
\hline Threshold $a_{1}$ & $-5.681(1.361)^{*}$ & $-5.548(1.384)^{*}$ & $-4.049(1.286)^{*}$ & $-3.865(1.335)^{*}$ & $-5.630(1.541)^{*}$ & $-3.243(1.487)^{*}$ & $-4.129(1.685)^{*}$ \\
\hline Threshold $a_{2}$ & $-4.554(1.337)^{*}$ & $-3.243(1.487)^{*}$ & $-3.148(1.271)^{*}$ & $-3.033(1.318)^{*}$ & $-4.723(1.516)^{*}$ & $-2.760(1.463)^{*}$ & $-3.787(1.669)^{*}$ \\
\hline Threshold $a_{3}$ & $-3.128(1.327)^{*}$ & $-2.760(1.462)$ & $-1.808(1.263)$ & $-1.500(1.306)$ & $-3.415(1.501)^{*}$ & $-1.122(1.430)$ & $-2.863(1.648)^{*}$ \\
\hline Threshold $\mathrm{a}_{4}$ & $1.569(1.307)^{*}$ & $1.000(1.351)^{*}$ & $2.392(1.270)^{*}$ & $3.264(1.326)^{*}$ & $1.732(1.493)$ & $3.520(1.452)^{* *}$ & $3.358(1.645)^{*}$ \\
\hline
\end{tabular}

a $1 \mathrm{GEL}=2.98$ Euro; * $p \leq 0.05$ 
Table 6.5c: Ordinal regression of perceived service quality of childbirth care and immediate post-natal care ( 1 = strongly disagree, 2 = disagree, 3 = neither agree nor disagree, 4 = agree, $5=$ strongly agree

\begin{tabular}{|c|c|c|c|c|c|c|c|c|c|c|}
\hline & \multicolumn{5}{|c|}{ Reliability $N=400$} & \multicolumn{5}{|c|}{ Empathy $\mathrm{N}=\mathbf{4 0 0}$} \\
\hline & $\begin{array}{c}\text { Natal and } \\
\text { postnatal } \\
\text { caregiver was } \\
\text { adequately skilled }\end{array}$ & $\begin{array}{c}\text { I felt secured } \\
\text { to natal and } \\
\text { postnatal care and } \\
\text { decisions } \\
\text { of provider }\end{array}$ & $\begin{array}{l}\text { Doctors' decision } \\
\text { of childbirth } \\
\text { method was } \\
\text { correct }\end{array}$ & $\begin{array}{c}\text { No excess } \\
\text { tests were advised }\end{array}$ & $\begin{array}{c}\text { Prescribed } \\
\text { drugs were } \\
\text { needed }\end{array}$ & $\begin{array}{c}\text { Caregivers were } \\
\text { attentive } \\
\text { to listen my } \\
\text { problems }\end{array}$ & $\begin{array}{l}\text { Caregivers } \\
\text { provided adequate } \\
\text { mental support }\end{array}$ & $\begin{array}{l}\text { Adequately } \\
\text { considered for } \\
\text { making decision } \\
\text { about childbirth } \\
\text { and postnatal } \\
\text { period }\end{array}$ & $\begin{array}{c}\text { Financial ability } \\
\text { was considered by } \\
\text { care } \\
\text { providers }\end{array}$ & $\begin{array}{l}\text { Was timely see } \\
\text { and touch my } \\
\text { baby when } \\
\text { I wanted }\end{array}$ \\
\hline & \multicolumn{5}{|c|}{ Coefficient E (S.E) } & \multicolumn{5}{|c|}{ Coefficient E (S.E) E (S.E) } \\
\hline \multicolumn{11}{|l|}{ Age } \\
\hline $15-24=0$ & $-0.130(1.038)$ & $0.471(1.063)$ & $-1.033(1.026)$ & $-1.443(1.047)$ & 0.635 (1.159) & $-0.440(0.977)$ & $0.530(0.992)$ & $0.355(0.956)$ & $2.082(0.891)^{*}$ & 1.199 (1.050) \\
\hline $25-29=1$ & $-0.297(1.024)$ & $0.764(1.025)$ & $-0.760(0.989)$ & $-1.224(1.004)$ & $0.535(1.107)$ & $-0.635(0.944)$ & $0.145(0.957)$ & $-0.123(0.921)$ & $2.018(0.865)^{*}$ & 1.045 (1.012) \\
\hline $30-34=2$ & $0.391(1.031)$ & $1.489(1.034)$ & $0.042(0.990)$ & $-0.726(1.008)$ & 0.599 (1.114) & $0.084(0.946)$ & $1.175(0.964)$ & $0.303(0.926)$ & $1.472(0.865)^{* *}$ & $0.790(1.012)$ \\
\hline $35-39=3$ & $-0.104(1.065)$ & $1.021(1.078)$ & $-0.338(1.034)$ & $-0.557(1.052)$ & $1.696(1.170)$ & $0.008(0.986)$ & $1.011(1.003)$ & $0.943(0.971)$ & $-1.149(0.898)$ & $1.367(1.070)$ \\
\hline $40-44=4$ & oa & oa & oa & oa & oa & oa & oa & oa & oa & oa \\
\hline \multicolumn{11}{|l|}{ Education } \\
\hline Grade $5-6=0$ & $1.380(1.155)$ & $1.574(1.182)$ & $1.382(1.154)$ & $2.013(1.181)$ & $2.237(1.213)$ & $1.521(1.130)$ & $2.293(1.156)^{*}$ & $1.854(1.173)$ & 2.139 (1.089)* & 2.239 (1.183)* \\
\hline Grade $10-12=1$ & $0.124(0.371)^{* *}$ & $-0.749(0.393)$ & $-0.329(0.363)$ & $-0.660(0.378)$ & $-0.190(0.421)$ & $-0.091(0.336)$ & $0.658(0.343)^{*}$ & $-0.294(0.327)$ & $-0.237(0.293)$ & $0.006(0.364)$ \\
\hline College $=2$ & $0.741(0.360)$ & 0.005 (0.384). & $0.411(0.350)$ & $0.648(0.376)$ & $0.716(0.424)$ & $0.250(0.333)$ & $0.468(0.335)$ & $-0.344(0.320)$ & $-0.252(0.291)$ & $0.181(0.356)$ \\
\hline University $=3$ & oa & oa & oa & oa & oa & oa & oa & oa & oa & $\left.0^{a}\right)$ \\
\hline \multicolumn{11}{|l|}{ Place of living } \\
\hline Urban $=0$ & $0.282(0.313)$ & $0.559(0.528)$ & $0.058(0.494)$ & $-0.227(0.532)$ & $0.790(0.585)$ & $0.672(0.466)$ & $0.076(0.266)$ & $0.370(0.474)$ & $0.174(0.238)$ & $0.512(0.529)$ \\
\hline Rural = 1 & oa & oa & $0^{a}$ & oa & oa & oa & oa & oa & oa & oa \\
\hline \multicolumn{11}{|l|}{$\begin{array}{l}\text { Antenatal care } \\
\text { complications }\end{array}$} \\
\hline Yes $=0$ & $0.007(0.328)$ & $0.142(0.332)$ & $0.337(0.306)$ & $0.206(0.354)$ & $0.206(0.354)$ & $-0.007(0.288)$ & $-0.267(0.282)$ & $-0.113(0.279)$ & $0.214(0.251)$ & $0.314(0.301)$ \\
\hline $\mathrm{No}=1$ & oa & oa & oa & oa & oa & oa & oa & oa & oa & oa \\
\hline \multicolumn{11}{|l|}{ Place of Natal Care } \\
\hline Primary care level $=0$ & $-0.557(0.729)$ & $-1.145(0.734)$ & $-0.642(0.253)$ & $0.525(0.294)$ & $-0.191(0.381)$ & $0.221(0.644)$ & $-0.471(0.235)$ & $0.126(0.225)$ & $9.251(0.207)$ & $-0.469(0.267)^{*}$ \\
\hline Secondary care level $=1$ & $0.409(0.608)$ & $0.740(0.604)$ & $1.024(0.671)$ & $0.610(0.783)^{*}$ & $-0.452(0.652)$ & $-0.239(0.539)$ & $0.305(0.643)$ & $-0.323(0.616)$ & $-0.381(0.560)$ & $1.149(0.761)$ \\
\hline Tertiary care level = 2 & oa & oa & $0 a$ & 0a & oa & oa & $0 a$ & 0a & oa & $0 a$ \\
\hline \multicolumn{11}{|l|}{ Mode of childbirth } \\
\hline C-section $=0$ & $-0.636(0.273)^{*}$ & $-0.336(0.272)$ & $-0.291(0.247)$ & $0.238(0.290)$ & $0.238(0.290)^{*}$ & $-0.045(0.298)$ & $-0.055(0.233)$ & $0.118(0.226)$ & $-0.110(0.207)$ & $0.391(0.265)$ \\
\hline Vaginal Childbirth $=1$ & oa & oa & oa & oa & oa & oa & oa & oa & oa & $0 a$ \\
\hline
\end{tabular}


Table 6.5c: Ordinal regression of perceived service quality of childbirth care and immediate post-natal care

( 1 = strongly disagree, 2 = disagree, 3 = neither agree nor disagree, 4 = agree, $5=$ strongly agree) (continuation)

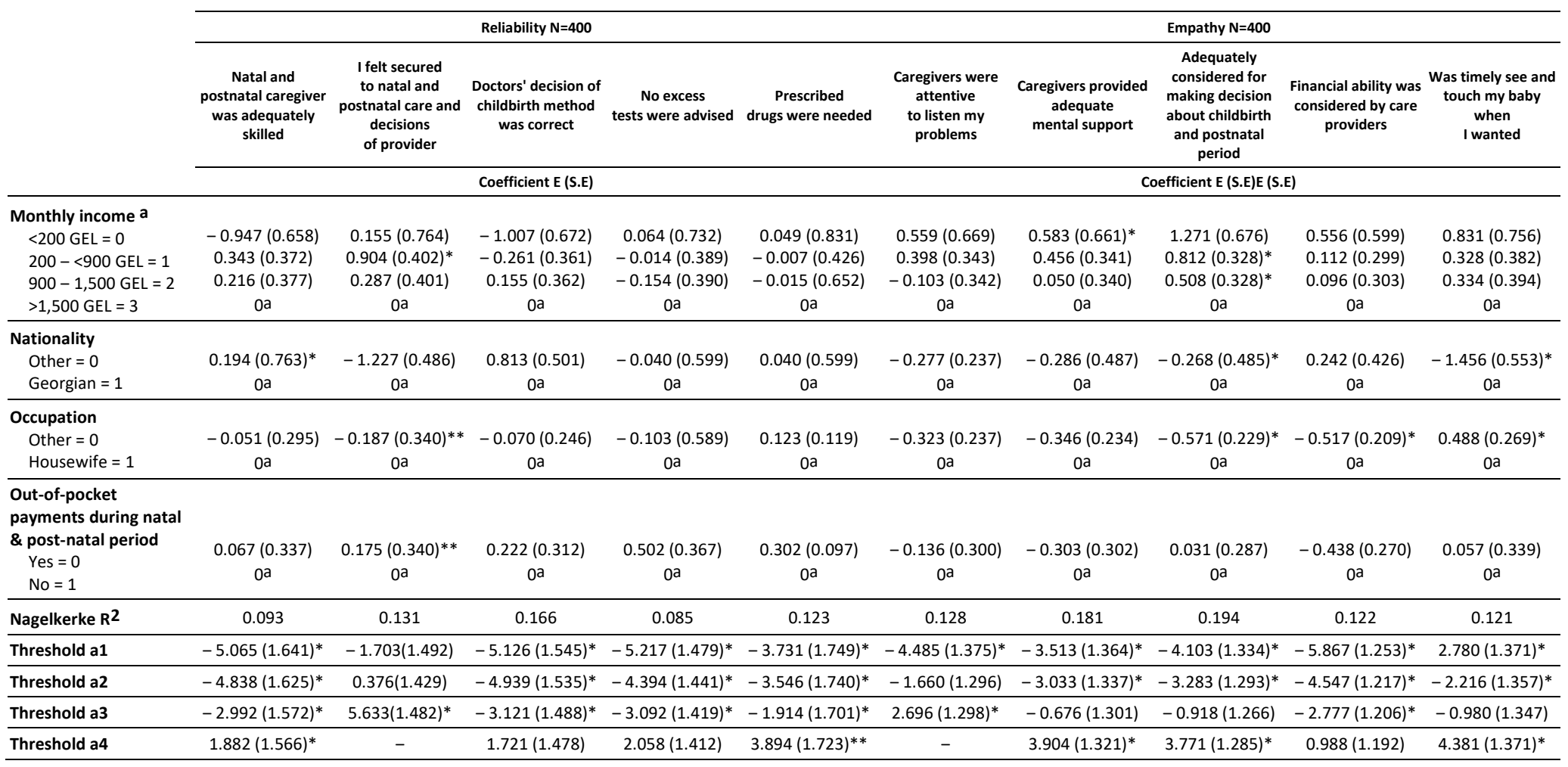

a $1 \mathrm{GEL}=2.98$ Euro; $* \mathrm{p} \leq 0.05$ 
Table 6.5d: Ordinal regression of perceived service quality of childbirth care and immediate post-natal care ( 1 = strongly disagree, 2 = disagree, 3 = neither agree nor disagree, 4 = agree, 5 = strongly agree)

\begin{tabular}{|c|c|c|c|c|c|c|}
\hline & \multicolumn{3}{|c|}{ Communication $\mathrm{N}=400$} & \multicolumn{3}{|c|}{ Courtesy $\mathrm{N}=400$} \\
\hline & $\begin{array}{l}\text { Caregiver clearly explained } \\
\text { information related to post- } \\
\text { natal care }\end{array}$ & $\begin{array}{l}\text { Natal and post-natal } \\
\text { complications were clearly } \\
\text { explained }\end{array}$ & $\begin{array}{l}\text { I was given adequate } \\
\text { time during and } \\
\text { after childbirth }\end{array}$ & $\begin{array}{l}\text { Childbirth and post-natal } \\
\text { caregiver/s } \\
\text { were respectful }\end{array}$ & $\begin{array}{l}\text { Childbirth and post-natal } \\
\text { caregiver/s } \\
\text { were friendly }\end{array}$ & $\begin{array}{c}\text { Childbirth and post-nata } \\
\text { caregiver maintained } \\
\text { my privacy }\end{array}$ \\
\hline & \multicolumn{3}{|c|}{ Coefficient E (S.E) } & \multicolumn{3}{|c|}{ Coefficient E (S.E) } \\
\hline \multicolumn{7}{|l|}{ Age } \\
\hline $15-24=0$ & $-1.141(1.127)$ & $-0.960(1.107)$ & $-0.411(1.296)$ & $1.129(0.937)$ & $-0.727(01.283)$ & $-0.960(1.522)$ \\
\hline $25-29=1$ & $-1.103(1.097)$ & $-0.950(1.075)$ & $-0.858(1.256)$ & $1.766(0.899)^{*}$ & $-0.778(1.246)$ & $-0.481(1.475)$ \\
\hline $30-34=2$ & $-0.246(1.101)$ & $-0.586(1.078)$ & $-0.243(1.259)$ & $2.350(0.913)^{*}$ & $0.538(1.248)$ & $0.082(1.481)$ \\
\hline $35-39=3$ & $-0.423(1.143)$ & $-0.083(1.122)$ & $-0.400(1.307)$ & $2.543(0.967)^{*}$ & $0.239(1.295)$ & $-0.606(1.539)$ \\
\hline $40-44=4$ & oa & oa & oa & oa & oa & oa \\
\hline \multicolumn{7}{|l|}{ Education } \\
\hline Grade $5-6=0$ & $2.524(1.186)$ & $3.236(1.191)^{* *}$ & $2.669(1.228)$ & $2.566(1.200)^{*}$ & $2.134(1.206)^{*}$ & $3.658(1.316)^{*}$ \\
\hline Grade $10-12=1$ & $0.131(0.376)$ & $0.634(0.363)$ & $0.054(0.405)$ & $0.156(0.382)$ & $-0.486(0.415)$ & $-0.177(0.519)$ \\
\hline College $=2$ & $-0.571(0.347)$ & $0.280(0.351)$ & $0.719(0.409)$ & $0.307(0.386)$ & $0.632(0.408)$ & $0.737(0.535)$ \\
\hline University $=3$ & oa & oa & oa & oa & oa & oa \\
\hline \multicolumn{7}{|l|}{ Place of living } \\
\hline Urban $=0$ & $0.723(0.489)$ & $0.979(0.493)$ & $-0.393(0.335)$ & $0.105(0.310)$ & $0.944(0.546)^{*}$ & $2.267(0.618)^{*}$ \\
\hline Rural = 1 & oa & oa & oa & oa & oa & oa \\
\hline \multicolumn{7}{|l|}{ Antenatal care complications } \\
\hline Yes $=0$ & $0.036(0.308)$ & $0.332(0.296)$ & $0.634(0.345)^{*}$ & $0.884(0.340)^{*}$ & $0.006(0.350)$ & $0.620(0.154)$ \\
\hline $\mathrm{No}=1$ & oa & oa & oa & oa & oa & oa \\
\hline \multicolumn{7}{|l|}{ Place of Natal Care } \\
\hline Primary care level $=0$ & $-0.489(0.255)$ & $-0.254(0.247)$ & $-0.116(0.381)$ & $0.154(0.268)$ & $-0.298(0.285)$ & $-0.550(0.368)$ \\
\hline Secondary care level $=1$ & $-0.039(0.670)$ & $-0.019(0.655)$ & $0.040(0.287)$ & $-0.167(0.721)$ & $-0.228(0.770)$ & $-0.266(0.855)$ \\
\hline Tertiary care level = 2 & oa & oa & oa & oa & oa & oa \\
\hline \multicolumn{7}{|l|}{ Mode of childbirth } \\
\hline C-section $=0$ & $-0.441(0.259)^{*}$ & $-1.144(0.276)$ & $-0.624(0.299)$ & $0.746(0.533)^{*}$ & $-0.255(0.286)$ & $0.401(0.362)$ \\
\hline Vaginal Childbirth $=1$ & oa & oa & oa & oa & oa & oa \\
\hline
\end{tabular}


Table 6.5d: Ordinal regression of perceived service quality of childbirth care and immediate post-natal care

( 1 = strongly disagree, 2 = disagree, 3 = neither agree nor disagree, 4 = agree, $5=$ strongly agree) (continuation)

\begin{tabular}{|c|c|c|c|c|c|c|}
\hline & \multicolumn{3}{|c|}{ Communication $\mathrm{N}=\mathbf{4 0 0}$} & \multicolumn{3}{|c|}{ Courtesy $N=400$} \\
\hline & $\begin{array}{c}\text { Caregiver clearly explained } \\
\text { information related to post- } \\
\text { natal care }\end{array}$ & $\begin{array}{l}\text { Natal and post-natal } \\
\text { complications were clearly } \\
\text { explained }\end{array}$ & $\begin{array}{l}\text { I was given adequate } \\
\text { time during and } \\
\text { after childbirth }\end{array}$ & $\begin{array}{l}\text { Childbirth and post-natal } \\
\text { caregiver/s } \\
\text { were respectful }\end{array}$ & $\begin{array}{l}\text { Childbirth and post-natal } \\
\text { caregiver/s } \\
\text { were friendly }\end{array}$ & $\begin{array}{l}\text { Childbirth and post-natal } \\
\text { caregiver maintained } \\
\text { my privacy }\end{array}$ \\
\hline & \multicolumn{3}{|c|}{ Coefficient E (S.E) } & \multicolumn{3}{|c|}{ Coefficient E (S.E) } \\
\hline \multicolumn{7}{|l|}{ Monthly income a } \\
\hline$<200 \mathrm{GEL}=0$ & $1.079(0.705)$ & $0.404(0.709)$ & $0.100(0.763)$ & $-0.461(0.720)$ & $0.524(0.799)$ & $2.350(1.022)^{*}$ \\
\hline $200-<900 \mathrm{GEL}=1$ & $1.136(0.370)^{*}$ & $-0.071(0.356)$ & $0.998(0.422)^{*}$ & $0.301(0.391)$ & $0.793(0.420)^{* *}$ & $1.474(0.546)^{*}$ \\
\hline $900-1,500 \mathrm{GEL}=2$ & $0.474(0.363)$ & $-0.139(0.361)$ & $0.231(0.411)$ & $-0.117(0.395)$ & $0.464(0.422)$ & $0.935(0.545)^{*}$ \\
\hline$>1,500 \mathrm{GEL}=3$ & oa & oa & oa & oa & oa & oa \\
\hline \multicolumn{7}{|l|}{ Nationality } \\
\hline Other $=0$ & $-0.276(0.543)$ & $1.334(0.541)$ & $-0.523(0.601)$ & $-0.741(0.533)$ & $-0.592(0.569)$ & $-1.195(0.697)^{* *}$ \\
\hline Georgian $=1$ & oa & oa & oa & oa & oa & oa \\
\hline \multicolumn{7}{|l|}{ Occupation } \\
\hline Other $=0$ & $0.025(0.253)$ & $-0.090(0.229)$ & $-0.137(0.289)$ & $0.042(0.270)$ & $-0.038(0.284)$ & $-0.310(0.361)$ \\
\hline Housewife $=1$ & oa & oa & oa & oa & oa & oa \\
\hline \multicolumn{7}{|c|}{$\begin{array}{l}\text { Out-of-pocket payments } \\
\text { during natal \& post-natal }\end{array}$} \\
\hline period & $-0.056(0.321)$ & $-0.446(0.326)$ & $-0.201(0.368)$ & $-0.024(0.341)$ & $0.283(0.359)$ & $-0.078(0.457)$ \\
\hline $\begin{array}{l}\text { Yes }=0 \\
\text { No }=1\end{array}$ & oa & oa & oa & oa & oa & oa \\
\hline Nagelkerke $\mathbf{R}^{2}$ & 0.124 & 0.079 & 0.107 & 0.127 & 0.146 & 0.173 \\
\hline Threshold a1 & $-4.875(1.559)^{*}$ & $-4.085(1.542)^{*}$ & $-4.569(1.800)^{*}$ & $-3.704(1.526)^{*}$ & $-6.006(1.933)^{*}$ & $2.883(1.890)$ \\
\hline Threshold a2 & $-4.068(1.554)^{*}$ & $-3.193(1.533)$ & $-4.273(1.788)^{*}$ & $-3.406(1.485)^{*}$ & $-5.142(1.883)^{*}$ & $-0.783(1.822)$ \\
\hline Threshold a3 & -3.425 (1.549) & $-2.686(1.530)^{*}$ & $-2.643(1.759)^{*}$ & $-1.781(1.513)^{*}$ & $-3.632(1.853)^{*}$ & $6.431(1.917)^{*}$ \\
\hline Threshold a4 & $1.745(1.571)^{*}$ & $2.462(1.532)^{*}$ & $3.049(1.768)^{*}$ & $3.461(1.495)^{*}$ & $2.075(1.843)^{*}$ & \\
\hline
\end{tabular}

a $1 \mathrm{GEL}=2.98$ Euro; ${ }^{*} p \leq 0.05$ 
Table 6.6a: Ordinal regression of satisfaction with antenatal care

( 1 = strongly disagree, 2 = disagree, 3 = neither agree nor disagree, 4 = agree, $5=$ strongly agree)

\begin{tabular}{|c|c|c|c|c|c|}
\hline \multicolumn{6}{|c|}{ Direct measures of satisfaction in antenatal care } \\
\hline $\begin{array}{l}\text { Adequately satisfied } \\
\text { with antenatal } \\
\text { care services }\end{array}$ & $\begin{array}{l}\text { Adequately satisfied with the } \\
\text { dealings of antenatal } \\
\text { caregivers }\end{array}$ & $\begin{array}{l}\text { Adequately satisfied } \\
\text { with overall services of the } \\
\text { antenatal care facility }\end{array}$ & $\begin{array}{l}\text { Recommend others } \\
\text { about my physician } \\
\text { for antenatal care }\end{array}$ & $\begin{array}{l}\text { Consider this antenatal service } \\
\text { in future } \\
\text { if I need }\end{array}$ & $\begin{array}{c}\text { Recommend others } \\
\text { to use this antenatal } \\
\text { care facility }\end{array}$ \\
\hline \multicolumn{6}{|c|}{ Coefficient E (S.E) } \\
\hline
\end{tabular}

\begin{tabular}{|c|c|c|c|c|c|c|}
\hline \multicolumn{7}{|l|}{ Age (years) } \\
\hline $15-24=0$ & $0.726(1.435)$ & $-0.487(1.170)$ & $0.690(0.990)$ & $-0.159(1.348)$ & $-0.566(1.171)$ & $-1.278(0.960)$ \\
\hline $25-29=1$ & $0.782(1.391)$ & $-0.406(1.141)$ & $0.499(0.957)$ & $0.345(1.310)$ & $-0.083(1.143)$ & $-0.654(0.930)$ \\
\hline $30-34=2$ & $-0.296(1.395)$ & $-0.086(1.146)$ & $0.575(0.961)$ & $0.315(1.316)$ & $-0.041(1.147)$ & $-0.004(0.931)$ \\
\hline $35-39=3$ & $0.609(1.441)$ & $-0.486(1.183)$ & $0.759(1.002)$ & $0.104(1.264)$ & $0.417(1.187)$ & $0.133(0.969)$ \\
\hline $40-44=4$ & oa & oa & oa & oa & oa & oa \\
\hline \multicolumn{7}{|l|}{ Education } \\
\hline Grade $5-6=0$ & $1.819(1.230)$ & $1.074(1.322)$ & 1.934 (1.171) & $1.531(1.255)$ & 1.772 (1.195) & $1.916(1.131)^{*}$ \\
\hline Grade $10-12=1$ & $-0.462(0.465)$ & $-0.070(0.362)$ & $0.157(0.347)$ & $-0.061(0.442)$ & $-0.979(0.369)^{*}$ & $0.159(0.326)$ \\
\hline College $=2$ & $-0.074(0.458)$ & $-0.075(0.362)$ & $-0.406(0.321)$ & $0.240(0.438)$ & $0.223(0.386)$ & $0.100(0.317)$ \\
\hline University $=3$ & oa & oa & oa & oa & oa & oa \\
\hline \multicolumn{7}{|l|}{ Place of living } \\
\hline Urban $=0$ & $0.114(0.609)^{*}$ & $0.237(0.591)$ & $0.829(0.869)^{*}$ & $0.596(0.610)$ & $0.375(0.516)$ & $0.158(0.456)^{*}$ \\
\hline Rural = 1 & oa & oa & oa & oa & oa & oa \\
\hline \multicolumn{7}{|c|}{ Antenatal care complication } \\
\hline Yes $=0$ & $0.617(0.397)^{*}$ & $-0.711(0.327)^{*}$ & $0.146(0.286)$ & $-0.239(0.383)^{*}$ & $0.488(0.320)$ & $0.276(0.271)$ \\
\hline No $=1$ & oa & oa & oa & oa & oa & oa \\
\hline \multicolumn{7}{|l|}{ Monthly income a } \\
\hline$<200 \mathrm{GEL}=0$ & $0.050(0.883)$ & $-0.948(0.677)$ & $-0.889(0.633)$ & $-0.611(0.827)$ & $-0.674(0.694)$ & $-0.178(0.629)$ \\
\hline $200-<900 \mathrm{GEL}=1$ & $0.682(0.470)$ & $0.245(0.375)$ & $-0.074(0.346)$ & $0.003(0.452)$ & $-0.156(0.391)$ & $-0.312(0.332)$ \\
\hline $900-1,500 \mathrm{GEL}=2$ & $0.006(0.477)$ & $-0.193(0.378)$ & $-0.253(0.347)$ & $0.008(0.460)$ & $-0.172(0.401)$ & $-0.592(0.336)$ \\
\hline$>1,500 \mathrm{GEL}=3$ & oa & oa & oa & oa & oa & oa \\
\hline \multicolumn{7}{|l|}{ Nationality } \\
\hline Other $=0$ & $1.100(0.600)^{*}$ & $1.003(0.536)^{*}$ & $-0.485(0.525)$ & $-0.422(0.645)$ & $-1.077(0.540)^{*}$ & $-0.946(0.469)^{*}$ \\
\hline Georgian $=1$ & oa & oa & oa & oa & oa & oa \\
\hline
\end{tabular}


Table 6.6a: Ordinal regression of satisfaction with antenatal care

( 1 = strongly disagree, 2 = disagree, 3 = neither agree nor disagree, 4 = agree, $5=$ strongly agree) (continuation)

\begin{tabular}{|c|c|c|c|c|c|}
\hline \multicolumn{6}{|c|}{ Direct measures of satisfaction in antenatal care } \\
\hline $\begin{array}{l}\text { Adequately satisfied } \\
\text { with antenatal } \\
\text { care services }\end{array}$ & $\begin{array}{l}\text { Adequately satisfied with the } \\
\text { dealings of antenatal } \\
\text { caregivers }\end{array}$ & $\begin{array}{l}\text { Adequately satisfied } \\
\text { with overall services of the } \\
\text { antenatal care facility }\end{array}$ & $\begin{array}{l}\text { Recommend others } \\
\text { about my physician } \\
\text { for antenatal care }\end{array}$ & $\begin{array}{l}\text { Consider this antenatal service } \\
\text { in future } \\
\text { if I need }\end{array}$ & $\begin{array}{l}\text { Recommend others } \\
\text { to use this antenatal } \\
\text { care facility }\end{array}$ \\
\hline \multicolumn{6}{|c|}{ Coefficient E (S.E) } \\
\hline $0.019(0.325)$ & $-0.484(0.261)^{*}$ & $0.006(0.238)$ & $-0.340(0.317)$ & $-0.660(0.275)$ & $-0.456(0.228)$ \\
\hline oa & oa & oa & oa & oa & oa \\
\hline
\end{tabular}

\begin{tabular}{|c|c|c|c|c|c|c|}
\hline \multicolumn{7}{|l|}{ Occupation } \\
\hline Other $=0$ & $0.019(0.325)$ & $-0.484(0.261)^{*}$ & $0.006(0.238)$ & $-0.340(0.317)$ & $-0.660(0.275)$ & $-0.456(0.228)$ \\
\hline Housewife = 1 & oa & oa & oa & oa & oa & oa \\
\hline \multicolumn{7}{|c|}{$\begin{array}{l}\text { Out-of-pocket payments } \\
\text { during antenatal period }\end{array}$} \\
\hline Yes $=0$ & $-0.199(0.421)^{*}$ & $-0.068(0.311)^{*}$ & $-0.455(0.315)$ & $-0.233(0.245)^{*}$ & $0.132(0.387)$ & $-0.378(0.289)^{*}$ \\
\hline No $=1$ & oa & oa & oa & oa & oa & oa \\
\hline Nagelkerke $\mathbf{R}^{\mathbf{2}}$ & 0.121 & 0.170 & 0.085 & 0.066 & 0.131 & 0.202 \\
\hline Threshold a1 & $-4.319(2.062)^{*}$ & $-4.215(1.617)^{*}$ & $-4.375(1.460)^{*}$ & $-5.267(1.951)^{*}$ & $-5.177(1.629)^{*}$ & $-5.204(1.330)^{*}$ \\
\hline Threshold a2 & $-4.209(2.059)^{*}$ & $-4.184(1.616)^{*}$ & $-1.997(1.423)$ & $-5.009(1.943)^{*}$ & $-4.871(1.622)^{*}$ & $-5.077(1.328)^{*}$ \\
\hline Threshold a3 & $-3.365(2.044)^{*}$ & $-3.830(1.613)^{*}$ & $2.700(1.439)^{*}$ & $-3.976(1.923)^{*}$ & $-3.732(1.606)^{*}$ & $-4.301(1.319)^{*}$ \\
\hline Threshold a4 & $2.911(2.041)^{*}$ & $1.427(1.605)^{*}$ & - & $1.848(1.904)^{*}$ & $1.520(1.595)$ & $0.043(1.296)$ \\
\hline
\end{tabular}

a $1 \mathrm{GEL}=2.98$ Euro; $^{*} \mathrm{p} \leq 0.05$ 
Table 6.6b: Ordinal regression of satisfaction with childbirth care natal and immediate post-natal care

( 1 = strongly disagree, 2 = disagree, 3 = neither agree nor disagree, 4 = agree, $5=$ strongly agree)

\begin{tabular}{|c|c|c|c|c|c|c|}
\hline & \multicolumn{6}{|c|}{ Direct measures of satisfaction in childbirth and immediate post-natal care } \\
\hline & $\begin{array}{l}\text { Adequately satisfied } \\
\text { with childbirth and } \\
\text { post-natal care services }\end{array}$ & $\begin{array}{l}\text { Adequately satisfied with } \\
\text { overall dealings of childbirth } \\
\text { and post-natal caregivers }\end{array}$ & $\begin{array}{l}\text { Adequately satisfied with } \\
\text { overall services of the } \\
\text { childbirth and postnatal }\end{array}$ & $\begin{array}{l}\text { Recommend others about } \\
\text { my physician/midwife for } \\
\text { childbirth and post-natal }\end{array}$ & $\begin{array}{l}\text { Consider this childbirth } \\
\text { and post- natal service } \\
\text { in future if I need }\end{array}$ & $\begin{array}{l}\text { Recommend others } \\
\text { to use this childbirth and } \\
\text { post-natal care facility }\end{array}$ \\
\hline & \multicolumn{6}{|c|}{ Coefficient E (S.E) } \\
\hline \multicolumn{7}{|l|}{ Age } \\
\hline $15-24=0$ & $0.325(1.085)$ & $-0.174(1.110)$ & $-0.308(1.115)$ & $-0.308(1.115)$ & $-0.024(0.999)$ & $-0.532(1.372)$ \\
\hline $25-29=1$ & $0.672(1.049)$ & $-0.163(1.072)$ & $-0.247(1.074)$ & $-0.247(1.074)$ & $0.435(0.970)$ & $0.020(1.363)$ \\
\hline $30-34=2$ & $1.607(1.059)$ & $0.349(1.076)$ & $0.247(1.079)$ & $0.247(1.079)$ & $1.373(0.978)$ & $0.720(1.347)$ \\
\hline $35-39=3$ & $1.566(1.104)$ & $1.249(1.115)$ & $0.670(1.125)$ & $0.670(1.125)$ & $1.051(1.017)$ & $-0.176(1.352)$ \\
\hline $40-44=4$ & oa & oa & oa & oa & oa & oa \\
\hline \multicolumn{7}{|l|}{ Education } \\
\hline Grade $5-6=0$ & $1.889(1.206)$ & $2.528(1.191)^{*}$ & $0.704(1.503)$ & $0.704(1.503)$ & $0.771(1.297)$ & $0.475(1.265)$ \\
\hline Grade $10-12=1$ & $-0.393(0.376)$ & $0.162(0.367)$ & $0.297(0.390)$ & $0.297(0.390)^{*}$ & $-0.095(0.335)$ & $0.154(0.345)$ \\
\hline College $=2$ & $0.181(0.372)$ & $0.753(0.377)$ & $0.645(0.388)$ & $0.645(0.388)$ & $0.459(0.337)$ & $-0.035(0.334)$ \\
\hline University $=3$ & oa & oa & oa & oa & oa & oa \\
\hline \multicolumn{7}{|l|}{ Place of living } \\
\hline Urban $=0$ & $-0.810(0.511)^{*}$ & $0.024(0.530)$ & $0.072(0.549)$ & $-0.072(0.549)$ & $0.246(0.476)$ & $0.967(0.473)$ \\
\hline Rural = 1 & oa & oa & oa & oa & oa & oa \\
\hline \multicolumn{7}{|l|}{ Antenatal care complications } \\
\hline Yes $=0$ & $0.617(0.321)^{*}$ & $0.884(0.315)^{*}$ & $-1.024(0.331)^{*}$ & $0.962(0.334)^{*}$ & $1.060(0.286)^{*}$ & $1.060(0.286)^{*}$ \\
\hline $\mathrm{No}=1$ & oa & oa & oa & oa & oa & oa \\
\hline \multicolumn{7}{|l|}{ Place of Natal Care } \\
\hline Primary care level $=0$ & $-1.014(0.708)^{*}$ & $-0.094(0.254)$ & $0.002(0.267)$ & $-0.121(0.267)^{*}$ & $0.050(0.235)$ & $0.427(0.312)$ \\
\hline Secondary care level $=1$ & $0.025(0.587)^{*}$ & $-1.016(0.695)$ & $0.472(0.734)$ & $-0.893(0.733)^{*}$ & $-0.096(0.640)$ & $-0.095(0.022)$ \\
\hline Tertiary care level $=2$ & oa & oa & oa & oa & oa & oa \\
\hline \multicolumn{7}{|l|}{ Mode of childbirth } \\
\hline C-section $=0$ & $-0.059(0.256)$ & $-0.007(0.255)$ & $0.630(0.275)^{*}$ & $0.307(0.269)$ & $-0.051(0.237)$ & $-0.510(0.237)$ \\
\hline Vaginal Childbirth = & oa & oa & oa & oa & oa & oa \\
\hline
\end{tabular}


Table 6.6b: Ordinal regression of satisfaction with childbirth care natal and immediate post-natal care

( 1 = strongly disagree, 2 = disagree, 3 = neither agree nor disagree, 4 = agree, $5=$ strongly agree) (continuation)

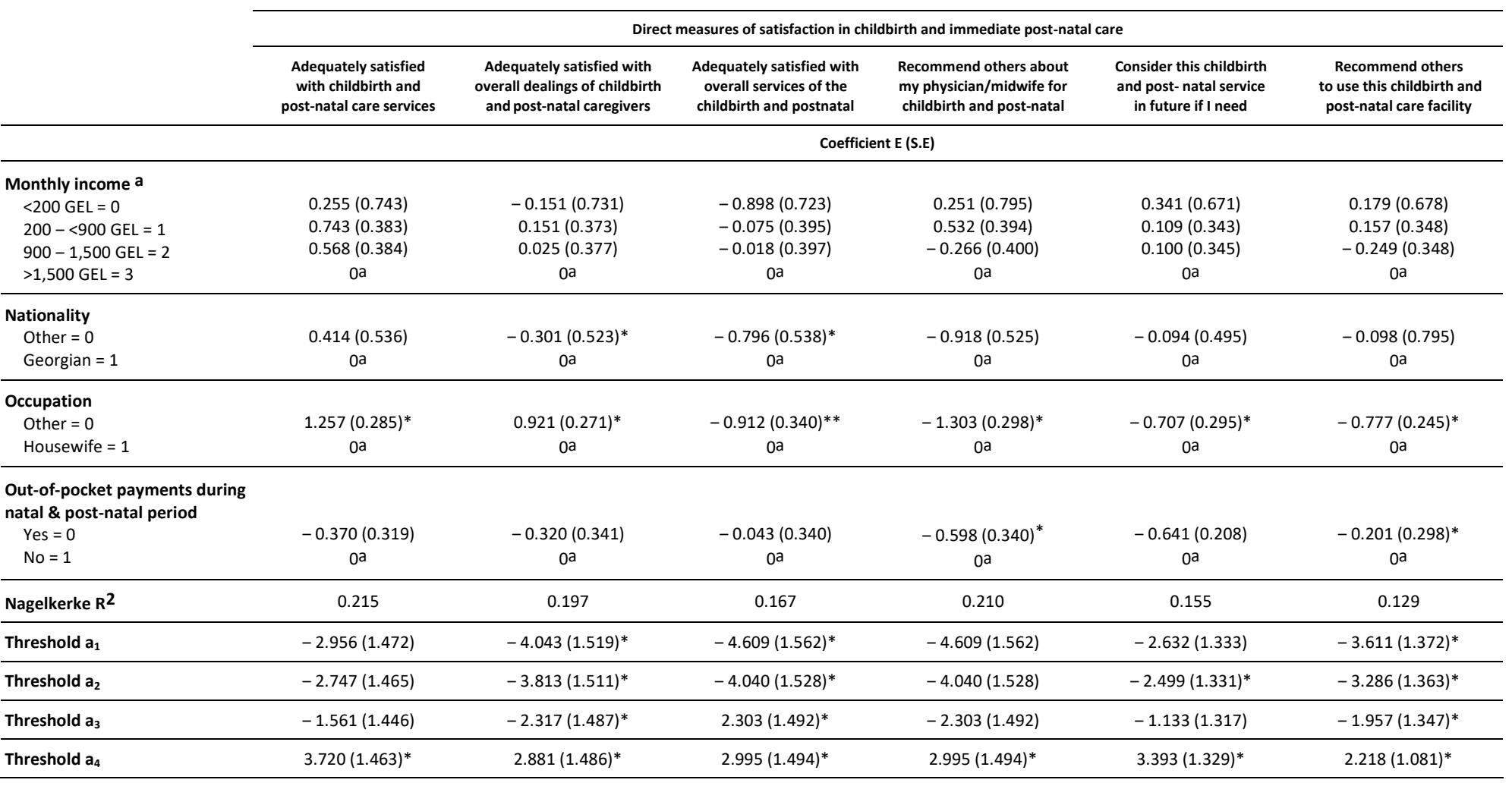

a $1 \mathrm{GEL}=2.98$ Euro; ${ }^{*} \mathrm{p} \leq 0.05$ 


\subsection{DISCUSSION}

We have investigated women's opinions about maternal care quality and women's satisfaction with maternal care in Georgia, as well as the association with women's background characteristics. We discuss the key findings below.

We found that utilization of antenatal care is nearly $99.8 \%$ and most of the participants were satisfied with antenatal care services. About $85 \%$ of the respondents received eight or more antenatal care visits which is considerably more than the statescheduled four visits. Based on other studies, the high satisfaction with antenatal services is associated with the women's freedom of choice of provider of antenatal care, which has been ensured by the recent decree of the government of Georgia (148, 149). Although, the State has implemented the antenatal care program to meet pregnant women's needs and demands, these women often need to pay extra service costs beyond the state coverage. In Georgia, the high number of antenatal visits is often not need-driven but the result of the providers' interests in gaining extra income (26). From 2018, the State increased the number of standard antenatal visits based on the latest recommendation of the WHO $(150,151)$. Currently, the state provides eight free antenatal care visits which are consistent with our findings. This approach is implemented to meet pregnant women's needs.

Our findings suggest that women in the lowest education group more often agree with the statements about the tangibility of maternal care as well as with the availability of common diagnostic tests and medicines than women with the highest education level. Some studies have shown that a higher education is associated with higher demands and expectations which in turn are related to lower satisfaction $(152,153)$. Our findings are consistent with those findings. Also, we found that younger women have a lower opinion of tangibility which is probably because compared with the older women, the younger ones cannot remember the large, damp and cold health facilities from the Soviet period $(153,154)$. Older women may more positively evaluate the replacement of the huge Soviet hospital infrastructure with the privately owned smaller, more attractive and modernized facilities, and see it as a positive effect of the health system reform (143). The replacement of the hospital infrastructure was done through the total privatization of health facilities. Apparently, the change of the Soviet health infrastructure was a good decision. However, due to the total privatization and liberalization of the health market, the achieved progress was halted and replaced by stagnation especially in the rural part of the country. The lack of regulation and monitoring mechanisms further negatively affect the development of maternal care. 
Regarding the accessibility of antenatal care, we found that those who had antenatal complications more often agreed with the statement about the affordability of the consultation fee during antenatal care but they more often disagreed with the statement that the "cost of required medicines was affordable". Additional medicines are paid by OPPs and this presents an extra burden for the pregnant women and their households. OPPs tend to be regressive $(155,156)$ and frequently include unexpected expenses, especially in case of pregnancy complications.

As mentioned above, we found that overall women in urban areas were more positive about the tangibility of maternal care and the availability of the provider than those in rural areas. This could be due to structural factors of the maternal care settings. In spite of fact that basic maternal care services are ensured in the entire country. The maternal services in the rural areas do not always meet women's expectation. That leads to inequality in maternal care. Furthermore, comprehensive maternal care services are concentrated in the big cities (26). For example, out of a total of 89 maternal houses in the country, 23 are located in the capital Tbilisi (126). Pregnant women most often utilize services from the regional antenatal and natal providers rather than from the nearby rural-based facilities. This is related to the rural women's higher direct and indirect cost. Moreover, many rural women start receiving antenatal care from rural facilities and often switch to providers in urban facilities which cause a breach of continuity of care. This finding is consistent with other studies which find that the absence of continuity of maternal care is related to mistrust between physicians and patients (145).

More than $80 \%$ of the respondents paid out of pocket for antenatal, natal and immediate post-natal care. In spite of fact that the State covers antenatal care visits and all types of childbirth $(48,49)$, pregnant women are paying for additional antenatal services and extra personal comfort during natal and post-natal care. Other studies showed that this extra payment was mostly related with a "personal doctor" (26). Women are paying to take away the "fear" that services are unavailable and because of the "word of mouth" that they will get more than those who does not pay (24). Our results regarding OPPs are mixed. We find that women who paid are less positive about the tangibility of antenatal care as well as the availability of necessary medicines. However, they felt more secure with caregivers and felt more privacy in the contact with the antenatal care providers. Moreover, our findings suggest that women who pay are overall less satisfied with antenatal care. Pregnant women pay out of pocket to have continuity of care which is not ensured by the State programs. This "do-ityourself" $(88,130)$ approach adopted by mothers and their relatives in the country, helps them to address their needs during antenatal, natal and immediate post-natal period. 


\section{Study strengths and weaknesses}

Our study has some limitations that need to be acknowledged. First, only women who gave birth to healthy babies during the preceding twelve months were included in the study. This means that complicated cases were not well represented in the survey. Second, the study provides limited information about ethnic minorities. Third, the study has a non- experimental cross-sectional nature and therefore, results should only be interpreted in terms of associations. However, this study is the first to assess women's satisfaction with maternal care services in Georgia, which makes the study relevant to health policy in Georgia.

\subsection{CONCLUSIONS}

Our survey is the first to investigate women's satisfaction with maternal care services in Georgia. In particular, the study provides evidence on women's satisfaction with antenatal, natal and immediate post-natal services. Out of ten regions and the capital, the study was conducted in Tbilisi and two regions of Georgia. However, selected areas represent nearly three-fifths of the total population of the country. In the study only mothers with good outcome of pregnancy participated.

Overall, women are satisfied with maternal care in Georgia as basic maternal care services are assured in the entire country. However, satisfaction does not indicate efficient use of resources invested by the government through the private health sector. The study showed that those who pay out of pocket are overall less satisfied. We found that women in urban settings were more satisfied with antenatal and natal care than in rural areas. It can be due to the improvement in structural factors of the maternal care such as tangibility, availability, accessibility in the cities. 



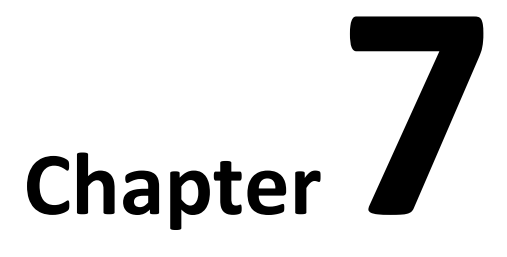

General Discussion 



\subsection{INTRODUCTION}

This dissertation is dedicated to maternal care in Georgia with a focus on the cost, access and quality of maternal care services. As outlined in Chapter 1, the motivation for this topic is the importance of obtaining more knowledge and insight to improve maternal health and to ensure the sustainability of maternal care, and the need for more evidence to support policymaking to achieve these goals as well.

We aimed to increase our understanding of maternal care financing, access, and quality in Georgia. To meet this aim, we have looked at the available evidence on the outcomes of the healthcare reforms in Georgia. We have also studied the changes in maternal care during the healthcare reforms in Georgia. Given the changes in maternal care, we have focused our attention on the adequacy of maternal care financing and access to maternal care services in Georgia. Also, we have studied factors influencing maternal care in terms of quality and satisfaction of mothers with the care they received.

As our analyses are not without limitations (see the discussion sections in Chapter 2-6), there is a need for further research - even after this dissertation - on maternal care in Georgia. However, the broad range of evidence, which we provide in this dissertation, contributes to our knowledge and insight on maternal care in Georgia. In this chapter, the key findings are presented in the form of statements and these statements are discussed from the perspective of policy and research. Conclusions on how to improve financing, access and quality of maternal care in Georgia, complete the chapter.

\subsection{MAIN CONCLUSIONS}

The first statement that summarizes the main conclusions from this dissertation is:

\section{The transition of the Georgian health system from the Semashko model to a privatized system has had effects on both efficiency and equity in healthcare.}

The analysis of the effects of the reforms during the transition period on efficiency and equity in healthcare has been presented in Chapter 2, Chapter 3 and Chapter 4 of this dissertation. Although we are unable to identify truly causal effects of the reforms, the analysis suggests that efficiency and equity in healthcare have been influenced by the changes in the health system, namely the transition from the Semashko model of 
health system of the Soviet era to a privatized one. In the three decades following the independence in 1991, Georgia has implemented several healthcare reforms (details on the impact of the healthcare reforms are presented in Chapter 2). Improvement of healthcare efficiency and equity are the objectives commonly assigned to healthcare policy. The review of Georgian healthcare reform, which is presented in Chapter 2 leads to the conclusion that efficiency was not substantially improved and equity was negatively influenced by the healthcare reforms. This resulted in a lack of cost control and reduced client trust in the healthcare sector.

The Semashko health system was oriented on curative rather than preventive care. The health system in the Soviet Union was the world's largest in terms of the number of medical doctors and hospital beds. The system was based on expanding capacity irrationally and was "quantity driven" $(158,159)$. All healthcare facilities were owned by the state and development was in accordance with centrally determined plans. Health services were provided free of (direct) charges (160- 163). Inefficiency in the health system was high. This was the result of shortcomings in planning and budgeting. There was a lack of interest to economize or to promote better quality of care. Absence of competition among providers of healthcare and structural inefficiency existed but were not recognized (164).

The Semashko model granted all citizens the right to free medical care, and its proclamation of being the first health system with UHC in the world. An extensive network of public medical facilities was created to ensure the basic human right to medical care. However, access to medical care was not equal for everyone. Employees of priority industries, residents of large cities, and officials were treated in medical institutions with the best equipment and staff (102). All Soviet republics, including Georgia, achieved the goal of providing universal protection of citizens against the risk of financial hardship due to illness. Healthcare services and inpatient medicines were free of charge. Nevertheless, patients and their families routinely made informal payments in cash and/or in kind to health staff, which reduced equity in financing. Only those who could afford to pay informally had good care (164).

The reforms during the perestroika ${ }^{3}$ period (1985-1991) in the Soviet Union were not able to correct the many deficiencies in the economy. Economic growth became negative, open inflation increased and the foreign debt burden rose significantly. These economic deficiencies contributed to the systemic crises that resulted in the

3 Was a political movement for reformation within the during the 1980s and 1990s and is widely associated with Soviet leader Mikhail Gorbachev and his glasnost (meaning "openness") policy reform (6). 
collapse of communist power $(165,166)$. During the latest Soviet era and initial transition period, in Georgia, as in other post-Soviet countries, health financing systems experienced numerous problems and by the early 1990s, it was clear that the inherited systems required radical reforms. Consequently, the main common target for health system reform in transitional countries was the downsizing of the healthcare service delivery infrastructure (6).

GDP in the independent Georgia dropped drastically during the early 1990's. GDP in 1995 was only approximately $28 \%$ of that in 1990 (164). The overview of empirical evidence on the outcome of the Georgian healthcare reform presented in Chapter 2 of this dissertation, shows that the reforms were the first attempt by a post-Soviet country with very low levels of public spending on health, to narrow coverage breadth. The non-poor population was explicitly excluded and public spending was concentrated on the poorest households(2).

As presented in Chapter 2, the frequent, non-systematical policy changes during the healthcare reforms endangered the financial sustainability of the health system. The direction and priorities of the reforms varied according to the willingness of the ruling party and the principle "new lord, new laws" was practiced. For example, in the early 1990's, social insurance and decentralization was introduced by the government (88). Later, due to the lack of local capacity, the system was centralized again. The social insurance scheme failed and informal payments were blooming. Efficiency as well as equity was compromised during this period. Due to the resource constraints people faced, the utilization of healthcare services fell radically during the last two decades. As explained in Chapter 3, maternal houses during the last two decades of 20st century were huge, uncomfortable and frozen (65).

After the reformers took charge in 2003 (2), health policy was changed radically. The efficiency-oriented changes were implemented and the huge Soviet health infrastructure was totally privatized and replaced by a smaller one. The number of hospital services and hospital beds were reduced which was one of the good outcomes of the reform $(2,66,168)$. However, the private healthcare sector was completely deregulated. Fee-for-services were manipulated by the profit-oriented monopolists of the newly established private market. At the same time, the introduction of private ownership in the healthcare sector abolished informal payments, which was a very positive aspect of this wave of the reform.

After the privatization, OPPs significantly increased, as shown by the examples in Chapter 4. The variation in the fee-for-services depended on the reputation of the maternal house and the provision of additional comfort services such as separate room, personal medical doctor and nurse. Since 1995, the State recommended and 
paid for four antenatal visits which were free for all in the private women's consuItation center and maternal houses. However, most women used more than 10 visits (Chapter 3). This indicates that the private owners encouraged mothers to utilize more services.

The MAP introduced during the second wave of the reform was aimed at providing health insurance for the poor population. The program improved equity and protected the poor from catastrophic health expenditure. Nevertheless, due to the high cost of pharmaceuticals, the overall utilization of healthcare services decreased (2).

The deregulated private health insurance companies freely manipulated the selection criteria and risk-rated premiums. During this period, the Georgian health system looked like a HMO model (details in Chapter 2). With the HMO model, inequity increased in the health system. The population did not have a chance to choose their healthcare provider freely. They were obliged to get services from the local healthcare providers. Thereby, cream skimming was common. People were discouraged to obtain insurance voluntarily and the risk of impoverishment remained because of the unpredictable and intolerable healthcare expenses (2). Although efficiency improved during the second stage of the reform in terms of downsizing, the huge hospital infrastructure and reduction in the length of hospital stay, equity still was a concern.

Our results indicated that in 2013, the implementation of the UHC program significantly improved protection from catastrophic health expenditure. As stated in Chapter 3, with the UHC program the utilization of healthcare services became easier. For example, the UHC program covered, beside other services, also childbirth and Csection services that were not covered during the previous stage of the reform. However, the equal financing of poor and rich people led to regressive financing. Moreover, after the implementation of the UHC program, the government abolished the MAP with further adverse effects on equity. For example, the UHC in maternal care reflects the individual rights of pregnant women and social solidarity in Georgia (99). Nevertheless, there was a need to focus on equity and take into account of the social determinants and needs of subgroups, especially the vulnerable groups (168). Later, in 2017, the government excluded from the UHC program those who participated in the private health insurance scheme or have an income of more than 40 000 GEL per year. People whose income was between $1000 \mathrm{GEL}$ and $40000 \mathrm{GEL}$ could participate in the program only partially (82).

Overall, the healthcare reform has had a positive influence on efficiency. However, due to the lack of regulatory control over the private market and the existence of information asymmetry, massive privatization without effective regulatory mechanisms, the absence of regulated market competition and cost control, resulted in market failures. 


\section{Suggestion for further research:}

The health system reforms to enhance efficiency and equity were largely depended on the political decisions of the ruling elite of the country rather than on actual evidence. More research on the actual effects on efficiency and equity after the implementation of the UHC program is needed to be able to thoroughly evaluate the policy. Particularly, it is worthwhile to study the effect of the UHC program on efficiency and equity in the use of curative and preventive services. Also, it is advisable to study the cost effectiveness of the separate vertical health program whenever the UHC program is implemented. Given the crucial role of private providers, more research should be done on how to line up public private relationship as well as on how to align demand and supply-side measures for better performance of the Georgian healthcare sector.

\section{The second statement that summarizes the main conclusions from this dissertation is:}

\section{The phenomenon of a "personal doctor" has improved the quality of mater- nal care and the autonomy of choice}

The phenomenon of a "personal doctor" has been presented in Chapter 3, Chapter 4 and Chapter 5 of this dissertation. This phenomenon plays a significant role in maternal care services in Georgia. The term "personal doctor" was introduced several decades ago in maternal care. Due to sub-standard quality of maternal care services, pregnant women and their households try to utilize services for antenatal care or/and childbirth by an obstetrician who is most popular. Our findings suggest that there are many determining factors to search and pay extra for a "personal doctor", such as safety, responsiveness and personal comfort. Discrepancies in maternal care were inherited from the Soviet period (81), during which there was an emphasis on the continuous expansion of medical staff and facilities as well as an extensive system of parallel health services. Moreover, salary of medical staff was very low and informal payments were generally accepted by society (169). Therefore, accessibility and affordability of good quality of care was limited. The informal payments expressed not only gratitude towards medical doctors but also provided assurance for good quality care (169). After the reform of the Georgian health system, informal payments were eliminated. The driver for informal payments was to get good quality care. However, privatization and deregulation made that health providers manipulated user fees and salaries of medical doctors, for example user fee for C-section varies from one to another maternal house/unit. All this negatively influenced quality of maternal care and reduced the trust in the medical doctors. Later, pregnant women started to apply for a "personal doctor" and pay out of pocket. As a consequence, the informal payments were transformed into the formal OPP for "personal doctor". 
The phenomenon of a "personal doctor" was a reaction of society to the poor quality of maternal care. Chapter 3 and Chapter 4 show that pregnant women and their families prefer to pay for the service of a "personal obstetrician" to ensure better care. Services of a "personal obstetrician" ensure clinical and social quality of care as well as continuity of care. Some studies found that the pregnant women's perception of continuity of care was related to the continuity of the relationship with the same medical doctor during pregnancy (100).

Maternal care in Georgia is segmented into several parts, such as antenatal care, natal care and post-natal care. It is quite a challenge to maintain comprehensiveness and continuity of care. The reason for this is that most pregnant women utilize antenatal care in one facility and have childbirth in another. This creates a major barrier for obstetricians to follow pregnancy from the very beginning. Moreover, the price for a "personal doctor" varies between $300 \mathrm{GEL}$ and $1000 \mathrm{GEL}$ which is a significant amount for most families in Georgia. Therefore, not everyone can afford a "personal doctor". This leads to inequalities and disparities among mothers as not everybody can afford a "personal physician" and those who do not, might receive substandard care. Even more, as Chapter 3 and Chapter 4 have shown, some pregnant women have two "personal doctors": one in antenatal care and another at the maternal house. This leads to a double burden of OPPs. However, some use a "personal doctor" only during childbirth and immediate post-natal care.

The cost of a "personal doctor" depends on the extent to which he or she is involved in the management of the pregnancy. Another indication for the price is the experience and popularity of the obstetrician. As Chapter 4 shows, pregnant women and their family members make decisions regarding the "personal doctor" based on their own experience or the opinion of friends or/and relatives. Despite the fact that the State implemented free antenatal care visits and childbirth, pregnant women prefer to have a "personal obstetrician" from the very beginning of the pregnancy. Our findings also show that having a "personal doctor" means extra antenatal visits and medical investigations beyond the State allocation. Thus safe, timely and patient-centered care under the State program is questionable. We found that most of the pregnant women are willing to pay extra to get good pregnancy outcomes. This pushes them to be financially prepared for the cost of pregnancy and childbirth. However, they choose a "personal doctor" according to their ability to pay as well as taking into account direct and indirect costs. For example, one of the participants of the FGDs mentioned that her mother had to pay all expenses, including, the services of a "personal doctor" during the last pregnancy. All this leads to inequities and disparities between women. 
Healthcare reforms and public-private partnership with human capacity influence maternal care quality (100). The State implements free antenatal and natal care in the private sector without proper regulation. Moreover, there is no CPD for physicians in the country. All this contributes to substandard maternal care. The lack of medical skills and knowledge among obstetricians / gynecologists is one of the reasons to utilize services of a "personal doctor". Epidemiological surveillance of maternal mortality carried out by the NCDC of Georgia showed that maternal mortality is higher among lower-middle and low-income groups because lower income groups utilize fewer maternal care services due to the direct and indirect costs (120). The country developed national guidelines and protocols on the management of antenatal, natal and post-natal period nearly two decades ago. However, the implementation of those guidelines is obligatory but not monitored. Evidence shows that medical doctors not always treat mothers based on the best available evidence (120).

A "personal doctor" is one of the possibilities to maintain autonomy of choice for pregnant women. For example, the State antenatal care program was always linked with a voucher system provided by the antenatal care clinics. According to the later regulation, pregnant women are free to choose their provider before registration for antenatal care. The facility where pregnant women registered provided e-vouchers for eight free antenatal visits as well as free natal and immediate post-natal care. However, after the registration, the change of the antenatal providers is limited (170). If pregnant women want to change provider, they should have sufficient reason to do so, like a change of the living place and being stated in the Georgian birth registry. All this makes that women do not utilize the free antenatal care visits provided by the State and they are seeking services from the "personal obstetrician".

As Chapter 5 showed, women pay for the "personal doctors" just to ensure the services that are already available. Women pay for their "fear" and for "positive word-ofmouth" that they are getting more than those who do not pay.

\section{Suggestion for further research:}

The phenomenon of "personal doctors" arose because of multiple factors, such as the tradition of informal payments, privatization and deregulation of maternal care services. As the Georgian Health system inherited the same problems from the Semashko healthcare model as other Soviet republics, it is relevant to further explore the phenomenon of "personal doctors" on households' health catastrophic expenditure. Also, it is advisable to conduct a cross post-Soviet country study on maternal care quality and the ways to reform the Health system. 
The third statement that summarizes the main conclusions from this dissertation is:

\section{The absence of continuity of maternal care has led to an overuse of maternal care services and has compromised quality of care in Georgia}

The continuity of maternal care and its influence on the use of maternal care services has been presented in Chapter 2, Chapter 3 and Chapter 4 of this dissertation. The findings show that maternal care services have become fragmented since the introduction of the Semashko model of healthcare. The organization of the maternal health system during and after the Soviet system was divided into two parts: the antenatal care services and the maternal houses. The same structure was maintained after the independence. The link between antenatal care clinics and maternal houses was ensured by the special exchange card. The exchange card was given to the pregnant woman during her last antenatal care visit and delivered by her to the maternal house. The content of the exchange card was verylimited and provided only basic information about pregnancy, like gestation weeks, age of woman, address and so on. As Chapter 2 presents, the transformation of maternal care started with the reform of the Georgian health system. The number of independent women consultation centers decreased gradually during the healthcare reforms. Consequently, the number of antenatal care providers increased and these became integrated into the maternal houses or units. The fragmentation of maternal care negatively influenced maternal care quality because obstetricians involved in the antenatal care did not communicate with those who work in the maternal ward. Moreover, obstetricians working in the antenatal care clinic did not have the right to work in the maternal house. All this led to a decrease of skills and knowledge of obstetricians about antenatal care. Moreover, in case of a bad outcome of pregnancy or complications, obstetricians complained about the poor management of pregnancy (170).

Chapter 2 shows that the average number of antenatal care visits increased after the reform. Since 1995, the State provided 4 free-of-charge antenatal care visits. However, as presented in Chapter 2, the number of antenatal visits increased during the last two decades. Moreover, it has grown significantly after the privatization and deregulation of the health system. The content of the antenatal visits and mistrust of the medical doctors motivated pregnant women to change antenatal care providers frequently (Chapter 3 ) and utilize more antenatal services than those was provided by the State. Short visits and lack of courtesy by some medical doctors cause pregnant women to visit obstetrician frequently and each extra visit was related with OPPs. The pregnant woman's expectation is to have continuity of care across pregnancies (100) and therefore women arrange "personal doctor". 
The absence of a link between antenatal and natal care providers, compromises the continuity and quality of maternal care. Accordingly, it also increases the number of antenatal care visits. The WHO recommends women-centered maternal care that assure flexible and appropriate care of women according to their circumstances and needs (156). Chapter 3 and Chapter 4 indicate that the number of antenatal visits is not associated with good quality of care. We found that most pregnant women visited obstetricians because of medical doctors' request or due to fear of pregnancy complications. We also found that extra antenatal visits are always related with extra lab tests. Additional antenatal care visits are paid by pregnant women. OPPs tend to be regressive since they present an extra burden on those with lower incomes especially, during complications $(26,117)$.

The gaps in the continuity of maternal care compromise trust in the medical doctor and in the system. Chapter 3 shows that the increased number of antenatal visits is often not needed. It results from the providers' interests of generating extra income. Maternal care providers receive a double income for antenatal and natal services. First, the State pays them for the implementation of free antenatal visits and natal services. Second, due to overuse of maternal care services pregnant women pay out of pocket, which is an extra source of income for providers.

We also found that some providers do not participate in the State maternal care programs. According to them, the government allocation for specific services is quite marginal and not enough to make a profit for private providers. This often-reduced private providers' interest to join public healthcare programs. However, only wellestablished maternal care providers can be independent players on the healthcare market. Others can survive only because of the State maternal care program. As a result, in the deregulated maternal care system, responsiveness of pregnant women and their household is high. As Chapter 5 showed, a "do-it-yourself" approach was adopted by mothers and their relatives to address their demands and needs during antenatal, natal and immediate post-natal period. This means that patients purvey "alternative politics" (171) to ensure continuity and quality of care. Moreover, overuse of maternal care services is one of the ways to get what is not guaranteed by the state.

\section{Suggestion for further research:}

As indicated by our results, quality and continuity of maternal care services is compromised in Georgia. The country implemented eight free antenatal care visits in 2018. More research should be done on the effects of increasing the number of antenatal care visits on continuity and quality of maternal care. It is also desirable to assess the cost-effective and the cost- benefit analysis of the antenatal care package provided by the State. 
The fourth statement that summarizes the main conclusions from this dissertation is:

\section{The concentration of facilities in urban areas has influenced equitable access to maternal care in Georgia}

The influence of the concentration of maternal care facilities on geographical and financial access was analyzed in Chapter 2, Chapter 3 and Chapter 4 of the dissertation. Our findings show that maternal care in Georgia is very complex and fragmented. There are 328 antenatal care providers and 86 maternal houses in the country where $30 \%$ of childbirth takes place. There are 59 secondary and eleven tertiary maternal houses in the country. Most of the facilities are concentrated in the capital. 22 secondary and tertiary facilities are in Tbilisi (172). However, the concentration of the maternal care facilities does not mean that all of them are providing good quality care. As Chapter 3 and 4 have shown, there are significant disparities in quality of maternal care provided by the facilities in the capital as well as in the regions. Moreover, our study indicates that pregnant women from the regions almost always prefer to utilize services in the capital.

Chapter 2 indicates that the concentration of the tertiary and secondary level facilities in the capital and big cities was inherited from the Soviet period. For example, during the late Soviet period and immediately after the independence, women's consultation centers' provided antenatal care to pregnant women on an outpatient basis, concentrated in the urban areas, and carried out outreach programs into the communities using ambulatory facilities. Moreover, childbirth services provided by the State maternal houses were also concentrated in urban settings (90). The first private obstetric clinics started after 1995 in urban areas and mostly in the capital. They provided obstetric and diagnostic services only based on OPPs (90).

Chapter 3 and Chapter 4 showed that the complexity and incontinence of the healthcare reforms lead to the deregulation and liberalization of the healthcare market (117). However, the Soviet tendency of the distribution of medical facilities was maintained after the independence. During the first wave of the reform, a publicbased tertiary maternal house was established in Tbilisi, in 2003. Since then, all pregnancy-related complications and near-miss cases were transported and managed in that particular maternal house (117). This fact, besides the above mentioned, supported pregnant women's perception that maternal care services are better in the capital than in the regions. As stated in Chapter 3 and Chapter 4, pregnant women from rural areas seek antenatal or natal services by themselves just to avoid complications. However, utilization of maternal care services in the capital or in the big cities entail 
direct and indirect cost, which increase the financial burden on pregnant women, compromise financial access and increase inequity.

As mentioned above, Chapter 3 and Chapter 4 indicate, that most pregnant women visit their "personal doctors" in the regional centers or in the capital. This is justifiable as most of the facilities are concentrated in the capital. Georgia always had high levels of medical staffing, particularly medical doctors (88). The number increased during the last decade and reached 705.6 per 100000 population in 2017. The number of obstetricians/gynaecologists has also increased from 38.0 in 2008 to 50.9 per 100000 population in 2017 (26). However, although there are a large number of obstetricians in the country, they are very unevenly distributed. There is a concentration of obstetricians in Tbilisi $(26,173)$. Remote and rural areas find it particularly difficult to recruit and retain obstetricians. Due to the lack of obstetricians, quality of care in the regions is compromised, as was shown in Chapter 4. In Chapter 5, we found that overall women in urban settings were more satisfied with antenatal and natal services than in rural areas. Basic maternal care services are ensured in the entire country. The maternal services in rural areas do not meet women's expectations.

Chapter 3 and Chapter 4 showed that the movement of pregnant women from rural areas to the big cities was determined by poor quality of maternal care in rural places. Moreover, all popular and experienced medical doctors are concentrated in the regional centers or in Tbilisi. Our studies explored that most women have a "personal doctor" in the big cities. The service of a "personal doctor" always related to OPPs, however, visiting the capital for utilization of this services also increases health associated expenditure for the households. Moreover, not everyone can afford to visit a medical doctor at the regional level or in the capital. Thus, the concentration of facilities in urban areas has a negative effect on equitable access to maternal care.

\section{Suggestion for further research:}

As explored by the dissertation, the concentration of maternal care facilities in urban places has a negative effect on geographical and financial access to maternal care services. More study on best practices should be done to explore how high-income countries ensure good quality of care in more remote areas.

The fifth statement that summarizes the main conclusions from this dissertation is:

\section{OPPs for maternal care in Georgia are associated with low satisfaction with maternal care.}


OPPs and their association with low satisfaction with maternal care are analyzed in Chapter 2, Chapter 4, Chapter 5 and Chapter 6. Our findings indicate that OPPs are a significant burden for pregnant women in Georgia. As presented in Chapter 2 and Chapter 4, since 2013, Georgia has implemented the UHC through the private healthcare sector. This reform has fundamentally altered the health system financing through the introduction of a single purchaser for the government's BBP. This replaced the previous system where competing private insurance companies provided a statefunded package of benefits to a tightly defined group of recipients (2). Most pregnant women have a "personal doctor" for antenatal as well as natal and immediate postnatal services and pay out of pocket. The cost of the services of "personal doctor" is quite high, as was shown in our study. However, an attempt to receive a good quality of maternal care is related not only with payment but also to healthcare delivery characteristics such as access and quality of care.

As Chapter 4 showed, that after the implementation of the UHC program, all citizens receive a universal basic package of high-quality health services, protection from financial risks, prevention of diseases and coverage of emergency care using globally approved mechanisms. The expenses for childbirth are, for all income groups, a part of the UHC program. Besides this, the State finances an antenatal care vertical program. Since the implementation of the UHC program, the State budget for health increased dramatically and reached US\$ 416 million in 2017 (26). The UHC program has made significant progress in improving financial access to health services; however, OPPs continue to dominate the THE (26).

Chapter 2 showed that since the independence, the health sector has been allocated a small share of GDP. The rapid transformation of the "Semashko" tax-based financing into financing through OPPs was accompanied by lower access, affordability and utilization of healthcare services. Consequently, morbidity and mortality increased in the early stages of the healthcare reforms. This resulted in general dissatisfaction among the population and mistrust of the health system. Till 2012, the emphasis was on targeting these limited resources to the poorest segment of the population. However, during the last stage of the reform, the emphasis has shifted to providing UHC. The UHC program has succeeded in reducing OPP spending in the health system. It decreased from $73 \%$ in 2010 to $57 \%$ in 2015 (113). Our study showed that in the deregulated and privatized health system, health facilities have established rates for service. For example, as Chapter 3 and Chapter 4 showed, the state established fixed costs for vaginal childbirth and $\mathrm{C}$-section. However, the prices for services differ from provider to provider and are mainly based on the perceived purchasing ability of the population served. Direct payments increase due to payments for a "personal doctor". Chapter 6 indicated that pregnant women pay for a "personal doctor" due to fear of 
pregnancy complications. They also pay out of pocket for extra care and attention form a "personal doctor" frequently as they are facing a lack of transfer of information during antenatal or natal care. As was discussed in this dissertation the maternal services in rural areas do not always meet women's expectation. These factors lead pregnant women to utilize services in big cities. That increases indirect and direct health services related to the cost. All this influence negatively the access to a good quality of maternal care services.

Chapter 4 and Chapter 5 showed that the State does not regulate the cost of healthcare services, but only fixes prices for medical intervention or/and lab examinations. However, most of the providers believe that the State pays less for services than the real cost. Chapter 4 discusses the attitude of some providers towards the State antenatal care program, and showed that some of them refuse to participate in the program due to the low reimbursement provided by the State. The facilities participate in the program mostly to motivate pregnant women to utilize more services than designated by the State. All these related to OPPs and increase the financial burden of the pregnant and their householders. OPPs are related to inequity in healthcare.

Chapter 3 showed that all income quartiles are paying out of pocket As after the implementation of the UHC program, all income groups are getting the same type of maternal care services and the same amount they are paying for additional services or a "personal doctor". Moreover, in Georgia, the cost of medicines is nearly three times higher than the average cost in other European countries (34) which is also directly linked to OPPs. The burden of OPPs is related to delays and avoidance of antenatal care services utilization and medications which are not included in the UHC program (Chapter 5). The presence of OPPs in maternal care constitutes a risk that may hamper the health and socio-economic protection of households and may also be an obstacle for achieving the goals of the UHC program. As presented in our findings, the average price for a C-section and physiological childbirth were 667.2 GEL and 385.3 GEL respectively. Later, the government included childbirth in the UHC program and is paying $600 \mathrm{GEL}$ and $800 \mathrm{GEL}$ for physiological childbirth and C-section respectively. The price fixed by the State is more than the average paid by the population. However, almost all maternal houses provide the same services for a higher price. Additionally, most pregnant women pay extra to cover the cost of a "personal doctor". As a result, OPPs for the antenatal, natal and immediate post-natal care are significant. Our findings indicate that the high price does not ensure high quality of maternal care services. Pregnant women and their households are paying out of pocket to get the best available services in the country. At the same time, those who pay are less satisfied and less motivated to recommend the services to others. That indicates that 
maternal care services are substandard and lead to an extra financial burden on pregnant women.

\section{Suggestion for further research:}

Further research on the factors affecting the presence of OPPs in maternal care should be undertaken to provide more evidence and explore the robustness of our results. The quantitative analysis could be extended by including other post-Soviet countries as well as indicators on economic and social-cultural factors. We recognize that the situational factors might play a crucial role in OPP policy. Hence, a study based on primary data might provide more insight into the context of UHC and maternal care policy.

\subsection{CONCLUDING REMARKS}

Our results show that maternal care was challenged by the healthcare reforms in Georgian. The need for enhancement of maternal care services in terms of quality, access and cost, is not recognized by healthcare providers and policy makers. As we mentioned above, to improve maternal health, action is required to ensure good quality maternal care for all women and girls, and to ensure access to comprehensive care. Police makers should implement the regulative mechanisms for advancing maternal care services. Recognizing the need of pregnant women can also facilitate the implementation of financialprotection.

As described in Chapter $1-6$, the Georgian maternal care system faces numerous challenges, including those resulting from the Soviet era. The healthcare reforms coupled with the overall improvement of the economic situation in the country, brought some positive changes, such as the replacement of the Soviet hospital infrastructure and a shift from curative care to more preventive healthcare programs. Maternal care was influenced positively by the healthcare reforms as well. However, there is more to be done to adequately address the maternal care problems. This requires a revision of the existing maternal care programs which would lead to substantial changes in the implementation of maternal care services. In doing so, a clear strategy for planning and managing the implementation of change is essential, especially, when estimation of those mother who can be potentially affected by the reform. 
Maternal care in Georgia is jointly funded by the UHC program and the vertical maternal care programs, as well as by OPPs. Geographical and financial access to basic maternal care services is ensured by the State maternal care programs. However, our results show some weaknesses in this policy, namely a high burden of OPPs, substandard quality of maternal care and lack of access to the comprehensive maternal care services. The government should not neglect those types of problems.

Furthermore, the current level of financial burden of maternal care can be decreased by a more effective exemption mechanism. Better targeting of vulnerable groups is the precursor for a better implementation of the exemption mechanism. Future policies should be more pro-poor oriented but also take in account accessibility and affordability. However, pregnant women face not only a financial burden but also poor quality of maternal care. The difficulties in the organization of maternal care also have observed in the absence of CPD. This dissertation has provided evidence on the quality, access and the cost of maternal care. Challenges of antenatal, natal and immediate post-natal care are reported. The inclusion of all stakeholders in improvement of the maternal care can decrease the problems.

The thirty years of maternal care reforms in the Georgian healthcare provide valuable lessons that should not be overlooked. Policy makers should learn from previous mistakes, establish feasible reforms that are be compatible with the time of implementation. Moreover, the maternal care reform should be logical, consequent and account for previous reform initiatives, leading to the implementation of continuity and comprehensive maternal care. 

Valorization 



\section{Introduction}

Maternal health depends on the functioning of the health system of a country, particularly, on the adequacy of maternal care services. With a background in medicine and global public health, the author of this dissertation is aware that maternal care is influenced by a complex set of factors. Empirically, maternal care services can be characterized along three dimensions: access to care, quality of care, and costs of care. However, to ensure financial and geographical access with good quality of maternal care, it is still a challenge for low- and middle-income countries. The shortcomings in access, quality and financing of maternal care that persisted during the transition period, are important factors attributable to the public health problems in Georgia. Therefore, a comprehensive analysis of these shortcomings is crucial to improve the health and well-being of mothers.

\section{Target audience}

During the last three decades, Georgia was challenged by healthcare reforms, which also influenced maternal health. The dissertation aims to increase our understanding of the financing, access, and quality of maternal care in Georgia. Thus, policymakers, hospital managers and medical doctors in the health system, are the prime target audiences of this dissertation, while reproductive age women and their households are the ultimate beneficiaries.

\section{Products and contents related to results}

This dissertation has determined that the absence of regulated market competition and cost control resulted in market failures in the Georgian health system. That leads to a poor quality of maternal care. The transition of the Georgian health system from the Semashko model to a privatized system had a positive influence on efficiency. However, this research found that due to the lack of regulatory control over the private market and the existence of information asymmetry, massive privatization without effective regulatory mechanisms, the absence of regulated market competition and cost control, resulted in market failures. The empirical findings suggest that healthcare reforms and public-private partnership with human capacity influence maternal care quality. The State implements free antenatal and natal care in the private sector without proper regulation. Moreover, there is no CPD for physicians in the country. All these contribute to substandard maternal care. The lack of medical skills and knowledge among medical staff is one of the reasons to utilize services of a 
"personal doctor". In the deregulated maternal care system, responsiveness of pregnant women and their household is high. A "do-it-yourself" approach was adopted by mothers and their relatives to address their demands and needs during antenatal, natal and immediate post-natal period. Therefore, overuse of maternal care services is one of the ways to get what is not guaranteed by the state. Most of the pregnant women pay extra to cover the cost of a "personal doctor". Our findings indicate that the high price does not ensure high quality of maternal care services. Pregnant women and their households are paying out of pocket to get the best available services in the country.

To improve quality of and access to maternal care services, establishment a regulatory mechanism and reimplementation of CPD is high priority. Furthermore, recognition of the needs of pregnant women and the implementation pro-poor oriented policies are crucial to facilitate desired outcome of maternal health. Based on the target stakeholders' opinion and effective evidence-based practices, this dissertation argues that deconcentrating the maternal care facilities from urban to the rural settings and equitable access to good quality maternal care for the entire population would improve efficiency and reduce unethical practices in the health system. These steps would promote the effective use of scarce public resources as well as protect populations from health-related expenditures. Additionally, instituting a national maternal care policy that would be logical, consequent and account for previous policies would improve maternal care in Georgia. This dissertation addressed loopholes in the overall maternal care reforms and proposes strategies to close them.

\section{Dissemination of products}

Effective implementation of the research findings depends on the motivation of policymakers, capacity building for maternal care providers, adequate regulation, policy creation and consensus building among key stakeholders. Depending on the context and feasibility, the following approaches are chosen to disseminate the research findings. The key findings of the dissertation will be discussed with and submitted to the National Council of Maternal and Child Health as well as MoLHSA and the Director General of the NCDC. To further dissemination the findings, a workshop will be arranged involving maternal care providers, medical doctors, representatives of Georgian Association of Obstetricians and Gynecologists. The dissertation will be presented to the country's developing partners, including WHO, UNFPA, UNICEF, World Bank and the Ambassador of the Kingdom of the Netherlands in Georgia. The candidate will play an active role in dissemination the results within following year successful completion of the PhD project. 


\section{Projected impacts}

The methodology of an inclusive approach to investigating access, quality and cost of maternal care services has a number of social and scientific implications, as it addresses macro and micro-environment factors of healthcare. The methodological approaches and findings will be applicable in cross-border settings with similar contexts. The methodological approaches and findings will be applicable in crossborder settings with similar contexts. The strategies for improving maternal care services are based on empirical findings, and the effects of these measures will be cross-checked with effective practices elsewhere. Moreover, a complete and in-depth understanding of access, quality and cost of maternal care services will reduce frustrations during analysis of maternal care services.

This project also illustrates the effects of health reforms in a post-Soviet country like Georgia and the factors underpinning these; additionally, being funded by the Dutch Government, this research itself serves as valuable input in the debate on the impact of globalization. This dissertation will provide a solid foundation for future researchers to investigate healthcare reforms in Georgia. Successful implementation of the recommendations with the necessary adaptations will ultimately contribute to equitable access to and quality of maternal care services, as well as to countries economic development.

Lastly, the candidate's motivation to play a role in promoting the maternal health of the global population though research and involvement in academia also contributes to achieving the vision and mission of Maastricht University. 

References 

1. World Health Organization. Sustainable Development Goals. 2016 Available from: https://www.un.org/sustainabledevelopment/ [Accessed 19th November 2017].

2. Gamkrelidze A, Atun R, Gotsadze G, MacLehose L. Healthcare Systems in Transition Georgia. World Health Organization. 2002. Volume 4.2 ${ }^{\text {nd }}$ edition.

3. The World Health Organization. Health in the post - 2015 United Nations development agenda. 2016. Available from: https://www.who.int/topics/millennium_development_goals/ post2015/en/[Accessed 21th November 2017].

4. The World Health Organization. The Global Strategy for Women's, Children's and Adolescents' Health (2016-2030). 2016

5. WHO. Quality, Equity, Dignity. The network to improve quality of care for maternal, new-born and child health. Strategic Objectives. Available from: https://apps.who.int/ iris/bitstream/handle/10665/272612/9789241513951-eng.pdf?ua=1 [Accessed 25th March 2018].

6. Chanturidze T, Ugulava T, Durán A, Ensor T, Richardson E. Health Systems in Transition Georgia. World Health Organization. 2009. Volume 11. 8th edition

7. Kissick W. Medicine's Dilemmas: Infinite Needs versus Finite Resources. Yale University Press. New Haven CT. 1994.

8. Berwick D, Nolan T, Whittington J. The Triple Aim: Care, Health and Cost. Health Affairs. 2008; 27(3):759- 669 .

9. Institute for Healthcare Improvement. The IHI Triple Aim. Available from: http://www.ihi.org/Engage/Initiatives/TripleAim/Pages/ [Accessed 26th March 2017].

10. The Vermont Business Roundtable. Can We Have It All? Balancing Access, Quality, and Cost in Healthcare. Available from: http://vbr.i9e.co/wp- content/uploads/sites/31/2015/08/ HCCanwehaveitall1999.pdf [Accessed 20th April 2017].

11. Berki S, Ashcraft M. HMO enrollment: who joins what and why: a review of the literature. The Milbank Memorial Fund Quarterly. Health and Society on JSTOR.1980; 58(4), 588-632.

12. Abiiro G, Allegri M. Universal health coverage from multiple perspectives: a synthesis of conceptual literature and global debates. 2015. BMC International Health and Human Rights.

13. Government of Georgia. About Georgia. 2018. Available from: http://gov.ge/ index.php?lang_id=ENG\&sec_id=193 [Accessed 10th November 2018].

14. National Statistics Office of Georgia. Living Conditions 2018. Available from: https://www.geostat.ge/en/modules/categories/316/population-and-demography [Accessed 21st February 2019].

15. UNICEF. Statistics Georgia. Available from: https://www.unicef.org/georgia/search? force $=0 \&$ query $=$ data\&search_date_range_picker $=\&$ created $\% 5 \mathrm{Bmin} \% 5 \mathrm{D}=\&$ created $\% 5 \mathrm{Bmax}$ $\% 5 \mathrm{D}=[$ Accessed 20st February 2017].

16. UNDP. About Georgia. Available from: http://www.ge.undp.org/content/georgia/en/ home/countryinfo/ [Accessed 19st January 2017].

17. Tamar Gotsadze T, Amaya A, Chikovani I, Gotsadze G. Transition From Global Fund Support and Programmatic Sustainability Research in Four CEE/CIS Countries Georgia Country Report. Curatio International Foundation. 2015

18. Rukhadze T. An overview of the healthcare system in Georgia: expert recommendations in the context of predictive, preventive and personalised medicine. EPMA Journal. 2013; 4(1): 8. 
19. Welfare Foundation. Civil Monitoring of Universal Healthcare Program Assessment of budget spending efficiency. 2016

20. Government of Georgia decree of December 302016 \#638 on Approval of state health programs for 2017. Available from: http://ssa.gov.ge/files/01_GEO/KANONMDEBLOBA/ Kanon\%20Qvemdebare/206.pdf [Accessed 10th June 2017].

21. The World Bank. Country Context 2017 Georgia. Available from: https://www.worldbank.org/en/country/georgia/overview. [Accessed 16th July 2017].

22. The World Bank. Word Development Indicators. Georgia 2017. Available from: https://www.worldbank.org/en/publication/wdr2017 [Accessed 16th July2017].

23. Government of Georgia. The State Concept 2014 - 2020 Universal Healthcare and Quality Management for Protection of Patients Rights. Ordinance No 724. December 26, 2014. Available from: https://matsne.gov.ge/en/document/view/2657250?publication=0 [Accessed 23th July 2018].

24. National Center for Disease Control and Public Health of Georgia. Statistic Yearbook 2016. Available from: http://www.ncdc.ge/Handlers/GetFile.ashx?ID=31eee2a3- 6bf5- 4558659b-a4b92f600555 [Accessed 6th May 2018].

25. National Center for Disease Control and Public Health of Georgia. Reproductive Age Women Mortality Survey 2014. Available from: http://www.ncdc.ge/Handlers/GetFile.ashx? ID =87835a52- 0a31- 4383-6d16-afffdaa84d91 [Accessed 21st March 2017]

26. Richardson E, Berdzuli N. Health Systems in Transition. Georgia. World Health Organization. 2017; Volume10.

27. National Center for Disease Control and Public Health of Georgia. Reproductive Age Mortality Survey Georgia. 2008. Available from: http://www.ncdc.ge/Handlers/ GetFile.ashx?ID=b9b2ef94-a053-470f-6864-0dcde3fa66d0. [Accessed 10th February 2016]

28. Gvedashvili N. Reducing maternal mortality in Georgia. Global voices: Caucasus. 2016. Institute for War and Peace Reporting

29. Would Health Organization. 2010. The World Health Report. Health Systems Financing. The path to universal coverage

30. National Center for Disease Control and Public Health of Georgia. Reproductive health survey of Georgia 2000. Available from: http://www.ncdc.ge/Handlers/ GetFile.ashx? ID=0427be87-dd57-4a55- 6b86-69d1f52130e3 [Accessed 12th June 2017].

31. National Center for Disease Control and Public Health of Georgia. Reproductive health survey of Georgia 2005. Available from: http://www.ncdc.ge/Handlers/GetFile.ashx? ID=0ae0ab5f- 0c1c- 455f-a5e6- 5818e3f89c59 [Accessed 12th June 2017].

32. The World Health Organization. Antenatal care randomized trial: manual for the implementation of the new model. Available from: (http://www.who.int/ reproductivehealth/publications/maternal_perinatal_health/RHR_01_30/en/) [Accessed 11st April 2017].

33. The World Health Organization. World Health Statistics 2017: Monitoring health for the SDGs. Available from: https://apps.who.int/iris/bitstream/handle/10665/255336/ 9789241565486-eng.pdf?sequence=1\&isAllowed=y [Accessed 23th Septemeber 2018].

34. Witter S, Adjei S, Armar-Klemesu M, Graham W. 2018. Providing free maternal healthcare: ten lessons from an evaluation of the national delivery exemption policy in Ghana. Global Health Action. 2009; 2: 10.3402/gha.v2i0.1881.

35. The World Health Organization. WHO recommendations Intrapartum care for a positive childbirth experience. Available from: https://apps.who.int/iris/bitstream/handle/10665/ 260178/9789241550215- eng.pdf?sequence=1 [Accessed 14th Septemeber 2018]. 
36. Berki S, Ashcraft M. HMO enrollment: who joins what and why: a review of the literature. The Milbank Memorial Fund Quarterly Health and Society. 1980; 58(4), 588- 632.

37. Abiiro G, Allegri M. Universal health coverage from multiple perspectives: a synthesis of conceptual literature and global debates. BMC International Health and Human Rights. 2015;15.

38. Hulka B, Cassel J, Kupper L, Burdette J. Communication, compliance, and concordance between physicians and patients with prescribed medications. American Journal of Public Health. 1976;66:847-53.

39. Linder-Pelz S. Toward a theory of patient satisfaction. Social Science \& Medicine. 1982; 16:577-582.

40. Williams B. Patient satisfaction: a valid concept? Social Science and Medicine. 1994; 38:50916.

41. Dencker A, Taft C, Bergqvist L, Lilja H, Berg M. Childbirth experience questionnaire (CEQ): development and evaluation of a multidimensional instrument. BMC Pregnancy Childbirth. 2010;10:81.

42. Uhlmann R, Inui T, Carter W. Patient requests and expectations. Definitions and clinical applications. Medical Care. 1984; 22:681-5.

43. Alazri $M, N e a l ~ R$. The association between satisfaction with services provided in primary care and outcomes in Type 2 diabetes mellitus. Diabetic Medicine. 2003; 20:486-90.

44. Linn MW, Linn BS, Stein SR. Satisfaction with ambulatory care and compliance in older patients. Medical Care. 1982; 20:606-14.

45. Kerr EA, Hays RD, Mitchinson A, Lee M, Siu AL. The influence of gatekeeping and utilization review on patient satisfaction. Journal General Internal Medicine.1999;14:287-96.

46. Schauffler $\mathrm{HH}$, Rodriguez T. Availability and utilization of health promotion programs and satisfaction with health plan. Medical Care. 1994; 32:1182-96.

47. Borowsky SJ, Cowper DC. Dual use of VA and non-VA primary care. Journal General Internal Medicine. 1999; 14:274-80.

48. Rubin H, Gandek B, Rogers W, Kosinski M, McHorney C, Ware J. Patients' ratings of outpatient visits in different practice settings. Results from the Medical Outcomes Study. Journal of the American Medical Association. 1993; 270: 835-40.

49. Hall J, Dornan MC. What patients like about their medical care and how often they are asked: a meta-analysis of the satisfaction literature. Social Science and Medicine.. 1988; 27:935-9.

50. Hall J, Irish J, Roter D, Ehrlich C, Miller L. Satisfaction, gender, and communication in medical visits. Medical Care. 1994; 32: 1216-31

51. Israel G. Determining sample size. Available from: http://scholar.google.nl/scholar_url? url=http://zulsidi.tripod.com/pdf/Determining

SampleSizes.pdf\&hl=en\&sa=X\&scisig=AAGBfm3TI-- $\quad$ 19NxQAhETQhOB89eewl7jJw\&nossl $=1 \& o i=s c h o l a r r \& v e d=0 a h U K E w i t g 4 Y 7 a \_Q A h V C K s A K H R I Z A X A Q g A M I K C g A M$ AA. [Accessed 4th October 2018].

52. Balabanova D, McKee M, Pomerleau J, Rose R, Haerpfer $C$. Health service utilization in the former Soviet Union: Evidence from eight countries. Health Service Research. 2004; 39: 1927- 1950.

53. Badurashvili I, McKee M, Tsuladze G, Meslé F, Vallin J, Shkolnikov V. Where there are no data: What has happened to life expectancy in Georgia since 1990? Public Health. 2001; 115: 394- 400 . 
54. World Health Organization. The World Health Report 2000. Health Systems: Improving performance. Available from: https://www.who.int/whr/2000/en/whr00_en.pdf?ua=1 [Accessed 5th March 2016].

55. Rowland D, Telyukov A. Soviet healthcare from two prospective. Health Affairs. 1991; 3: 71- 66.

56. Latsis O. Progress of economic reform in The USSR. World Marxist Review. 1989.

57. Telyukov A, Caper P. The year after Kobuleti: What difference does it make? PubMed. 1991;19: 167- 66.

58. Tabata Sh, Fiscal Policy and Tax System. Economic and Social Research Institute.2001

59. Mossialos E, Dixon A, Figueras J, Kutzin J. Funding healthcare: Options for Europe. European Observatoryon HealthcareSystem Series, GreatBritain. 2002.

60. Collins T. The aftermath of health sector reform in the Republic of Georgia: Effects on people's health. Journal Community Health. 2003; 28: 99- 113.

61. Kalandadze T, Bregvadze I, Takaishvili R, Archvadze A, Moroshkina N. Development of State Health Insurance System in Georgia. CroatianMedical Journal 1999; 40: 216- 220.

62. Gotsadze G, Zoidze A, Rukhadze N. Household catastrophic health expenditure: Evidence from Georgia and its policy implications. BMC Health Services Research. 2009; 9: 69

63. Veillard J, Champagne F, Klazinga N, KazandjianV, Arah A. A performance assessment framework for hospitals: The WHO regional office for Europe PATH project. International Journal for Quality in Healthcare. 2005; 17: 487- 496

64. Djakeli K. The Georgian Healthcare Reforms Before and After Rose Revolution. Fulbright Scholar at Yale University, School of Public Health. 2011.

65. World Health Organization. Georgia health system performance assessment. 2009. Available from: http://www.euro.who.int/_data/assets/pdf_file/0012/43311/E92960.pdf [Accessed 5th March 2016].

66. Kalandadze T, Bregvadze I, Takaishvili R, Archvadze A, Moroshkina N. Development of State Health Insurance System in Georgia. State of Georgia Medical Insurance Company. 1999; 40: 2

67. World Bank. Georgia Statistics. Available from: https://www.worldbank.org/en/country/ georgia [Accessed 10th May2015].

68. World Health Organization. Georgia-Country Profile. Available from: https://www.who.int/ countries/geo/en/ [Accessed 10th May 2015].

69. Ministry of Internal Displaced Persons from Occupied Teritories, Labor, Health and Social Affairs. Expectations always exceed the reality in healthcare 2014. Available from: https://www.moh.gov.ge/ka/453/ [Accessed 15th May 2015].

70. Critical Appraisal of Systematic Reviews. Available from: https://casp-uk.net/ [Accessed 23th June 2016].

71. Ministry of Internal Displaced Persons from Occupied Teritories, Labor, Health and Social Affairs. Health for All. Available from: http://ssa.gov.ge/index.php?lang_id=\&sec_id=888 [Accessed 15th May 2015].

72. Ministry of Financing of Georgia. Budget of the Country and financial grows [in Georgian. Available from: https://www.mof.ge/en/4545 [Accessed 9th April 2017].

73. Khishtovani G. Predicted financial impact of the healthcare reforms on private insurance companiesbetween 2006-2013in Georgia-The CaseofAldagi-BCl. Working Paper. 
74. Curatio International Foundation. Barometer of healthcare system of Georgia. Available from: http://curatiofoundation.org/experts-evaluations-of-changes-taking-place-in-thehealthcare/ [Accessed 10th April 2016].

75. Jorbenadze A, Zoidze A, Gzirirshvili D, Gotsadze G, (1999) Health reform and hospital financing in Georgia. Curatio International Foundation. 40: 2.

76. The National Desease Control and Public Health Center of Georgia. (2012) Healthcare Statistical Year Book. Available from: http://www.ncdc.ge/Handlers/GetFile.ashx? ID=3d7deed7-ca5b- 4f14- 601f- 922ef3aadc9d [Accessed 19th May 2015].

77. Schecter K. The privatization of the Georgian healthcare system. American International HealthAllianceAnthropologyofEastEuropeReview.2011;29.

78. Hou X, Chao S. An evaluation of the initial impact of the medical assistance program for the poor in Georgia. Policy Research Working Paper. World Bank. 2008

79. Djibuti M, Shakarishvili R. Influence of clinical, demographic and socioeconomic variables on quality of life in patients with epilepsy: Findings from Georgian study. NeurolNeurosurg Psychiatry. 2003; 74:570- 573.

80. Zoidze A, Rukhadze N, Chkhatarashvili K, Gotsadze G. Health insurance for poor: Georgia's path to universal coverage? Curatio International Foundation. 2012.

81. Gotsadze G, Bennett S, Ranson K, Gzirishvili D. Healthcare-seeking behavior and out-ofpocket payments in Tbilisi, Georgia. Curatio International Foundation. 2005.

82. Skarbinski J, Walker H, Baker L, Kobaladze A, Kirtava Z. The burden of out-of- pocket payments for healthcare in Tbilisi. The Journal of the American Medical Association. 2002;287(8):1043-6

83. Gotsadze G, Zoidze A, Vasadze O. Reform strategies in Georgia and their impact on healthcare provision in rural areas: Evidence from a household survey. Social Science and Medicine. 2005; Feb;60(4):809-21.

84. Gotsadze G, Cashin C, Zoidze A, Valdin J. Descriptive background to healthcare financing reform strategy developing Georgia. HCF Discussion Paper. 2005.

85. Bonilla-Chacin E, Murrugarra E, Temourov M. Healthcare during transition and health systems reform: Evidence from the poorest CIS countries. Social Policy and Administration. 2005; 39(4):381 - 408

86. Jugens E, Shengelia L, Asatiani T, Bijlmakers L. Clients' and providers' perspectives on Caesarean sections. An operational study into the high Caesarean Section rate in Georgia. Tbilisi. 2011.

87. The Ministry of Internal Displaced Persons from Occupied Teritories, Labor, Health and Social Affairs. Assessment of the perinatal healthcare system 2013. Available from: https://www.moh.gov.ge/ka/671/dedaTa-da-bavSvTa-janmrTeloba-perinataluri-regionalizacia \{Accessed 9th July 2016]

88. John Snow Incorporation. Sustain Final Report Georgia. USAID Publishing. Available from: https://www.jsi.com/JSIInternet/Resources/publication/display.cfm?txtGeoArea=INTL\&id $=16338$ \& thisSection=Resources [Accessed 8th March 2018].

89. WHO. 2015. WHO, UNICEF, UNFPA, World Bank Group and the United Nations Population Division. Trends in MaternalMortality: 1990 to 2015. 2015. WHO /RHR/15.23

90. National Center for Disease Control and Public Health of Georgia. Reproductive health survey of Georgia 2010. Available from: http://www.ncdc.ge/Handlers/GetFile.ashx? $I D=5$ ef5f86a- 62f8- 431c- 6c23-6cc58c207e3b [Accessed 12th June 2017]. 
91. Gzirishvili D, Mataradze G. Healthcare Reforms in Georgia: An Analytical Overview. United Nations Children's Fund. 2015. Available from: http://webcache.googleusercontent.com/ search?q=cache:IODozc6Yge4J:curatiofoundation.org/wp-content/uploads/2015/09/ 117. pdf $+\& c d=1 \& h l=e n \& c t=c \mid n k \& g l=g e$ [Accessed 9th June 2017].

92. Gotsadze G, Mataradze G, Zoidze A. A Study of Georgian Healthcare Financing: Impacts of Alternative Options. 1998. Tbilisi,Georgia.

93. National Statistics Office of Georgia. Census 2002. Available from: https://www.geostat.ge/ en/page/shinameurneobebi-da-fizikuri-pirebi [Accessed 10th June 2017].

94. State Statistical Committee of the Republic of Azerbaijan. Demographic and Health Survey. 2006. Available from: http://ghdx.healthdata.org/record/azerbaijan-demographic-andhealth-survey- 2006 [Accessed 24th April 2018]

95. National Statistical Service of the Republic of Armenia. (2005). Demographic and Health Survey. Available from: https://microdata.worldbank.org/index.php/catalog/1324 [Accessed 24th April 2018]

96. International Monetary Fund and World Bank. Recent Policies and Performance of the LowIncome CIS Countries: an Update of the CIS- 6 Initiative. 2004. Available at http://www.imf.org/external/np/oth/042304.pdf [Accessed 12th July 2016].

97. Division of Reproductive Health Centers for Disease Control and Prevention. Atlanta Reproductive, Maternal and Child Health in Eastern Europe and Eurasia: A ASTERN Comparative Report. Atlanta, GA 30333 USA. 2003. Available from: https://dhsprogram.com/pubs/pdf/OD28/00FrontMatter.pdf\#[1,\{\%22name\%22:\%2 2FitH\%22\},787]. [Accessed 9th January 2016]

98. CoReform Project. Review and Analysis of Reproductive Health Legislation and Policy in Georgia. USAID. 2005.Tbilisi, Georgia

99. Shengelia L, Pavlova M, Groot W. Impact of Healthcare Reform on Universal Coverage in Georgia: A Systematic Review. Diversity and Equality in Health and Care. 2016. 13(5): 349- 356

100. National Center for Disease Control and Public Health of Georgia. Reproductive Age Mortality Survey Georgia. 2008. Available from: http://www.ncdc.ge/Handlers/ GetFile.ashx?ID=b9b2ef94-a053- 470f- 6864- 0dcde3fa66d0. [Accessed 10th February 2016]

101. Parkhurst J, Penn-Kekana L, Blaauw D, Balabanova D, Danishevski K, Rahman S, Onama V, Ssengooba $F$. Health systems factors influencing maternal health services: a four-country comparison. Health Policy. 2005; 73 127-138

102. Rishardson E. Health Systems in Transition Armenia. World Health Organization. 2013. volume 15. 4th edition. Available from:

http://www.euro.who.int/_data/assets/pdf_file/0008/234935/HiT- Armenia.pdf?ua=1. [Accessed 19th March 2017]

103. Ibrahimov F, Ibrahimova A, Kehler J, Rishardson E. Health Systems in Transition Azerbaijan. World Health Organization. 2010; volume 12. 3th edition. Available from: http://www.euro.who.int/ data/assets/pdf_file/0004/118156/E94132.pdf [Accessed 30th April 2016]

104. Lekhan V, Rudiy V, Shevchenko M, Kaluski N, Rishardson E. Health Systems in Transition Armenia. World Health Organization. 2013. Volume 15. 4nd edition. Available from: http://www.euro.who.int/_data/assets/pdf_file/0008/234935/HiT-Armenia.pdf?ua=1 [Accessed 30th April 2016] 
105. Popovich L, Potapchik E, Shishkin S, Rishardson E, Vacroux A, Mathivet B. Health Systems in Transition Russia. World Health Organization. 2011. Volume 17. 2nd edition. http://www.euro.who.int/_data/assets/pdf_file/0006/157092/HiT- Russia_EN_web-withlinks.pdf?ua=1 [Accessed 30th April 2016]

106. World Health Organization. WHO Statement on Caesarean Section Rates. 2015. Available from: https://apps.who.int/iris/bitstream/handle/10665/161442/WHO_RHR_15.02_eng.p df?sequence $=1$ [Accessed 5th April 2017]

107. World Health Organization. Millennium development goals 4 and 5. Available from: https://www.who.int/pmnch/about/about_mdgs/en/ [Accessed 16th May 2016]

108. Evans D. Universal health coverage and universal access. World Health Organization. 2013;546(91):8.

109. World Health Organization. Indicator and monitoring framework for the global strategy for Women's, Children's and Adolescents' health. Available from: https://www.who.int/lifecourse/publications/gs-Indicator-and-monitoring- framework.pdf [Accessed 16th May 2016]

110. Ministry of Internally Displaced Persons from the Occupied Territories, Labour, Health and Social Affairs of Georgia. Healthcare annual Reprot. Available from: https://www.moh.gov.ge/ka/453/[Accessed 13th June 2017]

111. World Health Organization. Georgia. Statistics 2017. Available from: http://www.euro.who.int/en/countries/georgia [Accessed 19th June2018]

112. National Center for Disease Control and Public Health of Georgia. Maternal and child health state program. 2016. Available from: http://www.ncdc.ge/Pages/User/ Documents.aspx?ID=7c83b393-fc53-4a66-bf65- ebb58fc98d5e\&language=ka-GE [Accessed 8th August 2017]

113. Huby M, Bradshaw J, Gugushvili D. How do Georgian children and their families cope with the impact of the financial crisis? Report on the Georgia welfare monitoring survey 2009. UNICEF.

114. Hsieh $\mathrm{H}$, Shannon S. Three approaches to qualitative content analysis. Qualitative Health Research. 2005;15(9):1277-88.

115. Bernard HR, Ryan GW, Wutich AY. Analyzing qualitative data, systematic approach. London: SAGE Publications; 2010.

116. Maarse $\mathrm{H}$. The privatization of healthcare in Europe: an eight-country analysis. Health Politics, Policy and Law. 2006; 31(5):981- 1014.

117. Belli $P$, Gotsadze G, Shahriari H. Out-of-pocket and informal payments in health sector: evidence from Georgia. Health Policy. 2004;70(1):109-23.

118. Cohen N. Informal payments for healthcare - the phenomenon and its context. Health Economics Policy Law. 2012;7(03):285-308.

119. Stepurko T, Pavlova M, Levenets O, Gryga I, Groot W. Informal patient payments in maternal hospitals in Kiev, Ukraine. The International Journal of Health Planning and Management. 2013;28(2):e169-e87.

120. Shengelia L, Trapaidze D, Chiraqadze S, Sturua L. Epidemiological surveillance of maternal mortality 2014. National Center for Disease Control and Public Health of Georgia.

121. Brolan C, Hill P. Universal health Coverage's evolving location in the post - 2015 development agenda: key informant perspectives within multilateral and related agencies during the first phase of post - 2015 negotiations. Health Policy and Planning. 2016;31(4):514-21. 
122. National Center for Disease Control and Public Health of Georgia. Healthcare statistical yearbook 2014. Available from: http://www.ncdc.ge/Handlers/GetFile.ashx?ID=989ce6996b6b-4bb8-66df- 70c7125595a6 [Accessed 2nd February 2015]

123. The American College of Obstetrics and Gynecologists. Cesarean delivery on maternal request. Available from: https://www.acog.org/Clinical-Guidance-and-Publications/ Committee-Opinions/Committee-on-Obstetric-Practice/Cesarean-Delivery-on-MaternalRequest?IsMobileSet=false [Accessed 13th March 2015]

124. World Health Organization. Maternal and new-born health. Available from: http://www.euro.who.int/en/health-topics/Life-stages/maternal-and-new-born- health [Accessed 28th March 2017]

125. World Health Organization. Promoting Effective Perinatal Care Essential Antenatal, Perinatal and Postpartum Care. Available from: http://www.euro.who.int/data/assets/pdf_file/ 0013/131521/E79235.pdf [Accessed 20th February 2016]

126. National Center for Disease Control and Public Health of Georgia. Healthcare Statistical Yearbook 2015. Available from: [Accessed 14th March 2016]

127. Filippi V, Ronsmans C, Campbell OM, Graham WJ, Mills A, Borghi J, Koblinsky M, Osrin D. Maternal health in poor countries: the broader context and a call for action. 2006. The Lancet. 368 (9546), 1535- 1541.

128. Soltani H, Fair F, Hakimi S. Reduction in global maternal mortality rate 1990- 2012: Iran as a case example. Midwifery. 2015; 31(2), 271-273.15

129. UNFPA. UNFPA and Iran's MoLHSA Mark International Day of the Midwife Retrieved from. Available from: https://asiapacific.unfpa.org/en/news/unfpa-and- iran\%E2\%80\%99sministry-health-mark-international-day-midwife [Accessed 11st Septemeber 2017]

130. Roy A, Weijden T, Vries N. Predictors and consequences of rural clients' satisfaction level in the district healthcare system of Bangladesh. Global Health Research and Policy. 2017; 2: 31.

131. Hekkert KD, Cihangir S, Kleefstra SM, van den Berg B, Kool RB. Patient satisfaction revisited: a multilevel approach. Soc Sci Med. 2009;69:68-75.

132. Birk H, Gut R, Henriksen L. Patients' experience of choosing an outpatient clinic in one county in Denmark: results of a patient survey. BMC Health Services Research 2011;11:1.

133. Goodman P, Mackey M, Tavakoli A. Factors related to childbirth satisfaction. Issues and Innovations in Nursing Practice. 2004, 46:212-219.

134. Department of Health. Equity and excellence. Available from: https://assets.publishing. service.gov.uk/government/uploads/system/uploads/attachment_data/file/213823/ dh_117794.pdf [Accessed 1st October 2018]

135. Hodnett E. Pain and women's satisfaction with the experience of childbirth: a systematic review. American JournalofObstetrics \& Gynecology. 2002, 186:160- 172.

136. Redshaw M. Women as consumers of maternal care: measuring "satisfaction" or "dissatisfaction"? Birth. 2008, 35:73-76.

137. Harvey S, Rach D, Stainton M, Jarrell J, Brant R. Evaluation of satisfaction with midwifery care. Midwifery. 2002, 18:260-267.

138. Waldenstrom U, Hildingsson I, Rubertsson C, Radestad I: A negative birth experience: prevalence and risk factors in a national sample. Birth. 2004, 31:17-26.

139. Bleich SN, Ozaltin E, Murray CJ. How does satisfaction with the health-care system relate to patient experience? Bulletin World Health Organization. 2009; 87: 271-8. 
140. Bjertnaes OA, Sjetne IS, Iversen HH. Overall patient satisfaction with hospitals: effects of patient-reported experiences and fulfilment of expectations. BMJ Quality and Safety. 2012; 21:39-46.

141. Dencker A, Taft C, Bergqvist L, Lilja H, Berg M: Childbirth experience questionnaire (CEQ): development and evaluation of a multidimensional instrument. BMC Pregnancy Childbirth. 2010;10:81.

142. Bramadat I, Driedger M. Satisfaction with childbirth: theories and methods of measurement. Birth 1993; 20(I):22-29.

143. Haines $\mathrm{H}$, Hildingsson I, Pallant J, Rubertsson C. The role of women's attitudinal profiles in satisfaction with the quality of their antenatal and intrapartum care. Journal of Obstetric, Gynecologic, Neonatal Nursing. 2013; 42(4):428-41.

144. World Health Organization. Making Pregnancy Safer: The Critical Role of the Skilled Attendant: AJoint Statement by WHO, ICM, FIGO. Geneva, Switzerland: WHO; 2004.

145. Donabedian A. Evaluating the quality of medical care. The Milbank Quarterly, 83(4), 691729. 2005

146. Choi KS, Cho, WH, Lee $\mathrm{S}$, Lee $\mathrm{H}$, Kim C. The relationships among quality, value, satisfaction and behavioral intention in healthcare provider choice: A South Korean study. Journal of Business Research, 57 (8), 913-921. 2004

147. Georgian Statistics Office of Georgia. Country statistics. 2017. Available from: https://www.geostat.ge/en [Accessed 4th October 2018].

148. Carquillat P, Vendittelli F, Perneger Th, Guittier M, Development of a questionnaire for assessing the childbirth experience (QACE). BMC Pregnancy Childbirth. 2017; 17: 279.

149. Fawole A, Okunlola M, Adekunle A. Clients' Perceptions of the Quality of Antenatal Care. 2008;100(9):1052- 6 .

150. Ministry of Internal Displaced People from Occupied Territories, Labour, Health and Social Affairs of Georgia. Order N660. 2015. Available from: https://www.moh.gov.ge/en/459/ [Accessed 7th December 2018].

151. World Health Organization. 2018. WHO recommendations on antenatal care for a positive pregnancy experience. Available from: https://www.who.int/ reproductivehealth/ publications/maternal_perinatal_health/anc-positive-pregnancy-experience/en/[Accessed 15th March 2019].

152. Hildingsson I, Radestad I. Swedish women's satisfaction with medical and emotional aspects of antenatal care. Journal of Advanced Nursing. 2004; 52(3):239-249

153. Esimai O, Omoniyi-Esan G. Wait time and service satisfaction at Antenatal Clinic, Obafemi Awolowo University lle-Ife. East African Journal of Public Health. 2009. 6(3):312-314

154. Feranti D. Paying for Health Services in Developing Countries. World BankStaff Working Papers 721. Available from: http://documents.worldbank.org/curated/en/ 485471468739208102/ Paying-for-health-services-in-developing-countries-an-overview [Accessed 12th April 2016].

155. Akin J, Birdsall N, Ferranti DM. Financing Health Services in Developing Countries: An 1985Agenda for Reform. World Bank Publishing. 1987. Volume 34.

156. Peyrot M, Cooper P, Schnapf D. A consumer satisfaction and perceived quality of outpatient health services. Journal of Healthcare Marketing. 1993;13:24-33.

157. Davis C., 1983. The economics of the Soviet health system. In: U.S. Congress, Joint Economic Committee, The Sovieteconomy in the 1980's: problems and prospects. Washington, DC, United States Government Printing Office:228-264. 
158. Kaser M., 1976. Healthcare in the Soviet Union and eastern Europe. British Medical Journal.

159. Field M, Kotz D, Bukhman G. The Health and Demographic Crisis in Post-Soviet Russia: A Two-Phase Development. Russia's Torn Safety Nets. Palgrave Macmillan, New York. 2000.

160. Kim JY, Millen JV, Irwin A, Gershman J. Dying for growth: global inequality and the health of the poor. Common Courage Press. 1st edition: 2000; 155-173.

161. Ryan M. The organization of Soviet medical care. Journal of Social Policy. Volume 8, Issue 3. 1979; pp. 422- 423

162. Davis $\mathrm{C}$. The organization and performance of the contemporary Soviet health system. In: Lapidus G, Swanson G, eds. State and welfare, USA/ USSR: contemporary policy and practice. Berkeley, CA, University of California Berkeley Institute of International Studies: 1988; 95-142.

163. Davis C. The Soviet health system: a national health service in a socialist society. In: Field $\mathrm{M}$, ed. Success and crisis in national health systems: a comparative approach. London, Routledge: 1989; 233-262.

164. Kutzin J, Cashin Ch, Jakab M. Implementing Health Financing Reform. Lessons from countries in transition. World Health Organization.2010.

165. Schöpflin G. 1993. Politics in eastern Europe 1st Edition. Oxford, Blackwell.

166. Gregory P, Stuart R. Comparative economic systems, 6th Ednition. Boston, Houghton Mifflin. Oxford living dictionary. 1999.

167. Baranov A., Maternal and child health Problems in the USSR. Archives of Disease in Childhood. 1991; 66: 542- 545

168. Jenkins MG, Ford JB, Todd AL, Forsyth R, Morris JM, Roberts M, Christine L. Women's views about maternal care: how do women conceptualise the process of continuity? Midwifery. 2015; Volume 31, Issue: 1, Page: 25- 30

169. Reducing Maternal Mortality and Morbidity. Improving Birth Outcomes: Meeting the Challenge in the Developing World. The Natural Academy Press. 2003.

170. Ministry of Internally Displaced Persons from the Occupied Territories, Labour, Health and Social Affairs of Georgia. Regionalization of Perinatal Care Services. 2018. https://www.moh.gov.ge/ka/671/dedaTa-da-bavSvTa-janmrTeloba- perinataluriregionalizacia

171. National Center for Disease Control and Public Health of Georgia. Health Statistics 2017. Available from: http://www.ncdc.ge/Handlers/GetFile.ashx?ID=114b7ef6- 0fa1- 424a6c01- 6af08ffa63cc [Accessed 18 Septemeber 2018]

172. Oxford Policy Management. Planning human resources for health in Georgia. OPM-DFID PHC Reform. Support Programme: Discussion Paper. Oxford, Oxford Policy Management.

173. World Bank. Georgia Public Expenditure Review: Building a Sustainable Future Report No: 114062-GE. Washington DC, World Bank Group. 2017 
Appendix 



\section{APPENDIX 1. LIST OF EVIDENCE-BASED PUBLICATION INCLUDED IN THE REVIEW}

1. Balabanova D, McKee M, Pomerleau J, Rose R, Haerpfer C. Health service utilization in the former Soviet Union: Evidence from eight countries. Health Service Research. 2004; 39: 1927- 1950.

2. Badurashvili I, McKee M, Tsuladze G, Meslé F, Vallin J, Shkolnikov V. Where there are no data: What has happened to life expectancy in Georgia since 1990? Public Health. 2001; 115: 394- 400.

3. World Health Organization. The World Health Report 2000. Health Systems: Improving performance. Available from: https://www.who.int/whr/2000/en/whr00_en.pdf?ua=1

4. Rowland D, Telyukov A. Soviet healthcare from two prospective. Health Affairs. 1999; 3: 71- 66.

5. Latsis O. Progress of economic reform in The USSR. World Marxist Review. 1989.

6. Telyukov A, Caper P. The year after Kobuleti: What difference does it make? PubMed. 1999;19: 167- 66.

7. Kalandadze T, Bregvadze I, Takaishvili R, Archvadze A, Moroshkina N. Development of State Health Insurance System in Georgia. State of Georgia Medical Insurance Company. 1999; 40: 2

8. Jorbenadze A, Zoidze A, Gzirirshvili D, Gotsadze G, Health reform and hospital financing in Georgia. 1999.Curatio International Foundation. 40:2.

9. Tabata Sh, Fiscal Policy and Tax System. Economic and Social Research Institute. 2001

10. Mossialos E, Dixon A, Figueras J, Kutzin J. Funding healthcare: Options for Europe. European Observatory on Healthcare System Series, Great Britain. 2002.

11. Gamkrelidze A, Atun R, Gotsadze G, MacLehose L. Healthcare Systems in Transition Georgia. World Health Organization. 2002. Volume 4. $2^{\text {nd }}$ edition.

12. Collins T. The aftermath of health sector reform in the Republic of Georgia: Effects on people's health. Journal Community Health. 2003; 28: 99-113.

13. Gotsadze G, Zoidze A, Rukhadze N. Household catastrophic health expenditure: Evidence from Georgia and its policy implications. BMC Health Services Research. 2009; 9: 69

14. Veillard J, Champagne F, Klazinga N, KazandjianV, Arah A. A performance assessment framework for hospitals: The WHO regional office for Europe PATH project. International Journal for Quality in Healthcare. 2005; 17: 487- 496

15. Djakeli K. The Georgian Healthcare Reforms Before and After Rose Revolution. Fulbright Scholar at Yale University, School of Public Health. 2011.

16. Chanturidze T, Ugulava T, Durán A, Ensor T, Richardson E. Health Systems in Transition Georgia. World Health Organization. 2009. Volume 11. 8th edition

17. World Health Organization. Georgia health system performance assessment. 2009. Available from: http://www.euro.who.int/data/assets/pdf_file/0012/43311/ E92960.pdf

18. World Bank. Georgia Statistics. 2015. Available from: https://www.worldbank.org/en/ country/georgia

19. World Health Organization. Georgia-Country Profile. 2016. Available from: https://www.who.int/countries/geo/en/

20. Ministry of Internal Displaced Persons from Occupied Teritories, Labor, Health and Social Affairs. Expectations always exceed the reality in healthcare 2014. Available from: 
https://www.moh.gov.ge/ka/453/

21. World Health Organization. Poverty and social exclusion in the WHO European Region: Health Systems Respond. 2010.42- 51.

22. Ministry of Internal Displaced Persons from Occupied Teritories, Labor, Health and Social Affairs. Health for All. Available from: http://ssa.gov.ge/index.php? lang_id=\&sec_id=888

23. Ministry of Financing of Georgia. Budget of the Country and financial grows [in Georgian. Available from: https://www.mof.ge/en/4545

24. Agency of Social Affairs of Georgia. The State Program Health for All. 2014

25. Khishtovani G. Predicted financial impact of the healthcare reforms on private insurance companiesbetween2006 - 2013inGeorgia-TheCaseofAldagi-BCI.Working Paper.

26. Curatio International Foundation. Barometer of healthcare system of Georgia. 2017. Available from: http://curatiofoundation.org/experts-evaluations-of-changes-takingplace-in-the-healthcare/

27. The National Desease Control and Public Health Center of Georgia. Healthcare Statistical Year Book. 2012. Available from: http://www.ncdc.ge/Handlers/GetFile.ashx? ID=3d7deed7-ca5b-4f14-601f- 922ef3aadc9d

28. Schecter K. The privatization of the Georgian healthcare system. American International Health Alliance Anthropology of East Europe Review. 2011; 29.

29. Hou X, Chao S. An evaluation of the initial impact of the medical assistance program for the poor in Georgia. Policy Research Working Paper. World Bank. 2008

30. Djibuti M, Shakarishvili R. Influence of clinical, demographic and socioeconomic variables on quality of life in patients with epilepsy: Findings from Georgian study. NeurolNeurosurg Psychiatry. 2003; 74: 570- 573.

31. Zoidze A, Rukhadze N, Chkhatarashvili K, Gotsadze G. Health insurance for poor: Georgia's path to universal coverage? Curatio International Foundation. 2012.

32. Gotsadze G, Bennett S, Ranson K, Gzirishvili D. Healthcare-seeking behavior and out- ofpocket payments in Tbilisi, Georgia. Curatio International Foundation. 2005.

33. Skarbinski J, Walker H, Baker L, Kobaladze A, Kirtava Z. The burden of out-of-pocket payments for healthcare in Tbilisi. The Journal of the American Medical Association. 2002;287(8):1043-6

34. Gotsadze G, Zoidze A, Vasadze O. Reform strategies in Georgia and their impact on healthcare provision in rural areas: Evidence from a household survey. Social Science and Medicine. 2005; Feb;60(4):809-21.

35. Gotsadze G, Cashin C, Zoidze A, Valdin J. Descriptive background to healthcare financing reform strategy developing Georgia. HCF Discussion Paper.2005.

36. Bonilla-Chacin E, Murrugarra E, Temourov M. Healthcare during transition and health systems reform: Evidence from the poorest $\mathrm{CIS}$ countries. Social Policy and Administration. 2005; 39(4):381 - 408

37. Jugens E, Shengelia L, Asatiani T, Bijlmakers L. Clients' and providers' perspectives on Caesarean sections. An operational study into the high Caesarean Section rate in Georgia. Tbilisi. 2011.

38. Ministry of Internal Displaced Persons from Occupied Teritories, Labor, Health and Social Affairs. Assessment of the perinatal healthcare system 2013. Available from: https://www.moh.gov.ge/ka/671/dedaTa-da-bavSvTa-janmrTeloba-perinataluriregionalizacia. 
APPENDIX 2. INSTITUTIONAL REVIEW BOARD APPROVAL LETTER FOR THE PROJECT “AN IMPACT OF THE HEALTHCARE REFORM IN GEORGIA ON MATERNAL HEALTH" 


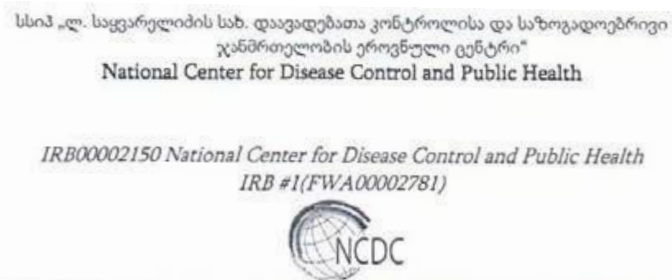

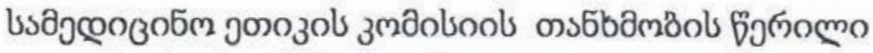 Institutional Review Board Approval Letter
}

\author{
PI: Lela Shengelia \\ Head of the maternal and child health division \\ The National Center for Disease Control and Public Health \\ mobile.: +995 (591) 706794 \\ E-mail: 1 .shengelia@ncdc.ge
}

IRB \# 2015-023

Dear Dr. Shengelia

This letter is an official notification that National Center for Disease Control and Public Health Institutional Review Board has carried out review of the application for the project "An Impact of the healthcare reform in Georgia on maternal health" and has determined that your research qualifies for Exempt status.

This determination is valid from Mav 12, 2015 until Mav 12, 2016. If you wish to continue your research after this date, you must complete and submit a Continuation Application.

Level of review: Exempt

Date of review: May 12, 2015

You are responsible for immediately informing the Institutional Review Board of any changes to your protocol/procedures/data collection tools/consent forms before they are implemented, and of any previously unforeseen risks to the research participants.

For further assistance please conact us on (995-322) 398946 or via email at t.komakhidze@ncdc.ge

Sincerely,

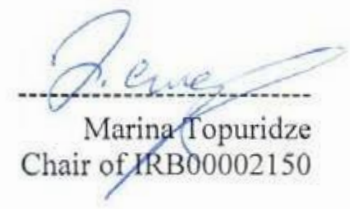

3. susonobinu 9, obonenolin 0177; 9 M.Asatiani st., Tbilisi, 0177, Georgia ; Phone: (995-322) 3989 46, Fax: (995-322) 31 14 85.

E-mail: ncdc@ncdc.ge 


\section{APPENDIX 3. GUIDE FOR FOCUS GROUP DISCUSSIONS TO STUDY STAKEHOLDERS' VIEWS ON THE STRENGTHS AND WEAKNESSES OF MATERNAL CARE IN GEORGIA}

Below is a general guide for leading the focus group discussions. This guide may be slightly modified as needed (e.g. for the following focus group discussion based on the previous one) but without changing the content of the questions. During the discussions additional clarifying questions can be posed. Before the focus group discussion, note down the code of the focus group.

\section{Introduction (15 MIN)}

- Welcome participants and introduce yourself.

Welcome to all of you and thank you for accepting our invitation to participate in this group discussion. Your participation is highly important to us. Let me first present myself: ... I will be guiding the discussion today. I would like to introduce ..., she is a principal investigator of this project and ... who will assist us today during the discussion.

The discussion will run for about 2 hours including one break.

- Explain the general purpose of the discussion.

This focus group discussion is organized to elicit your opinion and attitudes related to the impact of healthcare reform on maternal care in Georgia

It is a part of a research project focused on the assessment of influence of healthcare reform on maternal health in Georgia. This is a project of University of Maastricht and funded by the Netherlands government. Based on the results of the focus group discussions will be made with purely scientific objectives.

- Explain why the participants were chosen.

You have been invited to participate in the focus group discussion as representatives of a specific population namely women who delivered less than two years ago.

- Introduce the participants to each other.

Let us find out some more about each other by going around the room one at a time.

Please, tell us your name and the job you have. Let us start here: ... Please, write your name on the paper in front of you. 


\section{- Discuss the process of the focus group discussion.}

Before we start, some details about the discussion process.

There will be several main questions that we will discuss together. In addition to this, you will be asked to fill in a short questionnaire related to the topic of the focus group discussion.

Please, keep in mind that for us, there are no right or wrong answers. We are interested in your personal opinion. It is highly important that everyone speaks up.

We encourage you to respond directly to the comments that other participants make.

Still, we would like to ask you to talk one at a time.

If you do not understand a question, please, let us know.

If we seem to be stuck on a topic, we may interrupt you and move on to make sure that we cover all topics.

\section{- Address the issue of confidentiality.}

This group discussion has purely academic purposes.

Information discussed is going to be analyzed as a whole and participants' names will be never used in any analysis of the discussion or in any report.

We hope you will feel free to speak openly.

\section{- Explain the presence and purpose of recording equipment and introduce observers.}

We will be tape recording the discussion because we do not want to miss any of your comments. No one outside of this room will have access to these tapes.

- Ask the participants to sign the Informed Consent form.

All details that I have just explained are described in our Informed Consent form. Please, read this form and sign it to confirm that you agree to participate.

Give each participant 2 copies of the Informed Consent form filled in and signed by the principle investigator. Collect one of the forms signed by each participant.

\section{- Make sure that the participants are ready to start.}

Does anyone have any questions? May we turn on the tape recorder?

Turn on tape recorder and pronounce the code of the focus group discussion. 


\section{Initial Discussion on the State Maternal Healthcare Program (30 MINUTES)}

- Describe again the purpose of the focus group discussion.

Let us get started. As I have already explained, this group discussion is focused on maternal care. We are specifically interested in your own perspective on this topic.

- Clarify the definition of maternal care.

In this discussion, we will consider maternal care services.

These are the State healthcare programs that the State implements through healthcare facilities and other healthcare providers.

The government of Georgia by the State healthcare programs cover the following services: 4 antenatal care check-up, free delivery/labor and Caesarean section, identification and testing of high-risk pregnant women.

The private healthcare insurance also covers some maternal care services, like delivery.

Do you have any questions with regard to our definition of maternal care?

If necessary, clarify the definition.

- Discuss the attitudes of the participants towards the maternal health in Georgia.

Are you satisfied with the maternal care services? if yes, why? if not, what was the main problem?

Did exist healthcare services met all your needs? if yes, why? if not, what was the main problem?

After the responses from this prompt have been exhausted, move on.

- Discuss the attitudes of the respondent towards out-of-pocket payment or co-payment for maternal health services.

Do you think that out-of-pocket payments or co-payments should be applied to the following services?

Show Card 1 to the participants.

\begin{tabular}{|c|c|c|}
\hline $\begin{array}{l}\overrightarrow{0} \\
\text { 定 }\end{array}$ & $\begin{array}{l}\text { 1. Ante natal care } \\
\text { 2. Service of specialist } \\
\text { 3. Delivery services } \\
\text { 4. Near miss services } \\
\text { 5. Post-natal care }\end{array}$ & 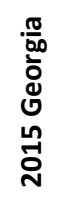 \\
\hline
\end{tabular}


If not, why not?

If it happened do you think that you will be able to pay for these services? Will these services be affordable for you?

After the responses from this prompt have been exhausted, move on.

\section{- Elicit opinion about the level of payment for maternal care}

Show Card 1A to the respondent and present the levels of maternal care payment in Georgia for ante natal care, service of specialist, delivery services, near miss services and post-natal care.

\section{Card $1 \mathrm{~A}$ should be provided by the project members.}

\begin{tabular}{|c|c|c|c|}
\hline \multirow{6}{*}{$\begin{array}{l}\overrightarrow{1} \\
\stackrel{\alpha}{\overleftarrow{s}}\end{array}$} & Services & Patient payment fee & \multirow{6}{*}{ 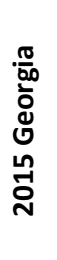 } \\
\hline & ante natal care & & \\
\hline & service of specialist & & \\
\hline & delivery services & & \\
\hline & near miss services & & \\
\hline & post-natal care & & \\
\hline
\end{tabular}

Do you think that these levels of fees are adequate from providers prospective?

- If maternal care services payments do not exist in Georgia:

Show again Card 1 to the respondent and ask about the opinion of the respondent in general:

What levels of payment would be adequate for these services for providers?

After the responses from this prompt have been exhausted, move on.

Do you think that the payments for maternal care were the problem for you to access/use certain services? Is it resulting low utilization form your side? Have you taken any loan from your family, friends or bank to cover health expenditure? Was it that related with maternal?

Did you ever have to pay for maternal care unofficially in cash or kind?

- If yes, what was the reason for it? (e.g. gratitude, ensuring quality, it is widely accepted method).

- Have you asked to give some amount or gift to the medical staff? if yes, Was it direct negotiation or hint? 


\section{- Elicit opinion about the quality of antenatal healthcare services in Georgia.}

Quality of care might be divided in following parts: financing of maternal care, clinical quality and social quality. Clinical quality is focused on technical competence and clinical appropriateness. Whereas Social quality is focused on the environmental tangibility of the health facility (Berki and Ashcraft 1980)

The main purpose of the maternal care service is to protect pregnant women/young mothers.

Please, see Card 2 and explain us your opinion

Show Card 2 to the participants.

$\left.\begin{array}{|l|l|l|}\hline & \begin{array}{l}\text { 1. Antenatal care consists of } 4 \text { visits that is enough for management } \\ \text { of physiological pregnancy. }\end{array} \\ \begin{array}{l}\text { 2. Antenatal care consists of } 4 \text { visits that is not enough for } \\ \text { identification of pregnancy complications. }\end{array} \\ \begin{array}{l}\text { 3. The antenatal care cover outreach services/home } \\ \text { visitation/referral }\end{array} \\ \text { 4. The feedback is implemented in the antenatal care. }\end{array}\right)$

In your opinion, what limits the quality of antenatal care in Georgia to all pregnant women irrespective of their socio-economic status and health conditions?

In your opinion, what are the barriers to have adequate access? Please explain your opinion?

After the responses from this prompt have been exhausted, move on.

Do you think that the limited quality of antenatal healthcare services (Clinical and social quality) was a barrier for you to seek for the maternal care (e.g. poor attitude, conditions in healthcare unit, treatment itself)? Could you explain why?

- Elicit opinion about the quality of delivery/labor care services in Georgia.

To maintain a good quality of delivery/labor care services is one of the main ways to protect pregnant women/young mothers.

Please, see Card 3 and express your opinion.

1. The quality of care during delivery/labor is the same in the whole country

2. The affordability and accessibility to the high quality is the same in all financial quarterlies

3. There is main cause of the disparities low capacity building

4. The feedback is implemented in the delivery care 
In your opinion, what limits the quality of care during delivery/labor in Georgia to all pregnant women irrespective of their socio-economic status and health conditions? Please explain your opinion.

- How many of you experienced C-section? Was it mostly emergency need or planed? If it was planned C-section why you decided to do so? What is your opinion about $C$ - section?

- How many of you experienced any pregnancy delivery or postpartum complication, like preeclampsia, haemorrhage, etc? If any, what was the outcome?

- How many of you experienced stillbirth, preterm delivery or infant mortality?

- Did you experience any maternal care services being not available in the area you live (either not existent or shortage of availability) during antenatal, delivery or post-natal period?

- Was that a barrier to seek for the health service?

How you will describe the health provider where you received last services? Hypothetically how you will grade it? Was it high or low level services?

\section{- Elicit opinion about accessibility to the maternal care services in Georgia}

Access to the healthcare services can be distinguished into special and temporary dimensions. Special access refers to the geographical accessibility, whereas temporary access refers to the waiting time.

- Did you experience any accessibility problems in maternal care during antenatal, delivery or post-natal period in terms of distance or time?

- Was that a barrier to seek for the necessary maternal care service?

- How do you perceive a need to receive maternal care services during all the 3 phases - pre/post-natal and delivery?

- Could you tell whether there are any maternal care services that you think are not necessary/important?

- Is that a reason you did not seek for them?

- Did you feel like you were missing information on the use of maternal services? What was source of information for you?

- Where there any other reasons that held you back from or were a barrier of using maternal care services provided by healthcare professional (e.g. culture, religion, gender relationship in family)

After the responses from this prompt have been exhausted, move on. 


\section{Generation of a List with Assessment Criteria (20 MINUTES)}

\section{- Brainstorm on relevant assessment criteria}

Now, we are going to brainstorm. I have the following question for you.

Show Card 5 to the participants and read the text on it.

\begin{tabular}{|c|c|c|}
\hline 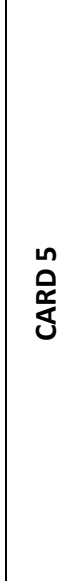 & $\begin{array}{l}\text { Imagine that you need to assess the adequacy of the maternal care services that } \\
\text { are implemented or considered for implementation in a country. What } \\
\text { assessment criteria would you take into account? please see the list below: } \\
\text { - Safety } \\
\text { - Delay of care } \\
\text { - Accountability } \\
\text { - Confidentiality } \\
\text { - Attitude of medical staff } \\
\text { - Clearness of provided advices } \\
\text { - Cee for services } \\
\text { - Responsiveness } \\
\text { - Facility outlook } \\
\text { - Cleanliness }\end{array}$ & 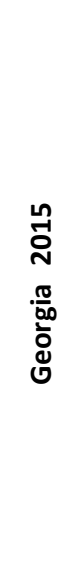 \\
\hline
\end{tabular}

Please, keep in mind that for us, there are no right or wrong answers. We are interested in your personal opinion. Please, also keep in mind that we aim at a broad range of assessment criteria (incl. economic, social, institutional, geographical, ethical, cultural and demographic).

This is primarily a brainstorm exercise. Participants can add as many ideas as they occur to them. Prompt for economic, social, institutional, historical geographical, ethical, cultural and demographic.

After the responses from this prompt have been exhausted, announce the break.

\section{General Discussion on Maternal Healthcare (20 MINUTES)}

- Ask the participants to reflect on the discussion.

Is there anything we have not discussed that seems relevant to you?

After the responses from this prompt have been exhausted, move on. 
- Ask the participants to reflect on the link between payments for maternal care services and quality of care.

What do you think about payments for maternal care in the healthcare sector?

What do you think about maternal care services quality in your region/rayon? Do you think that there is relation between quality and access?

After the responses from this prompt have been exhausted, move on.

\section{- Ask the participants to reflect on the link among healthcare} reforms and quality and accessibility of maternal care

What do you think, does changes that happened during last period in healthcare influence quality of maternal care?

What do you think, does changes that happened during last period in healthcare influence access to maternal care services?

What do you think, about reliability of the healthcare reform (universal coverage)? What do you think, does maternal health priority for the government?

- Make sure that the discussion has been comprehensive.

Would anyone like to make any final comments?

After the responses from this prompt have been exhausted, move on.

\section{Closing part (5 MIN)}

\section{- Thank the participants}

This is the end of our focus group discussion. Thank you very much for your input during the discussion. Your opinion is highly valuable for our study.

- Explain once again what will happen with the information collected

As I explained at the beginning, this group discussion had purely academic purposes. No one outside of this room will have access to these tapes. The information will be analyzed as a whole and participants' names will be never used in any analysis of the discussion or in any report. 


\section{APPENDIX 4. THE GUIDE FOR IN-DEPTH INTERVIEWS TO STUDY STAKEHOLDERS' VIEWS ON THE STRENGTHS AND WEAKNESSES OF MATERNAL CARE IN GEORGIA}

I. Below is a general guide for leading the in-depth interviews. This guide may be slightly modified as needed (e.g. for the following interview based on the previous one) but without changing the content of the questions. During the interview additional clarifying questions can be posed. Before the interview, note down the code of the interview.

\section{Introduction (5 MIN)}

- Thank the respondent and introduce yourself.

Thank you for accepting our invitation for this interview. Your participation is highly important to us. Let me first present myself: ... The interview should last about 60-60 minutes.

- Explain the general purpose of the interview.

The questions prepared for this interview concern your opinion and attitudes related to the maternal health. This interview and similar interviews with policy-makers, international and national NGOs, health insurance representatives and service providers are carried out for a research project focused on the assessment of maternal health in Georgia. Based on the results of these interviews will be made with purely scientific objectives.

- Explain the process of the interview.

There will be several main questions during the interview.

This interview has purely academic purposes. Information discussed is going to be analyzed as a whole and respondent's name will be never used in any analysis of the discussion or in any report.

- Explain the presence and purpose of recording equipment and introduce observers.

I will need to tape record the discussion because I would not want to miss any of your comments. No one outside of this room will have access to these tapes. 
- Ask the respondent to sign the Informed Consent form.

All details that I have just explained are described in our Informed Consent form. Please, read this form and sign it to confirm that you agree to participate.

Give the respondent 2 copies of the Informed Consent form filled in and signed by the principle investigator. Collect one of the forms signed by the respondent.

- Make sure that the respondent is ready to start.

Do you have any questions? May we turn on the tape recorder?

Turn on tape recorder and pronounce the code of the in-depth interview.

\section{Initial Discussion on maternal care in Georgia (20 MINUTES)}

- Describe again the purpose of the interview.

Let us get started. As I have already mentioned, this interview is focused on maternal care in Georgia. We are specifically interested in your own perspective on this topic.

- Clarify the definition of maternal care.

In this interview, we will consider maternal care services. Maternal health refers to the health of women during pregnancy, childbirth and the postpartum period.

- Describe the State healthcare programs that cover maternal care services in Georgia.

There are several maternal care vertical programs:

Maternal and child health program that covers:

- Four antenatal visits

- Screening of all pregnant women on HIV, Hepatitis $B$ and Gonorea and conformation of positive cases

- Early detection and examination of high-risk pregnant women on genetic disorders by screening with triple test at 14- 16 weeks of pregnancy,

- Pre-, intra and post-partum healthcare of high-risk pregnant women 
- Management of pregnancy and delivery complications during first six days

- Treatment of post-partum syphilis

- Invasion examination of pregnant women -Amniocentesis karyotype method

- "Health for All" ensure free delivery and C-section

- Discuss the attitudes of the respondent towards the State maternal care program

- Do you think that the State maternal care program covers all needs of pregnant women and young mothers? Why?

- What about health insurance, which part of maternal care does it covers? Is it sufficient or not?

After the responses from this prompt have been exhausted, move on.

- Discuss the attitudes of the respondent towards out of pocket payments in maternal care services.

- co-payments

- userfees,

- user charge

- fee for services

- informal payment

- payment for pharmaceuticals

Give examples of official patient payments in antenatal clinics or in maternal houses. After the responses from this prompt have been exhausted, move on.

- Discuss the attitudes of the respondent towards the burden of out of pocket payment and co-payment in maternal care services.

Do you think that out of pocket payment should exist in Georgia, Why?

Do you think that co-payment should exist in Georgia, Why?

- Discuss the attitudes of the respondent towards payments for given services.

Do you think that payments should be applied to the following services? 
Show Card 1 to the respondent.

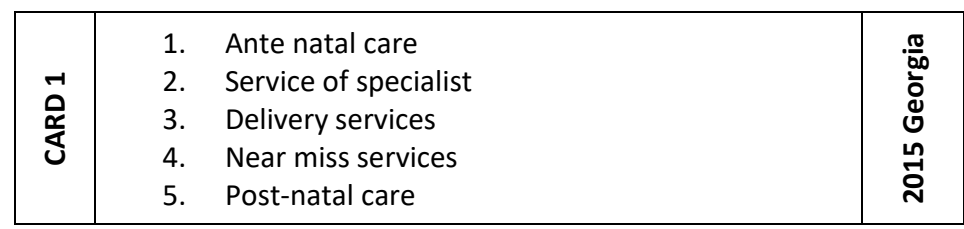

If not, why not?

If it happened do you think that pregnant women will be able to pay for these services?

After the responses from this prompt have been exhausted, move on.

\section{- Elicit opinion about the level of payment fees for maternal care}

- If payments for maternal care exist in your country:

Show Card 1A to the respondent and present the levels of maternal care payment in your country for ante natal care, service of specialist, delivery services, near miss services and post-natal care.

Card 1A should be provided by the project members.

\begin{tabular}{|c|c|c|c|}
\hline \multirow{6}{*}{ 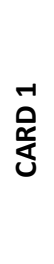 } & Services & Patient payment fee & \multirow{6}{*}{ 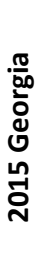 } \\
\hline & ante natal care & & \\
\hline & service of specialist & & \\
\hline & delivery services & & \\
\hline & near miss services & & \\
\hline & post-natal care & & \\
\hline
\end{tabular}

Do you think that these levels of fees are adequate for the patients?

Show again Card 1 to the respondent and ask about the opinion of the respondent in general:

What levels of payment would be affordable for these services for patients?

After the responses from this prompt have been exhausted, move on.

According to you what should be the types of payments in Georgia for ante natal care, service of specialist, delivery services, near miss services and post-natal care? Please explain your opinion?

What are other ways to extend of payment.

Show again Card 1 to facilitate the answer. 


\section{- Discuss the role of the MoLHSA in maternal care financing and quality of care in Georgia.}

Show Card 2 to the respondent and explain briefly the objectives presented there.

\begin{tabular}{|c|c|c|}
\hline 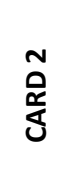 & $\begin{array}{l}\text { 1. Discouraging unnecessary use of healthcare services } \\
\text { 2. Generating additional resources for the health system } \\
\text { 3. Allowing hospitals/clinics to generate additional resources } \\
\text { 4. Increasing the income of individual healthcare providers } \\
\text { 5. Controlling the overall healthcare expenditure }\end{array}$ & مِ \\
\hline
\end{tabular}

According to you, what should be the primary policy objectives to protect pregnant women and their households from healthcare expenditure in Georgia?

According to you, what should be the primary policy objectives to provide high quality maternal care services in the whole country?

After the responses from this prompt have been exhausted, move on.

\section{Generation of a list with Assessment Criteria (20 MINUTES)}

\section{- Ask the respondent to suggest relevant assessment criteria}

Imagine that you need to assess the adequacy of financial spending on maternal care services that are implemented or considered for implementation in a country. What assessment criteria would you take into account?

Show Card 2 to the respondent.

\begin{tabular}{|c|c|c|}
\hline 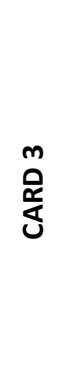 & $\begin{array}{l}\text { Imagine that you need to assess the adequacy of maternal care services } \\
\text { that are implemented or considered for implementation in a country. } \\
\text { What assessment criteria would you take into account? } \\
\text { - Safety } \\
\text { - } \text { Delay of care } \\
\text { - } \text { Accountability } \\
\text { - } \text { Confidentiality } \\
\text { - } \text { Consultation time } \\
\text { - } \text { Facility outlook }\end{array}$ & مِ \\
\hline
\end{tabular}

Please, keep in mind that for us, there are no right or wrong answers. We are interested in your personal opinion. Please, also keep in mind that we aim at a broad range of assessment criteria (incl. economic, social, institutional, historical geographical, ethical, cultural, demographic and sector-specific criteria). 


\section{- Discuss the capacity of the maternal care service providers}

Discussion about the influence of manpower, referral/ transportation system and technical capacity on quality of care.

Show Card 4 to the respondent and explain briefly the objectives presented there.

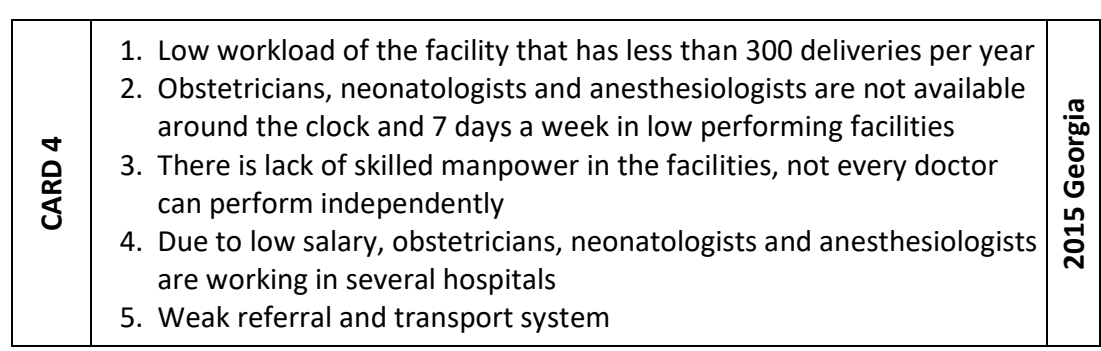

According to you, what is the main obstruct for the quality of maternal care. Which of the issues listed in the CARD 6 stated as the problem in Georgia?

If any, according to you, what should be done to solve the problems?

\section{- Discuss the outcome of maternal care in Georgia}

Discussion about the outcome of the maternal care.

Show Card 5 to the respondent and explain briefly the objectives presented there.

\begin{tabular}{|l|l|l|}
\hline \multicolumn{1}{|l|}{} & 1. Maternal mortality & \\
2. Management of Pregnancy Related Hypertension & \\
3. Infant mortality & \\
4. Rate of C-section & 5. Proportion of hemorrhage & \\
6. Proportion of low birth weight & 7. Proportion of preterm delivery \\
& 8. Proportion of women with systemic infection or in post-natal \\
period, including readmissions & \\
\hline \multirow{2}{*}{} & \\
\hline
\end{tabular}

\section{- Discuss the outcome of maternal care in Georgia with European counties}

In your opinion, is there any difference among maternal health indicators of Georgia and European countries?

If yes, please express your opinion.

- Discuss the measurability of each criterion.

Prompt discussion about the measurability of each criterion. If the respondent thinks that a given criterion is difficult to measure, ask him/her 
to suggest another proxy that can be measured.

After the responses from this prompt have been exhausted, move on.

- Discuss the attitudes of the respondent towards the privatization and marketization

- In your opinion, does privatization influence maternal care? if yes, how?

- In your opinion, does libarization of the health market influence maternal care? if yes, how?

- In your opinion, how deregulation influence maternal care?

- In your opinion, how all these changes influence quality of the maternal care?

- In your opinion, how all these changes influence the access to the maternal care services

- In your opinion, how the implementation of universal coverage influence maternal care? In which direction?

- In your opinion, what are areas to be improved?

\section{General Discussion on Payments for Maternal Healthcare Services (15 MINUTES)}

- Ask the respondent to reflect on the discussion.

Is there anything we have not discussed that seems relevant to you?

After the responses from this prompt have been exhausted, move on.

- Ask the respondent to reflect on the link between patient payment and quality of care.

What do you think about patient payments in the maternal care sector?

After the responses from this prompt have been exhausted, move on.

- Make sure that the discussion has been comprehensive.

Would you like to make any final comments?

After the responses from this prompt have been exhausted, move on.

\section{Closing part (5 MIN)}

- Thank the respondent 


\section{APPENDIX 5. QUESTIONNAIRE FOR ASSESSING CLIENTS' SATISFACTION IN MATERNAL CARE IN GEORGIA}

Interviewer's ID:

Questionnaire ID:

Section 1: Respondents' socio-demographic background

\begin{tabular}{|c|c|c|c|}
\hline Ques ID. & Question & Response & Codes \\
\hline \multirow{3}{*}{1.1} & \multirow{3}{*}{$\begin{array}{l}\text { Which region } \\
\text { do you live? }\end{array}$} & D Tbilisi & 1 \\
\hline & & $\square$ Imereti & 2 \\
\hline & & $\square$ Adjara & 3 \\
\hline \multirow{2}{*}{1.2} & \multirow{2}{*}{$\begin{array}{c}\text { Where do you } \\
\text { live? }\end{array}$} & $\square$ Rural & 1 \\
\hline & & $\square$ Urban & 2 \\
\hline \multirow{3}{*}{1.3} & \multirow{3}{*}{$\begin{array}{l}\text { What is your } \\
\text { religion }\end{array}$} & $\square$ Christianity & 1 \\
\hline & & $\square$ Islam & 2 \\
\hline & & $\square$ Others & 3 \\
\hline \multirow{4}{*}{1.4} & \multirow{4}{*}{ Ethnicity } & $\square$ Georgian & 1 \\
\hline & & $\square$ Armenian & 2 \\
\hline & & $\square$ Azeri & 3 \\
\hline & & $\square$ Others & 4 \\
\hline
\end{tabular}

What was your

1.5 age at last birthday?

..Years (in absolute number)

\begin{tabular}{|c|c|c|c|}
\hline \multirow{5}{*}{1.6} & \multirow{5}{*}{$\begin{array}{c}\text { What is your } \\
\text { educational } \\
\text { level }\end{array}$} & $\square$ Completed $1-4$ grades & 1 \\
\hline & & $\square$ Completed $5-6$ grades & 2 \\
\hline & & $\square$ Completed $10-12$ grades & 3 \\
\hline & & $\square$ Completed Technical Education (college) & 4 \\
\hline & & $\square$ Completed university & 5 \\
\hline \multirow{4}{*}{1.7} & \multirow{4}{*}{$\begin{array}{l}\text { What is your } \\
\text { marital status? }\end{array}$} & $\square$ Married & 1 \\
\hline & & $\square$ Unmarried & 2 \\
\hline & & $\square$ Divorced & 3 \\
\hline & & $\square$ Others & 4 \\
\hline
\end{tabular}




\begin{tabular}{|c|c|c|c|}
\hline Ques ID. & Question & Response & Codes \\
\hline \multirow{6}{*}{1.8} & \multirow{6}{*}{$\begin{array}{l}\text { What is your } \\
\text { occupation? }\end{array}$} & $\square$ House wife & 1 \\
\hline & & $\square$ Business & 2 \\
\hline & & $\square$ Student & 3 \\
\hline & & $\square$ Day-labor & 4 \\
\hline & & $\square$ Official job & 5 \\
\hline & & $\square$ Others & 6 \\
\hline \multirow{4}{*}{1.9} & \multirow{4}{*}{$\begin{array}{l}\text { What is the } \\
\text { approximate } \\
\text { monthly income } \\
\text { of you/your } \\
\text { family? }\end{array}$} & $\square<200 \mathrm{GEL}$ & 1 \\
\hline & & $\square 200-<900 \mathrm{GEL}$ & 2 \\
\hline & & $\square 900-<1500 \mathrm{GEL}$ & 3 \\
\hline & & $\square \geq 1500$ & 4 \\
\hline \multirow{3}{*}{1.10} & \multirow{3}{*}{$\begin{array}{l}\text { Does your family } \\
\text { receive social } \\
\text { benefits? }\end{array}$} & $\square$ Yes & 1 \\
\hline & & $\square$ No & 2 \\
\hline & & $\square$ Don't know & 3 \\
\hline
\end{tabular}

\section{Regarding utilization of antenatal care}

\begin{tabular}{|c|c|c|c|}
\hline Ques ID. & Question & Response & Codes \\
\hline \multirow{2}{*}{2.1} & \multirow{2}{*}{$\begin{array}{l}\text { Did you receive } \\
\text { antenatal care? }\end{array}$} & $\mathbf{J}$ yes & 1 \\
\hline & & $\square$ No -if not go to $Q-3.1$ & 2 \\
\hline \multirow{7}{*}{2.2} & \multirow{7}{*}{$\begin{array}{l}\text { If yes, where did you } \\
\text { receive antenatal care } \\
\text { (i.e., type of maternal } \\
\text { care facility) }\end{array}$} & Primary care clinic & 1 \\
\hline & & Women's consultation center & 2 \\
\hline & & Jegional maternal house & 3 \\
\hline & & City maternal house & 4 \\
\hline & & Referral hospital & 5 \\
\hline & & Home & 6 \\
\hline & & Others & 7 \\
\hline 2.3 & $\begin{array}{l}\text { How many antenatal } \\
\text { visits have you had? }\end{array}$ & ..................... visits & \\
\hline \multirow{4}{*}{2.4} & \multirow{4}{*}{$\begin{array}{l}\text { Who provided most } \\
\text { antenatal care }\end{array}$} & Obstetrician/gynaecologist & 1 \\
\hline & & Midwife & 2 \\
\hline & & Family doctor & 3 \\
\hline & & Others & 4 \\
\hline
\end{tabular}




\begin{tabular}{|c|c|c|c|}
\hline Ques ID. & Question & Response & Codes \\
\hline \multirow{2}{*}{2.5} & \multirow{2}{*}{$\begin{array}{l}\text { Did you have any } \\
\text { complications during } \\
\text { antenatal period }\end{array}$} & $\square \quad$ Yes & 1 \\
\hline & & $\square \quad$ No if not go to Q 2.8 & 2 \\
\hline \multirow{5}{*}{2.6} & \multirow{5}{*}{$\begin{array}{l}\text { If yes, what kind of } \\
\text { complications you had }\end{array}$} & Bleeding & 1 \\
\hline & & High blood pressure & 2 \\
\hline & & Infections & 3 \\
\hline & & Others; please specify: & - \\
\hline & & ......... & \\
\hline \multirow{2}{*}{2.7} & \multirow{2}{*}{$\begin{array}{l}\text { Did you hospitalize due } \\
\text { to complications? }\end{array}$} & $\square \quad$ Yes & 1 \\
\hline & & No & 2 \\
\hline \multirow{2}{*}{2.8} & \multirow{2}{*}{$\begin{array}{l}\text { Did you pay for } \\
\text { antenatal care }\end{array}$} & Yes & 1 \\
\hline & & $\square \quad$ No if not go to Q 2.11 & 2 \\
\hline
\end{tabular}

2.9 If yes, how much did you pay? GEL

\begin{tabular}{|c|c|c|c|}
\hline \multirow{4}{*}{2.10} & \multirow{4}{*}{$\begin{array}{c}\text { Sources of antenatal } \\
\text { care cost }\end{array}$} & Self-financing & 1 \\
\hline & & Relatives & 2 \\
\hline & & Loan with interest & 3 \\
\hline & & Loan without interest & 4 \\
\hline \multirow{4}{*}{2.11} & \multirow{4}{*}{$\begin{array}{l}\text { Why do you choose } \\
\text { that particular } \\
\text { antenatal care facility? }\end{array}$} & Past pleasant experience & 1 \\
\hline & & Recommendation from others & 2 \\
\hline & & Cost is cheaper than other facilities & 3 \\
\hline & & The facility is near my home & 4 \\
\hline
\end{tabular}

\section{Regarding utilization of childbirth and immediate post-natal care}

\begin{tabular}{|c|c|c|c|c|}
\hline Ques ID. & Question & & Response & Codes \\
\hline \multirow{6}{*}{3.1} & \multirow{6}{*}{$\begin{array}{l}\text { Where did you give } \\
\text { your last childbirth? }\end{array}$} & $\square$ & Primary care clinic & 1 \\
\hline & & $\square$ & Women's consultation center & 2 \\
\hline & & $\square$ & Regional maternal house & 3 \\
\hline & & $\square$ & City maternal house & 4 \\
\hline & & $\square$ & Referral hospital & 5 \\
\hline & & $\square$ & Home & 6 \\
\hline
\end{tabular}




\begin{tabular}{|c|c|c|c|c|}
\hline Ques ID. & Question & & Response & Codes \\
\hline \multirow{5}{*}{3.2} & \multirow{5}{*}{$\begin{array}{l}\text { Why do you choose } \\
\text { that particular } \\
\text { antenatal care facility? }\end{array}$} & $\square$ & Past pleasant experience & 1 \\
\hline & & $\square$ & Recommendation from others & 2 \\
\hline & & $\square$ & Cost is cheaper than other facilities & 3 \\
\hline & & $\square$ & The facility is near my home & 4 \\
\hline & & $\square$ & Referred by doctor & 5 \\
\hline
\end{tabular}

3.3

What was gestational age at last childbirth? weeks

\begin{tabular}{|c|c|c|c|}
\hline \multirow{2}{*}{3.4} & \multirow{2}{*}{$\begin{array}{c}\text { What was the method } \\
\text { of childbirth? }\end{array}$} & Normal vaginal delivery if not go to Q 3.6 & 1 \\
\hline & & $\mathrm{C} /$ section & 2 \\
\hline \multirow{4}{*}{3.5} & \multirow{4}{*}{$\begin{array}{l}\text { If it was } \mathrm{C} / \text { section; } \\
\text { Why it was needed? }\end{array}$} & Suggested by doctor & 1 \\
\hline & & Self-choice to avoid pain & 2 \\
\hline & & History of previous bad obstetric history & 3 \\
\hline & & Others; please specify: & - \\
\hline \multirow{4}{*}{3.6} & \multirow{4}{*}{$\begin{array}{l}\text { Who conducted } \\
\text { childbirth care? }\end{array}$} & Obstetrician/gynaecologist & 1 \\
\hline & & Midwife & 2 \\
\hline & & Family doctor & 3 \\
\hline & & Others & 4 \\
\hline \multirow{4}{*}{3.7} & \multirow{4}{*}{$\begin{array}{c}\text { Who provided } \\
\text { immediate post-natal } \\
\text { care? }\end{array}$} & Obstetrician/gynaecologist & 1 \\
\hline & & Nurses & 2 \\
\hline & & Family doctor & 3 \\
\hline & & Others & 4 \\
\hline \multirow{2}{*}{3.8} & \multirow{2}{*}{$\begin{array}{l}\text { Did you pay for } \\
\text { antenatal care }\end{array}$} & Yes & 1 \\
\hline & & No if not go to $Q 11$ & 2 \\
\hline 3.9 & $\begin{array}{c}\text { If yes, how much did } \\
\text { you pay? }\end{array}$ & 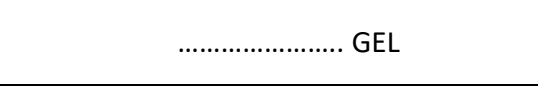 & \\
\hline \multirow{4}{*}{3.10} & \multirow{4}{*}{$\begin{array}{l}\text { Sources of antenatal } \\
\text { care cost }\end{array}$} & Self-financing & 1 \\
\hline & & Relatives & 2 \\
\hline & & Loan with interest & 3 \\
\hline & & Loan without interest & 4 \\
\hline
\end{tabular}

After how many days

3.11 following childbirth you were discharged days from health facility? 


\section{Perceived service quality in antenatal care: indirect measures of satisfaction}

\section{Rating of responses:}

1 = Strongly disagree; 2 = Disagree; 3 = Neutral; 4 = Agree;

5 = Strongly agree

\subsection{Tangibility}

\begin{tabular}{lllllll}
\hline Q. No. & \multicolumn{1}{c}{ Statement } & \multicolumn{5}{c}{ Respondent's rating } \\
\hline 4.1 .1 & Clinic building and environment was attractive & $\mathbf{1}$ & $\mathbf{2}$ & $\mathbf{3}$ & $\mathbf{4}$ & $\mathbf{5}$ \\
\hline 4.1 .2 & Medical equipment was up-dated & $\mathbf{1}$ & $\mathbf{2}$ & $\mathbf{3}$ & $\mathbf{4}$ & $\mathbf{5}$ \\
\hline 4.1 .3 & Cleanliness was maintained & $\mathbf{1}$ & $\mathbf{2}$ & $\mathbf{3}$ & $\mathbf{4}$ & $\mathbf{5}$ \\
\hline 4.1 .4 & Prescriptions were clearly written and attractive & $\mathbf{1}$ & $\mathbf{2}$ & $\mathbf{3}$ & $\mathbf{4}$ & $\mathbf{5}$ \\
\hline
\end{tabular}

\subsection{Availability}

\begin{tabular}{lllllll}
\hline Q. No. & \multicolumn{1}{c}{ Statement } & \multicolumn{4}{c}{ Respondent's rating } \\
\hline 4.2.1 & Common diagnostic tests were available & $\mathbf{1}$ & $\mathbf{2}$ & $\mathbf{3}$ & $\mathbf{4}$ & $\mathbf{5}$ \\
\hline 4.2.2 & Specialized diagnostic tests were available & $\mathbf{1}$ & $\mathbf{2}$ & $\mathbf{3}$ & $\mathbf{4}$ & $\mathbf{5}$ \\
\hline 4.2.3 & Necessary specialized care was available & $\mathbf{1}$ & $\mathbf{2}$ & $\mathbf{3}$ & $\mathbf{4}$ & $\mathbf{5}$ \\
\hline 4.2.4 & Necessary medicines were available & $\mathbf{1}$ & $\mathbf{2}$ & $\mathbf{3}$ & $\mathbf{4}$ & $\mathbf{5}$ \\
\hline
\end{tabular}

\subsection{Accessibility (financial)}

\begin{tabular}{clccccc}
\hline Q. No. & Statement & \multicolumn{3}{c}{ Respondent's rating } \\
\hline 4.3.1 & Consultation fee was affordable & $\mathbf{1}$ & $\mathbf{2}$ & $\mathbf{3}$ & $\mathbf{4}$ & $\mathbf{5}$ \\
\hline 4.3.2 & Costs of required medicines were affordable & $\mathbf{1}$ & $\mathbf{2}$ & $\mathbf{3}$ & $\mathbf{4}$ & $\mathbf{5}$ \\
\hline 4.3.3 & Costs of required diagnostics were affordable & $\mathbf{1}$ & $\mathbf{2}$ & $\mathbf{3}$ & $\mathbf{4}$ & $\mathbf{5}$ \\
\hline 4.3.4 & Costs of Transport were affordable & $\mathbf{1}$ & $\mathbf{2}$ & $\mathbf{3}$ & $\mathbf{4}$ & $\mathbf{5}$ \\
\hline
\end{tabular}




\subsection{Responsiveness}

\begin{tabular}{|c|c|c|c|c|c|c|}
\hline Q. No. & Statement & \multicolumn{5}{|c|}{ Respondent's rating } \\
\hline 4.4.1 & Waiting time was approximately & & & & $\min$ & \\
\hline 4.4.2 & Waiting time was acceptable & 1 & 2 & 3 & 4 & 5 \\
\hline 4.4 .3 & Doctor/midwife was timely available & 1 & 2 & 3 & 4 & 5 \\
\hline 4.4 .4 & Pharmacist was timely available & 1 & 2 & 3 & 4 & 5 \\
\hline 4.4 .5 & Laboratory staff and reports were timely available & 1 & 2 & 3 & 4 & 5 \\
\hline
\end{tabular}

\subsection{Reliability}

\begin{tabular}{clccccc}
\hline Q. No. & Statement & \multicolumn{3}{c}{ Respondent's rating } \\
\hline 4.5 .1 & Antenatal caregiver was professionally competent & $\mathbf{1}$ & $\mathbf{2}$ & $\mathbf{3}$ & $\mathbf{4}$ & $\mathbf{5}$ \\
\hline 4.5 .2 & I felt secured to his/her care and decisions & $\mathbf{1}$ & $\mathbf{2}$ & $\mathbf{3}$ & $\mathbf{4}$ & $\mathbf{5}$ \\
\hline 4.5 .3 & I think, no excess tests were advised & $\mathbf{1}$ & $\mathbf{2}$ & $\mathbf{3}$ & $\mathbf{4}$ & $\mathbf{5}$ \\
\hline 4.5 .4 & I think, the prescribed drugs were needed & $\mathbf{1}$ & $\mathbf{2}$ & $\mathbf{3}$ & $\mathbf{4}$ & $\mathbf{5}$ \\
\hline
\end{tabular}

\subsection{Empathy}

\begin{tabular}{clllllll}
\hline Q. No. & \multicolumn{1}{c}{ Statement } & \multicolumn{3}{c}{ Respondent's rating } \\
\hline 4.6.1 & $\begin{array}{l}\text { Antenatal caregiver was attentive to listen my } \\
\text { problems }\end{array}$ & $\mathbf{1}$ & $\mathbf{2}$ & $\mathbf{3}$ & $\mathbf{4}$ & $\mathbf{5}$ \\
\hline 4.6.2 & $\begin{array}{l}\text { Antenatal caregiver provided adequate mental } \\
\text { support and assurance to overcome my concerns of } \\
\text { pregnancy }\end{array}$ & $\mathbf{1}$ & $\mathbf{2}$ & $\mathbf{3}$ & $\mathbf{4}$ & $\mathbf{5}$ \\
\hline 4.6.3 & Antenatal caregiver considered my financial ability & $\mathbf{1}$ & $\mathbf{2}$ & $\mathbf{3}$ & $\mathbf{4}$ & $\mathbf{5}$ \\
\hline
\end{tabular}




\subsection{Communication}

\begin{tabular}{clccccc}
\hline Q.No. & \multicolumn{1}{c}{ Statement } & \multicolumn{3}{c}{ Respondent's rating } \\
\hline \multirow{2}{*}{4.7 .1} & $\begin{array}{l}\text { Antenatal caregiver clearly explained information } \\
\text { related to nutrition, alcohol abuse, smoking, } \\
\text { contraception, childbirth, child care with breastfeeding }\end{array}$ & $\mathbf{1}$ & $\mathbf{2}$ & $\mathbf{3}$ & $\mathbf{4}$ & $\mathbf{5}$ \\
\hline 4.7 .2 & $\begin{array}{l}\text { Antenatal caregiver clearly explained information } \\
\text { related to pregnancy complications }\end{array}$ & $\mathbf{1}$ & $\mathbf{2}$ & $\mathbf{3}$ & $\mathbf{4}$ & $\mathbf{5}$ \\
\hline 4.7 .3 & I was given adequate time for consultation & $\mathbf{1}$ & $\mathbf{2}$ & $\mathbf{3}$ & $\mathbf{4}$ & $\mathbf{5}$ \\
\hline 4.7 .4 & $\begin{array}{l}\text { Doctor gave me ............................... minutes for } \\
\text { consultation }\end{array}$ & $\mathbf{1}$ & $\mathbf{2}$ & $\mathbf{3}$ & $\mathbf{4}$ & $\mathbf{5}$ \\
\hline
\end{tabular}

\subsection{Courtesy}

\begin{tabular}{clccccc}
\hline Q. No. & Statement & \multicolumn{5}{c}{ Respondent's rating } \\
\hline 4.8 .1 & Antenatal caregiver was respectful & $\mathbf{1}$ & $\mathbf{2}$ & $\mathbf{3}$ & $\mathbf{4}$ & $\mathbf{5}$ \\
\hline 4.8 .2 & Antenatal caregiver maintained my privacy & $\mathbf{1}$ & $\mathbf{2}$ & $\mathbf{3}$ & $\mathbf{4}$ & $\mathbf{5}$ \\
\hline 4.8 .3 & Antenatal caregiver was friendly & $\mathbf{1}$ & $\mathbf{2}$ & $\mathbf{3}$ & $\mathbf{4}$ & $\mathbf{5}$ \\
\hline
\end{tabular}

\section{Perceived service quality of childbirth and immediate post-natal care: Indirect measures of satisfaction}

Rating of responses:

1 = Strongly disagree; 2 = Disagree; 3 = Neutral; 4 = Agree;

5 = Strongly agree

\subsection{Tangibility}

\begin{tabular}{llllllll}
\hline Q. No. & \multicolumn{1}{c}{ Statement } & \multicolumn{5}{c}{ Respondent's rating } \\
\hline 5.1 .1 & Childbirth facility building was attractive & $\mathbf{1}$ & $\mathbf{2}$ & $\mathbf{3}$ & $\mathbf{4}$ & $\mathbf{5}$ \\
\hline 5.1 .2 & Medical equipment was up-dated & $\mathbf{1}$ & $\mathbf{2}$ & $\mathbf{3}$ & $\mathbf{4}$ & $\mathbf{5}$ \\
\hline 5.1 .3 & Cleanliness was maintained & $\mathbf{1}$ & $\mathbf{2}$ & $\mathbf{3}$ & $\mathbf{4}$ & $\mathbf{5}$ \\
\hline 5.1 .4 & Prescriptions were clearly written and attractive & $\mathbf{1}$ & $\mathbf{2}$ & $\mathbf{3}$ & $\mathbf{4}$ & $\mathbf{5}$ \\
\hline
\end{tabular}




\subsection{Availability}

\begin{tabular}{lllllll}
\hline Q. No. & \multicolumn{1}{c}{ Statement } & \multicolumn{5}{c}{ Respondent's rating } \\
\hline 4.2 .1 & Common diagnostic facilities were available & $\mathbf{1}$ & $\mathbf{2}$ & $\mathbf{3}$ & $\mathbf{4}$ & $\mathbf{5}$ \\
\hline 4.2 .2 & Specialized diagnostic facilities were available & $\mathbf{1}$ & $\mathbf{2}$ & $\mathbf{3}$ & $\mathbf{4}$ & $\mathbf{5}$ \\
\hline 4.2 .3 & Necessary specialized care was available & $\mathbf{1}$ & $\mathbf{2}$ & $\mathbf{3}$ & $\mathbf{4}$ & $\mathbf{5}$ \\
\hline 4.2 .4 & Necessary medicines were available & $\mathbf{1}$ & $\mathbf{2}$ & $\mathbf{3}$ & $\mathbf{4}$ & $\mathbf{5}$ \\
\hline
\end{tabular}

\subsection{Accessibility (financial)}

\begin{tabular}{clccccc}
\hline Q. No. & \multicolumn{1}{c}{ Statement } & \multicolumn{5}{c}{ Respondent's rating } \\
\hline 5.3.1 & Fee for childbirth (NVD or C/Section) was affordable & $\mathbf{1}$ & $\mathbf{2}$ & $\mathbf{3}$ & $\mathbf{4}$ & $\mathbf{5}$ \\
\hline 5.3.2 & Costs of required medicines were affordable & $\mathbf{1}$ & $\mathbf{2}$ & $\mathbf{3}$ & $\mathbf{4}$ & $\mathbf{5}$ \\
\hline 5.3.3 & Costs of required diagnostics were affordable & $\mathbf{1}$ & $\mathbf{2}$ & $\mathbf{3}$ & $\mathbf{4}$ & $\mathbf{5}$ \\
\hline 5.3.4 & Costs of hospitalization were affordable & $\mathbf{1}$ & $\mathbf{2}$ & $\mathbf{3}$ & $\mathbf{4}$ & $\mathbf{5}$ \\
\hline
\end{tabular}

\subsection{Responsiveness}

\begin{tabular}{llllllll}
\hline Q. No. & \multicolumn{1}{c}{ Statement } & \multicolumn{5}{c}{ Respondent's rating } \\
\hline 5.4 .1 & Waiting time was approximately ..................................................... minutes \\
\hline 5.4 .2 & Waiting time was acceptable & $\mathbf{1}$ & $\mathbf{2}$ & $\mathbf{3}$ & $\mathbf{4}$ & $\mathbf{5}$ \\
\hline 5.4 .3 & Doctor/midwife was timely available during childbirth & $\mathbf{1}$ & $\mathbf{2}$ & $\mathbf{3}$ & $\mathbf{4}$ & $\mathbf{5}$ \\
\hline 5.4 .4 & $\begin{array}{l}\text { Doctor/midwife was timely available during post-natal } \\
\text { period }\end{array}$ & $\mathbf{1}$ & $\mathbf{2}$ & $\mathbf{3}$ & $\mathbf{4}$ & $\mathbf{5}$ \\
\hline
\end{tabular}

\subsection{Reliability}

\begin{tabular}{cllllll}
\hline Q. No. & Statement & \multicolumn{4}{c}{ Respondent's rating } \\
\hline 5.5 .1 & Natal and post-natal caregiver was adequately skilled & $\mathbf{1}$ & $\mathbf{2}$ & $\mathbf{3}$ & $\mathbf{4}$ & $\mathbf{5}$ \\
\hline 5.5 .2 & I felt secured to childbirth care and decisions & $\mathbf{1}$ & $\mathbf{2}$ & $\mathbf{3}$ & $\mathbf{4}$ & $\mathbf{5}$ \\
\hline 5.5 .3 & Doctor's decision of method of delivery was correct & $\mathbf{1}$ & $\mathbf{2}$ & $\mathbf{3}$ & $\mathbf{4}$ & $\mathbf{5}$ \\
\hline 5.5 .4 & I think, no excess tests were advised & $\mathbf{1}$ & $\mathbf{2}$ & $\mathbf{3}$ & $\mathbf{4}$ & $\mathbf{5}$ \\
\hline 5.5 .5 & I think, the prescribed drugs were needed & $\mathbf{1}$ & $\mathbf{2}$ & $\mathbf{3}$ & $\mathbf{4}$ & $\mathbf{5}$ \\
\hline
\end{tabular}




\subsection{Empathy}

\begin{tabular}{clrrrrr}
\hline Q. No. & \multicolumn{1}{c}{ Statement } & \multicolumn{5}{c}{ Respondent's rating } \\
\hline 5.6 .1 & $\begin{array}{l}\text { Childbirth and post-natal caregivers were attentive to } \\
\text { listen my problems }\end{array}$ & $\mathbf{1}$ & $\mathbf{2}$ & $\mathbf{3}$ & $\mathbf{4}$ & $\mathbf{5}$ \\
\hline 5.6 .2 & $\begin{array}{l}\text { Childbirth and post-natal caregiver provided adequate } \\
\text { mental support and assurance to overcome my } \\
\text { concerns of childbirth and my baby }\end{array}$ & $\mathbf{1}$ & $\mathbf{2}$ & $\mathbf{3}$ & $\mathbf{4}$ & $\mathbf{5}$ \\
\hline 5.6 .3 & $\begin{array}{l}\text { My wishes were adequately considered for making } \\
\text { decision related to childbirth and post-natal period }\end{array}$ & $\mathbf{1}$ & $\mathbf{2}$ & $\mathbf{3}$ & $\mathbf{4}$ & $\mathbf{5}$ \\
\hline 5.6 .4 & My financial ability was considered by care providers & $\mathbf{1}$ & $\mathbf{2}$ & $\mathbf{3}$ & $\mathbf{4}$ & $\mathbf{5}$ \\
\hline 5.6 .5 & I was timely seen and touch my baby when I wanted & $\mathbf{1}$ & $\mathbf{2}$ & $\mathbf{3}$ & $\mathbf{4}$ & $\mathbf{5}$ \\
\hline
\end{tabular}

\subsection{Communication}

\begin{tabular}{clrrrrr}
\hline Q. No. & \multicolumn{1}{c}{ Statement } & \multicolumn{5}{c}{ Respondent's rating } \\
\hline 5.7 .1 & $\begin{array}{l}\text { Childbirth and post-natal caregiver clearly explained } \\
\text { information related to nutrition, contraception, child } \\
\text { care with breastfeeding }\end{array}$ & $\mathbf{1}$ & $\mathbf{2}$ & $\mathbf{3}$ & $\mathbf{4}$ & $\mathbf{5}$ \\
\hline 5.7 .2 & $\begin{array}{l}\text { Childbirth and post-natal caregiver clearly explained } \\
\text { information about probable post-natal complications }\end{array}$ & $\mathbf{1}$ & $\mathbf{2}$ & $\mathbf{3}$ & $\mathbf{4}$ & $\mathbf{5}$ \\
\hline 5.7 .3 & I was given adequate time during and after childbirth & $\mathbf{1}$ & $\mathbf{2}$ & $\mathbf{3}$ & $\mathbf{4}$ & $\mathbf{5}$ \\
\hline
\end{tabular}

\subsection{Courtesy}

\begin{tabular}{clrrrrr}
\hline Q. No. & \multicolumn{1}{c}{ Statement } & \multicolumn{4}{c}{ Respondent's rating } \\
\hline 5.8 .1 & Childbirth and post-natal caregiver/s were respectful & $\mathbf{1}$ & $\mathbf{2}$ & $\mathbf{3}$ & $\mathbf{4}$ & $\mathbf{5}$ \\
\hline 5.8 .2 & $\begin{array}{l}\text { Childbirth and post-natal caregiver maintained my } \\
\text { privacy }\end{array}$ & $\mathbf{1}$ & $\mathbf{2}$ & $\mathbf{3}$ & $\mathbf{4}$ & $\mathbf{5}$ \\
\hline 5.8 .3 & Childbirth and post-natal caregiver/s were friendly & $\mathbf{1}$ & $\mathbf{2}$ & $\mathbf{3}$ & $\mathbf{4}$ & $\mathbf{5}$ \\
\hline
\end{tabular}




\section{Direct measures of satisfaction in antenatal care}

\section{Rating of responses:}

1 = Strongly disagree; 2 = Disagree; 3 = Neutral; 4 = Agree;

$5=$ Strongly agree

\begin{tabular}{|c|c|c|c|c|c|c|}
\hline Q. No & Statement & & por & len & $\mathrm{ra}$ & \\
\hline 6.1 & I am adequately satisfied with antenatal care services? & 1 & 2 & 3 & 4 & 5 \\
\hline 6.2 & $\begin{array}{l}\text { I am adequately satisfied with the dealings of antenatal } \\
\text { caregivers? }\end{array}$ & 1 & 2 & 3 & 4 & 5 \\
\hline 6.3 & $\begin{array}{l}\text { I am adequately satisfied with overall services of the } \\
\text { antenatal care facility? }\end{array}$ & 1 & 2 & 3 & 4 & 5 \\
\hline 6.4 & $\begin{array}{l}\text { I shall recommend others about my doctor for antenatal } \\
\text { care }\end{array}$ & 1 & 2 & 3 & 4 & 5 \\
\hline 6.5 & I would consider this antenatal service in future if I need & 1 & 2 & 3 & 4 & 5 \\
\hline 6.6 & $\begin{array}{l}\text { I shall recommend others to use this antenatal care } \\
\text { facility }\end{array}$ & 1 & 2 & 3 & 4 & 5 \\
\hline
\end{tabular}

\section{Direct measures of satisfaction in childbirth and immediate post- natal care}

Rating of responses:

1 = Strongly disagree; 2 = Disagree; 3 = Neutral; 4 = Agree;

$5=$ Strongly agree

\begin{tabular}{clrrrrr}
\hline Q. No & \multicolumn{1}{c}{ Statement } & \multicolumn{3}{c}{ Respondent's rating } \\
\hline 7.1 & $\begin{array}{l}\text { I am adequately satisfied with childbirth and post-natal } \\
\text { care services? }\end{array}$ & $\mathbf{1}$ & $\mathbf{2}$ & $\mathbf{3}$ & $\mathbf{4}$ & $\mathbf{5}$ \\
\hline 7.2 & $\begin{array}{l}\text { I am adequately satisfied with overall dealings of } \\
\text { childbirth and post-natal caregivers? }\end{array}$ & $\mathbf{1}$ & $\mathbf{2}$ & $\mathbf{3}$ & $\mathbf{4}$ & $\mathbf{5}$ \\
\hline 7.3 & $\begin{array}{l}\text { I am adequately satisfied with overall services of the } \\
\text { childbirth and post-natal? }\end{array}$ & $\mathbf{1}$ & $\mathbf{2}$ & $\mathbf{3}$ & $\mathbf{4}$ & $\mathbf{5}$ \\
\hline 7.4 & $\begin{array}{l}\text { I shall recommend others about my doctor/ midwife for } \\
\text { childbirth and post-natal }\end{array}$ & $\mathbf{1}$ & $\mathbf{2}$ & $\mathbf{3}$ & $\mathbf{4}$ & $\mathbf{5}$ \\
\hline 7.5 & $\begin{array}{l}\text { I would consider this childbirth and post-natal service in } \\
\text { future if I need }\end{array}$ & $\mathbf{1}$ & $\mathbf{2}$ & $\mathbf{3}$ & $\mathbf{4}$ & $\mathbf{5}$ \\
\hline 7.6 & $\begin{array}{l}\text { I shall recommend others to use this childbirth and post- } \\
\text { natal care facility }\end{array}$ & $\mathbf{1}$ & $\mathbf{2}$ & $\mathbf{3}$ & $\mathbf{4}$ & $\mathbf{5}$ \\
\hline
\end{tabular}

This is the end of the survey. Thank you very much for your time and kind cooperation. 


\section{APPENDIX 6. INSTITUTIONAL REVIEW BOARD APPROVAL LETTER FOR THE PROJECT “ASSESSING MOTHERS \\ SATISFACTION WITH ANTENATL AND CHILDBIRTH SERVICES IN GEORGIA"}

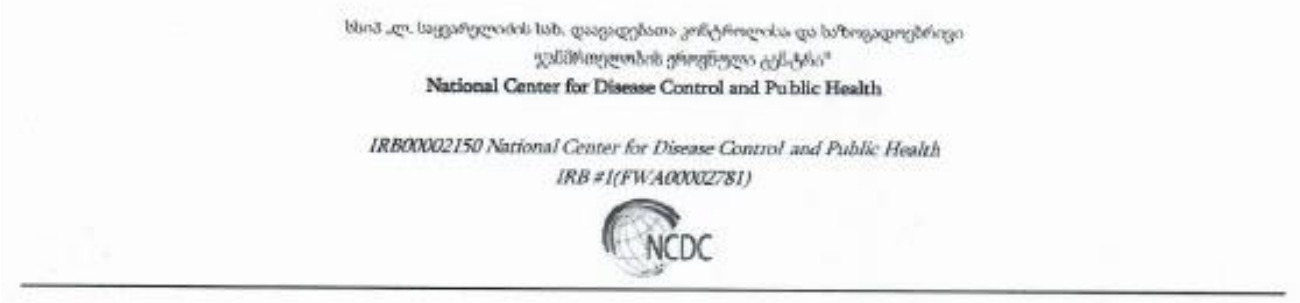

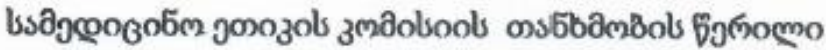 Institutional Review Board Approval Letter}

PI: Lela Shengelia

Head of the maternal and child health division

The National Center for Disease Control and Public Health

mobile.: 577726141

E-mail: L.shengelia $a$ ncdc.ge

IRB \# 2017-055

Dear Dr. Shengelia

This letter is an official notification that National Center for Disease Control and Public Health Institutional Review Board has carried out protocol review of the project "Assessing mothers satisfaction with antenatal and childbirth services in Georgia" and approved protocol for the Protection of Human Subjects.

This determination is valid from November 1,2017 until November 1,2018. If you wish to continue your research after this date, you must complete and submit a Continuation Application.

Level of review: Expedited

Date of review: October 29, 2017

You are responsible for immediately informing the Institutional Review Board of any changes to your protocol/procedures/data collection tools/consent forms before they are implemented, and of any previously unforeseen risks to the research participants.

For further assistance please conact us at (995-322) 398946 or via email at irb.ncdc@gmail.com. Sincerely,

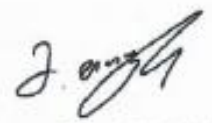

Marina Topuridze, MD, MS

IRB (IRB00002150) Chair

National Center for Disease Control and Public Health of Georgia 
Summary 

Cost, access and quality of maternal care are concerns in health systems all over the world. Maternal health depends on the functioning of the health system of a country. Although some countries have made efforts to reduce the fee-for-services for maternal care in recent years, good quality maternal care still remains too expensive for many women. It also should be emphasized that better access to maternal care services is not sufficient to improve maternal health outcomes. The quality of care a woman receives during pregnancy, childbirth and postpartum affects her health, the health of her child and her and her child's future life. Remarkably, the potential impact of cost, access and quality on pregnancy outcomes during health system reforms on maternal care has been largely unexplored. In this context, the dissertation evaluates the cost, access and quality of maternal care in a health system in transition. In particular, the dissertation focuses on the capital and two regions of Georgia, where these aspects of maternal care provision are especially problematic. The key stakeholders' opinions and evaluation of maternal care are also taken into account.

The aim of this dissertation is to examine access, quality and financing of maternal care services in Georgia. The dissertation consists of seven chapters. Below, the main findings from each chapter are summarized.

Chapter 1 presents a broad overview of the development of the health system in Georgia, as well as the current status. The chapter also outlines the concept of access, quality and financing. We focus on these aspects of maternal care in Georgia. We provide this background information to understand the results of the dissertation. In this chapter, we also outline the aim, objectives and methodology used in this dissertation. As mentioned above, the aim of this dissertation is to examine aspects of access, quality and cost of maternal care in Georgia. To achieve this aim, we first explore the empirical evidence on the outcomes of the reform to provide an evidencebased appraisal of the reform (Chapter 2). Furthermore, we assess the changes in maternal care during the healthcare reforms in Georgia (Chapter 3). In Chapter 4 and 5 , we explore the adequacy of maternal care financing and access of mothers of such services in Georgia and study factors influencing maternal care in terms of quality and access. Chapter 6 addresses women's satisfaction with maternal care services in Georgia. Chapter 7 presents the main findings of the dissertation followed by suggestions for further research and policy recommendations.

In this dissertation, we used a combination of research approaches. In Chapter 2, we used a systematic review of the empirical evidence on the outcomes of the healthcare reforms in Georgia. In Chapter 3, we carried out secondary analysis on three waves of the Reproductive Health Surveys (RHSs) of Georgia which were conducted in 1999-2000, 2005 and 2010. In Chapter 4 and 5, we applied qualitative data analysis. Data for the 
analysis in Chapter 4 and 5 are obtained from a qualitative study among the following stakeholder groups: women who had used maternal care services during the past 4 years, healthcare providers and decision makers (health-care policy makers, health insurance representatives, representatives of international organizations). Due to the different characteristics of the groups (e.g. size, diversity), qualitative data among women were obtained through focus group discussions (FGDs), 6 group discussions in total. The data among the other stakeholders were obtained through face-to-face indepth interviews (IDIs) (15 interviews). In Chapter 6, we used data from a crosssectional survey specifically conducted for this dissertation to study women's satisfaction with maternal care.

In Chapter 2, we review the empirical evidence on the effects of the healthcare reforms in Georgia. The objective of this systematic literature review is to identify the challenges for health financing and universal access to healthcare and to determine interventions that may help to overcome barriers to the implementation of the reforms. It reviews the healthcare reforms in Georgia on their financial sustainability, allocative and technical efficiency, equity in access and finance, transparency and accountability, utilization and quality of care.

Only 38 articles and reports in English and 3 in Georgian met the relevant criteria and presented evidence-based data. Overall, the evidence presented in the studies reviewed, was not enough to conduct a thorough impact evaluation of the healthcare reform of the Georgian healthcare sector. This is due to the limited number of studies and limitations of each study. However, our analysis outlines several conclusions relevant to policy and research.

Our results suggest that the initial goal to reorganize the post-Soviet healthcare sector was achieved after several stages of healthcare reforms. The country faced multiple challenges during the reforms. The direction and priorities of the reforms depend on the ruling party and this corroborates the principal - "new lords, new laws". A highlevel of out-of-pocket payments (OPPs) accompanied the healthcare reforms since independence. Given the resource constraints people face, the utilization of healthcare services fell dramatically during the last two decades. The total privatization and liberalization of the health market made the Georgian health reform unique. The decision to privatize nearly all public health facilities was motivated by the obsolescence of the Soviet healthcare infrastructure. The financial crisis, weak governance, population dissatisfaction and a strong influence of private investors on the government played also a significant role in the privatization decision. In the private market, there were mergers between pharmaceutical companies and health facilities. Supplier induced demand for healthcare services were quite common in the private 
health market. Due to a lack of regulatory control over the costs, healthcare providers increased their fee-for-services. As a result, the potential risk of catastrophic health expenditure increased.

In the second stage of the reform, private health insurance was established in the country. The insurance companies freely manipulated the selection criteria and riskrated premiums concentrating on their own profits. Increased OPPs created barriers for access to healthcare services and compromised equity. At the same time, the marketbased health system had a negative effect on the quality of healthcare during the second stage of the healthcare reform.

The 2013 Universal Health Coverage (UHC) program was implemented in the country. Since the implementation of the "Health for All" program, the government has taken steps to improve the quality of care. The perinatal service providers have been graded by their functional capabilities and a reorganization of the referral and emergency system has started.

Chapter 3 assesses the changes in maternal care during the different stages of the reforms as well as their effect on the utilization of maternal care. In particular, we analyzed the data of three waves of the RHSs which were collected in 1999-2000, 2005 and 2010. As outlined in Chapter 3, the previous literature has considered that during the Soviet period, women in Georgia gave birth in large, damp, cold maternal rooms, four to six women in a room, without a partner or family being present. It was a necessity to transform maternal care and the country-initiated healthcare reforms including a maternal care reform. The reform of the maternal health system was necessitated by the high and increasing pregnancy-related mortality and morbidity.

In Chapter 3, we present a secondary analysis of the three RHSs. For the assessment, from all three waves of the RHSs, we selected a sample of women who had experienced childbirth during the last 5 years. In total, 7684 respondents from all three waves met the inclusion criterion. We only analyzed data on pregnancy outcome, type of childbirth, access and utilization of antenatal, natal and immediate post-natal care, as these are the main indicators for the evaluation of maternal health and maternal care. We also used socio-demographic and health status characteristics of the womenrespondents. Descriptive, binary and multinomial analyses were performed.

Our findings show that maternal care changed during the healthcare reforms. In 1999, during the first stage of healthcare reform, the State implemented the national program on the development of reproductive services with several components, such as family planning, STI-AIDS/HIV, antenatal and perinatal, surveillance, sexual education; and training for health professionals. The State implemented four free antenatal 
care visits which was a progressive policy approach. Utilization of antenatal care services from the very beginning of the implementation of the program was quite high (92.1\%). This increased to $95.1 \%$ in the second wave and $98.2 \%$ in the third wave. The places where women received maternal care, particularly antenatal care changed through the years.

Antenatal services were provided mostly by the primary healthcare centers, such as rural dispensaries or women consultation center during the first wave. However, the centralized public provision of healthcare was reformed into a market-based system through a massive privatization of healthcare facilities and the delivery system including maternal care. Accordingly, the last wave shows that antenatal care services were provided only by women consultation centers or by the maternal houses.

The second stage of the healthcare reforms started with the privatization of maternal houses and women consultation centers. Consequently, due to private owners' interest, the use of private antenatal services increased between 1999 and 2005. During this period, the number of providers of antenatal care services increased as the maternal houses started providing antenatal check-up and they established women consultation centers within the maternal houses. More women could freely use antenatal services in maternal houses and choose their own provider, i.e., "personal doctors". In the market-based health system, competition between providers to deliver good quality care became evident, which was nearly absent during previous centralized health system.

Similar to studies in other countries, we found that a significant predictor of the use of antenatal care visits in Georgia is education: low and mid-level educated women utilize maternal care services less often than higher educated women. Moreover, rural women utilize such services less. The healthcare reforms in Georgia aimed to ensure access to the basic services including maternal care services, specifically antenatal care. However, there are additional factors that also influence access to services such as religion and socioeconomic status. All these factors were strong predictors of the use of services and they play a role even if access to basic antenatal service is ensured. The RHS waves provide limited information about the quality of maternal care. The presented secondary analysis only provides proxy indicators of quality of maternal care, like blood pressure measurement and utilization of ultrasound examination during the last pregnancy of respondents, which had gradual increasing trends over the years.

In Chapter 4, we presented a qualitative study to explore the opinion of key stakeholders about the adequacy of maternal care financing and financial protection of pregnant women in Georgia. This chapter contains the results of six FGDs and fifteen face-to-face IDIs, that were conducted in the capital Tbilisi, as well as in Adjara and 
Imereti regions of Georgia. The study was done in 2015. Each FGD consisted of 7- 6 mothers who had utilized maternal care services during the 4 years. A total of 41 women (primipara $n=19$; multipara $n=22$ ) participated in six FGDs and 15 other stakeholders: Policymakers, medical doctors, and representatives of private health facilities, international organizations, and professional organization were participants of the IDIs. We used a mixed convenience and purposive sampling method to select these stakeholders depending on their known involvement and experience in maternal care.

We find that the privatization played a crucial role in service provision in maternal care as it influences the development of the health system. The decision of the government to privatize the entire health sector is an outcome of a policy-driven process, but it is not followed by strong regulation mechanisms and this gives room to private ownership of the maternal houses, to manipulate the user fees. The consensus among stakeholders showed that the 2013 UHC program was implemented to protect mothers from financial burden. However, weaknesses in regulation are also observed.

Chapter 4 also discusses the burden of OPPs for pregnant women in Georgia. We find that the antenatal care period as well as the natal period come with extra OPPs. The burden of OPPs increases in case of complications. Moreover, OPPs are also related to the phenomenon of a "personal doctor". Overall, our results confirm that the current financial reform is regressive. Although both the poor and the rich have equal access to state facilities, whenever needed, the richer segment has access to specialized services through OPPs but the poor segment is not supported by the State program for the specialized services.

Chapter 5 describes the findings of a qualitative study on the stakeholders' opinion on the quality of and access to maternal care in Georgia. Chapter 5 used data collected in the same qualitative study as the data for Chapter 4. As explained above, the study was conducted in 2015 and consisted of six FGDs (7-6 mothers per group) and 15 faceto-face IDIs with other stakeholders. The method of mixed convenience and purposive sampling was used to select these stakeholders.

We examined maternal care in terms of quality and access. Quality was divided into clinical quality, social quality, continuity of care and comprehensiveness of maternal care. We tested clinical quality by medical doctors' knowledge and skills of diagnosis and treatment, medical doctors' and nurses' responsiveness, as well as the quality of lab investigations. We assessed the following aspects of social quality: maintenance of privacy and respect for the mothers, mental support, attentiveness to the problems presented, communication, and tangibility. Continuity was assessed in terms of mothers' adherence to doctors' advices and specific maternal care facilities. We also 
assessed the effects of the doctor-client relationship on continuity of maternal care. The comprehensiveness of maternal care was assessed in terms of 'one door shopping'. Also, we assessed spatial access in terms of the geographical distribution of maternal care facilities both in rural and urban areas. Whereas, temporal access was assessed in terms of the respondents' opinions about waiting time for ambulatory and emergency care and the referral process.

Based on the analysis, we observed that the majority of respondents support maternal care reforms. However, our findings suggest that the lack of clinical skills of medical doctors is related to either misdiagnosis or delay in the identification of pregnancy complications. Continuity of care is interrupted because of the lack of skills of medical doctors, providers' financial interest and an ineffective referral system. Absence of continuous professional development (CPD) for physicians also negatively influences clinical as well as the social quality of care. Findings indicate urbanization of comprehensive maternal care in Georgia. Privatization also played a significant role in the concentration of services in the big cities. However, spatial access to basic maternal care services has been improved as a result of the UHC program. In general, there have been some improvements in the maternal care system. However, to meet the population's expectations and to achieve the target outcomes of maternal care, substantial improvements in quality and access need to be made.

In Chapter 6, we present the findings of a survey that was conducted in the capital and two regions of Georgia. In total, 400 women, who gave birth to healthy babies during the preceding twelve months before the date of data collection, were the target population. We measured women's opinion about the organization of maternal care (tangibility, availability, accessibility) and process features (responsiveness, reliability, empathy, communication and courtesy). We also studied women satisfaction with antenatal, natal and post-natal services.

Our findings indicate that the utilization of antenatal care is nearly $99.5 \%$ and most of the participants were satisfied with antenatal care services. About $85 \%$ of the respondents received more than eight antenatal care visits which are considerably more than the state- scheduled four visits. Our findings suggest that women with the lowest level of education, are more satisfied than women with the highest education level. Some studies have shown that higher education is associated with higher demands and expectations which in turn relate to lower satisfaction. Our results also confirm that women in urban areas are more satisfied with antenatal and natal services than those in rural areas. Pregnant women most often utilize services from the regional antenatal and natal providers rather than from the nearby rural-based facilities. Moreover, many rural women start receiving antenatal care from rural 
facilities and often switch to providers in urban facilities which cause a breach of continuity of care.

Overall, our survey indicates that women are satisfied with maternal care in Georgia and that the basic maternal care services are ensured in the entire country. However, this satisfaction of women does not imply efficient use of resources invested by the government through the private health sector. We find that women in urban settings were more satisfied with the antenatal and natal services than in rural areas. Moreover, those who pay out of pocket are less satisfied.

Chapter 7 outlines the main findings of the dissertation, followed by the general conclusion and policy implications of the dissertation.

As discussed in this chapter, in almost three decades the Georgian health system changed from the Semashko model of health financing to a privatized one. Through this period the country implemented several healthcare reforms. Our findings indicate that efficiency and equity are influenced negatively by the changes in the health system. It resulted in a lack of cost control and client trust in the system.

The phenomenon of a "personal doctor" plays a significant role in maternal care services in Georgia. The term "personal doctor" was established already several decades ago in maternal care in Georgia. Due to substandard maternal care services, pregnant women and their households try to utilize services for antenatal care or/and childbirth from an obstetrician who is most popular in their environment. Our findings suggest that there are many determining factors to search and pay extra for a personal obstetrician, such as safety, responsiveness and personal comfort. Often pregnant women utilize antenatal care in one facility and have childbirth in another. This poses a big barrier for continuity of care. The price for a "personal doctor" varies between 300 GEL and 1000 GEL. Not everyone can afford a "personal doctor" which leads to inequalities and disparities among mothers. The State implemented free antenatal care visits and childbirth; however, pregnant women prefer to have a "personal obstetrician" from the very beginning of the pregnancy. Our findings indicate that having a "personal doctor" means extra antenatal visits and medical investigations. Thus safe, timely and patient-centered care under the State program is questionable. Another perspective of having a "personal doctor" is to maintain the autonomy of choice. At the same time, findings indicate that women pay for the "personal doctors" just to ensure the services that are already in the place. They pay because of "fear" and "positive word-of-mouth" that they are getting more than those who do not pay.

The fragmentation and absence of continuity of maternal care was inherited from the Soviet period. The organization of the maternal health system is still divided into two 
parts, the antenatal care services and the maternal houses. After the transformation of maternal care, the number of independent women consultation centers decreased gradually. Thus, the antenatal care providers integrated into the maternal houses or units increased. Fragmentation of maternal care negatively influences maternal care quality as obstetricians involved in antenatal care did not have communication with those who work in the maternal ward. The absence of a link between antenatal and natal care providers compromises continuity, quality of maternal care and trust in the doctor and in the system. Thus, the "do-it-yourself" approach was adopted by mothers and their relatives in Georgia as an alternative politics" to address the abovementioned gap of the system.

The concentration of facilities in urban areas has influenced geographical and financial access to maternal care. Most of the maternal care facilities are concentrated in the capital which presents significant disparities in quality of care. This situation makes that pregnant women from the regions almost always prefer to utilize services in the capital. The concentration of the tertiary and secondary level facilities in the capital and big cities was inherited from the Soviet period. The Soviet approach to the distribution of medical facilities was maintained after independence. The first publicbased tertiary maternal house was established in Tbilisi in 2003. Since then the most complicated or near-miss case were transported and managed in that particular maternal house. The preference to utilize services in the urban places is determined by the poor quality of maternal care in rural places. Also, the most popular and experienced medical doctors are concentrated in the regional centers and in Tbilisi. However, utilization of maternal care services in the capital and in the big cities come with direct and indirect costs which increase the financial burden for pregnant women, compromise financial access and equity in the country.

OPPs comprise one of the challenges of maternal care. As already mentioned most pregnant women have a "personal doctor" for antenatal as well as natal and immediate post-natal services and pay out of pocket. The cost of the services of "personal doctor" is quite high. However, to receive good quality maternal care is determined by healthcare delivery characteristics, such as access and quality of care. The childbirth expenses for all income groups are part of the UHC program and in 2017, the country implemented perinatal regionalization. In spite of this, almost all pregnant women are paying out of pocket. Our findings indicate that a high price does not ensure high quality of maternal care services. Moreover, those who pay are less satisfied and less motivated to recommend the services to others. Thus, maternal care is substandard and poses an extra financial burden on pregnant women in Georgia.

Our results suggest that geographical and financial access to the basic maternal care 
services is ensured by the State maternal care programs. However, our results show some weaknesses in this policy, namely the high burden of OPPs, substandard quality of maternal care and lack of access to the comprehensive maternal care services. 

Curriculum vitae 

Lela Shengelia was born on 24 June 1969 in Georgia, one of the fifteen republics of the Soviet Union. She commenced her journey in education in 1975 and completed primary and secondary schools by 1987.

In 1990, she was admitted in Tbilisi Medical Institute, Georgia, for studying medicine and in 1996, she successfully completed Doctor of Medicine degree. In 1998, she was awarded a postgraduate degree 'Obstetrician and Gynaecologist' from the State Medical Academy of Postgraduate Education, Georgia. She was awarded Master of Public Health degree from the Royal Tropical Institute (Vrije University), Amsterdam, in 2010 as a NUFFIC scholar.

Having started her professional career since 2001, Ms. Shengelia has been working with national and international NGOs, health professional and research organizations, and public health sector institutions. She has contributed substantially in developing sexual and reproductive health in the post-Soviet Georgia as a: (i) practicing obstetrician and gynaecologist for 'the women rehabilitation center, Georgia', (ii) Project Manager of 'Prevention of mother to child transmission of HIV' project of the Global Fund, (iii) Consultant of the 'Maternal healthcare improvement in Georgia' project of the USAID, (iv) Principal Investigator of the project 'Caesarean Section in Georgia' of ECT Crystal, the Netherlands, (v) Consultant of the project of JSI - 'RAMOS', and 'assessment of perinatal service providers', (vi) Consultant of 'perinatal services in Georgia, a project of CIC Curatio Georgia, (vii) Trainer for the research project of JSI on 'Healthy Women in Georgia' and (viii) as the 'Head of the maternal and child division' of the NCDC of Georgia.

Since 2011 till today, Ms. Shengelia has remarkable achievements in her current position in developing policy guidelines for maternal and child morbidity and mortality surveillance and action plans, conducting survey on 'Early marriage in Georgia' (a bilateral project with UNFPA), establishing the 'Birth and death registration system in Georgia' (aided by UNICEF), and coordinating the assessment the 'Human rights in the context of sexual and reproductive health and well-being in Georgia' and providing recommendations (a multiparty project involving Public Defenders Office of Georgia and UNFPA).

Ms. Shengelia also successfully joined national and international trainings from recognized institutes and organizations; some example: 'Professional development programme' at Royal Infirmary of Edinburgh and Chalmers Sexual and Reproductive Health center (funded by UNFPA/EBCOG), 'Certificate course in Sexual and Reproductive Health Research' of Geneva Foundation for Medical Education and Research, and WHO', 'Working with the private sector to achieve public health goals' at 


\section{Curriculum vitae}

Ethiopia (funded by NUFFIC)', 'Gender, Reproductive and Sexual Health and Fertility Master's in Medical Anthropology program' at the University of Amsterdam', 'Maternal and Infant Health Columbia Seminar in Salzburg, Austria, and 'Regional Program on Human Rights' at Raoul Wallenberg Institute, Sweden.

Ms. Shengelia voluntarily served as a founding member of an NGO providing maternal care in Georgia and also as a member of the Georgian Association of Ob/Gyn. She is an alumnus of the Royal Tropical Institute and an active contributor to the GeorgiaNUFFIC alumni association in Georgia.

Ms. Shengelia professionally is well-focused and committed to contribute in developing maternal care services system in Georgia and beyond. 
Publication lists 

- Bel-Serrat $S$, Ojeda-Rodríguez $A$, Heinen $M M$, Buoncristiano $M$, Abdrakhmanova S, Duleva V, Sant'Angelo V, Fijałkowska A, Hejgaard T, Huidumac C, Hyska J, Kujundzic E, Milanović SM, Ovezmyradova G, PérezFarinós N, Petrauskiene A, Rito Al, Shengelia L, Taxová R, Braunerová $M$, Rutter $\mathrm{H}$, Murrin CM, Kelleher CC, Breda J. Clustering of Multiple Energy Balance-Related Behaviors in School Children and its Association with Overweight and Obesity-WHO European Childhood Obesity Surveillance Initiative. Nutrients. 2019; 27.11(3)

- Zamper K, Dekanosidze T, Shengelia L, Jalagania L, Human Rights in the Context of

- Sexual and Reproductive Health and Well-being in Georgia: Country Assessment Public Defender's Office with the support of the Country Office of the United Nations Population Fund of Georgia. 2019.

- Shengelia L, Jalagania L, Dekanosidze T. Sexual and Reproductive Health and Rights Country Inquiry. Public Defender's Office with the support of the Country Office of the United Nations Population Fund of Georgia. 2019.

- Shengelia, L., Pavlova, M., \& Groot, W. (2019). Quality and Access to Maternal Care in Georgia: A Qualitative Study among Stakeholders (abstract). European Journal of Obstetrics \& Gynecology and Reproductive Biology, 234, e32-e33.

- Miteniece E, Pavlova M, Shengelia L, Rechel B, Groot W. Barriers to accessing adequate maternal care in Georgia: a qualitative study. BMC Health Servces Research. 2018;13;18(1):631.

- Gupta TP, Taylor A, Lauro G, Shengelia L, Sturua L. Exploring Harmful Practices of Early/Child Marriage and FGM/C in Georgia- Results from a Qualitative Research National Center for Disease Control and Public Health of Georgia, Promundo US, United Nations Population Fund. United Nations Children's Fund. 2018.

- Shengelia L, Pavlova M, Groot W, Stakeholders' views on the strengths and weaknesses of maternal care financing and its reform in Georgia. BMJ Health Services Research. 2017;17; 544.

- Roy A, Shengelia L. A Review on Situation of Congenital Disorders and Access to Community Genetics Services in Bangladesh. Annals of Clinical and Laboratory Research, 2016; 4(2), 1-4. 
- $\quad$ Roy A, Shengelia L, Dupont HB. Towards harm reduction of injecting drug users: A Priority Action for Preventing HIV in Bangladesh. Journal of Drug Abuse. 2016; 2(3), 1-5.

- Roy A, Shengelia L. An Analysis on Maternal Healthcare Situation in Bangladesh : A Review. Divers Equal Heal Care. 2016.13(5), 360-364.

- Shengelia L, Pavlova M, Groot W. Impact of Healthcare Reform on Universal Coverage in Georgia: A Systematic Review. Diversity and Equality in Health and Care. 2016; 13(5): 349- 356

- Misho P, Kristesashvili J, Gegechkori M, Shengelia L, Shishniashvilis M, Abutidze G. Manual for reproductive health, Healthy life style and first aid in the School. Manual for the school doctors. National Center for Disease Control and Public Health of Georgia. United Nations Population Fund. 2016.

- Shengelia L, Gabelaya L, Demetrashvili N, Katsitadze G, Chkhaidze I, Sturua L, Kazzi

- Z. Childhood Lead Screening in Tbilisi, Republic of Georgia. 2016. MENATOX

- $\quad$ Shengelia L, Trapaidze D, Chiraqadze S, Sturua L. Epidemiological surveillance of maternal mortality. 2014. National Center for Disease Control and Public Health of Georgia.

- Jugens E, Shengelia L, Asatiani T, Bijlmakers L. Clients' and providers' perspectives on Caesarean sections. An operational study into the high Caesarean Section rate in Georgia. Tbilisi. 2011

- Shengelia L. Healthcare financing reform in Georgia: Impact on accessibility and affordability of services. MPH thesis. Vrije University. 2011. 

